$12 / 9 / 30 / 96$ os 8

August $1996 \cdot$ NREL/TP-430-21612

\title{
Evaluation of Gasification and Novel Thermal Processes for the Treatment of Municipal Solid Waste
}

RECFIVED

DEC 091996

OSTI

Walter R. Niessen

Charles H. Marks

Robert E. Sommerlad

Camp Dresser \& McKee

Cambridge, Massachusetts

MASTER

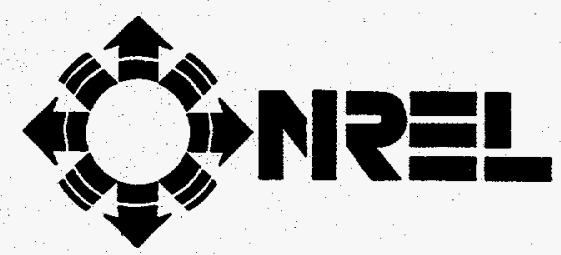

National Renewable Energy Laboratory

1617 Cole Boulevard

Golden, Colorado 80401-3393

A national laboratory of the U.S. Department of Energy

Managed by Midwest Research Institute

for the U.S. Department of Energy

under Contract No. DE-AC36-83CH10093 


\section{Evaluation of Gasification and Novel Thermal Processes for the Treatment of Municipal Solid Waste}

NREL Technical Monitor:

Phil Shepherd

Walter R. Niessen

Charles H. Marks

Robert E. Sommerlad

Camp Dresser \& McKee

Cambridge, Massachusetts

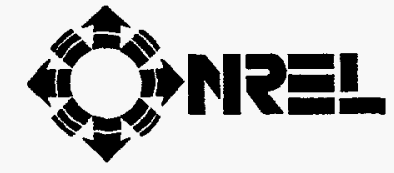

National Renewable Energy Laboratory 1617 Cole Boulevard Golden, Colorado 80401-3393

A national laboratory of the U.S. Department of Energy Operated by Midwest Research Institute for the U.S. Department of Energy

Prepared under Contract No. DE-AC36-83CH10093

Under Subcontract No. YAR-5-15116-01

August 1996 
This publication was reproduced from the best available camera-ready copy submitted by the subcontractor and received no editorial review at NREL.

\section{NOTICE}

This report was prepared as an account of work sponsored by an agency of the United States government. Neither the United States govemment nor any agency thereof, nor any of their employees, makes any warranty, express or implied, or assumes any legal liability or responsibility for the accuracy, completeness, or usefulness of any information, apparatus, product, or process disclosed, or represents that its use would not infringe privately owned rights. Reference herein to any specific commercial product, process, or service by trade name, trademark, manufacturer, or otherwise does not necessarily constitute or imply its endorsement, recommendation, or favoring by the United States govemment or any agency thereof. The views and opinions of authors expressed herein do not necessarily state or reflect those of the United States government or any agency thereof.

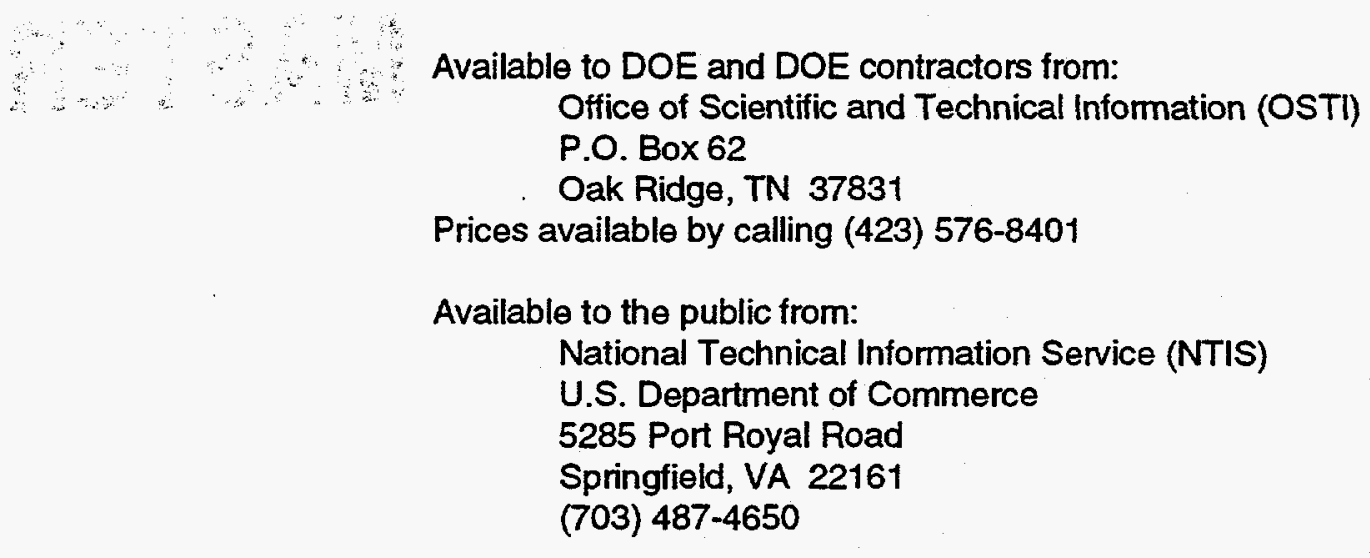




\section{DISCLAIMER}

Portions of this document may be illegible in electronic image products. Images are produced from the best available original document. 


\title{
Acknowledgments
}

A project such as this, although it rests in the hands of a research contractor, depends heavily for its success on the cooperation and contributions from firms being evaluated and from other resource persons, agencies, and companies participating. The project team received generous cooperation from the many engineering and business professionals of the over 40 process development firms initially screened and, more particularly, from those seven reported upon in detail. Also, we acknowledge the assistance of the researchers, facility owners, pilot plant technicians, and others that were important in the field trip experiences

The project team wishes to express its appreciation to Mr. Philip Shepherd, the Project Manager at NREL and Mr. Simon Friedrich, the Program Manager at DOE for their on-going guidance and counsel. Also, we express our appreciation to the remainder of the Project Steering Committee for their technical contributions and review activities. They include:

\author{
Mr. James Kilgroe USEPA-AEERL \\ Dr. Richard Bain NREL \\ Mr. Lory Larson Southern California Edison \\ Mr. Carlton C. Wiles NREL
}

\author{
Walter R. Niessen, P.E. $\quad$ Project Team Leader \\ Charles H. Marks, P.E. Team Member \\ Robert E. Sommerlad, P.E. Team Member
}




\section{Contents}

Section 1: $\quad$ Executive Summary $\quad 1-1$

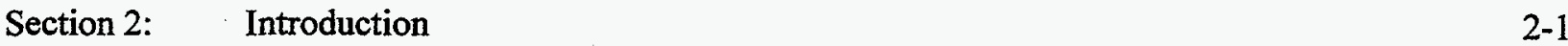

Section 3: $\quad$ Energy Products of Idaho (EPI) 3-1

Section 4: $\quad$ TPS Termiska Processer AB (TPS)

Section 5: $\quad$ Proler International Corporation $\quad 5-1$

Section 6: Thermoselect Incorporated $\quad$ 6-1

$\begin{array}{llr}\text { Section 7: } & \text { Battelle } & 7-1\end{array}$

Section 8: $\quad$ Pedco Incorporated $\quad 8-1$

Section 9: ThermoChem $\quad 9-1$

Section 10: Refuse Combustion and Gasification in 1995-A Summary Overview 10-1

Appendix A: List of Gasification and Thermal Process Firms and Processes

Appendix B: FAX Request for Basic Data

Appendix C: Preliminary Request for Data

Appendix D: Waste Gasification or Novel Thermal Processing Facilities

Appendix E: Conversion Factors, Conventions, and Methodologies 


\section{Section 1}

\section{EXECUTIVE SUMMARY}

\section{A. INTRODUCTION}

This report summarizes the state of the art for seven technologies involving gasification, or other innovative thermal processing technologies, for application to municipal solid waste (MSW). The technologies are all at the level of "incipient commercial availability." They have passed through the "idea" stage and through laboratory and bench-scale testing; their prototypes have been demonstrated at an MSW feed rate of at least several tons per hour.

The target audience for this report is the town, city, or regional official responsible for the management of MSW. This individual, with input from engineering, financial, and environmental specialists, is invited to consider these technologies in addition to the well-proven conventional alternatives.

The objective of this analysis was not to determine the "best process." The concept of "best" is valid solely in the context of local values, constraints, and problems. Rather, this work presents the technical, environmental, and economic characteristics of each individual process. After reading the presentation and determining that there is a good match with local needs, an individual or entity can find a point of contact in the report to facilitate follow-up.

\section{B. OVERVIEW}

Proper management of solid waste is an important element of municipal sanitation and a major line item in municipal budgets. In years past, waste management created a significant opportunity for thermal processing with energy recovery from MSW. In recent years, several developments have sharply curtailed the market:
- The problem of ensuring a reliable supply
- The low price of energy
- Changing financial mechanisms and capability
- Changing social attitudes

Prospective owners of waste management systems need a reliable supply of MSW to support their capital borrowing; they need firm, long-term contracts for waste disposal. To draw wastes from large areas, it was often necessary to require waste collectors to use a proposed waste management facility. However, recent U.S. Supreme Court decisions have restricted the right to direct waste. Unless the Court finding is redressed by act of the Federal Congress, the basic capital-raising mechanism for waste processing facilities will be greatly weakened or lost. Thus the financial risk of project development will be much greater, with a concomitant effect on bonding costs to the communities and counties. 
Low energy prices affect thermal processing facilities by reducing the flow of revenue from the sale of electricity or steam. During the 1980 s and up to the present, the trend in energy prices has been downward. Consequently, the effective break-even tipping fee for proposed plants has increased, making community acceptance and financing more difficult.

Environmental issues have also affected MSW combustion. Initially, pressure was focused on visible emissions. The Clean Air Act and its Amendments drove the industry away from simple refractory enclosures and toward waterwall boiler designs. This change in direction brought the technical sophistication and systems view of the commercial boiler and combustion industry to the MSW incineration market. In 1977 the pollutant "dioxin" emerged as a new issue. Emissions of acid gases- $\mathrm{HCl}$ and $\mathrm{SO}_{2}$, nitrogen oxides $\left(\mathrm{NO}_{x}\right)$, and toxic elements also became of increasing concern. Other interests focused on ash.

Although environmental concerns have not driven thermal processing out of business, they have resulted in significantly higher costs, increased system complexity, and long delays in moving projects through the public review and regulatory approval processes. Interestingly, the situation in Europe is similar to that in the U.S., but the result is different. Recent legislation in Germany, France, and the Netherlands has mandated an end to raw waste landfilling. This legislation will help to further emphasize the role of thermal processing in solid waste management, where waste turned into energy has already assumed a commanding position. However, driven by stringent air emissions limits in some European nations, waste management costs will be very much higher than in the U.S.

Several new or enhanced technologies to thermally process MSW are now well established. One class, which burns waste in the same physical form as it is generated (mass-burn incinerators), is coupled with elaborate back-end air and residue treatment. Another burns wastes alone or with fossil fuels after preprocessing of the waste to a refuse-derived fuel (RDF).

Beyond these well-proven combustion processes, a new technology class has emerged-refuse gasification. During this process, the organic fraction of MSW is heated to drive off a gas with a substantial fuel value. This gas can be cleaned and burned in a gas engine or gas turbine to generate electricity. Emissions data generally show very low rates for dioxins, acid gases, and other problematic pollutants.

The processes studied in detail, identified by the name of the developer, are:

- Energy Products of Idaho (EPI)

- TPS Termiska Processer AB

- Proler International Corporation

- Thermoselect Inc.

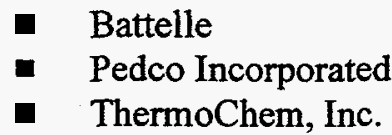

- Battelle
- Pedco Incorporated
- ThermoChem, Inc.

Of these seven emerging technologies, two-Energy Products of Idaho and Pedco Incorporated-use full combustion, but in novel contexts. The other five processes-TPS Termiska Processor AB, Proler International Corporation, Thermoselect Inc., Battelle, and ThermoChem Inc.-use gasification methods followed by cleanup and use of the fuel gas. In niche market sectors and in the broader market, the five gasification technologies studied during this project are emerging as "commercially-ready" alternatives.

The penetration of the thermal processing market by advanced technologies is paced by their environmental, economic, and performance acceptability. From an environmental viewpoint, the project team saw the seven technologies as a sound response to the regulatory challenges of the revised New Source 
Performance Standards (NSPS) and the Maximum Achievable Control Technology (MACT) rules. The environmental characteristics of the seven processes are summarized in Table 1.1.

In the U.S., economics has always been a critical and probably pacing factor affecting the penetration of thermal processing technology in MSW practice. Tables $1.2 \mathrm{a}$ and $1.2 \mathrm{~b}$ summarize, in metric and English units respectively, the economic data collected and developed in this study. Capital costs of most of these processes are comparable to the $\$ 110,000 / \mathrm{Mg} / \mathrm{d}(\$ 100,000 / \mathrm{t} / \mathrm{d})$ typical of contemporary mass burn systems. The net operating costs for the gasification technologies, which are equivalent to the break-even tipping fee, are comparable to those for owner-operated mass-burn facilities. The revenue stream from selling energy continues to be critical to overall economic acceptability.

Results are less clear concerning "performance acceptability." Most, except for the EPI and Thermoselect processes, require an RDF feed. Historically, most RDF facilities have incurred substantial postconstruction rework, capital investment, capacity downrating, etc. Landfills are still required. Many systems in this study have significant development tasks ahead of them. Unfortunately, the catalyst of vigorous market activity to push this development and to foster risk-taking is weak. Further, many systems are quite complex. This complexity presents some problems when seeking acceptance by client communities, by regulatory authorities, and from financial and engineering entities involved in concept selection and project implementation.

\section{PROJECT APPROACH}

The first task was to prepare a detailed work plan. Then, a two-stage screening process was begun to select the firms for detailed evaluation, the criterion for such evaluation being that they had thermal processes under development worldwide. This screening was followed by process evaluation, facility inspections, and ultimately, by preparation of this summary report. Initially, the project team contacted over 40 firms identified as possible candidates. The data received were analyzed to produce a recommendation for the final seven processes. The selection of the final seven was discussed and confirmed at a meeting with the Project Steering Committee.

The scope of the detailed evaluation effort for the seven selected technologies was broad. Based on a faxed request and answers to a detailed questionnaire, data for the evaluation were obtained from the developers. The evaluation included exploration of technical issues affecting the basic process feasibility, reliability, worker safety, operability, and maintainability. Of importance was the remaining degree of scale-up from the present level of development to commercially useful equipment. Operating experience was also considered critical.

Environmental issues covered the total emissions profile of the operations. Environmental acceptability is a basic requirement for the viability of any process. Since almost any process can comply with environmental regulations if sufficient resources are assigned to the task, this requirement is one of ensuring that each process system includes the necessary features, equipment, and staff to meet 1996 emissions codes. 
Table 1.1 Environmental Comparison of Developing Technologies

\begin{tabular}{|c|c|c|c|c|}
\hline Process Name & $\begin{array}{c}\text { Thermal Treatment } \\
\text { Technology }\end{array}$ & Air Pollution Control & $\begin{array}{c}\text { Water Pollution } \\
\text { Control }\end{array}$ & $\begin{array}{c}\text { Residue Treatment } \\
\text { or Disposal }\end{array}$ \\
\hline EPI, Inc. & $\begin{array}{l}\text { Bubbling Fluid Bed } \\
\text { Combustor }\end{array}$ & $\begin{array}{l}\text { Lime Spray Dryer Absorber, Fabic } \\
\text { Filter, Selective Noncatalytic } \\
\text { Reduction, Activated Cabon Injection }\end{array}$ & None: Dry System. & Landfill \\
\hline $\begin{array}{l}\text { TPS Termiska } \\
\text { AB }\end{array}$ & $\begin{array}{l}\text { Circulating Fluid Bed } \\
\text { Gasifier with Dolomite } \\
\text { Cracker }\end{array}$ & $\begin{array}{l}\text { Scrubbing of Fuel Gas to Remove } \\
\text { Particulate Matter, Condensable } \\
\text { Organics, and Acid Gasses, } \mathrm{NO}_{\mathrm{x}}{ }^{1}\end{array}$ & $\begin{array}{l}\text { Cleanup of Scrubber } \\
\text { Liquor. Not } \\
\text { specified. }^{2}\end{array}$ & Landfill \\
\hline $\begin{array}{l}\text { Proler } \\
\text { International }\end{array}$ & $\begin{array}{l}\text { Rotary Reactor Gasifier } \\
\text { and Cyclonic Ash Vitrifier }\end{array}$ & Fabric Filter, Wet Scrubber, $\mathrm{NO}_{x}{ }^{1}$ & $\begin{array}{l}\text { Cleanup of Scrubber } \\
\text { Liquor. Not } \\
\text { specified. }^{2}\end{array}$ & $\begin{array}{l}\text { Proposed Sale as } \\
\text { Vitrified Aggregate; } \\
\text { Otherwise landfill. }\end{array}$ \\
\hline $\begin{array}{l}\text { Thermoselect, } \\
\text { Inc. }\end{array}$ & Raw Waste Gasifier & $\begin{array}{l}\text { Acidic and Alkaline Scrubber, } \mathrm{H}_{2} \mathrm{~S} \\
\text { Removal, Activated Coke, } \mathrm{NO}_{x}{ }^{1}\end{array}$ & $\begin{array}{l}\text { pH Adjustment, Metal } \\
\text { Precipitation, } \\
\text { Filtration, Distillation. }\end{array}$ & $\begin{array}{l}\text { Proposed Sale as } \\
\text { Vitrified Aggregate; } \\
\text { Otherwise Landfill. } \\
\end{array}$ \\
\hline Battelle & $\begin{array}{l}\text { Circulating Fluid Bed } \\
\text { Gasifier and Combustor }\end{array}$ & Wet Scrubber, $\mathrm{NO}_{\mathrm{x}}{ }^{1}$ & $\begin{array}{l}\text { Cleanup of Scrubber } \\
\text { Liquor. Not } \\
\text { Specified. }{ }^{2}\end{array}$ & Landfill \\
\hline $\begin{array}{l}\text { Pedco } \\
\text { Incorporated }\end{array}$ & $\begin{array}{l}\text { Rotary Cascading Bed } \\
\text { Combustor }\end{array}$ & $\begin{array}{l}\text { Lime Spray Dryer/Absorber, Fabric } \\
\text { Filter, Selective Noncatalytic } \\
\text { Reduction, Activated Carbon Injection. }\end{array}$ & None. Dry System. & Landfill \\
\hline ThermoChem & $\begin{array}{l}\text { Pulse-Heated Circulating } \\
\text { Fluid Bed Gasifier }\end{array}$ & Wet Scrubber, $\mathrm{NO}_{\mathrm{x} \cdot}{ }^{1}$ & $\begin{array}{l}\text { Cleanup of Scrubber } \\
\text { Liquor. Not } \\
\text { specified. }^{2}\end{array}$ & Landfill \\
\hline
\end{tabular}

1. $\mathrm{NO}_{\mathrm{x}}$ control may be required for the gas engine or turbine combustor.

2. Details of treatment were no specified by the developer. 
Table 1.2a Summary of Statistics for Developing Technologies (per ton quantities relate to raw MSW, metric units)

\begin{tabular}{|c|c|c|c|c|c|c|}
\hline Process & $\begin{array}{c}\text { Product Energy } \\
\text { Form }\end{array}$ & $\begin{array}{c}\text { Plant Size } \\
\text { Evaluated } \\
\left(\mathbf{M g} / \mathbf{d}_{\text {raw }}\right)\end{array}$ & $\begin{array}{l}\text { Capital Cost } \\
\quad(\$ 000)\end{array}$ & $\begin{array}{l}\text { Process Capital } \\
(\$ 000)\end{array}$ & $\begin{array}{l}\text { Proprietary } \\
\text { Capital (\%) }\end{array}$ & $\begin{array}{l}\text { Capital Cost } \\
\text { (\$/Mg/d) }\end{array}$ \\
\hline EPI Inc. & Steam & 780 & 79,415 & 28,015 & 35.3 & 101,800 \\
\hline PS Termiska Processor AB & Gas & 1600 & 170,675 & 58,875 & 33.3 & 106,700 \\
\hline Rroler International Corp. & Gas & 1247 & 153,625 & 57,625 & 37.5 & 123,200 \\
\hline Thermoselect inc. & Gas & 1440 & 236,790 & 192,790 & 81.4 & 164,400 \\
\hline Battelle & Gas & 849 & 80,532 & 12,532 & 15.6 & 94,900 \\
\hline Pedco Incorporated & Steam & 800 & 87,067 & 28,167 & 32.4 & 108,800 \\
\hline ThermoChem Inc. & Gas & 849 & 91,733 & 20,983 & 22.9 & 108,800 \\
\hline
\end{tabular}

\begin{tabular}{|c|c|c|c|c|c|c|}
\hline Process & $\begin{array}{l}\text { Gross Operating } \\
\text { Cost }(\$ / M g)^{*}\end{array}$ & $\begin{array}{c}\text { Gross Power } \\
\text { (kWh/Mg) }\end{array}$ & $\begin{array}{l}\text { Net Power } \\
(\mathrm{kWh} / \mathrm{Mg})\end{array}$ & $\begin{array}{c}\text { Net Operating } \\
\text { Cost } \\
(\$ / \mathrm{Mg}) \dagger\end{array}$ & $\begin{array}{c}\text { Gross Heat } \\
\text { Rate } \\
(\mathrm{MJ} / \mathbf{k W h}) \S\end{array}$ & $\begin{array}{c}\text { Net Heat Rate } \\
(\text { MJ/kWh }) \S\end{array}$ \\
\hline TPS Termiska Processor AB & 71.84 & 1230 & 1024 & 38.91 & 8.57 & 10.29 \\
\hline Proler International Corp. & 99.15 & 1281 & 1091 & 59.47 & 8.23 & 9.67 \\
\hline Battelle & 79.37 & 1001 & 871 & 47.63 & 10.53 & 12.11 \\
\hline Pedco Incorporated & 78.87 & 886 & 868 & 52.29 & 11.89 & 12.15 \\
\hline ThermoChem Inc. & 81.17 & 1149 & 1004 & 44.56 & 9.17 & 10.50 \\
\hline
\end{tabular}

*Gross operating cost/ton raw refuse-total of capital charges, insurance, labor, maintenance, and supplies before energy credits. †Net operating cost/ton raw refuse-gross operating cost less energy credit.

$\S$ Heat rate-factor relating the fuel value in the raw refuse (assumed at $11.6 \mathrm{MJ} / \mathrm{kg}, 14 \mathrm{MJ} / \mathrm{kg}$ as RDF) to the gross or net generation. 
Table 1.2b Summary of Statistics for Developing Technologies (per ton quantities relate to raw MSW, English units)

\begin{tabular}{|c|c|c|c|c|c|c|}
\hline Process & $\begin{array}{c}\text { Product Energy } \\
\text { Form }\end{array}$ & $\begin{array}{c}\text { Plant Size } \\
\text { Evaluated } \\
\left(\mathrm{t} / \mathrm{d}_{\text {raw }}\right)\end{array}$ & $\begin{array}{c}\text { Capital Cost } \\
(\$ 000)\end{array}$ & $\begin{array}{c}\text { Process Capital } \\
(\$ 000)\end{array}$ & $\begin{array}{l}\text { Proprietary } \\
\text { Capital (\%) }\end{array}$ & $\begin{array}{c}\text { Capital Cost } \\
(\$ / t / d)\end{array}$ \\
\hline EPl lnc. & Steam & 860 & 79,415 & 28,015 & 35.3 & 92,343 \\
\hline TPS Termiska Processor AB & Gas & 1760 & 170,675 & 58,875 & 33.3 & 96,974 \\
\hline Proler International Corp. & Gas & 1370 & 153,625 & 57,625 & 37.5 & 112,135 \\
\hline Thermoselect Inc. & Gas & 1585 & 236,790 & 192,790 & 81.4 & 149,394 \\
\hline Battelle & Gas & 935 & 80,532 & 12,532 & 15.6 & 86,130 \\
\hline Pedco Incorporated & Steam & 880 & 87,067 & 28,167 & 32.4 & 98,940 \\
\hline Thermochem Inc. & Gas & 935 & 91,733 & 20,983 & 22.9 & 98,110 \\
\hline
\end{tabular}

\begin{tabular}{|c|c|c|c|c|c|c|}
\hline Process & $\begin{array}{l}\text { Gross Operating } \\
\text { Cost }(\$ / t)^{*}\end{array}$ & $\begin{array}{c}\text { Gross Power } \\
(\mathrm{kWh} / \mathrm{t})\end{array}$ & $\begin{array}{c}\text { Net Power } \\
(k W h / t)\end{array}$ & $\begin{array}{c}\text { Net Operating } \\
\text { Cost } \\
(\$ / t) t \\
\end{array}$ & $\begin{array}{l}\text { Gross Heat Rate } \\
(\text { Btu/kWh)§ }\end{array}$ & $\begin{array}{c}\text { Net Heat Rate } \\
\text { (Btu/kWh)§ }\end{array}$ \\
\hline EPI Inc. & 77.46 & 899 & 740 & 47.88 & 11,117 & 13,522 \\
\hline TPS Termiska Processor AB & 65.31 & 919 & 748 & 35.37 & 10,879 & 13,362 \\
\hline Proler international Corp. & 90.12 & 1059 & 901 & 54.06 & 9,445 & 11,094 \\
\hline Thermoselect Inc. & 112.03 & 895 & 643 & 86.29 & 11,176 & 15,549 \\
\hline Battelle & 71.60 & 827 & 720 & 42.81 & 12,087 & 13,896 \\
\hline Pedco Incorporated & 85.16 & 879 & 717 & 56.47 & 11,376 & 13,938 \\
\hline ThermoChem Inc. & 73.60 & 950 & 830 & 40.41 & 10,529 & 12,052 \\
\hline
\end{tabular}

*Gross operating cost/ton raw refuse-total of capital charges, insurance, labor, maintenance, and supplies before energy credits.

†Net operating cost/ton raw refuse-gross operating cost less energy credit.

$\S$ Heat rate-factor relating the fuel value in the raw refuse (assumed at $5000 \mathrm{Btu} / \mathrm{lb}, 6050 \mathrm{Btu} / \mathrm{lb}$ as RDF) to the gross or net generation. 
Business issues revolved around the financial and manpower resources of the firms that could be harnessed to achieve commercial viability. Important factors in the award of disposal contracts are the prospective capital and operating costs of the system. To keep the focus on the thermal processing aspect of the process, standardized costs were developed for the preparation of MSW to RDF and for the conversion of the energy product - the high-pressure steam or a fuel gas - into electricity. The resultant cost information for these technologies is thus an economic picture of a generic plant with standardized feedstock and energy conversion components-a plant that perhaps is not optimal. A serious buyer should contact the developer organizations to give them the opportunity to propose their costs for any specific situation.

\section{TECHNOLOGY SUMMARIES}

\section{Energy Products of Idaho (EPI).}

EPI is a limited partnership with headquarters in Coeur d'Alene, Idaho. EPI's basic business is the design and fabrication of fluid bed combustion systems. Although their corporate experience favors the full-combustion mode for their systems, they have pilot plant and commercial plant experience, with three commercial systems, in a "starved-air" gasification mode. Their most proven product, however, is the fullcombustion system.

The EPI incineration system uses a bubbling-type fluid bed concept that accepts a prepared 10-cm (4-in.) top size RDF. Within the bed, RDF particles are exposed to a vigorously turbulent hot environment that promotes rapid drying, gasification, and char burnout. In the bed EPI's proprietary design features provide continuous removal of oversized noncombustible materials. The hot gases from the bed are passed through a boiler to generate the high-pressure, superheated steam that is used either to produce electricity or for process applications.

The combustion technology offered by EPI is presently at the point of commercial availability. EPI has installed five furnaces in the U.S., with capacities of more than $50 \mathrm{Mg} / \mathrm{d}(60 \mathrm{t} / \mathrm{d})$, burning an RDF fuel. Between 1982 and 1985, EPI designed and built three wood-waste-fired, gasification-mode fluid bed systems. They also have acquired in-house operating experience with RDF in their pilot plant gasifier; but at the time of this study, they had no operating commercial-scale plants on RDF in the gasification mode.

Therefore, in matters of technical maturity and commercial verification, the EPI system can be implemented with limited risk in the combustion mode. The gasification mode is much less developed and will require some additional testing, operating experience, and design maturation. Thus potential users will encounter substantially greater risk at present.

\section{TPS Termiska Processer, AB}

TPS Termiska Processer (Thermal Processes), or TPS, is a small, independent Swedish company with about 50 employees, working in the specialized field of energy and environmental process research and technology development. Their technology involves the starved-air gasification of RDF in a combined bubbling- and circulating-type fluid bed. Following the gasification bed, they insert a second circulatingbed "cracker." In the second bed, ground dolomite is injected to catalyze the conversion of highmolecular-weight gasification by-products into much lower molecular-weight compounds. This system generates fuel with a medium heat content. 
The technology offered by TPS is presently close to the point of commercial availability. In 1992 a commercial, two-bed unit was installed in Gréve-en-Chianti in Italy. It had a combined capability of 30 MW to gasify 100-percent pelletized RDF fuel. Limited RDF availability since early 1995 had led to the use of biomass (coarsely shredded wood or agricultural wastes) from time to time.

The manufacturing methods for the TPS-design gasifier systems, the long-term operability of their beds with acceptable management of bed solids, the projected emissions control performance, the feeders, etc., have been tested at Gréve in MSW-based RDF service. Therefore, in matters of technical maturity and commercial verification, the TPS system can most likely be implemented with only moderate technological risk.

\section{Proler International Corporation}

The Proler SynGas Process is a patented technology to reform hydrocarbon-containing wastes into a gaseous product. It is represented by a $1.8-\mathrm{Mg} / \mathrm{h}(2-\mathrm{t} / \mathrm{h})$ demonstration plant in Houston, Texas. Although the process was originally developed for the gasification of automobile shredder wastes, limited runs have demonstrated its suitability for gasifying MSW. The process accepts preshredded material and feeds it into a rotating, kiln-like reactor. In the proposed commercial embodiment of the process, the reactor is fired with the exhaust from a "vitrifier" auxiliary that uses fuel gas, carbon char, and oxygen to melt the mineral residue. The process produces fuel gas with a medium heat content; after cleanup, this fuel gas is suitable for power generation. The residue is discharged in a form that is stated to be a commercially useful byproduct.

According to Proler, the preliminary design work has been completed for a full-scale $865-\mathrm{Mg} / \mathrm{d}$ (960-t/d) commercial facility using MSW as feedstock. The facility consists of two process lines at $18 \mathrm{Mg} / \mathrm{h}(20 \mathrm{t} / \mathrm{h})$ each. However, some technical issues require resolution before successful commercialization for MSW can be ensured:

- Although the demonstration plant is processing RDF at a top size of $5.08 \mathrm{~cm} \mathrm{(2} \mathrm{in.),} \mathrm{the}$ commercial plant is expected to accept shredded material with a top size of $15.24 \mathrm{~cm}(6 \mathrm{in}$.). This premise has not yet been sufficiently tested.

- The demonstration plant has operated with shredded MSW on a limited basis only. An extended campaign of operation appears essential to evaluate potential problems.

- The reliability and performance of the vitrifier and the integration of this equipment with the existing gasifier have not yet been accomplished.

- The planned commercial size at $11.3 \mathrm{~kg} / \mathrm{s}(40 \mathrm{t} / \mathrm{h}) \mathrm{MSW}$ represents a scale-up of $5.5: 1$ on a perline basis. Past experience with other combustion and thermal process development scenarios indicates that such a substantial step implies a high risk factor when processing MSW.

Further testing with MSW to resolve these issues seems desirable. Proler has indicated an intent to guarantee the performance of its process. 


\section{Thermoselect Inc.}

The Thermoselect system processes commingled MSW into what are stated to be environmentally safe products. The products include a reactor gas, vitrified solid granules, elemental sulfur, and sodium salts. No liquid effluents are discharged into the environment. The process is intended to minimize formation and emission of particulates and other pollutants.

Gasification is achieved at a high temperature. The mixture of solid refuse and char reaches $800^{\circ} \mathrm{C}$ $\left(1472^{\circ} \mathrm{F}\right)$ as it reaches the discharge end of a preprocessing section, described by Thermoselect as the degasification channel. The products of gasification are then held in the reactor at $1200^{\circ} \mathrm{C}\left(2192^{\circ} \mathrm{F}\right)$ for more than 4 seconds. The resultant gas is quenched in a spray chamber to below $90^{\circ} \mathrm{C}\left(194^{\circ} \mathrm{F}\right)$. Data indicate that this combination of time and temperature destroys the complex organic compounds produced in the gasification process and yields a gaseous product that has nearly reached chemical equilibrium. The raw gas is cleaned in a gas purification system that removes acid gases, hydrogen sulfide, particulates, and volatile heavy metals. Air emissions result only from the combustion of the cleaned reactor gas as heat is produced in the boilers or from other means for generating electric power.

The Thermoselect demonstration facility is located at Fondotoce, Italy, near Lago Maggiore in the southern foothills of the Alps. The equipment consists of one process line with a nominal capacity of $4 \mathrm{Mg} / \mathrm{h}$ $(4.4 \mathrm{t} / \mathrm{h})$ or $100 \mathrm{Mg} / \mathrm{d}(106 \mathrm{t} / \mathrm{d})$. The line at the pilot plant includes all of the process units (acid and alkaline scrubbers, hydrogen sulfide-removal scrubber, coke filter, etc.) that are envisioned in the full-scale commercial plant. Test results indicate only minute traces of organic compounds in the reactor gas. Other than traces of polychlorinated dibenzo p-dioxin (PCDD) and polychlorinated dibenzo furan (PCDF), no chlorinated aromatic hydrocarbons were detected.

This system should comply with U.S. environmental regulations. The demonstration plant is stated to have gone through 20,000 hours of operation and operates continuously for 5 days a week, processing unshredded municipal and industrial wastes. The plant uses product gas for driving an engine generator and heating the degasification channel.

Major unresolved areas appear to be:

- Optimization of energy use.

- Use of Thermoselect's reactor gas in gas turbines-untested as of early 1996, but not expected to be a problem.

- Replacement of natural gas (now used at Fondotoce) with reactor gas-should not be a problem.

- Waste-heat recovery to improve overall plant thermal efficiency, including finding uses for lowgrade heat.

- Continuity and reliability of operation, since the demonstration plant has only been operated on a 5-day/week cycle. Continuous, around-the-clock operation is yet to be demonstrated.

- Scale-up. The current demonstration plant is reported to have a "nominal capacity of $4 \mathrm{Mg} / \mathrm{h}$ $(4.4 \mathrm{t} / \mathrm{h})$," but experience to date shows that the unit appears to operate at an actual throughput of only $3.8 \mathrm{Mg} / \mathrm{h}(4.2 \mathrm{t} / \mathrm{h})$. The "Standard Design" two-line capacity is $10 \mathrm{Mg} / \mathrm{h}(11 \mathrm{t} / \mathrm{h})$ or $240 \mathrm{Mg} / \mathrm{d}(264 \mathrm{t} / \mathrm{d})$. Therefore, there is a scale-up factor of about $2.7: 1$ based on actual operating 
$240 \mathrm{Mg} / \mathrm{d}(264 \mathrm{t} / \mathrm{d})$. Therefore, there is a scale-up factor of about $2.7: 1 \mathrm{based}$ on actual operating experience. The success of the planned commercial-size facility is yet to be proved.

\section{Battelle}

The Battelle High Throughput Gasification System (BHTGS) uses indirect heating in a twin, circulating fluidized bed (CFB) gasifier and combustor. RDF is gasified in a CFB using steam as the fluidizing medium to generate an 18.6 to $22.4 \mathrm{MJ} / \mathrm{Nm}^{3}$ ( 500 to $600 \mathrm{Btu} / \mathrm{sft}^{3}$ ) medium-heating-value gas without oxygen. Residual char is consumed in an associated CFB combustor. A circulating sand phase provides heat transfer between the separate reactors.

Tests demonstrated the technical feasibility of the gasification process and provided the basis for preparing detailed process conceptual designs and projecting economics. In 1989 testing was conducted in a $25-\mathrm{cm}$ (10-in.)-ID, 6.9-m (22.7-ft)-high gasifier and a 1.0-m (40-in.) ID, 3.5-m (11.5-ft)-high combustor. Throughput was $0.65 \mathrm{Mg} / \mathrm{h}(0.72 \mathrm{t} / \mathrm{h})$. The longest continuous operating run was approximately 100 hours at $9.1 \mathrm{Mg} / \mathrm{d}(10 \mathrm{t} / \mathrm{d})$ with dry RDF. A 200-kW gas turbine installed on their Process Research Unit (PRU) has operated with recharges from wood for about 60 hours as an integrated gasifier/turbine system.

Battelle has licensed its BHTGS to Future Energy Resources Corporation (FERCO) in Atlanta, Georgia, for the North American market. A commercial-scale demonstration, using wood chips, is under way at Burlington Electric's McNeil Generating Station in Burlington, Vermont.

The BHTGS is said to produce gaseous emissions from the reactor that comply with EPA's NSPS for municipal waste combustors. Wastewater from the process contains only trace quantities of organic materials. The outlet of a simple industrial treatment system at Battelle's test site showed wastewater to be within EPA's drinking water standards.

Battelle's process development began in 1977. Detailed process development activities were begun in 1980 with the construction of Battelle's PRUs. Experimental data have been generated in 15-cm (6-in.) diameter and $25-\mathrm{cm}$ (10-in.) diameter gasifiers with dry RDF throughputs of 0.22 and $9.1 \mathrm{Mg} / \mathrm{d}(0.24$ and $10 \mathrm{t} / \mathrm{d}$ ) respectively. Data from these showed that extremely high throughputs, over $19.5 \mathrm{Mg} / \mathrm{h} \cdot \mathrm{m}^{2}$ $\left(4000 \mathrm{lb} / \mathrm{hr}^{\circ} \cdot \mathrm{ft}^{2}\right)$ could be achieved.

Important process issues relate to fuel preparation and reactor gas cleanup. The specific level of fuel preparation necessary for the process has not yet been determined, but data suggest that there will not be a requirement for fine shredding of the feedstock. Feed size range will be dictated by the feed system requirements. Product gas cleanup, to include tar cracking and particulate removal, is also important. Additional operation at PRU scale is necessary to confirm the preliminary results obtained during the 1989 study at Battelle. The overall design concept needs to be expanded from a development focused on gasifier technology to a full plant with all auxiliaries and subsystems.

\section{Pedco Incorporated}

Pedco Incorporated has its headquarters in Cincinnati, Ohio. The firm, originally formed in 1967, has gone through several stages of growth and spin-off. The present firm was formed in 1984 to pursue, among other interests, the development and commercialization of an innovative, solid-fuel combustor. 
The Pedco Rotary Cascading Bed Combustor (RCBC) is, in essence, a robust solid-fuel burner and heat-recovery system. It is not a gasifier. Among other solid fuels, such as coal or wood chips, it can burn prepared MSW. Pedco's basic business is the design of combustion systems using the RCBC concept.

The $\mathrm{RCBC}$ burner comprises a rotating, horizontal, cylindrical combustion chamber. A bundle of boiler tubes projects into one end of the chamber. The rotational speed of the chamber is high enough to keep a substantial fraction of the bed material continually airborne. This activity produces an environment similar to that of a fluid bed but, in this case, a mechanically fluidized bed. The hot falling solids cascade across the whole diameter so that the boiler tubes are submerged in hot fuel and bed material. The hot solids recycle preheats the combustion air, drying and igniting the incoming fuel.

Pedco has two furnaces now operating in the U.S. - a development unit at North American Rayon Corporation and a specialized unit based on Pedco design principles used by a commercial hazardous waste management firm near Houston, Texas. The plants are reported to have shown acceptable reliability, environmental emissions, and basic operability and maintainability characteristics.

Pedco prefers to provide their $\mathrm{RCBC}$ system as a factory-assembled RCBC burner with a waste-heat boiler configuration sized to make shipping by truck or rail feasible. The design heat release rate of the Pedco basic RCBC system is approximately $233,000 \mathrm{MJ} / \mathrm{h}\left(100 \times 10^{6} \mathrm{Btu} / \mathrm{h}\right)$, corresponding to a daily $\mathrm{RDF}$ rate of $168 \mathrm{Mg} / \mathrm{d}(185 \mathrm{t} / \mathrm{d})$. Air pollution trains for the $\mathrm{RCBC}$ system would use a sprog dryer/absorber (SDA) although some acid gas control is effected by adding low-cost, coarse limestone screenings to the bed. The SDA would normally be combined with a fabric filter unit. Pedco believes that its in-bed limestone addition and consequent acid gas absorption eliminate the necessity for the SDA used in many mass-burn plants. Additional data are needed to confirm this position.

Pedco has yet to develop and adopt a front-end waste system to produce a sized RDF feed for the $\mathrm{RCBC}$ system. Indeed, Pedco has only limited experience with RDF and has not yet established a firm basis on which to specify their optimum top size. Development of a generalized RDF flowsheet should not be a problem. However, almost all RDF facilities have required extensive redesign and reconstruction to bring RDF processing elements to an acceptable level of reliability and performance.

A few hours' operation of a robust combustor with RDF, however successful, does not constitute an adequate basis for facility design, nor for process and emissions guarantees, air pollution and other permit submissions, and long-term operating contracts. Of particular importance relative to the RCBC are:

- Fouling and plugging, separately or in combination, of the ash handling chutes with wire and oversized noncombustible materials

- Similar fouling problems for the boiler tubes

- Abrasion and corrosion problems.

These problems could result in both frequent equipment outages, affecting plant throughput and electrical revenue, and high maintenance expense. Experience with the cluster of boiler tubes inserted into the RCBC device has been limited to relatively low-pressure, saturated steam. To achieve maximum power production, higher pressures and superheated conditions are preferred. Higher skin temperatures on the tubes may affect their erosion and corrosion sensitivity and should be evaluated before making a commitment to a full-scale facility. 


\section{ThermoChem, Incorporated}

The Manufacturing and Technology Conversion International, Inc. (MTCI) Steam Reforming Process is an indirectly heated fluidized bed reactor, using steam as the fluidizing medium. Under a license from MTCI, ThermoChem, Inc., has exclusive rights to apply its Pulse-Enhanced ${ }^{\mathrm{TM}}$ heater and steam-reforming technology to a variety of applications.

Pulse Enhanced ${ }^{\mathrm{TM}}$ indirect heating, combined with fluidized bed and steam reforming, provides a process for converting organic material in RDF to fuel gas while separating the inorganics without oxidation or melting. The heart of the process is the Pulsed Enhanced ${ }^{\mathrm{TM}}$ heater that is immersed in the fluidized bed. The organic waste fed to the fluidized bed steam reformer reacts with steam to produce fuel gas.

MTCI's development efforts began in 1984. Experimental data have been generated in reactors from 9.1 to $2722 \mathrm{~kg} / \mathrm{h}(20$ to $6000 \mathrm{lb} / \mathrm{h})$ using various biomass and waste feedstocks. In 1991 and 1992, a 13.6$\mathrm{Mg} / \mathrm{d}$ (15-t/d) demonstration unit was operated on rejects from a cardboard recycle paper mill in Ontario, California. Later, this same unit was relocated to ThermoChem's test facility in Baltimore, Maryland, to process coal, wood chips, and straw.

Based on $6.8-\mathrm{kg} / \mathrm{h}(15-\mathrm{lb} / \mathrm{h})$ pilot plant tests, the ThermoChem Process appears to comply with EPA's NSPS for municipal waste combustors. Tests indicate the residue meets EPA Toxicity Characteristics Leaching Procedure (TCLP) criteria set for landfill disposal as a nonhazardous waste. Wastewater contains only trace amounts of organic materials.

ThermoChem envisions no problem areas when operating with RDF. They believe that tube corrosion, erosion, and plugging will not be a problem. However, experience in other RDF-based technologies strongly suggests that until full-scale trials are conducted over an extended period, the risks and potential cost of these problems should not be ignored. Other development experiences also suggest that there are many other issues that must be resolved satisfactorily to "marry" a workable process to a workable, reliable facility. The materials handling system needs work. The cyclones are subject to plugging, just as they are in conventional atmospheric fluid beds. The removal of solids from the bed can be a problem. Considerable demonstration work is clearly needed to address remaining uncertainties regarding air emissions; residue quality; plugging of the spaces between the tubes with wire, metal, and rocks; etc. These uncertainties translate into persistent risks that should be carefully considered before adopting this technology.

\section{E. RESULTS}

The review showed that an intense developmental activity applicable to the thermal processing of MSW is under way in the U.S. and Europe. We identified over 40 discrete efforts at some stage of process development. Most of the processes are based on MSW gasification, as opposed to full combustion. In part, the focus on gasification reflects the current stringent regulatory situation regarding the control of air emissions in both the U.S. and Europe. Thus processes that allow cleanup of the reactor gases before their combustion offer potential cost savings, since the volume of flow treated is small. The cleaned fuel gases can be burned in either gas engines or gas turbines to generate electricity or can be sold as a fuel for use in conventional fossil-fuel-fired boilers. 
Although many of the 40 processes are still at the bench or laboratory scale, several have progressed to a pilot or semiworks level, where the difficult problems of reliability, flexibility, and the like begin to show themselves. The seven processes selected for detailed study in this assignment are all very near to commercialization. Indeed, one technology has been implemented in four, full-scale commercial facilities. However, most processes still present some risk to a prospective owner. This risk could show itself as higher capital or operating costs, less reliability, or lower energy-recovery efficiency than have been forecast at this time. The development record for new MSW processing technologies suggests that such problems are probable for some processes as they move into full-scale commercialization.

The overall conclusion that can be drawn from the study is that competitive alternatives to conventional mass-burn or RDF combustors exist. The alternatives may not offer exceptional economic advantages. Almost all of the processes studied present a significantly lower air emissions profile than do conventional plants. This fact may merit investigation by communities or regional jurisdictions considering volume reduction technology. The economic analyses in Tables $1.2 \mathrm{a}$ and $1.2 \mathrm{~b}$ are intended to provide perspective; they are not directly applicable to any one situation. To be fair to both the potential user and to the developers, cost issues should be addressed directly with the firms.

Based on data from pilot facilities, each of these processes should be able to achieve full compliance with the U.S. EPA MACT standards and the NSPS for Municipal Waste Combustors that were promulgated in final form in December 1995. Since only one of the processes matches the technology groups used by EPA in their standard setting and many are gasifiers and not the full-combustion systems identified in the EPA standards, there is some uncertainty in knowing how the Federal standards will be applied. As with most permitting issues, the ultimate resolution of the questions must wait until actual permits have been submitted and final regulatory action is required.

The residues from the processes do not present problems in the TCLP leaching tests. However, the quantity of data in this area is limited, and experience in mass-burn plants suggests that significant variations can be expected in TCLP results. Two of the processes, Thermoselect and Proler, include process steps where the residues are melted (vitrified). For these processes, the TCLP results are exceptionally low because the metals are bound in a glass structure and cannot be readily solubilized. Both firms believe that the vitrified residue granules may be marketable and thus that their processes will have lower operating costs than are shown in Table 1.2a and Table 1.2b. As yet, however, the value of the granules, if any, has not been established in the U.S. marketplace.

\section{F. CLOSING}

The project team was very impressed with the professionalism, the high technical standards, and the business commitment in most of the development firms studied. Many developers have access to the capital resources that are so critically important to technology demonstration and evolution. Capital is crucial for the seven developers if they are to further the evolution and maturation of their technology and present to the marketplace convincing proof of the ability of their processes to meet the demands of MSW management. 


\section{Section 2}

\section{INTRODUCTION}

\section{A. PROJECT OBJECTIVES}

The project covered in this report was conducted to identify developers whose gasification or other innovative thermal processing technologies have the potential for treating the organic constituents in municipal solid waste (MSW). The processes recover heat directly, produce a fuel product, or produce a feedstock for a chemical process. Each of the seven technologies selected for detailed study, from more than $\mathbf{4 0}$ originally screened, is on the brink of commercial availability. ${ }^{*}$ Each has passed the idea stage, moved through laboratory and bench-scale testing, and finally been proved feasible at the prototype level at an MSW feed rate of at least several tons per hour.

This report summarizes project activities, describes the current status of each technology, and identifies the selected developers, all of whom have expressed an interest in applying their technology to MSW treatment. This section covers the Project Team's approach to the work; discusses the data requested of project participants; and evaluates business, cost, and economic issues. Sections 3 through 9 are detailed discussions of each project participant's technology. And finally, Section 10 presents a concise review and summary of the information gathered during the study.

\section{B. PROJECT APPROACH}

The initial task in the project was the preparation of a comprehensive Work Plan. After the plan was completed, the Team began a two-stage screening process. Candidates to be evaluated in detail were selected from companies with thermal processes under development worldwide. The two-stage screening process was followed by a candidate evaluation phase, during which such aspects as technical, environmental, and financial suitability were explored. The regulatory issues facing developers were also examined. Process evaluations, facility inspections, and preparation of this summary report formed the balance of the project.

\section{Screening Phase}

The overall objective of the screening effort was to narrow the number of processes under consideration from over 40 to the final 7 . The final candidates were those judged to have the greatest nearterm promise of technical and commercial success for MSW applications. They were not the only viable thermal processes among the many processes identified. Many others not as far along in their development at the time of the project (mid-1995) or those that were focused on other feedstocks (e.g., wood waste or sewage sludge) may be quite appropriate for another type of application now or for application to MSW at some time in the future, after additional testing and development are completed.

\footnotetext{
* Commercial availability in this case means that process developers could plausibly, in the near term, offer their processes as technically, economically, and environmentally sound alternatives for municipal waste management
} 


\section{a. Initial Screening}

The Project Team contacted each of the more than 40 firms identified as possible candidates (Appendix A). Basic process information was requested in the course of this initial conversation (Appendix B). The preliminary process information and the candidate characterization data collected during these calls became the basis for the initial screening to approximately 20 firms. The full list was discussed at a May 1995 project meeting with the project Steering Committee, during which a 20-firm short list was confirmed.

\section{b. Final Screening}

The remaining 20 candidates were scrutinized through further telephone interviews, during which additional information was solicited. The evaluation was a critique of the 20 according to the relative likelihood that their processes could be commercially implemented. These factors were considered:

- State of Development

- Technical Issues

- Business Issues

The detailed data received were analyzed in light of these additional screening criteria. The final seven processes were recommended, discussed, and confirmed.

\section{Candidate Evaluation Phase}

The scope of the detailed evaluation effort for the seven selected technologies was broad. Data for the evaluation were obtained from the developers based on a faxed request (Appendix C) and a detailed questionnaire (Appendix D).

The evaluation included exploration of technical issues affecting basic process feasibility, reliability, worker safety, operability, and maintainability. Environmental issues covered the total emissions profile of the operations. Environmental acceptability is a basic requirement for the viability of any process, and generally, any process can comply with environmental regulations if sufficient resources are assigned to the task. This requirement for environmental acceptability ensures that each process system includes the necessary features, equipment, and staff to achieve 1996 emissions codes. Business issues revolve around the financial and manpower resources of the developers to achieve commercial viability as well as the potential for the process to attract outside investment capital. Since grant funds to construct facilities are not available, the selected firm must demonstrate its ability to carry the new technology through the long and costly steps of finding clients, selling plants or service contracts within a competitive environment, and generating a positive cash flow. An important aspect of the potential for business success is the net cost of operation, including all capital costs, operating expenses, and by-product revenues reflected in a net management fee associated with solid waste disposal. 


\section{a. Technical Issues}

The technical summary and review for each process includes a description of the proposed technology. When provided by the respondent, this description includes a comprehensive process flow diagram, identifying each item of major equipment and its function. The usual measures of performance for mass-burn systems were used for the technologies studied. Such measurements include feed rate $[\mathrm{kg} / \mathrm{h}$ $(\mathrm{lb} / \mathrm{h})$ ], steaming rate [expressed as $\mathrm{kg}$ steam $/ \mathrm{kg}$ feed $(\mathrm{lb} / \mathrm{lb}) \mathrm{MSW}$, electrical generation $[\mathrm{kWh} / \mathrm{Mg}$ $(\mathrm{kWh} / \mathrm{t}) \mathrm{MSW}$, and boiler efficiency.

The various key pieces of a system are identified in the flow diagrams and schematics. Standardized nomenclature for chemical reaction, heat transfer, material handling, etc., facilitated comparisons and enhanced communication.

The state of development of each process step was characterized by asking the following questions:

- Which process steps are straightforward and well proved by the developers or elsewhere in conventional solid waste practice?

- Which are innovative and unique to the specific process?

- Which of the innovative or unique steps are critical to the success of the process?

- How many hours of continuous operation have been logged by these emerging system elements?

- What scale-up factor characterizes the ratio between demonstrated and commercial throughput rates?

The proposed requirements of the MSW preparation system were considered for each selected process. A typical, sorted MSW was assumed for all seven technologies studied. The MSW was, of course, sized to the developer's specifications, along with any other process-specific feed preparation requirements. The analysis included MSW handling and preparation steps and feed- and residue-handling steps.

MSW handling is one of the major challenges to successful implementation of any MSW system. Today's mass-burn systems employ combined manual/automatic equipment systems, which rely to a large extent on gravity feed and a mass of MSW as a pressure seal. Equipment includes a pit, a crane and bucket, a chute that provides a seal, and a feeder/stoker. The material in the chute provides a plug to prevent the hot gases from escaping to the atmosphere. This simple strategy is preferred over valves or lock hoppers because it results in continuous MSW feeding. Some batch feed systems use an arrangement of lock hoppers that periodically admit MSW to the combustion process. Such arrangements are usually found in small combustion systems. Many of the technologies studied during this project are in this size range, and they use such lock-hopper feeding systems.

Because most of the gasification technologies require precise control of the air entering the system, tramp air control of the MSW handling and metering subsystems is an important feature. Systems that operate under negative pressure are particularly vulnerable and are subject to process upset if the air is 
not metered properly. Likewise, systems that operate under positive pressure require special valving and seals to prevent the escape of hot gases. All mass flows entering and leaving the handling and preparation subsystems are accounted for in the mass and energy balances. Handling and preparation systems for operating facilities were carefully evaluated during the site visits.

A detailed heat and mass balance is essential to assess the energy conversion efficiency and to identify the liquid, solid, and gaseous sidestreams that require either additional treatment or disposal. The objective was to construct the balances using a "Reference Refuse" of consistent composition as the starting material--the feedstock for any refuse preparation systems, but not necessarily the feed to the gasifier. However, differences in the methods of analysis among the developers made this goal impossible. The heat balances provided by the developers were carefully reviewed and confirmed by data and calculations. Product gas was characterized by relative heat content (RHC) class:

- Low RHC gas [4 to $12 \mathrm{MJ} / \mathrm{Nm}^{3}$ (100 to $\left.300 \mathrm{Btu} / \mathrm{sft}^{3}\right)$ ]

- Medium RHC gas [12 to $24 \mathrm{MJ} / \mathrm{Nm}^{3}$ (300 to $\left.\left.600 \mathrm{Btu} / \mathrm{sft}^{3}\right)\right]$

- High RHC gas $\left[>24 \mathrm{MJ} / \mathrm{Nm}^{3}\left(>600 \mathrm{Btu} / \mathrm{sft}^{3}\right)\right]$.

Typically, the methanation reactions are important in lower-temperature systems, while the reforming reactions are more prominent in high-temperature systems. The reactions that predominate in the gasifier strongly depend on the presence of oxygen, water vapor, or a combination of the two. The team looked particularly at the means provided to control the input of the oxidant. It also focused on the reliability and state of development of the instrumentation and control system and on its effectiveness in achieving maximum gasification efficiency and avoiding upsets.

The basic objective of gasification-based processes is to convert a solid fuel with handling and pollutant-emissions problems into a combustible gas containing the maximum remaining heating value. In many cases, the combustible gas is burned in a gas engine or turbine combustor to generate electricity. Where warranted, heat recovery from the exhaust produces steam; the steam, in turn, is converted to a second quantity of electricity using a conventional steam turbine/generator. The total fuel energy cycle from raw waste to power is thus a reproducible scheme to compare a spectrum of processes.

An important measure of efficiency of a gasification system is the "cold gas efficiency." It is defined as the higher heating value (HHV) of the total gas flow at $15.5^{\circ} \mathrm{C}\left(60^{\circ} \mathrm{F}\right)$ divided by the $\mathrm{HHV}$ of the MSW. Such a process evaluation can be extended to include combustion of the gas with recovery of heat as high-pressure steam and its subsequent conversion to electricity. However, all of the gasification technologies studied where gas clean-up was extensive used the combined-cycle alternative. The "yardstick" of comparison for each evaluated gasification system was thus a mass-burn, waste-to-energy (WTE) plant where the steam is generated at $6.2 \mathrm{MPa}\left(911 \mathrm{lb} / \mathrm{in}^{2}\right.$-gage $) / 440^{\circ} \mathrm{C}\left(830^{\circ} \mathrm{F}\right)$ and where power is produced in an optimized, conventional Rankine steam cycle. For the seven technologies studied, the following data were requested:

- Material Balance. A summary material balance was requested that shows the MSW and all other streams entering the waste processing system and the gasification system, as well as the streams leaving the system or consumed internally. The balances were to show the gas product(s); liquid and solid by-products; char and ash; the water leaving with product(s), with ash, or by evaporation; and any plant fuel. An illustration of such a balance, on the basis that the MSW can be characterized by an elemental analysis, is shown in Table 2.1 . 
In addition to the composition shown in the table, the characteristic variables of pressure, temperature, and flow rates for all the major streams was sought. Each of the seven technologies was characterized by a size parameter-Mg/d (t/d) MSW entering the facility.

Table 2.1 MSW Characterization Parameters

\begin{tabular}{|c|c|}
\hline \multicolumn{2}{|c|}{ Input } \\
\hline Oxidant & Air, Oxygen, or Enriched Air \\
\hline Waste Analysis & $\begin{array}{l}\mathrm{C}, \mathrm{H}, \mathrm{O}, \mathrm{N}, \mathrm{S}, \mathrm{Cl}, \text { Ash, Moisture and Heavy } \\
\text { Metals (wt\%) }\end{array}$ \\
\hline Heating Value & $\mathrm{MJ} / \mathrm{kg}(\mathrm{Btu} / \mathrm{lb}) \mathrm{HHV}$ \\
\hline Auxiliary Fuel: Waste & MJ/Mg (Btu/t) \\
\hline Additives: Process Specific & $\mathrm{kg} / \mathrm{Mg}(\mathrm{lb} / \mathrm{t})$ \\
\hline \multicolumn{2}{|c|}{ Output } \\
\hline Raw Gas Composition & $\begin{array}{l}\mathrm{CO}, \mathrm{H}_{2}, \mathrm{CO}_{2}, \mathrm{H}_{2} \mathrm{O}, \mathrm{N}_{2}, \mathrm{CH}_{4}, \mathrm{C}_{n} \mathrm{H}_{m}, \mathrm{H}_{2} \mathrm{~S}, \mathrm{COS}, \\
\mathrm{NH}_{3}, \mathrm{HCN}, \mathrm{HCl}, \mathrm{Cl}_{2} \text {, and "Tars" (Vol\%) }\end{array}$ \\
\hline Residue & $\mathrm{kg} / \mathrm{Mg}(\mathrm{lb} / \mathrm{t})$ waste and its leachability \\
\hline Wastewater & $\begin{array}{l}\text { Volume/mass waste and its treatability } \\
\text { (metals, BOD, COD, etc.) }\end{array}$ \\
\hline Heating Value & $\mathrm{MJ} / \mathrm{Nm}^{3}\left(\mathrm{Btu} / \mathrm{sft}^{3}\right)$ \\
\hline
\end{tabular}

- Energy Balance. The Project Team sought to provide a comprehensive energy balance that shows the total heat release of the MSW entering the system and accounts for the entering MSW and fuel heating values in streams leaving the system. The balance was to show the energy flow associated with the gas product, liquid by-products, char, and export steam or power. Heat losses were to be accounted for by the latent heat of evaporation, stack sensible heat, and radiation losses.

- Plant Thermal Efficiency. The plant thermal efficiency was calculated from the energy balances as the output of the various power and potential fuel product energy divided by the MSW heat input. In most cases the potential fuel product fuel gas is converted to power with add-on systems

- Other Considerations. Minor contaminants and constituents that might seriously affect performance were considered in the evaluation. These contaminants include sulfides, heavy metals, and tars in sidestreams and in scrubber and cooling tower blowdown streams. Some of the 
minor constituents contain carcinogens as well as biologically active and other potentially dangerous constituents.

Other efficiency parameters such as $\mathrm{kWh} / \mathrm{Mg}(\mathrm{kWh} / \mathrm{t}) \mathrm{MSW}$ were determined, and comparisons were made between the technology under investigation and a reference mass-burn system. Although such a comparison did not always show a gas-producing technology to best advantage, it served as a consistent and real-world basis of comparison. Systems that generate both power and heat often have higher overall thermal efficiencies than power-only systems because the engine inefficiencies are not accounted for. Evaluation of systems that require elaborate waste preparation subsystems included their power input as part of the overall thermal efficiency calculation.

Another important consideration is the discharge rate of the minor sidestreams and pollutants that are an inherent part of energy release for gasification processes operating with a deficiency of oxygen.

An objective of the evaluation was to view and correlate each thermal processing technology in a consistent manner with MSW feedstock and then to compare inputs, outputs, efficiencies, emissions, side effects, etc. The objective of the overall project, however, was not to pick the "best" process. Defining "best" requires a client-specific set of values. The objective was simply to describe the seven very promising processes in a consistent manner.

\section{b. Environmental Issues}

Environmental issues are recognized as critical to the viability of refuse processes. While air emissions often dominate the "political" assessments of a given process, problems with all effluents and environmental consequences must be resolved as part of the permitting process.

1.) Regulatory Context. The new refuse gasification processes and other novel process technologies enter the regulatory arena without the regulatory history that characterizes older, conventional technologies in the existing regulatory structure. Appropriate questions include:

- Is a gasifier a "Municipal Waste Combustor"?

- Is the combustor burning fuel gas from a refuse gasifier a "Municipal Waste Combustor"?

- If the fuel gas contains carcinogens (e.g., benzene), does that make the combustor a "hazardous waste" incinerator?

- Into what category under the Clean Air Act Amendments (CAA) or New Source Performance Standards (NSPS) does a new rocking kiln or gasification-mode fluid bed furnace concept fall?

The answers can profoundly affect costs and acceptance by the public and the regulators. 
2.) Data Sought. Process developers provided data or correlations concerning the uncontrolled and controlled air effluents, water effluents, solid and sludge residues, and any sidestreams. Data concerning effluents that are of interest include:

- Mass rate

- Chemical composition

- Relationship to the feed stream, such as the observation that "X" pounds of pollutant "Y" are formed for each ton of refuse processed

- Treatability, such as the BOD and COD and biodegradation or other treatment technology characteristics of wastewater streams

n Prospective environmental impact, such as "very low" or "nil" for heavy metals trapped in a glassy slag

- Preferred or tested control technologies - what has been tested and with what results?

3.) Data Presentation in Process Evaluations. The environmental data are summarized and presented in tables that present the emissions measured in existing pilot plant facilities (where available). The data include:

- Uncorrected concentration rates (e.g., concentration per unit volume of flue gas or wastewater as emitted)

- Corrected concentration rates (e.g., concentration per unit volume of flue gas corrected to a dry basis and to a $7 \%$ oxygen concentration).

- Comparison with NSPS or current regulatory limits.

\section{c. Business Issues}

Similar to the evaluation in the screening process, issues relating to commercialization and implementation were evaluated to a limited degree. Issues explored included:

- Is the commercialization effort likely to bear fruit?

- Did the developer appear to understand the marketplace and acceptable cost and business relationships?

- Did the developer appear to understand the Federal and State regulatory and permitting requirements?

- Did the developer appear to have sufficient internal or outside funds?

\section{d. Cost/Economics Issues}

Although technical considerations in the analysis of the selected candidates are important, the evaluation eventually narrows to an issue of costs. If the technology is feasible, is it economically 
acceptable? Although they may be less innovative, are any of the proposed technologies economically more attractive than others? Are any of the candidates at such a primitive level of development that the cost of commercial-scale application is difficult to estimate with any degree of confidence? And, finally, what are the scale-up factors needed to reach full-scale application from the pilot stage?

1.) Capital Costs. Capital costs are recognized as still-evolving processes that cannot be established with any degree of confidence. However, estimates from the developers, adjusted to reflect Project Team experience and to provide a "level playing field" for similar process steps, provide a consistent, if approximate, cost picture. Cost elements included:

- Additional Development Costs. Present-day costs and costs at the point of design and guarantee for the first commercial plant include future equipment, process and other experimentation, construction of pilot plant and other test facilities, cost of sales, and other business development.

- Projected Scale-Up Factor: Rather than assume a range of design capacities to determine its costs, the analysis was limited to a practical plant size for the specific system under consideration.

- Range of Ancillary Equipment Needed. This category encompassed bag openers, feeders, gas cleaning equipment, the required size of building, etc. The capital cost of the RDF facilities and the facilities used to convert fuel gas or steam to electricity were developed for all seven technologies using cost curves generated by the Project Team (Figure 2.1 and Figure 2.2).

- Facility Envelope. Costs were evaluated at the delivery point of the gas-producing facility (i.e., in the form of product gas, electric power or steam but exclusive of any capital and operating costs borne by the ultimate user).

- Time Lapse to Commercial Acceptance. The time needed to ready the design for commercial application was estimated.

- Modifications Needed To Reach Full-Scale Application. In part, such modifications are waste- and residue-handling systems, materials of construction for the process vessel, needed gas-cleaning equipment, and control and instrumentation systems.

The developer's prototype costs as well as his estimates of full-scale costs were the starting point for capital cost estimates. The Team also drew heavily on its professional experience, vendor quotations, and other cost data to arrive at realistic capitalization estimates for the overall facility.

2.) Operating Costs. Resolution of the issues listed previously established the design of the facilities, their size, and their complexity. From this process scenario, manpower to operate the system was estimated and utility consumption and maintenance costs were projected. The cost analysis drew heavily on the Project Team's experience with many waste-to-energy facilities to resolve these cost elements into a fair and realistic estimate of net operating cost. As for the capital cost, operating costs associated with RDF preparation and energy conversion were developed as cost curves (Figures 2.3 and 2.4). The conversion analysis included a curve predicting the gross annual electrical generation 
$(\mathrm{MWh} / \mathrm{y})$ for combustible gas burned in either a gas engine or combined-cycle gas turbine and for a steam Rankine cycle as a function of hourly energy flux (as gas HHV or steam enthalpy), as shown in Figure 2.5. Cost data provided by the developers, such as developer-based labor, chemical use, power use, etc., were used.

To achieve the closest possible comparison, processes developing a fuel intermediate were assessed for capital and operating costs to the point of generation of the basic energy product. Then the costs for energy conversion to steam and to electricity were applied to produce the net cost for solid waste management on a \$/unit mass basis.

3.) RDF Preparation and Energy Conversion Costs. This portion of the investigation focused on thermal processing elements - the unique combustion or gasification step that distinguishes the several processes investigated. In general, the technology developers also direct their interests and energies toward the thermal processing element of the process. For that reason, a set of common cost curves was prepared to link the capital and operating costs for MSW preparation to a 10-cm (4-in.) top size and to conversion of either a fuel gas or steam to electricity in a stand-alone electricity-generating plant. In cases where a fuel gas is generated, the gas could also be marketed "over the fence" as a fuel for industrial or power plant boilers.

\section{(a.) RDF Processing Facility}

System Description. For many of the thermal processing systems evaluated, feedstock waste must be preprocessed into a 10-cm (4-in.) top-size fluff. Therefore, a conventional RDF processing facility prepares the solid waste material before it is subjected to the thermal processes. The proposed RDF processing facility consists of the following components:

\section{- Refuse Receiving. and Storage Area \\ - RDF Storage Area}

- RDF Processing Area

- Building.

The refuse receiving and storage area receives refuse deliveries and temporarily stores the raw waste before processing. The layout of the receiving and storage area is designed to accommodate packer, roll-off, and transfer trailer vehicles. Refuse vehicles enter the totally enclosed receiving building and tip their loads directly onto the tipping floor. A front-end loader stockpiles the waste before it is processed. Concrete push-walls facilitate stockpiling. Storage of raw refuse for 3 days is incorporated into the design. This storage capacity provides a degree of flexibility during periods of high refuse deliveries and allows continued operation during periods when deliveries are not received (e.g., holidays).

The RDF processing equipment is housed in a separate processing area. Two, independent processing lines are proposed, each sized to handle 50 percent of the design throughput in 16 hours. Two lines are recommended to permit a degree of flexibility in the event that one line needs to be shut down unexpectedly for maintenance. Each processing line includes a shredder, ferrous magnet, screen/trommel, and a series of belt conveyors. 

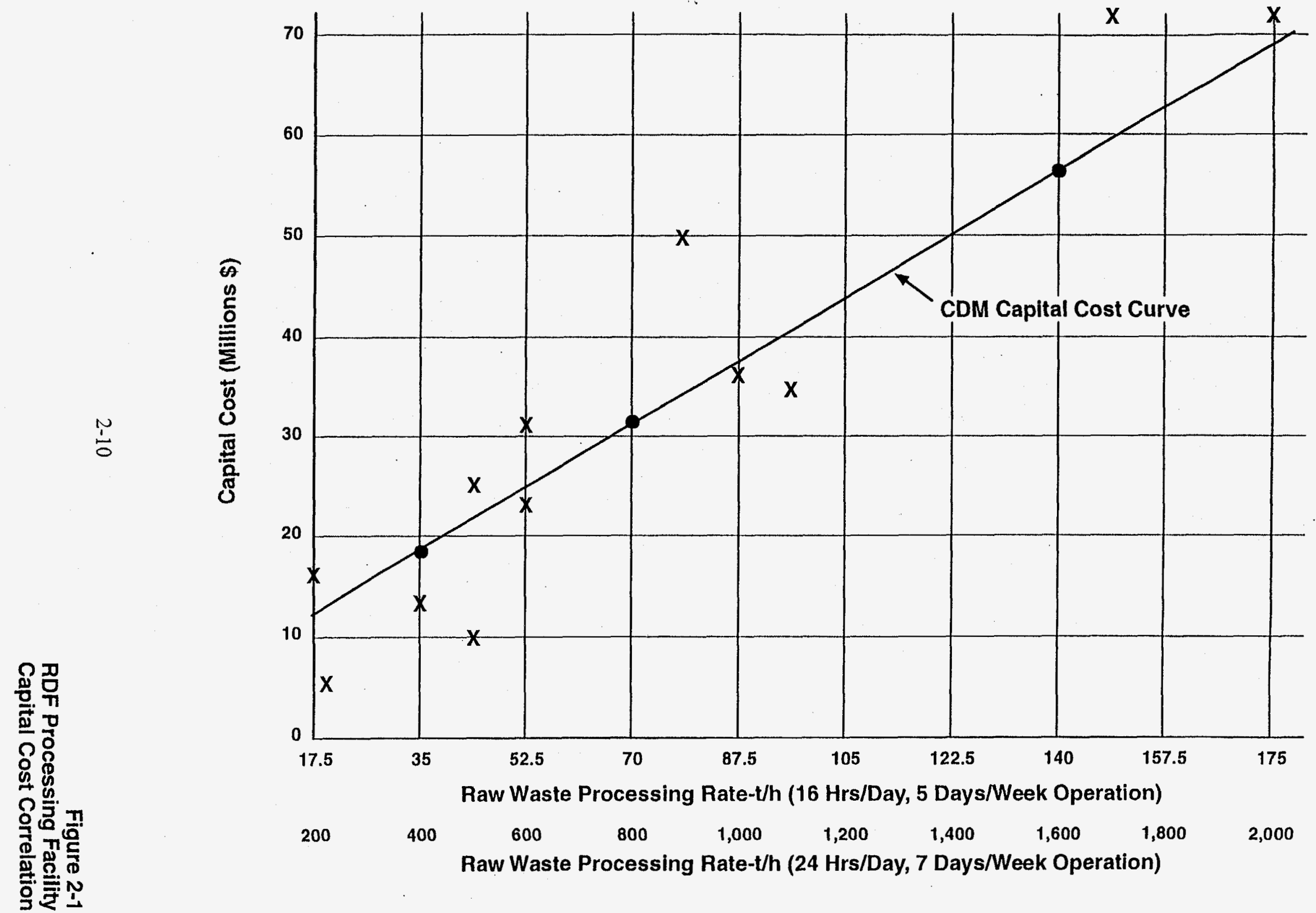


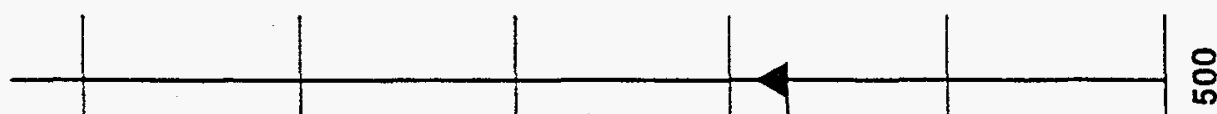

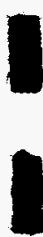

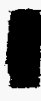

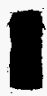
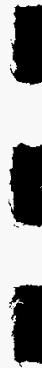

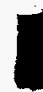
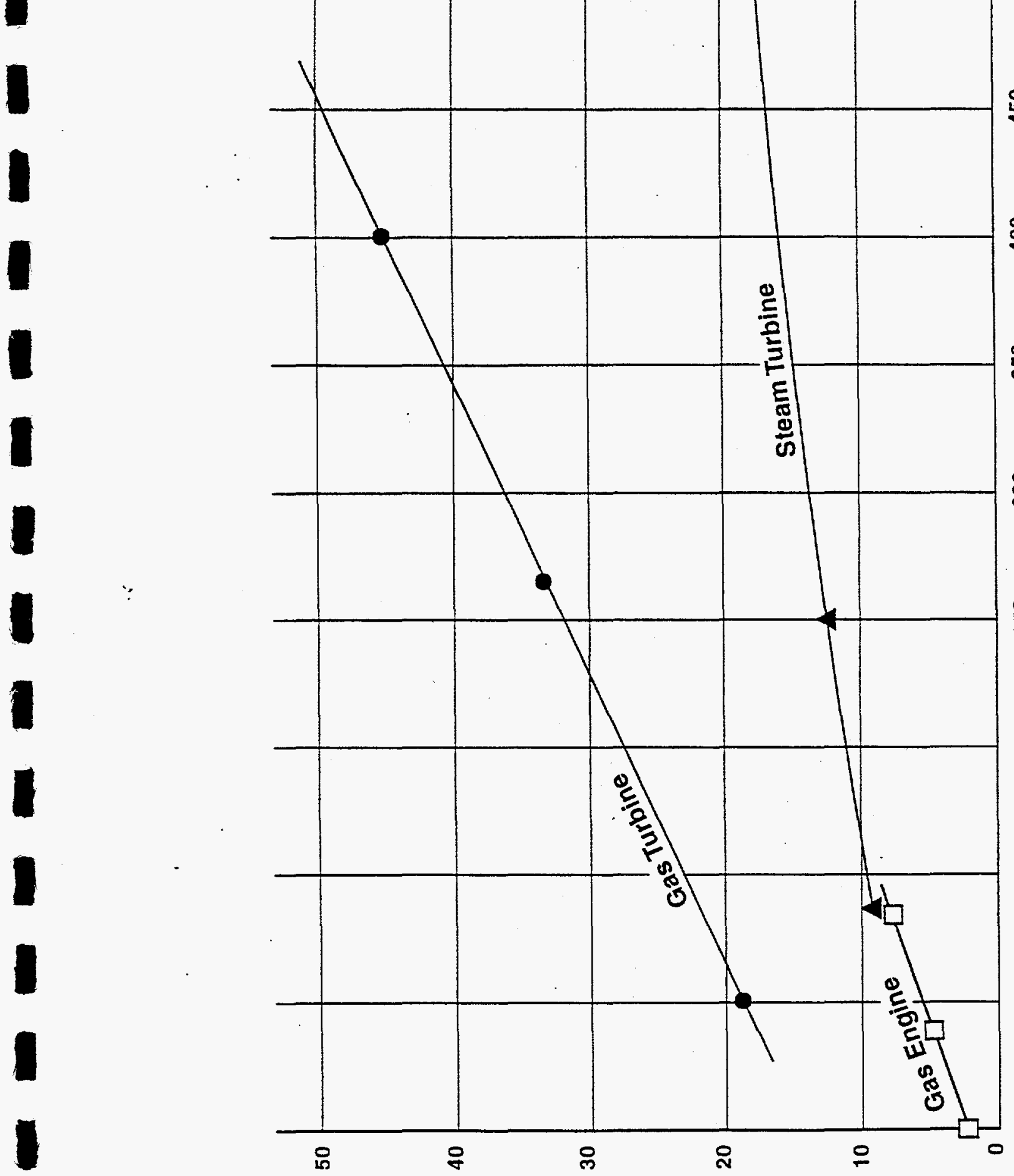

응

高
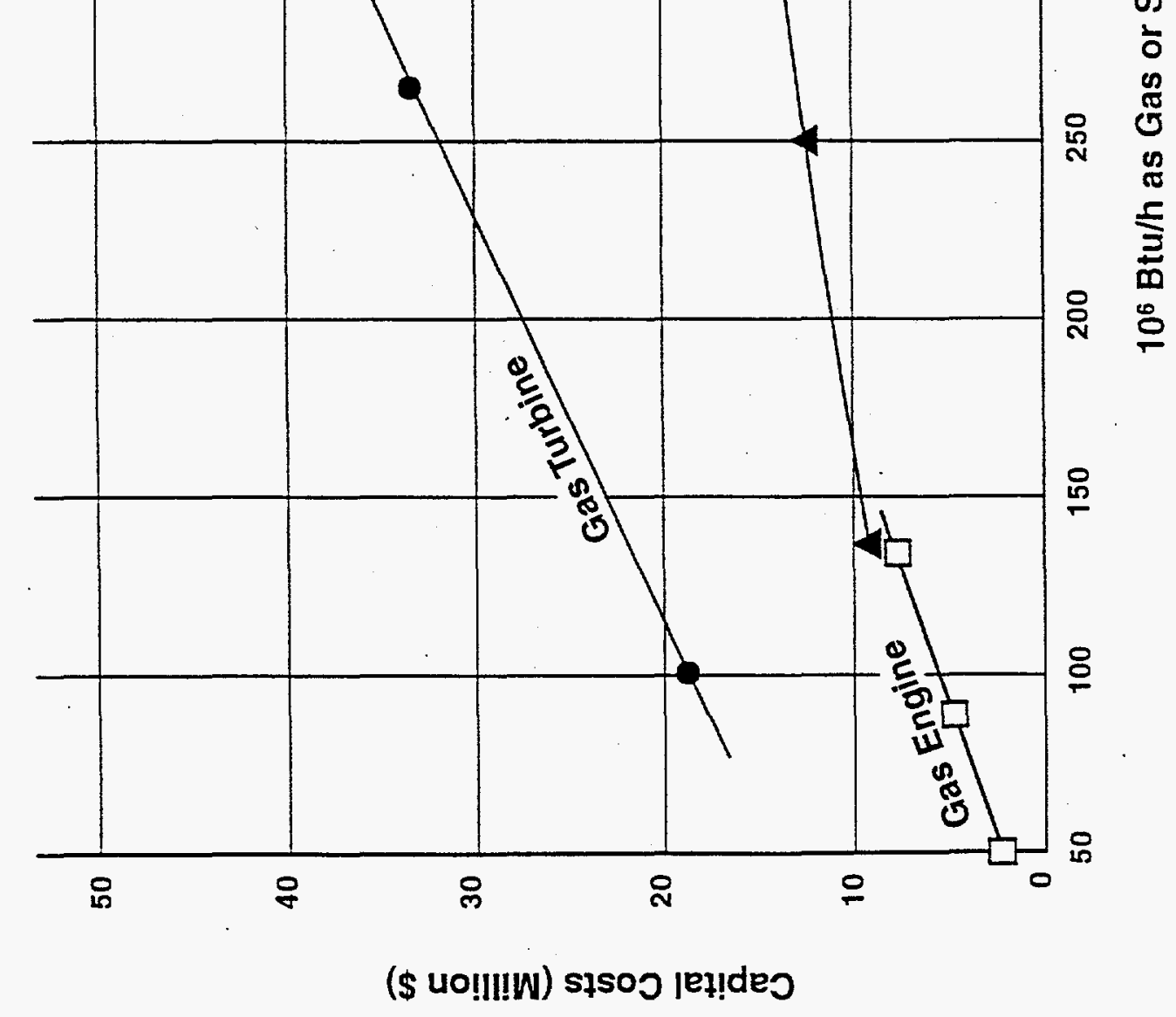

2-11

Figure 2-2 RDF Processing Facility Operating Costs 


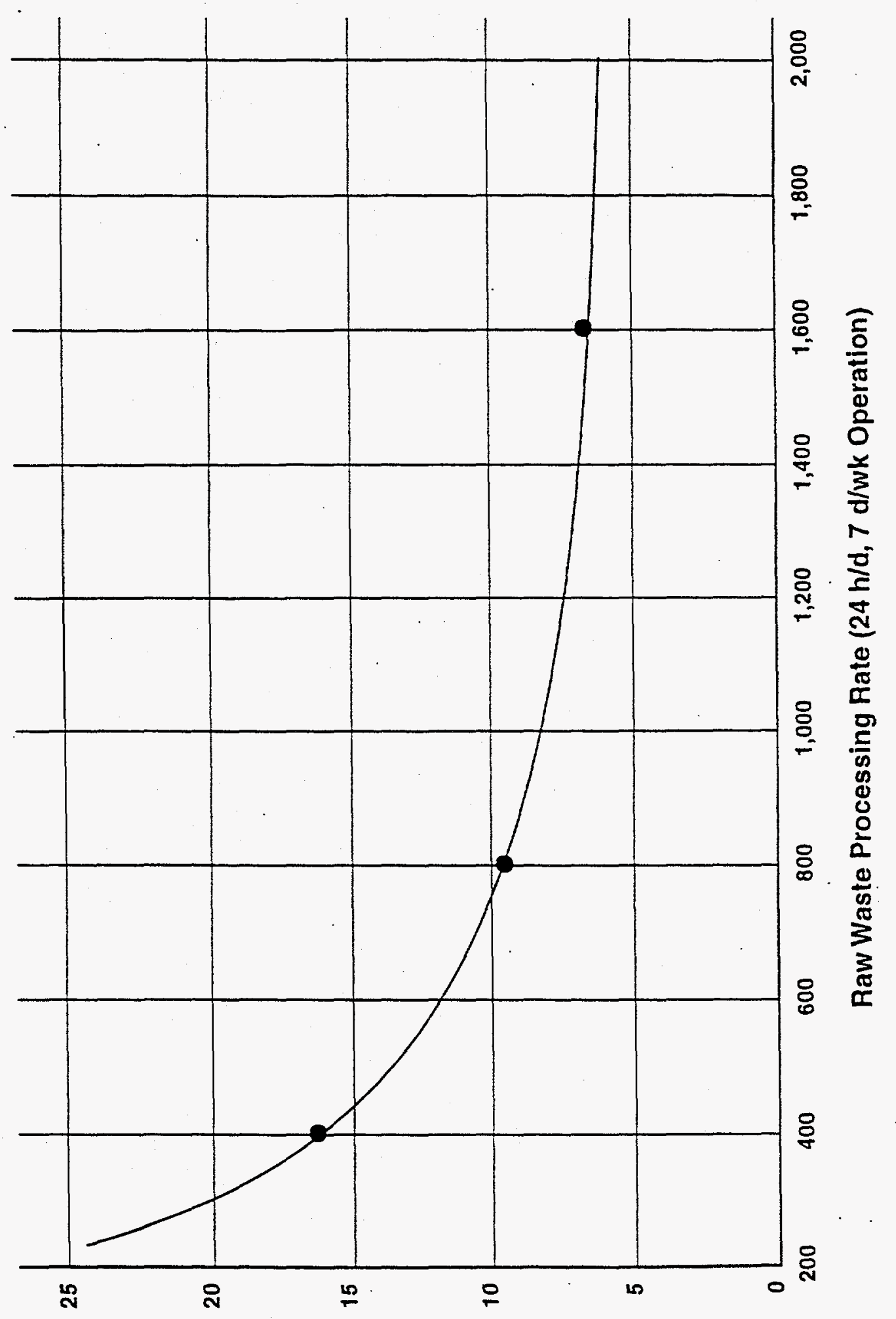

(passasodd uoy/\$) 1soj Gu!̣edado 


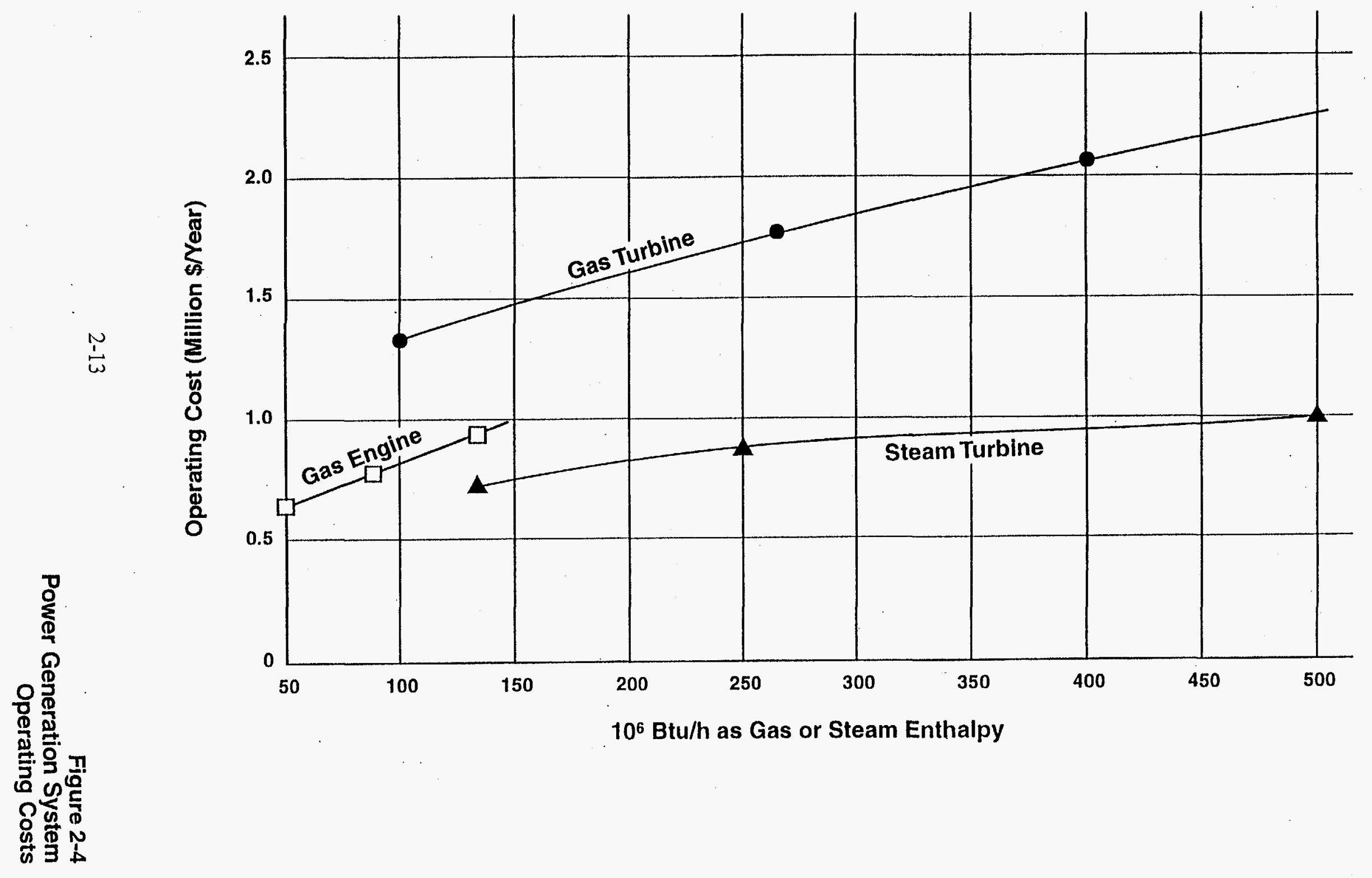




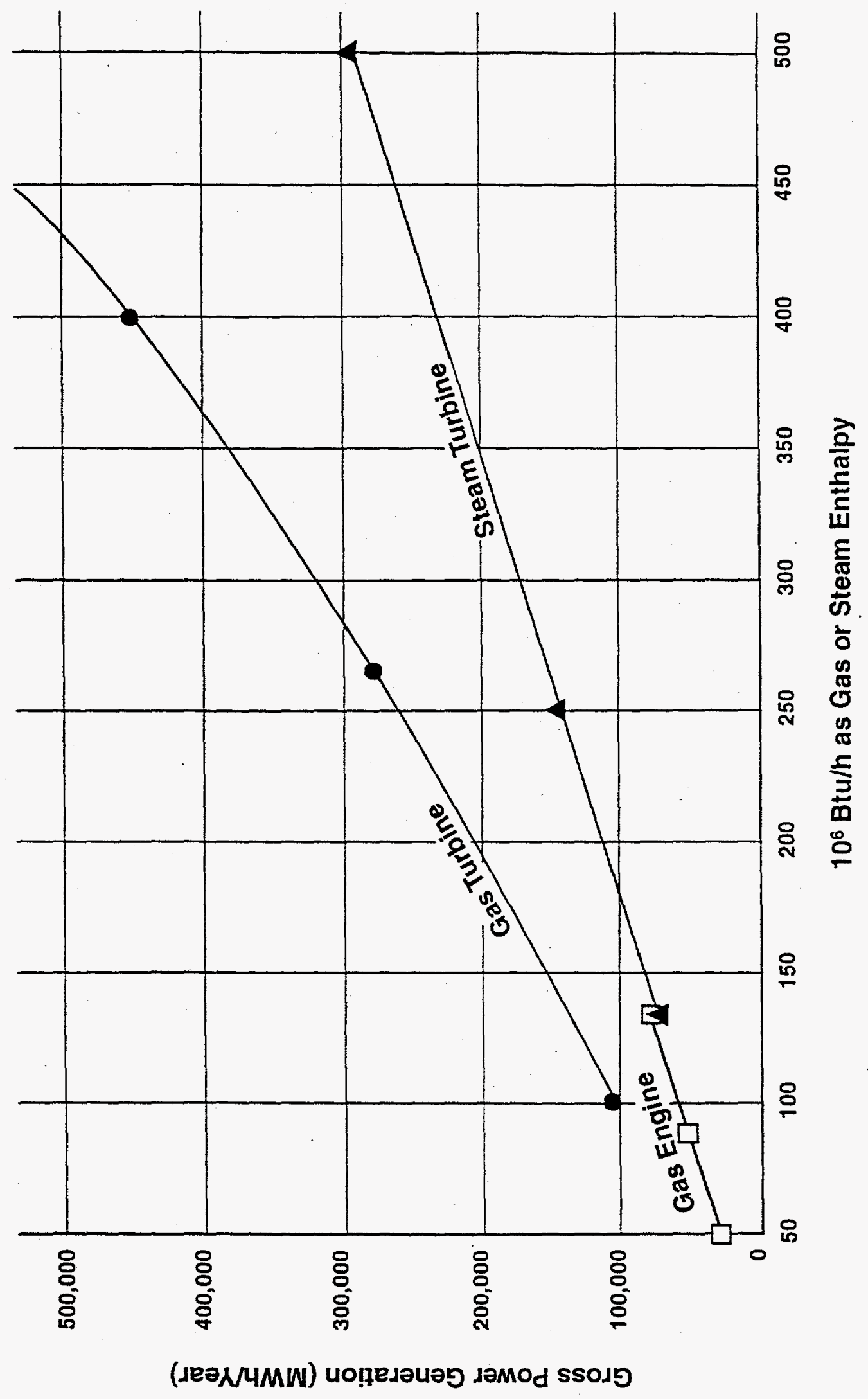

2-14

Figure 2-5 
The final product consists of a 10-cm (4-in.) nominal size fluff material free of glass, dirt and other fines, and ferrous metals. A front-end loader stacks the RDF fluff material and feeds the in-feed conveyors to the thermal processing system. The processing lines operate on a two-shift/day, 5 day/week basis. The hourly capacity of the processing equipment is greater than that of the thermal treatment system, which operates on a 24-hour/day, 7-day/week basis. Equipment maintenance is performed on the "off" shift or on weekends.

The RDF fluff material discharged from the processing lines is stockpiled on the floor in a dedicated storage area. The RDF storage area contains sufficient volume to store 3 days of material, permitting the thermal processing system to continue to operate over weekends and during holiday periods.

Capital Cost Estimates. The estimated capital costs for RDF processing facilities (Figure 2.1) are expressed as a function of both the "design" raw waste received and its processing rate and the "design" thermal processing rate. Investment estimates in terms of raw MSW for 18 dedicated and stand-alone RDF preparation facilities are plotted in Figure 2.1 against the cost correlation. The abscissa scale reflects operation in terms of raw waste passing through the processing system for 16 hours/day, 5 days/week and the thermal processing system for 24 hours/day, 7 days/week. The capital cost estimates include the equipment and building components listed earlier. Allowances of 10 and 20 percent were included for engineering and contingency respectively. No allowance was included for property costs.

Operating Cost Estimates. Operating costs estimates for RDF processing facilities, (Figure 2.3) are expressed as a function of the raw waste thermal processing rate. They include labor, utilities, maintenance, and insurance. Labor costs include regular time plus a 10-percent overtime allowance. Utility costs include electricity for lighting and equipment operation, as well as natural gas for building heating. Maintenance costs include annual allowances of 3 percent of equipment costs and 1 percent of building costs for equipment and building repair respectively. Insurance costs are based on 1 percent of the equipment and building costs.

\section{(b.) Energy Conversion Alternatives}

Energy Forms. Each of the thermal processes recover energy from the waste. If the waste material is in a solid form, nominally $10 \mathrm{~cm}$ (4 in.) or longer, it can be burned on a grate or in a fluidized bed. The systems in this study that burn waste in fluidized beds recover energy in a Rankine cycle - a boiler generating steam combined with a steam turbine and electric generator. If the waste material is converted to a gas, then the gas can be recovered in a combined cycle, a gas engine or turbine, and a heat-recovery steam generator combined with a steam turbine and electric generator. In a gas engine, the heat exchanger fluid is hot water from cooling the engine. The heated water generates lowpressure steam for heating or process purposes. Gas engines are now made in capacities up to $20 \mathrm{MW}$. With a gas turbine, the exhaust temperature is high enough to consider generating high-pressure steam. Thus power can be generated in both the gas turbine and the steam turbine. Gas turbines are now available in capacities as low as $2 \mathrm{~kW}$. For this study a capacity of $10 \mathrm{MW}$ was chosen as the general breakpoint-gas engines for less than $10 \mathrm{MW}$ and turbines for more than $10 \mathrm{MW}$. Raw waste can be used as a direct feed in a mass-burn system in a Rankine cycle. This approach has been the system of choice for the last three decades. 
Steam Turbine Generator Facility. The steam turbine generator facility consists of a common, condensing steam turbine coupled with a generator. Ancillary systems include steam condensers, surface and dump; cooling tower; electrical switchgear; piping and instrumentation; and controls. All of the equipment, with the exception of the cooling tower, is enclosed in a two-level building. The turbine is on the upper level, or deck, and the condensers and other ancillary systems are on the lower level. The cooling tower is outdoors.

Steam from each thermal treatment processing line is combined in a main steam header and piped directly to the steam turbine. The turbine is coupled to a generator. Exhaust steam from the turbine is condensed in a surface condenser. Heat removed in the condenser is dissipated to the atmosphere using an evaporative cooling tower. The condensate from the wet-well of the condenser is recirculated to the thermal treatment process boiler feedwater system. The dump condenser is a means to condense the high-pressure steam if the turbine generator is unavailable because of maintenance.

Gas Engine Generator Facility. The gas engine generator facility consists of multiple gas engines and generator sets. Ancillary systems include instrumentation and controls, piping, and electrical switchgear. All equipment is enclosed in a single-story preengineered building.

Low-heat-content gas from each thermal treatment processing line combines in a main gas line and is burned in gas-fired internal combustion engines. The gas engines are compressionignition engines using auxiliary fuel, or they are spark ignited to enhance combustion in the event of low gas quality. Each gas engine is outfitted with a generator set.

Gas Turbine Generator Facility. The gas turbine generator facility consists of a combined-cycle gas-fired turbine generator as the primary power generation equipment, with secondary power generation from a waste-heat boiler to recover heat from the turbine exhaust, and a steam turbine generator. Ancillary systems include surface and dump condensers, a cooling tower, boiler feedwater treatment, instrumentation and controls, piping, and electrical switchgear. All the equipment, with the exception of the cooling tower, is housed inside a two-level building. The cooling tower is outdoors.

Low-heat-content gas from each thermal treatment processing line is combined in a main gas line and burned in a gas-fired turbine. The gas turbine is connected directly to a generator. Waste heat in the turbine exhaust generates high-pressure steam in a heat-recovery steam generator. The high-pressure steam is directed to a steam turbine coupled to a generator. Exhaust steam from the turbine is condensed in a surface condenser. Heat removed in the condenser is dissipated to the atmosphere in an evaporative cooling tower. A bypass condenser is available to directly condense the steam generated in the waste-heat boiler when the steam turbine generator is off line for maintenance. Condensate from the condensers is recirculated to the boiler feedwater treatment system.

Capital Cost Estimates. The estimated capital cost for the alternative power generation schemes is presented in Figure 2.2. Capital costs are expressed as a function of the gross heat input $\left(10^{6} \mathrm{Btu} / \mathrm{h}\right)$, measured as gas fuel value or steam enthalpy, depending upon the process under evaluation. The capital cost estimates include the equipment and building components described earlier. Allowances of 10 and 20 percent are included for engineering and contingency respectively. No allowance has been made for property costs. 
Operating Cost Estimates. Operating cost estimates for each power generation alternative are presented in Figure 2.4. Operating costs are expressed as a function of the gross heat input $\left(10^{6} \mathrm{Btu} / \mathrm{h}\right)$, measured as gas or steam enthalpy. The operating costs include labor, maintenance, and insurance. Maintenance costs were estimated at 3 percent of the equipment capital cost plus 1 percent of the building cost. Insurance costs were estimated at 1 percent of the total equipment and building costs.

Power Generation Estimates. Gross power generation estimates for each alternative are presented in Figure 2.5. Gross power generation ( $\mathrm{MWh} / \mathrm{y})$ is expressed as a function of the gross heat input $\left(10^{6} \mathrm{Btu} / \mathrm{h}\right)$, measured as gas heat content or steam enthalpy.

\section{e. Operating Issues}

Because MSW is a bulky, biologically unstable material, the reliability and continuity of disposal/processing operations are essential features of useful processing technologies. Highly skilled and attentive operators, along with intensive maintenance, are important issues affecting both cost and system availability.

1.) Data Collected. Information collected regarding operation included numerical data, anecdotal information solicited from process development personnel, and engineering judgments made by the inspection team in the course of reviews and inspection visits. The information and perspectives include:

- Operator and maintenance staff skill requirements

- Sensitivity of the process to changes in waste characteristics

- Operating experience (on-line hours in 24-hour; 7-day service at rated capacity), to include frequency and severity of outages, nature of the problems precipitating shutdowns, and plans to resolve the problems, if they still persist

- Operating and maintenance staff requirements as a function of facility throughput.

2.) Data Presentation in Process Evaluations. A portion of the information collected under this category is reported in the technical discussion of the process-particularly in discussions concerning remaining areas for process development and problem solving. Staffing requirements are summarized in a table as a function of facility throughput. The staffing data and characterizations of needed staff skills, which affect hourly labor cost, are incorporated into the operating cost analysis. Reliability issues, if the Project Team believed they could not be solved, are incorporated into the cost analysis on the basis of their impact on the annual throughput and selection of the facility installed capacity needed to meet a given waste management requirement.

\section{f. Implementation Issues}

This portion of the process presentation summarizes technical, regulatory, financial, and business issues and any other issues that might help or hinder the commercialization process. All of the seven candidates were close to commercialization. However, with the exception of EPI, most will need further equipment development, confirmation of process control concepts, scale-up of key unit operations, or other refinement/development steps. These steps must be successful before the developer firm and its financial partners are prepared to accept the responsibility for a commercial waste 
management contract. Realistic assessment of these implementation issues provides a clear checklist of the problems and uncertainties that must be resolved before committing to the technology.

\section{Regulatory Aspects of the Gasification and Novel Thermal Technology}

Environmental regulations have become the most important force shaping the physical and economic character of waste processing and disposal facilities. Regulations may mandate process features or force add-on facilities before permits to construct, and subsequently to operate, are issued. These restrictions have a direct impact on capital and operating costs, and they often have consequences regarding such items as layout, reliability, and the design features of instrumentation and control systems.

All of the processes evaluated in this project involve an energy product or a chemical feedstock product for use by others. If the permitting process is extended to the prospective users of process fuels, steam, or chemical feedstocks derived from refuse, there could be a significant delay in market penetration by these emerging technologies. A user of fuel could be embroiled in a complex, costly, and highly public permitting process. Naturally, there is usually a level of market resistance bred of uncertainty about the performance and reliability of new processes. However, if the purchase makes the buyer seek a permit as a municipal waste combustor, such resistance will probably be enhanced.

There is an argument, however, that says that the refuse thermal processing system is a manufacturing process that is making a product - a fuel gas or synthesis gas. In that case, the identity of the original feedstock is substantially lost in the process, and the emissions and permitting requirements for gas users should be based on documented emissions of specification gas in boilers equipped with the burner type, excess air level, and other combustor features-not on use as a municipal waste combustor (MWC). The validity of this argument will only be known when a specific permit application is placed before a State or Federal agency.

\section{a. Meeting With EPA Office of Air Quality Planning and Standards}

As a first step and to gain input for the project, the Project Team, the Department of Energy and NREL, and the EPA Office of Air Quality Planning and Standards (OAQPS) met in Research Triangle Park, North Carolina. The objective of the meeting was to discuss the position that EPA might take when considering the seven new thermal processing and gasification processes being reviewed. This is a specific example of the situation for any new process where there is no regulatory history and little, if any, emissions data from commercial-scale plants.

The results of the discussion are an indication of the direction EPA might take when considering commercial-scale installation of the technologies reviewed in this report. They are not reported as a final policy decision by the EPA. Their position appeared clear. The Agency retains the linkage between the feedstock and the permit requirements until data and clear, replicable performance indicate that a new source category has emerged. In the near term, users of a fuel gas that involves combustion must meet all requirements for a Municipal Waste Combustor, with evaluation on a case-bycase basis for any specific new installation. 
If the new technologies are permitted as MWCs, they would fall under Section 129 of the 1990 Clean Air Act (CAA) Amendments. In the special case of co-fired plants where MSW is less than 30 percent or less of the total weight fired, Section 129 exempts the system from the MWC provisions summarized in Table 2.2 .

Most likely, any MWC systems will be required to meet the Good Combustion Practices requirements for MWCs (Table 2.3), although the proper category is often uncertain. Emissions limits for air toxics will probably be at least as stringent as the NSPS for MWCs (Table 2.4).

\section{b. Ongoing Regulatory Activity (Winter 1995-1996)}

The Innovative Technology Program of the Texas Natural Resources Conservation Commission (TNRCC) is exploring the regulatory issues surrounding the burning of synthesis gas made using a gasification technology applied to biomass. There are several synthesis gas users in the Houston Ship Channel area. In some of these industries, the gas is generated from wastes (some hazardous in nature) but meets definitive specifications regarding its higher hydrocarbon content, chlorine and sulfur content, etc. This gas is normally pumped into the "synthesis gas header" at the facility. Primarily, the gas is used as the starting point in making various petrochemicals, methanol, etc. To a varying degree, a portion of the gas flow is diverted to use in process heaters and boilers. This raises the question: "Is the ultimate combustor an incinerator or just a combustor with a known fuel and with known emissions characteristics?". The exchange of memoranda between the TNRCC and EPA's Clean Air Act Rule Interpretation Office in Washington DC has continued since November 1995. EPA's initial conclusion that the emissions should be considered as though they had been generated in a "BIF" source- $a$ boiler or industrial furnace burning hazardous waste and thus treated as a Resource Conservation and Recovery Act (RCRA) facility-is being challenged. This preliminary finding parallels the counsel given in the OAQPS meeting described earlier. The outcome of the TNRCC/EPA dialogue is important, however, since it is a "real case" that could have a direct impact on the permitting requirements for municipal waste gasifiers.

\section{c. Residue Regulations}

Recent U.S. Supreme Court decisions have clarified the status of the solid residues from MSW thermal processes. They are regarded as waste streams that may or may not require the special disposal measures taken for a hazardous waste, as determined by Toxicity Characteristics Leaching Procedure (TCLP) testing. In most cases, residues from MWC systems and the gasification and combustion technologies studied during this project pass such tests-particularly residues from the Proler International and Thermoselect Inc. processes, which are inherently vitrified in the process.. 
Table 2.2 Basis for Maximum Achievable Control Technology (MACT) Performance Performance Requirements-Municipal Waste Combustors* (40CFR Part 60, Federal Register, December 19, 1995)

\begin{tabular}{|c|c|c|}
\hline & Final Requirements & Basis for Emissions Limits ${ }^{\dagger}$ \\
\hline \multicolumn{3}{|c|}{ Emissions Guidelines (EG)_-Existing Plants } \\
\hline Small: & $\begin{array}{l}>35 \text { to } 225 \mathrm{Mg} / \mathrm{d} \text { (>38.5 to } \\
247.5 \mathrm{t} / \mathrm{d})\end{array}$ & $\mathrm{GCP}+\mathrm{DSI}+\mathrm{ESP}+\mathrm{Cl}$ \\
\hline Large: & $>225 \mathrm{Mg} / \mathrm{d}(>247.5 \mathrm{t} / \mathrm{d})$ & $\mathrm{GCP}+\mathrm{SD} / \mathrm{ESP}\left(\right.$ or SD/FF) $+\mathrm{Cl}+\mathrm{SNCR}^{\S}$ \\
\hline \multicolumn{3}{|c|}{ New Source Performance Standards (NSPS)-New Plants } \\
\hline Small: & $\begin{array}{l}>35 \text { to } 225 \mathrm{Mg} / \mathrm{d} \text { (>38.5 to } \\
247.5 \mathrm{t} / \mathrm{d})\end{array}$ & $\mathrm{GCP}+\mathrm{SD} / \mathrm{FF}+\mathrm{Cl}$ \\
\hline Large: & $>225 \mathrm{Mg} / \mathrm{d}(>247.5 \mathrm{t} / \mathrm{d})$ & $\mathrm{GCP}+\mathrm{SD} / \mathrm{FF}+\mathrm{Cl}+\mathrm{SNCR}$ \\
\hline
\end{tabular}

* Technologies providing equivalent or better performance may also be used.

$\dagger \mathrm{GCP}=$ Good Combustion Practice

$\mathrm{ESP} \quad=\quad$ Electrostatic Precipitator

DI = Dry Injection of Sorbent (FSI = Furnace Sorbent Injection and DSI = Duct Sorbent Injection)

$\mathrm{Cl}=$ Carbon Injection

SD/ESP $\quad=\quad$ Lime Spray Dryer Absorber and ESP

SD/FF = Lime Spray Dryer Absorber and Fabric Filter Baghouse

SNCR = Selective Noncatalytic Reduction

$\S$ No $\mathrm{NO}_{x}$ Control Requirements for small MWC plants or large, existing mass-burn refractory combustors. 
Table 2.3 Good Combustion Practice Requirements for MWCs (40CFR Part 60, Federal Register, December 19, 1995)

\begin{tabular}{|c|c|c|c|c|}
\hline \multirow[b]{2}{*}{ Type of Combustor } & \multicolumn{4}{|c|}{ CO Emissions Limits } \\
\hline & $\begin{array}{c}\text { EG } \\
\text { Limit, } \\
\text { ppm }\end{array}$ & $\begin{array}{l}\text { Average } \\
\text { Time, } \mathbf{h}\end{array}$ & $\begin{array}{l}\text { NSPS } \\
\text { Limit, } \\
\text { ppm }\end{array}$ & $\begin{array}{c}\text { Average } \\
\text { Time, } h\end{array}$ \\
\hline Mass-Burn Watenwall (MBWW) & 100 & 4 & 100 & 4 \\
\hline Mass-Burn Refractory Wall (MBRW) & 100 & 4 & 100 & 4 \\
\hline Mass-Burn Rotary Waterwall (RWW) & 250 & 24 & 100 & 24 \\
\hline Mass-Burn Rotary-Wall Refractory (RWR) & 100 & 24 & 100 & 4 \\
\hline Refuse-Derived Fuel Stokers (RDF) & 200 & 24 & 150 & 24 \\
\hline Fluidized Bed Combustors (FBC) & 100 & 4 & 100 & 4 \\
\hline Modular Combustion Units (MCU) & 50 & 4 & 50 & 4 \\
\hline \multicolumn{5}{|l|}{ Coal/RDF Mixed Fuel-Fired } \\
\hline - Spreader/Stokers (Coal-RDF/SS) & 250 & 24 & 150 & 24 \\
\hline - Pulverized Coal (Coal-RDF/PC) & 150 & 4 & 150 & 4 \\
\hline \multicolumn{5}{|c|}{$\begin{array}{l}\text { 2. Load not to exceed maximum load demonstrated during most recent PCDD/PCDF } \\
\text { compliance tests. }\end{array}$} \\
\hline \multicolumn{5}{|c|}{$\begin{array}{l}\text { 3. Particulate matter control device inlet temperature not to exceed } 17^{\circ} \mathrm{C}\left(31^{\circ} \mathrm{F}\right) \text { above the } \\
\text { maximum temperature demonstrated during most recent } \mathrm{PCDD} / \mathrm{PCDF} \text { compliance tests. }\end{array}$} \\
\hline \multicolumn{5}{|c|}{$\begin{array}{l}\text { 4. Chief facility operator, shift supervisors, and control room operators must meet training ano } \\
\text { certification requirements. }\end{array}$} \\
\hline
\end{tabular}

${ }^{*} E G=$ Emissions Guidelines 
Table 2.4 Emissions Limits for Municipal Waste Combustors* (40CFR Part 60, Federal Register, December 19, 1995)

\begin{tabular}{|c|c|c|c|}
\hline \multirow{2}{*}{$\begin{array}{l}\text { Pollutant } \\
\text { Measurement }\end{array}$} & \multicolumn{2}{|c|}{$\begin{array}{l}\text { Guideline Limits - Existing Plants } \\
\text { (or Percentage Reduction) }\end{array}$} & \multirow{2}{*}{$\begin{array}{c}\text { NSPS Limits- } \\
\text { New Plant } \\
\text { (or Percentage } \\
\text { Reduction) } \\
\text { Large and Small } \\
\geq 35 \mathrm{Mg} / \mathrm{d} \\
(\geq 38.5 \mathrm{t} / \mathrm{d})\end{array}$} \\
\hline & $\begin{array}{c}\text { Small } \\
>35 \text { to } 225 \mathrm{Mg} / \mathrm{d} \\
\text { (38.5 to } 247.5 \mathrm{t} / \mathrm{d})\end{array}$ & $\begin{array}{c}\text { Large } \\
>225 \mathrm{Mg} / \mathrm{d} \\
(247.5 \mathrm{t} / \mathrm{d})\end{array}$ & \\
\hline PCDD/PCDF, ng/dscm ${ }^{3}[]^{\dagger}$ & $125[30]$ & $60^{\S}[15]$ & $13[17]$ \\
\hline Particulate Matter, $\mathrm{mg} / \mathrm{dscm}^{3}$ & 69 & 27 & 15 \\
\hline Opacity ${ }^{\mathbb{I}}, \%$ & 10 & 10 & 10 \\
\hline $\mathrm{Cd}, \mathrm{mg} / \mathrm{dscm}^{3}$ & 0.10 & 0.04 & 0.01 \\
\hline $\mathrm{Pb}, \mathrm{mg} / \mathrm{dscm}^{3}$ & 1.6 & 0.50 & 0.10 \\
\hline $\mathrm{Hg}, \mathrm{mg} / \mathrm{dscm}^{3}$ & $0.08(85)$ & $0.08(85)$ & $0.08(85)$ \\
\hline $\mathrm{HCl}, \mathrm{ppm}(\mathrm{v})$ & $250(50)$ & $35(95)$ & $25(95)$ \\
\hline $\mathrm{SO}_{2}, \mathrm{ppm}(\mathrm{v})^{* *}$ & $80(50)$ & $35(75)$ & $30(80)$ \\
\hline $\mathrm{NO}_{x}, \mathrm{ppm}(\mathrm{V})^{* *}$ & None & $200-250^{11, * *}$ & $150^{7,55}$ \\
\hline
\end{tabular}

* All emissions corrected to 7-percent $\mathrm{O}_{2}$.

t Average of three stack tests using EPA Method 23. Values are weight of total tetra-through octa-cogeners. Values in brackets for [emissions limits to qualify for less frequent testing].

$\$$ Emissions limit for ESP-based air pollution control systems. Systems not ESP-based must comply with a $30 \mathrm{ng} / \mathrm{dscm}^{3}$ limit or the "less frequent testing" requirement.

I EPA Method 9. Limit for 6-minute averages.

$-$

24-hour averaging time.

\# $200 \mathrm{ppm}$ (v) for MBWW, $250 \mathrm{ppm}$ (v) for RWW, $250 \mathrm{ppm}$ (v) for RDF, $240 \mathrm{ppm}$ (v) for FBC, no $\mathrm{NO}_{x}$ control requirement for MBRW, and $200 \mathrm{ppm}(\mathrm{v})$ for others.

$\$ \$$ Applies to large plants only; $150 \mathrm{ppm}(\mathrm{v})$, except $180 \mathrm{ppm}(\mathrm{v})$ is allowed for the first year of operation. 


\section{Background Assumptions in Evaluations}

It is not the purpose of this report to compare technologies. Inevitably, comparisons incorporate the value system of the evaluators, their organizations, or both, and these comparisons are necessarily tied to a particular or local set of needs and priorities. There is value, however, in clustering many of the quantitative descriptions of the processes, especially the costs, around general norms for facility throughput, etc., and in using a consistent set of values or unit costs for input waste characteristics, labor, fuel, capital, etc.

\section{a. Solid Waste Quantities and Characteristics}

In the evaluation of processes, all the "Reference Waste" compositions and properties used by the developers were different. There was reluctance on their part to recalculate, redesign, or otherwise generate new systems to match a standard waste composition proposed by the Project Team. Thus the characteristics of the raw MSW and RDF considered in the technical and economic analyses differ slightly from process to process.

\section{b. Furnace and Facility Capacities}

Capital and operating costs are important characteristics of solid waste processing facilities. Because of factors such as the economy of scale or the effect of labor efficiency in larger facilities, cost comparisons vary with design and with actual throughput rate. Some of the technologies reviewed are tied to the low throughput rates of individual furnaces. These low rates may reflect actual process limitations or the predisposition of the developer at the time of this study. In any event, not all processes could be scaled to a common furnace size and facility throughput.

\section{c. Unit Costs and Economic Factors}

Table 2.5 shows unit costs and cost relationships. To keep a uniform basis of evaluation, the unit costs were used where possible for operating cost evaluations. 
Table 2.5 Unit Costs and Costing Relationships

\begin{tabular}{|c|c|c|}
\hline Labor (Fully Burdened) & \multicolumn{2}{|c|}{$\$ / \mathbf{h}$} \\
\hline Supervisor/Plant Manager & \multicolumn{2}{|c|}{45.00} \\
\hline Senior Operator & \multicolumn{2}{|c|}{32.00} \\
\hline Senior Maintenance & \multicolumn{2}{|c|}{$35.00 \mathrm{r}$} \\
\hline Operator & \multicolumn{2}{|c|}{30.00} \\
\hline Laborer & \multicolumn{2}{|c|}{25.00} \\
\hline Materials/Services & Metric Units & English Units \\
\hline Fuel (Natural Gas) & $\$ 3.79 \times 10^{-3} / \mathrm{MJ}$ & $\$ 4.00 / 10^{6} \mathrm{Btu}$ \\
\hline Process Water (potable) & $\$ 0.47 / \mathrm{m}^{3}$ & $\$ 1.80 / 1000 \mathrm{gal}$ \\
\hline Wastewater Treatment & $\$ 0.57 / \mathrm{m}^{3}$ & $\$ 2.15 / 1000 \mathrm{gal}$ \\
\hline Lime $(100 \%$ active $\mathrm{CaO})$ & $\$ 93.50 / \mathrm{Mg}$ & $\$ 85.00 / t$ \\
\hline Limestone & $\$ 33.00 / \mathrm{Mg}$ & $\$ 30.00 / t$ \\
\hline Liquid Ammonia (100\%) & $\$ 310.20 / \mathrm{Mg}$ & $\$ 282.00 / t$ \\
\hline Activated Carbon & $\$ 1,100.00 / \mathrm{Mg}$ & $\$ 1,000.00 / \mathrm{t}$ \\
\hline Liquid Oxygen (merchant, delivered) & $\$ 42.50 / \mathrm{Mg}$ & $\$ 38.66 / \mathrm{t}$ \\
\hline Liquid Nitrogen (merchant, delivered) & $\$ 38.50 / \mathrm{Mg}$ & $\$ 35.00 / \mathrm{t}$ \\
\hline Bypass Waste Landfill Disposal & $\$ 44.00 / \mathrm{Mg}$ & $\$ 40.00 / t$ \\
\hline Electricity (Purchase or Revenue) & -- & $\$ 0.04 / \mathrm{kWh}$ \\
\hline Other Cost Categories & \multicolumn{2}{|c|}{ Calculations } \\
\hline Financing Interest Structure & \multicolumn{2}{|c|}{$8.0 \%, 20$ years $(\mathrm{CRF}=10.19 \%$ ) } \\
\hline Maintenance (annual charges) & \multicolumn{2}{|c|}{$3.0 \%$ of Capital (unless data available) } \\
\hline Insurance (annual charge) & \multicolumn{2}{|c|}{$1.0 \%$ of Capital } \\
\hline
\end{tabular}

Note: $\mathrm{Mg}=$ Megagram (metric ton), $\mathrm{CRF}=$ Capital Recovery Factor. 


\section{Section 3}

\section{ENERGY PRODUCTS OF IDAHO (EPI)}

\section{A. SUMMARY}

EPI is a limited partnership with headquarters in Coeur d'Alene, Idaho. The company was formed in 1973 as Energy Products of Idaho. Idaho Energy Limited Partnership purchased the assets, technology, and business lines of EPI in July of 1994. EPI's basic business is involved with the design and fabrication of fluid bed combustion systems. Although their corporate experience favors the full-combustion mode for their systems, they have pilot plant and commercial plant experience (three commercial furnaces) in a "starved-air," gasification mode.

The EPI full-combustion system uses a bubbling-type fluid bed concept, accepting a prepared 10-cm (4in.) top size, refuse-derived fuel (RDF). Within the bed, the RDF particles are exposed to a vigorously turbulent hot environment that promotes rapid drying, gasification, and char burnout. EPI proprietary design features in the bed provide for the continuous removal of oversized nonburnables. The hot gases arising from the bed pass through a waste-heat boiler to generate high-pressure, superheated steam for electricity generation or, potentially, for process applications.

EPI has four full-scale combustion furnaces in the U.S., with their first plant having started up in 1981. The plants have shown reliability in excess of 85 percent, full compliance with environmental emissions limits, and good operability and maintainability characteristics.

\section{B. FINANCIAL AND BUSINESS ASPECTS}

\section{Projected Capital and Operating Cost}

The capital cost of a total EPI system burning prepared 10-cm (4-in.) RDF and generating electricity is shown in Table 3.1. The twin-furnace plant receives $782-\mathrm{Mg} / \mathrm{d}(860-\mathrm{t} / \mathrm{d})$ raw waste that it processes to $545-\mathrm{Mg} / \mathrm{d}(600-\mathrm{t} / \mathrm{d}) \mathrm{RDF}$. Combustion takes place in two $273-\mathrm{Mg} / \mathrm{d}(300-\mathrm{t} / \mathrm{d})$ EPI fluid beds. Limestone is injected into the bed to absorb $\mathrm{SO}_{2}$. Carbon and a lime slurry are added downstream of the boiler at the entrance to a spray-dryer/absorber. Particulates are controlled with a fabric filter. Steam from the boiler is converted to electricity with a conventional, condensing steam turbine-generator (Rankine cycle).

Table 3.2 presents operating cost estimates for such a plant. The net cost is $\$ 52.71 / \mathrm{Mg}$ $(\$ 47.85 / \mathrm{t})$. No credits have been assumed for any recovered materials. 
Table 3.1 Capital Cost: Energy Products of Idaho Thermal Processing System

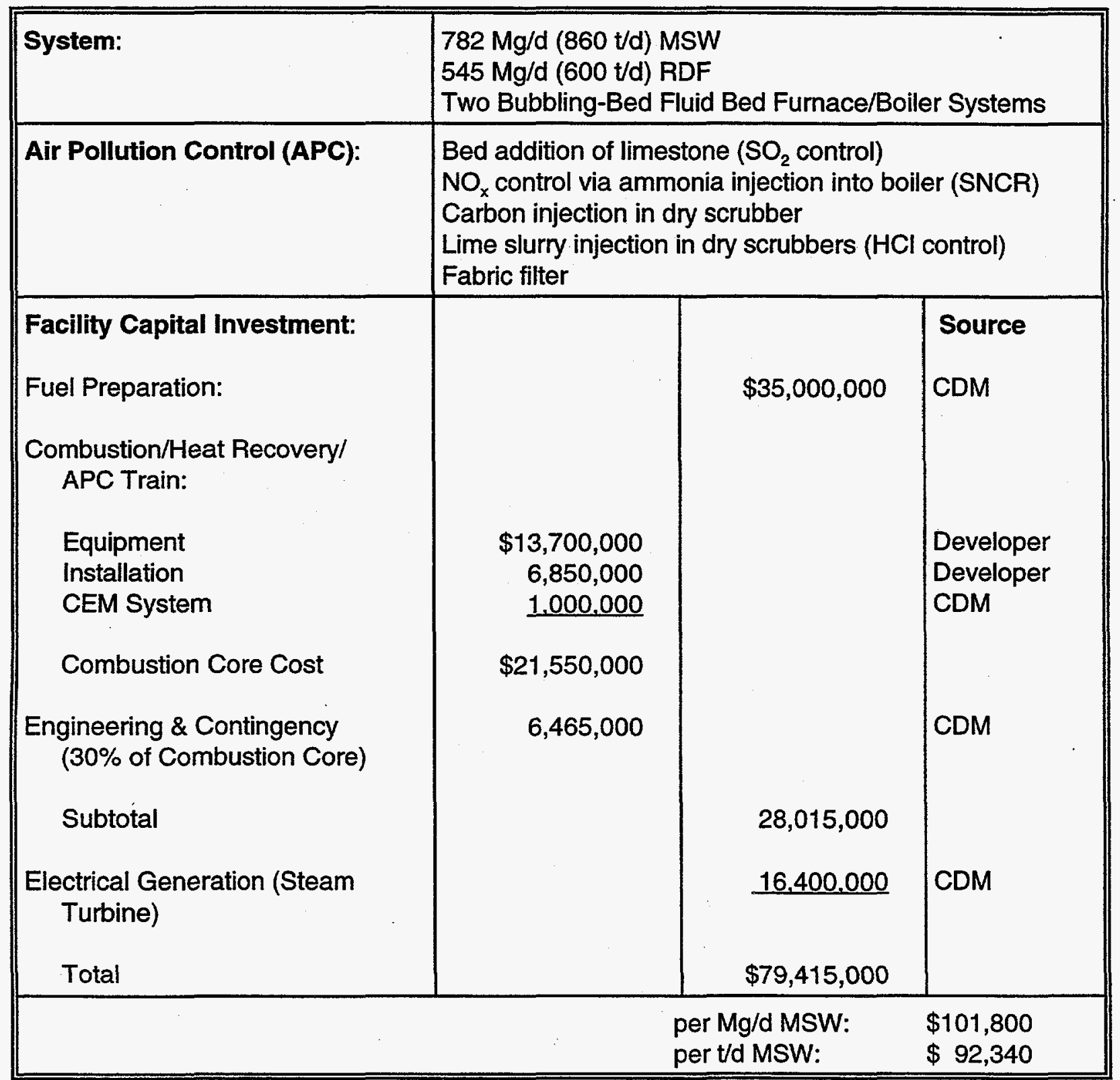


Table 3.2 Operating Costs for EPI Full Combustion System

\begin{tabular}{|c|c|c|c|c|c|}
\hline Cost Element & No./Shift & Basis & Unit Cost (\$) & Annual Cost (000) & Source \\
\hline \multicolumn{6}{|l|}{ Labor } \\
\hline Superintendent & - & 1 & 45.001 & $\$ 99$ & CDM \\
\hline Operator (Op.) & 1 & 4 & $32.00 \prime$ & $\$ 280$ & CDM \\
\hline Auxiliary Op. & 2 & 8 & 30.001 & $\$ 526$ & CDM \\
\hline Feed System Op. & 1 & 4 & $30.00 /$ & $\$ 263$ & CDM \\
\hline Plant Attendant & 2 & 8 & $25.00 /$ & $\$ 438$ & CDM \\
\hline Elect./Inst Maintenance & 2 & 8 & $35.00 \%$ & $\$ 613$ & CDM \\
\hline Mechanical Maintenance & 1 & 4 & $35.00 \%$ & $\$ 307$ & CDM \\
\hline Nat. Gas $\left(10^{6} \mathrm{Btu} / \mathrm{y}\right)$ & & 6000 & 4.00/10 6 Btu & $\$ 24$ & CDM \\
\hline Lime (t/yr) & & 0 & $85 / t$ & $\$ 0$ & CDM \\
\hline Limestone (t/y) & & 3,150 & $30 / t$ & $\$ 95$ & $\mathrm{CDM}$ \\
\hline Liq. $\mathrm{NH}_{3}(t / y)$ & & 740 & $292 / t$ & $\$ 216$ & $\mathrm{CDM}$ \\
\hline Carbon $(t / y)$ & & 265 & $1,000 / t$ & $\$ 265$ & $\mathrm{CDM}$ \\
\hline Maint.- Supplies & $\$ 28,015,000$ & Allowance & $1.5 \%$ of Capital & $\$ 420$ & $\mathrm{CDM}$ \\
\hline Maintenance & $\$ 28,015,000$ & Allowance & $3 \%$ of Capital & $\$ 840$ & CDM \\
\hline Insurance & $\$ 28,015,000$ & Allowance & $1 \%$ of Capital & $\$ 280$ & CDM \\
\hline Compliance Testing & & Allowance & & $\$ 300$ & CDM \\
\hline \multirow[t]{2}{*}{ Residue Landfill } & & 81,600 & $40 / t$ & $\$ 3,264$ & CDM \\
\hline & \multicolumn{3}{|c|}{ Total Cost for Combustion Core } & $\$ 8,229$ & \\
\hline Contingency & \multicolumn{3}{|c|}{$10 \%$ of Combustion Core Cost } & $\$ 823$ & CDM \\
\hline Debt Service & $\$ 79,415,000$ & & $10.19 \%$ of Capital & $\$ 8,092$ & CDM \\
\hline RDF Operations & N/A & $267 \times 10^{3}$ ty & $9.60 / t$ & $\$ 2,563$ & $\mathrm{CDM}$ \\
\hline \multirow[t]{2}{*}{ Electric Gen. Operations. } & N/A & $393 \times 10^{6} \mathrm{Btu} / \mathrm{h}$ & & $\$ 960$ & CDM \\
\hline & & & Total Gross Cost & $\$ 20,668$ & \\
\hline \multicolumn{6}{|c|}{ Electrical Revenue $(\$ 000)$} \\
\hline Gross Generation (Mwh/y) & $393 \times 10^{6} \mathrm{Btu} / \mathrm{h}$ & 240,000 & & & CDM \\
\hline RDF Power Use (MWh/y) & & $(6,675)$ & & . & CDM \\
\hline Internal Use (MWh/y) & & $(36,000)$ & & & \\
\hline \multirow[t]{4}{*}{ Net to Export (MWh/y) } & & 197,325 & $\$ 0.04 / \mathrm{kWh}$ & $(\$ 7,893)$ & \\
\hline & & & Net Annual Cost & $\$ 12,775$ & \\
\hline & & & Unit Cost/Ton & $\$ 47.85$ & \\
\hline & & & Unit Cost/Mg & $\$ 52.71$ & \\
\hline
\end{tabular}




\section{Business Aspects}

With over 5 million hours of operating experience in more than 70 fluid bed energy systems, EPI has established itself as a major participant in U.S. and international fluid bed technology. In 1972 EPI supplied the first fluid bed system in the U.S. to convert waste biomass (wood waste) to energy. Since that time the company has continued to provide systems for the disposal of waste materials, including three facilities that burn prepared RDF. They have also supplied three commercial systems that operate in the gasification mode to produce a low-heating-value gas.

In late 1995, EPI's operation supplied systems based on their proprietary fluid bed boilers. Their responsibility generally starts at the fuel metering bin and continues through fuel feeding, the fluid bed air supply, ash management and combustion systems, the boiler and all aspects of energy recovery, and air pollution control. This scope of supply includes all applicable process controls and systems for data collection and archiving. The RDF preparation facilities, general buildings, foundations, roads, and other civil works, plus all electrical generation equipment and switchgear, are normally designed and furnished by others.

As of late 1995, EPI's main office address and communications numbers were:

Energy Products of Idaho (EPI) Ltd. Partnership 4006 Industrial Avenue Coeur d'Alene ID 83814
Tel: (208) 765-1611

Fax: (208) 765-0503

\section{IMPLEMENTATION FEASIBILITY}

The combustion technology offered by EPI is at the point of commercial availability. EPI has installed five furnaces in the U.S. that burn RDF, with capacities of more than $55 \mathrm{Mg} / \mathrm{d}(60 \mathrm{t} / \mathrm{d})$. They include:

- For the City of Tacoma, Washington: A two-bed heat-recovery facility started in 1988

- For the Northern States Power Co. in LaCrosse, Wisconsin: The first of two boilers in 1981 and a second conversion in 1987.

These facilities do not routinely practice 100-percent RDF firing using RDF derived from MSW. Limited RDF availability leads to the use of biomass, a coarsely shredded wood, or coal for the four beds. The fifth furnace, started in 1990, burns a variety of prepared industrial plant wastes-wood, corrugated paper, plant "trash," polymer scrap, for example, at an adjacent E. I. DuPont de Nemours \& Co. medical film plant in Brevard, North Carolina.

EPI has also designed and built three wood-waste-fired, gasification-mode fluid bed systems (1982-1985). They have acquired, as well, in-house operating experience with RDF in their pilot plant gasifier, but at the time of this study (late 1995-1996), they had no commercial-scale plants operating on RDF in the gasification mode. However, whether for gasification or full combustion, the manufacturing methods for the furnaces, the long-term bed operating reliability with acceptable management of bed solids, emissions control performance, the feeders, etc., have all been proved in MSW-based RDF service. 
In matters of technical maturity and commercial verification, the EPI combustion system should be considered highly implementable with limited risk. The gasification mode is much less developed and will require some additional testing, operating experience, and design maturation. Thus the gasification mode currently presents potential users with substantially greater risk.

\section{Process Issues and Problem Areas}

The EPI system is a fully developed, commercial system available for full-combustion mode operation at RDF capacities from 25 to $230 \mathrm{Mg} / \mathrm{d}$ (50 to $500 \mathrm{t} / \mathrm{d}$ ) per furnace. RDF has been burned successfully on a continuing basis for over 8 years in facilities at Tacoma and LaCrosse, with more than 85-percent availability. Maintenance costs have been acceptable.

Gasification with an RDF feedstock has been studied by EPI in pilot plant facilities. However, no commercial-scale RDF gasification units are in the field at this time.

\section{Operating Issues and Problem Areas}

Corrosion of the old coal boilers at Tacoma has not been a problem. But there has been an attack on the welds in the Types 309 and 310 stainless steel bed tubes. The fluid bed includes $471 \mathrm{~m}^{2}\left(5077 \mathrm{ft}^{2}\right)$ of half-submerged bed tubes to remove $250,000 \mathrm{MJ} / \mathrm{h}\left(229 \times 10^{6} \mathrm{Btu} / \mathrm{h}\right)$ heat while evaporating $137 \mathrm{Mg} / \mathrm{h}$ $(300,000 \mathrm{lb} / \mathrm{h})$ water directly from the fluid bed. The present "fixes" for this problem have involved flame spraying of protective materials, extra-thick (Schedule 320) tubes for the submerged portion of the bed tubes, and coarse fins added to the bed tubes to break the bubbles.

There is some buildup of clinkers in the flue ducts and in the superheater, despite the furnace gas cooling with the bed tubes. The high alkalinity of the wood ash has been suggested as being a lowmelting binder for ash. Clinker buildup is a problem, since the massive ash accumulations may break off, fall into the bed, and bend or crush the bed tubes.

Air emissions from the fabric filter have been acceptable-opacity; particulates; $\mathrm{SO}_{\mathrm{x}} \mathrm{NO}_{\mathrm{x}}$; and, during operation, $\mathrm{CO}$ have been in compliance. Beyond the natural alkalinity of the wood ash, limestone $\left(\mathrm{CaCO}_{3}\right)$ is added to the bed for acid gas reduction. Because the air-supply ductwork was constructed of carbon steel, with a maximum working temperature $400^{\circ} \mathrm{C}\left(752^{\circ} \mathrm{F}\right)$, start-up presents a problem with excessive $\mathrm{CO}$ emissions. The plant has had occasional problems with back-end temperatures exceeding $200^{\circ} \mathrm{C}\left(392^{\circ} \mathrm{F}\right)$, threatening the fabric filter.

\section{Remaining Research and Development Needs}

There are no major equipment developments needed for commercialization.

\section{PROCESS DESCRIPTION}

\section{General}

A fluid bed combustor is a cylindrical or rectangular chamber containing coarse sand or a similar bed material. A gas passes through the bed at a rate that causes the sand bed to expand and to bubble, much as a liquid would. Contact between gas and solids is intimate, facilitating solids drying and size 
reduction. The large mass of the sand ("thermal inertia"), compared with that of the gas, acts as a flywheel to stabilize bed temperature.

The fluid bed concept was originally developed as a solids-to-gas contacting device for catalytic operations in the petroleum field. The principles of fluidization were soon extended to drying; ore processing; and ultimately, to combustion. Early interest in the fluid bed as a combustor was chiefly focused on the combustion of wastewater treatment sludge. In that application, the thermal inertia of the bed, its tolerance for high-moisture-content feedstocks and its effective and flexible response to changing feed characteristics made it especially useful. The fluid bed can present problems when burning refusebased materials because of the accumulation of massive non-burnables (stones, pieces of metal, etc.) in the bed. Thus the development of effective and reliable bed cleansing techniques was an important key to employing fluid beds for MSW applications.

As the feed to the furnace becomes drier and drier (i.e., as the feed becomes more like a fuel), the bed temperature rises. Eventually, the system approaches the state of bed defluidization, where the sand becomes sticky. Control of excess bed temperature by increasing the air rate is not desirable when heat recovery is important. Further, raising the level of excess air greatly augments the size of the air pollution control equipment and its cost. New technology added boiler surface area, removing heat from the bed walls and bayonet* tubes and from within the bed itself. These developments provided an important key to the use of the bubbling fluid bed as a general-purpose combustor for solid fuels such as coal, refuse, and wood.

\section{Combustion Mode}

Fluid bed technology has been used for refuse burning in several plants in Europe and in Japan and Korea, using "circulating fluid bed" technology. In this technology, the slow burning time of the solids is compensated for by:

- Increasing the flow velocities to transport all of the solids from the bed

- Putting a cyclone or other device in the exit gas flow to capture and recycle or discharge the solids.

In time, an acceptable level of burnout is achieved.

A second approach to the use of fluid bed technology involves modification of existing coal furnaces (suspension fired or stoker fired) or construction of new facilities that incorporate the distribution plate, high pressure air supply, sand management and other features of a bubbling fluid bed. RDF, coal, wood or almost any other feedstock that is compatible with a reasonable overall energy balance can be fed to the bed. The critical requirements incorporate features that can adequately handle the segregation and discharge of noncombustible material - called "tramp material" by EPI—and to remove enough heat from the bed to avoid fusion and bed defluidization.

\footnotetext{
* Bayonet tubes are "U"-shaped pipes projecting into the fluid bed and fed with boiler feedwater.
} 
EPI has developed such a tramp-tolerant system with acceptable heat control and has installed it in both the LaCrosse and Tacoma facilities and in several industrial applications. A typical flowsheet for a full combustion system is shown in Figure 3.1. The key elements of the system are the RDF preparation system, the intermediate RDF storage system, the RDF reclaiming and feeding system, the fluid bed boiler, and the air pollution control system.

\section{a. RDF Preparation}

Fuel preparation equipment is not normally supplied by EPI. Clearly, however, the quality and characteristics of the fuel are important to the process. The RDF fed to the fluid bed is produced through a sequence of mechanical processes-horizontal shaft hammermill or shear shredder-type primary shredding, secondary hammermill shredding, magnetic separation, air classification, and disc screening of the fines to remove glass and grit. In the Tacoma system, the RDF product is about $50 \mathrm{wt} \%$ of the original MSW stream.

The RDF feed specifications for the Tacoma system comprise:

$$
\begin{aligned}
& \text { - } 100 \text { percent }<15 \mathrm{~cm}(<6 \mathrm{in} \text {.) } \\
& \text { - } \quad 95 \text { percent }<7.6 \mathrm{~cm}(<3 \mathrm{in} \text {.) } \\
& \text { - } \quad \text { Glass content }<0.5 \text { percent }
\end{aligned}
$$$$
\text { - Ferrous metal content }<0.1 \text { percent }
$$

- Total noncombustibles $<11$ percent

\section{b. Intermediate RDF Storage}

Generally, RDF processing facilities operate for only one or two shifts daily. Because the installed processing capacity is often so high, such operation provides for protection if there is a prolonged outage as a result of explosions or major maintenance as well as for regular access to the equipment for routine maintenance. Thus it is common to incorporate some kind of intermediate RDF storage as a buffer between RDF preparation and the combustion facility. In some urban locations, the intermediate storage is a covered, live-bottom bin-type system that minimizes the opportunity for the processed RDF to compact and knit together. Subsequent withdrawal of the agglomerated RDF from storage thus becomes difficult. When space permits, a floor dump with reclaim from the top has proved low in cost and reliable.

\section{c. RDF Reclaiming and Feeding}

RDF is reclaimed from storage, moved to a small feed hopper and then fed to the furnace. The Tacoma plant recovers the RDF and biomass with a ladder-type chain reclaimer that "digs" the waste from the storage piles and deposits it onto a flat drag chain conveyor that runs the length of the building. The drag chain deposits the feed onto a belt conveyor for elevation to the feed-hopper level. Limestone can be added to provide in-bed absorption of acid gases $\left(\mathrm{HCl}\right.$ and $\left.\mathrm{SO}_{2}\right)$. An auger removes the $\mathrm{RDF}$ fuel from a holding hopper; it then passes through a rotary valve and chute to the combustor.

\section{d. Fluid Bed Boiler}

The heart of the EPI process is the fluid bed boiler. The system is a rectangular, atmospheric (bed operating at about $1 \mathrm{~atm}$ ), bubbling-type bed. Feed is distributed across the bed by pneumatic spreader/stokers designed by EPI. Twin refractory-lined 5.5-m (18-ft)-diam hot cyclones are interposed between 


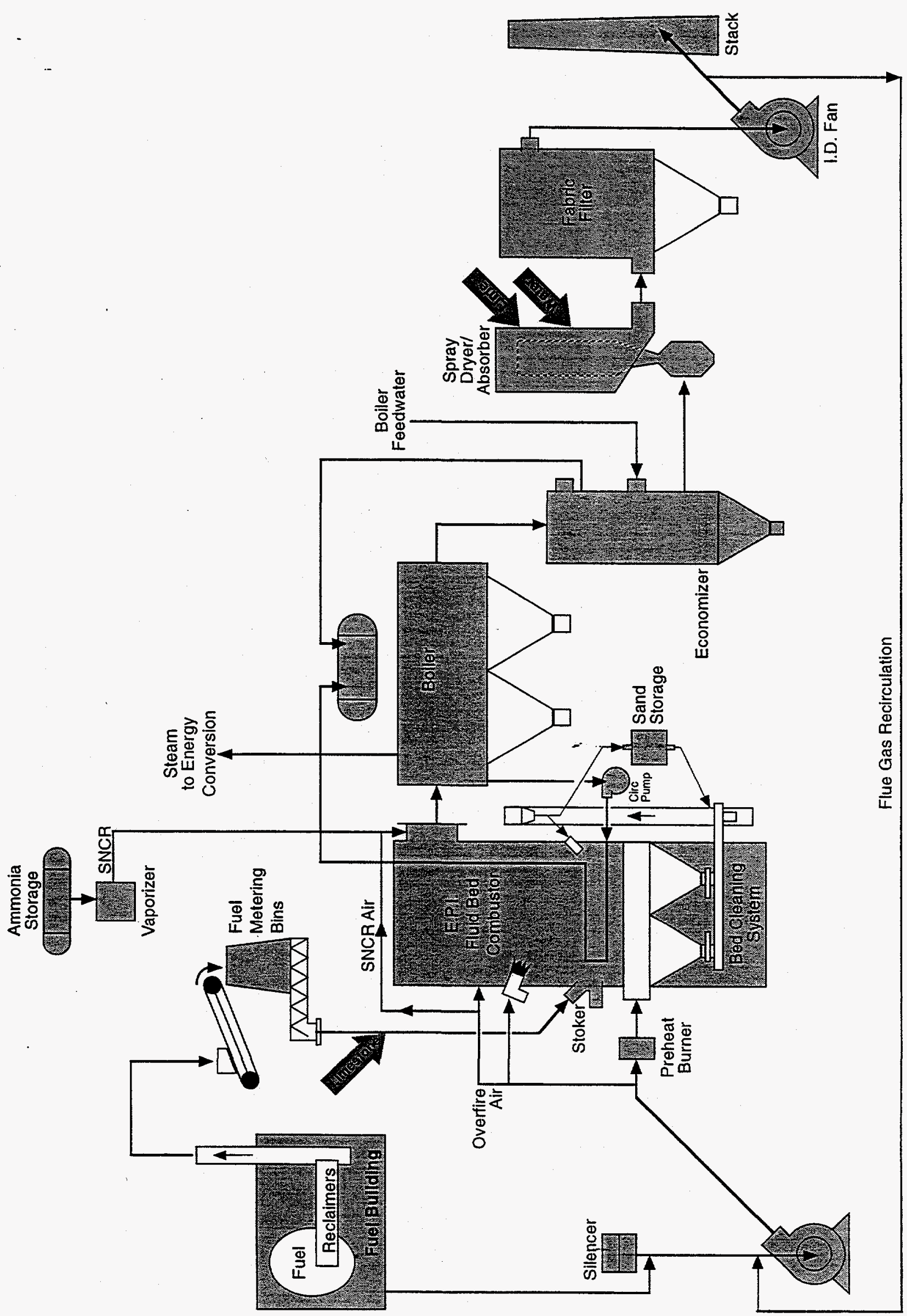

Figure 3-1 
the bed and the main boiler to capture and recycle the larger particles carried out of the combustion zone. The solids recycled by the cyclone significantly reduce the net unburned carbon losses. The beds can operate over a 2:1 range of heat-release rate. The bed is fitted with a number of shielded bayonet tubes mounted in the bed wall; they are equipped for forced-flow, in-bed cooling, using boiler water, to maintain bed temperature in a target range near $800^{\circ} \mathrm{C}\left(1500^{\circ} \mathrm{F}\right)$. At this temperature $\mathrm{SO}_{2}$ absorption is at a maximum, and $\mathrm{NO}_{\mathrm{x}}$ generation is low. The bed operates from 45- to 60-percent excess air in refuse service with typical RDF heat content and in-bed tubes for temperature control. This level of excess air is lower than the 90 to 110 -percent typical of mass-burn units.

Unlike the $1100^{\circ} \mathrm{C}\left(2000^{\circ} \mathrm{F}\right)$ combustion temperatures found in mass-burn systems, fluid bed combustion temperatures are relatively low, approximating 760 to $870^{\circ} \mathrm{C}\left(1400\right.$ to $\left.1600^{\circ} \mathrm{F}\right)$ in the higher density regions of the bed. Furnace absorption of $\mathrm{HCl}$ is effective at these temperatures; and with an average gas residence time of over $5 \mathrm{sec}$, burnout of combustible pollutants is excellent. Burnout of the combustible fraction of particulate matter is good; typically, less than 0.5-percent carbon content is observed. Combustion of the smaller fragments of RDF in the space above the fluidized bed-the "freeboard"-results in a final gas temperature of about $890^{\circ} \mathrm{C}\left(1800^{\circ} \mathrm{F}\right)$ where the gas enters the boiler convection banks.

One of the most important, and proprietary, features of the EPI design is the bed drawdown system. The system allows bed media to flow from an array of cone-shaped drains making up the bottom section of each combustor, with eight cones for each combustor. The material flows down the cones, through timed slide gates, and onto a divided, vibrating-pan conveyor. The vibrating pan is divided into two layers by a screen; the smaller particles are recycled, and the larger "tramp" material is rejected, removing the large quantities of oversized, noncombustible materials-rocks, metal, and glass-present in the fuels from time to time.

\section{e. Air Pollution Control}

In addition to the acid gas control achieved through in-bed lime addition, the combustion train is normally equipped with fabric filters for particulate reduction. Demonstrated sulfur oxides removal is over 70 percent. Ammonia injection is EPI's preferred approach for $\mathrm{NO}_{\mathrm{x}}$ control. Experience has shown about 80 percent $\mathrm{NO}_{\mathrm{x}}$ reduction at ammonia-to- $\mathrm{NO}_{\mathrm{x}}$ ratios of 3.4:1. Carbon injection can be provided for mercury control, although none of the existing RDF-burning plants included this feature. EPI offers a conventional spray dryer/absorber and fabric filter combination when there is a need for enhanced acid gas and condensible vapor removal. Because the fluid bed operates at lower excess-air, the size and capital cost of the spray dryer and the fabric filter are reduced by about one-fourth compared with conventional mass-burning systems of similar capacity.

\section{f. Typical Plant Configurations and Performance}

EPI can provide their fluid bed equipment in two styles:

- As a separated, waterwall construction, "combustion chamber," discharging hot gases into an existing boiler (e.g., Tacoma facility)

- As a combustion system integrated with the boiler furnace (e.g., LaCrosse, facility). 
Design heat-release rates of operating EPI beds range from 26,000 to $127,000 \mathrm{MJ} / \mathrm{h}$ ( 25 to 475 $\times 10^{6} \mathrm{Btu} / \mathrm{h}$ ), corresponding to daily RDF rates ranging from 23 to $230 \mathrm{Mg} / \mathrm{d}$ (50 to $500 \mathrm{t} / \mathrm{d}$ ). Air pollution trains, plus limestone added to the bed for acid gas control, would normally contain a fabric filter unit such as that installed at the Tacoma facility. For reliability, most owners of MSW-burning plants would favor a twin-furnace configuration.

\section{Gasification Mode}

An alternative illustration of the EPI fluid bed technology involves intentionally running the beds air-lean (substoichiometric) to produce a low-heat-content [0.16 to $0.26 \mathrm{MJ} / \mathrm{Nm}^{3}$ (150 to $250 \mathrm{Btu} / \mathrm{sft}^{3}$ )] fuel gas. The gasification reactor is considerably smaller and thus is lower in capital cost than a reactor in a full-combustion system. The high-pressure high-energy-consumption forced-draft fan and air pollution control system are also smaller and more cost-effective.

Although EPI has not constructed or operated commercial MSW-fired units in the gasification mode, three wood-waste-based systems have been built in the southeast and northwest U.S. In addition, EPI has carried out a comprehensive pilot plant exploration of RDF gasification performance using their 46-cm (18-in.)-diam fluid bed. In the gasification mode, sufficient air (oxygen) is supplied to oxidize most of the fixed-carbon fraction of the fuel. Heat from this reaction evaporates RDF moisture and volatilizes the remainder of the fuel. For a given operating temperature, the product gas heating value depends inversely on the RDF moisture content-the higher the moisture, the lower the heat. As the operating temperature drops, the gas quality improves, assuming there is no fall-off in the combustion efficiency for the fixed carbon. The optimum bed temperature is between 600 and $650^{\circ} \mathrm{C}\left(1100\right.$ and $\left.1200^{\circ} \mathrm{F}\right)$.

Wood-fired units have met energy and air pollution guarantees. Product gas characteristics are shown in Table 3.3. There have been problems with some feeding equipment-especially rotary "star" valves - and with boiler slagging. Although a proposed solution to the slagging problem is insertion of a cyclone between the gasifier and the boiler, the resultant carbon loss would degrade energy efficiency. EPI recommends more development work in this technical area.

\section{E. ENVIRONMENTAL ASPECTS}

\section{Process Emissions Characteristics (Air, Water, Solids)}

\section{a. Air Emissions}

Data are available from stack tests of the City of Tacoma system. The data in Tables 3.4 and 3.5 are for Tacoma when burning a blend of RDF, coal, and wood, as required by their permit. These data show that the plant complies with the applicable emissions codes. 
Table 3.3 EPI Fluid Bed Off-Gas Analysis (Gasification Mode)

\begin{tabular}{|l|c|c||}
\hline Component & $\begin{array}{c}\text { Vol\% } \\
\text { (Dry Basis) }\end{array}$ & $\begin{array}{c}\text { Percentage of Heating } \\
\text { Value }\end{array}$ \\
\hline \hline $\mathrm{CO}_{2}$ & 15.80 & None \\
$\mathrm{O}_{2}$ & 0.80 & None \\
$\mathrm{N}_{2}$ & 51.90 & None \\
$\mathrm{CO}$ & 17.50 & 32.53 \\
$\mathrm{H}_{2}$ & 5.80 & 10.88 \\
Methane & 4.65 & 27.19 \\
Acetylene & 0.18 & 1.51 \\
Ethylene & 1.49 & 13.89 \\
Ethane & 0.23 & 2.33 \\
Propylene & 0.00 & 5.49 \\
Propane & 0.01 & 1.95 \\
Other (as $\mathrm{C}_{6}$ ) & 0.15 & 4.21 \\
Unknown & 1.50 & 0.02 \\
Total & 100.00 & 100.00 \\
\hline
\end{tabular}

Table 3.4 Measured Air Emissions from Tacoma EPI System

\begin{tabular}{|l|l|}
\hline \multicolumn{1}{|c|}{ Pollutant } & Measured Emissions Rate \\
\hline \hline $\mathrm{CO}$ & $1 \mathrm{ppm}$ \\
\hline Particulate Matter & $0.013 \mathrm{gr} / \mathrm{dst}^{3}\left(7 \% \mathrm{O}_{2}\right)$ \\
\hline $\mathrm{HCl}$ & $101 \mathrm{ppm}\left(7 \% \mathrm{O}_{2}\right)$ \\
\hline $\mathrm{HF}$ & $0.405 \mathrm{ppm}\left(7 \% \mathrm{O}_{2}\right)$ \\
\hline $\mathrm{PAH}$ & $<$ Detection limit \\
\hline $\mathrm{VOC}$ & $<10 \mathrm{ppm}$ \\
\hline
\end{tabular}




\section{Table 3.5 Measured Polychlorinated Dioxin and Furan Data}

for Tacoma EPI System

\begin{tabular}{||l|l|c||}
\hline $\begin{array}{c}\text { Dioxins and } \\
\text { Furans }\end{array}$ & \multicolumn{1}{|c|}{$\begin{array}{c}\text { Measured Value } \\
\left(\mathbf{n g} / \mathbf{N m}^{\mathbf{3}}\right)\end{array}$} & $\begin{array}{c}\text { Detection Limit } \\
\left(\mathbf{n g} / \mathbf{N m}^{\mathbf{3}}\right)\end{array}$ \\
\hline \hline TCDF & 0.018 & 0.008 \\
\hline TCDD & 0.014 & 0.002 \\
\hline PeCDF & $<$ Detection Limit & 0.002 \\
\hline PeCDD & $<$ Detection Limit & 0.002 \\
\hline HxCDF & 0.001 & 0.0006 \\
\hline HxCDD & 0.011 & 0.0014 \\
\hline HpCDF & $<$ Detection Limit & 0.0015 \\
\hline HpCDD & 0.023 & 0.0027 \\
\hline OCDF & $<$ Detection Limit & 0.0021 \\
\hline OCDD & 0.044 & 0.0271 \\
\hline Total PCDD/PCDF & 0.110 & N/A \\
\hline \hline
\end{tabular}

Although process developers cannot publish emissions guarantees without associating them with a specific fuel analysis and system description, the emissions listed in Table 3.6 are "typical" of those they would expect from burning RDF in their system.

\section{b. Wastewater Emissions}

Other than boiler and cooling tower blowdown streams, there are no wastewater streams.

\section{c. Residue Characteristics}

Data from Toxicity Characteristics Leaching Procedure (TCLP) ash leaching tests for RDF combustion are limited. Table 3.7 presents data from EPI pilot plant testing using several mixed fuels. Although none of these data are for "pure" RDF, it is significant that the results are consistently more than an order of magnitude below the limit.

\section{Potential for Regulatory Compliance}

As described in "Section C. Implementation Feasibility," EPI has emissions data and ash characteristics from several full-size facilities burning RDF materials, data that can be the basis for permitting submissions. 
Table 3.6 EPI Emissions Guarantees

\begin{tabular}{|l|l|l||}
\hline \multicolumn{1}{|c|}{ Pollutant } & \multicolumn{1}{|c|}{$\begin{array}{c}\text { EPI Guaranteed Maximum } \\
\text { Emissions Rate }\end{array}$} & \multicolumn{1}{|c|}{$\begin{array}{c}\text { U.S. EPA - New Source } \\
\text { Performance Standards* }\end{array}$} \\
\hline \hline Particulate Matter & $15 \mathrm{mg} / \mathrm{Nm}^{3}\left(7 \% \mathrm{O}_{2}\right)$ & $15 \mathrm{mg} / \mathrm{Nm}^{3}\left(7 \% \mathrm{O}_{2}\right)$ \\
\hline $\mathrm{SO}_{2}$ & $30 \mathrm{ppm}(\mathrm{v})$ or $80 \%$ reduction & $30 \mathrm{ppm}(\mathrm{v})$ or $80 \%$ reduction \\
\hline $\mathrm{HCl}$ & $25 \mathrm{ppm}(\mathrm{v})$ or $95 \%$ reduction & $25 \mathrm{ppm}(\mathrm{v})$ or $95 \%$ reduction \\
\hline $\mathrm{CO}$ & $100 \mathrm{ppm}(\mathrm{v})$ & $100 \mathrm{ppm}(\mathrm{v})$ \\
\hline $\mathrm{NO}_{\mathrm{x}}$ & $150 \mathrm{ppm}(\mathrm{v})$ & $150 \mathrm{ppm}(\mathrm{v})$ \\
\hline Total Hydrocarbons & - & - \\
\hline
\end{tabular}

*Large Municipal Combustors.

Table 3.7 E.P. Toxicity and TCLP Tests for Ash From Pilot-Scale EPI Tests*

\begin{tabular}{||l|c|c|c|c|c||}
\hline \multicolumn{1}{|c|}{ Element } & $\begin{array}{c}\text { TCLP } \\
\text { Series 1t }\end{array}$ & $\begin{array}{c}\text { TCLP } \\
\text { Series 2§ }\end{array}$ & $\begin{array}{c}\text { E.P. } \\
\text { Toxicity } \\
\text { Series 31 }\end{array}$ & $\begin{array}{c}\text { E.P. } \\
\text { Toxicity } \\
\text { Series } \\
4^{* *}\end{array}$ & $\begin{array}{c}\text { Limit } \\
\text { (mg/l) }\end{array}$ \\
\hline \hline Arsenic & $<0.2$ & $<0.2$ & $<0.2$ & $<0.2$ & 5.0 \\
\hline Barium & 0.1 & 0.5 & 0.5 & $<0.2$ & 100. \\
\hline Cadmium & $<0.01$ & 0.53 & 0.76 & 0.53 & 1.0 \\
\hline Chromium & $<0.1$ & $<0.1$ & $<0.1$ & $<0.1$ & 5.0 \\
\hline Lead & 0.8 & 1.2 & 1.2 & 0.5 & 5.0 \\
\hline Mercury & $<0.005$ & $<0.005$ & 0.037 & $<0.005$ & 0.2 \\
\hline Selenium & $<0.02$ & $<0.02$ & 0.2 & $<0.02$ & 1.0 \\
\hline Silver & $<0.1$ & $<0.1$ & $<0.1$ & $<0.1$ & 5.0 \\
\hline
\end{tabular}

*Tested using Test Methods for Evaluating Solid Waste, July, 1987, Method 1310.

tSeries 1 - Cyclone catch burning RDF and wood.

§Series 2 - Baghouse catch burning 30\% coal/21\% RDF/49\% wood.

ISeries 3 - Baghouse catch burning $20.7 \%$ tires $/ 17.6 \%$ RDF $/ 61.7 \%$ wood.

$\star \star$ Series 4 - Ash burning RDF, coal, and wood. 


\section{F. FLOWSHEET}

\section{Heat and Material Balances}

\section{a. Combustion Mode}

Figure 3.2 is the process flow schematic for a single, full-combustion-mode EPI furnace system burning $680 \mathrm{Mg} / \mathrm{d}(600 \mathrm{t} / \mathrm{d}) \mathrm{RDF}$. This unit size corresponds to a plant receiving approximately $780 \mathrm{Mg} / \mathrm{d}$ $(860 \mathrm{t} / \mathrm{d}$ ) raw waste. Heat and material balances for this EPI system, given in Tables $3.8 \mathrm{a}$ and $3.8 \mathrm{~b}$ (metric and English units respectively), show the system from the subsystem feeding prepared through the combustor, heat-recovery boiler, and air pollution control system to the steam header.

\section{b. Gasification Mode}

As noted earlier, EPI has not constructed a gasification mode system for RDF. However, a $95-\mathrm{MJ} / \mathrm{h}\left(90 \times 10^{6} \mathrm{Btu} / \mathrm{h}\right)$ heat-release unit was started up in North Powder, Oregon, to accept chipped wood and tires. This system produces low-heat-content gases $\left[5.6 \mathrm{MJ} / \mathrm{Nm}^{3}\left(150 \mathrm{Btu} / \mathrm{ft}^{3}\right)\right.$, which are burned in an open-bottom A-type boiler rated at $27 \mathrm{Mg} / \mathrm{h}(60,000 \mathrm{lb} / \mathrm{h})$ of 30 -bar $\left(425 \mathrm{lb} / \mathrm{in}^{2}\right.$-gage) steam at $218^{\circ} \mathrm{C}$ $\left(825^{\circ} \mathrm{F}\right)$.

\section{End Product}

\section{a. Combustion Mode}

In the combustion mode, the EPI fluid bed boiler system generates steam for process or electrical generation. Units can be constructed to generate either saturated or superheated steam.

\section{b. Gasification Mode}

Operation of an EPI bed in the gasification mode produces a hot gas with a fuel heat content dependent on feed moisture. Because of the high dilution with nitrogen (from the air), refinement of this gas as a synthetic gas feedstock is unlikely; rather, it would be burned in a boiler for power generation. Gas cleaning before combustion is as option because of the high cost of particulate and acid gas control of the larger volume of burned gases. However, fluid bed off-gas cooling and cleaning results in the loss of up to 25 percent of the net heat content-the combination of sensible heat and fuel energy in the gas and particulate carbon. Losses of this magnitude and the capital and operating problems of adding this step suggest the merits of limiting precombustion gas cleanup to cyclone removal of particulates using a multicyclone and of using heat-recovery surface (a boiler) to cool the gases. This steps would reduce slagging in the boiler. Gas characteristics were described earlier.

\section{Proposed Interface With Other Processes}

The EPI fluid bed in the full-combustion mode can be combined with a boiler as an external combustor, made integral with the boiler, or used to generate a low-heat-content gas for use as a boiler fuel. In 

Table 3.8a Process Flow Diagram (Metric Units)—600 Mg/d RDF (Typical)

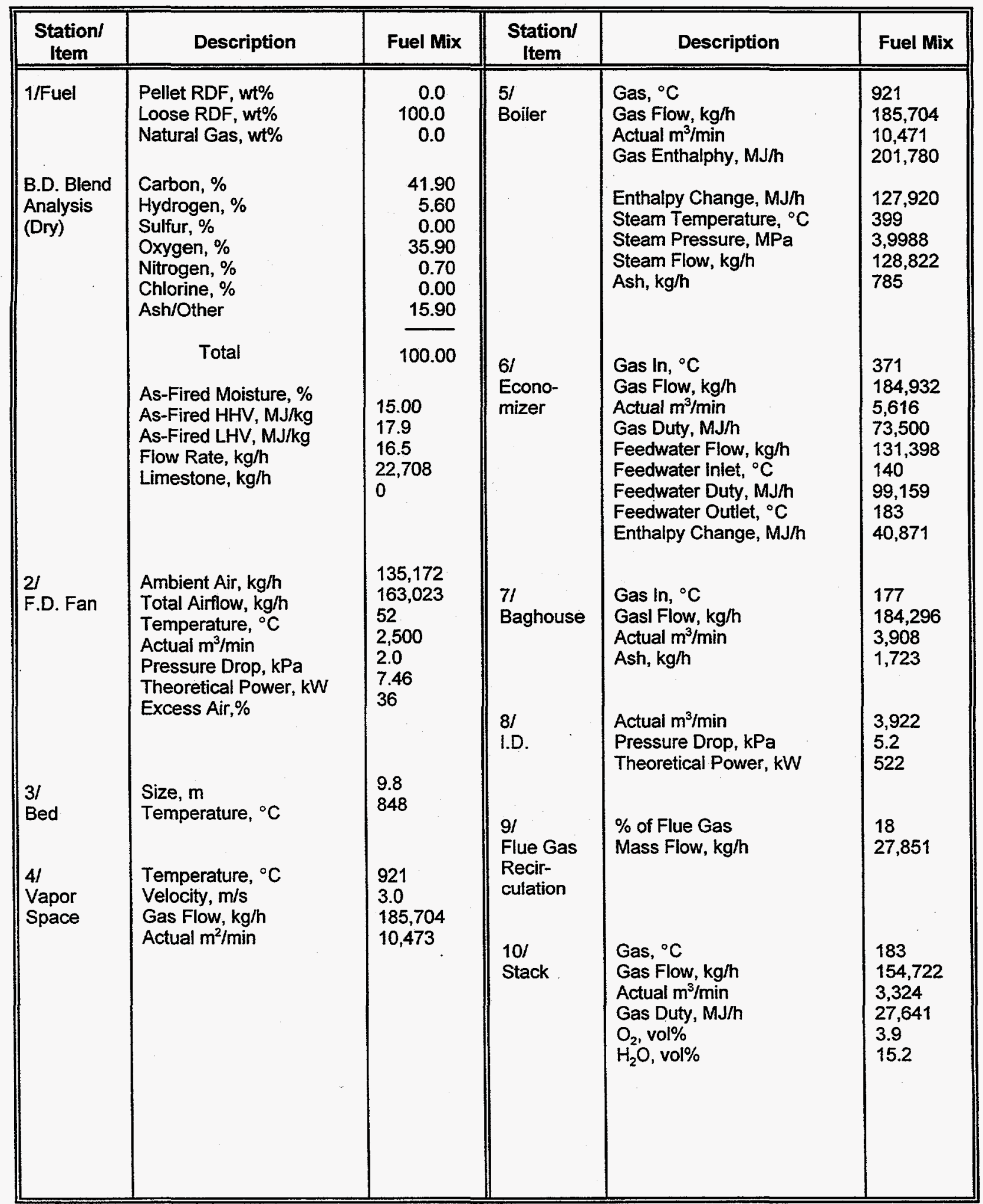


Table 3.8b Process Flow Diagram (English Units) -600 t/d RDF (Typical)

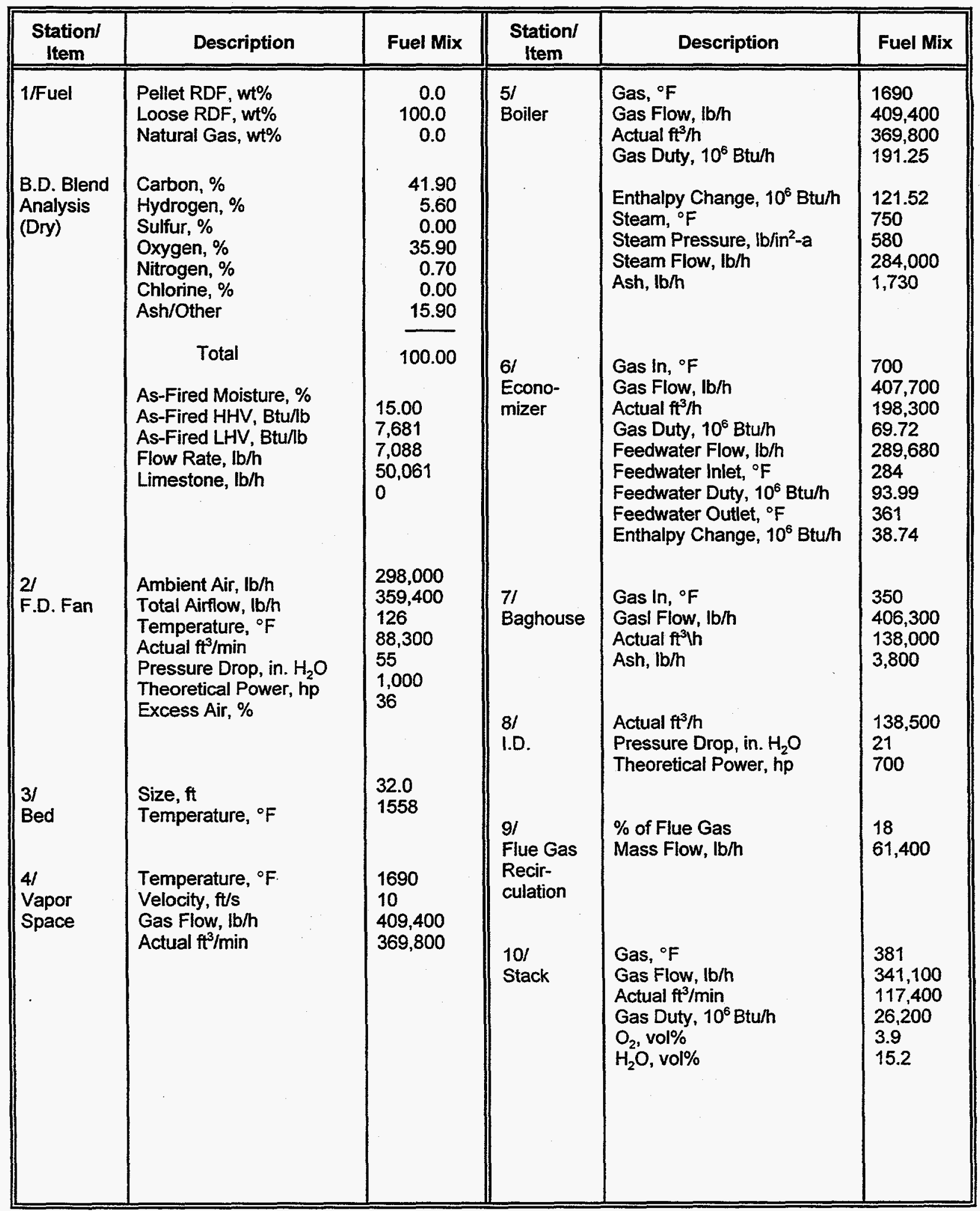


concept, the gas could be cleaned up to the point where it could be used as the fuel for a diesel or gas turbine, combined cycle for electrical generation. However, this latter flowsheet has not been tested by EPI, nor do they offer it at this time.

\section{G. DEVELOPMENT HISTORY}

\section{Current Status}

EPI produces their RDF combustors and gasifiers as standard equipment products. They have four units operating in the incineration mode with municipal or industrial RDF. They have also installed three plants for gasification of wood waste. EPI has more than 60 other furnaces burning wood, wastewater sludge, agricultural wastes, petroleum coke, and bark. In all instances except for the DuPont Brevard industrial waste project, EPI 's scope of supply was solely the combustion equipment (generally from the feeder to the stack). For the Brevard case, EPI expanded their scope of services to include construction and operations services.

\section{a. Combustion Mode}

The twin-boiler, $135-\mathrm{Mg} / \mathrm{h}(150,000-\mathrm{lb} / \mathrm{h})$ steaming rate at the LaCrosse facility of Northern States Power Co. involved the reconstruction of stoker-fired coal boilers, where the fluid bed replaced the stoker. The plant burns a mix of hogged, waste wood and RDF. The first conversion took place in 1981, and the second unit was brought on line in 1988. The facility has operated continuously since start-up.

In 1988, the Department of Public Utilities for the City of Tacoma retrofitted two 25-Mw stoker-fired boilers with fluid bed combustors. The fluid beds were configured as separate combustors, discharging hot gases into the boilers that had previously fired pulverized coal. In effect, the existing boilers became waste-heat boilers. Tacoma burns coal, hogged waste wood, and minus 7.5-cm (3-in.) RDF as fuels. The quantity of RDF available is much less than the burning capacity of the beds. The plant has operated for 8 years with an on-line availability exceeding 85 percent and acceptable owning and operating costs. The facility is equipped with the capability for adding limestone to control acid gas and a fabric filter (baghouse) for particulate control. Environmental emissions have been in compliance with Federal and State regulations. The system has been operated with 100-percent RDF from time to time. However, the system design and the air permit are based on burning a blend of 50-percent coal/35-percent wood/15 percent RDF, based on heat input.

RDF is prepared in a remote facility ( 10 miles away) near the Tacoma landfill. The MSW material is shredded to $1.9 \mathrm{~cm} \times 10 \mathrm{~cm}(0.75 \mathrm{in.} \times 4 \mathrm{in}$.) using a 500-hp horizontal-shaft hammermill. Ferrous metal is removed from the product and heavies are separated with an "air slice." The RDF material contains between 2- and 10-percent ash and has a higher heating value of about $13.8 \mathrm{MJ} / \mathrm{kg}(6000 \mathrm{Btu} / \mathrm{lb})$. The preparation plant achieves about a 50-percent yield of RDF and produces 10 to 11 loads [18.6 to $21 \mathrm{Mg}$ (20 to 23 tons) per truckload each day. The preparation plant operates on day shift only, 5 or 6 days a week. Some compaction occurs during hauling, but the material "re-fluffs" well on handling.

RDF is dumped in a special area in the feed house- a large, covered, metal building-type structure with four bays that hold and feed the RDF and wood waste. The RDF is moved about, as required, using a large, front-end loader. The present permit limits the holding time for RDF to 3 days. Wood waste is received in large, open-top, "semi" trailer-truck bodies, and with an automatic, tip-up-type unloader, is 
emptied into a holding hopper. The wood is then conveyed by belt conveyor to one of several bays in the feed house. Each bay has a drag conveyor; its "bite" into the pile is adjusted by an operator working from a second-story office overlooking the waste piles. The wood or RDF is dragged to the back wall of the feed house, dropping onto a belt conveyor that runs the length of the building. Toward the end of the building, the conveyor inclines upward, and the feed is elevated to a holding and feeding bin on the roof of the boiler house.

The wood, coal, and RDF are fed from the holding hopper atop the boiler, across a vibrating feed table, and through a metering feed system. These feed system is a rotating vane that provides both a metering action and an air lock between the combustor and the feed storage. The material then discharges from four points above the bed. The RDF is regarded as a good fuel with reliable characteristics. The most serious problem in its use is irregular feeding. RDF tends to hang up and then spurt, in a repetitive manner. The RDF tends to compress, leading to packing, with the slightest reduction in cross-section of a flow path. The average fuel firing rates are shown in Table 3.9

The Tacoma fluid bed is about 1 meter ( $3 \mathrm{ft}$ ) deep [0.7-m (2-ft) slumped depth]. Most of the 23.25 MJ/kg (10,000 Btu/lb) subbituminous coal, with 10-percent moisture/30-percent volatile matter, burns in the bed at 790 to $815^{\circ} \mathrm{C}\left(1450\right.$ to $\left.1500^{\circ} \mathrm{F}\right)$. The wood burns on the top of the bed. Refuse and coal fines burn in the freeboard at 870 to $900^{\circ} \mathrm{C}\left(1600\right.$ to $\left.1650^{\circ} \mathrm{F}\right)$.

The DuPont industrial EPI fluid bed incinerator in Brevard, North Carolina, offers another approach to the application of fluid bed technology to waste management. At this facility, the waste stream includes shredded, disc-screened waste plastics, $\mathrm{x}$-ray film, and plant trash. The shredders and disc screens produce a feed stream with 100 percent $<6-\mathrm{cm}\left(<3\right.$-in.) top size. $\mathrm{SO}_{2}$ and $\mathrm{NO}_{\mathrm{x}}$ are controlled with limestone and ammonia injection respectively. A fabric filter controls particulates. Since its start-up in 1991 , the plant has provided up to $32 \mathrm{Mg} / \mathrm{h}(70,000 \mathrm{lb} / \mathrm{h})$ steam to an adjacent manufacturing facility.

\section{b. Gasification Mode}

Gasification units installed by EPI include a 1985 biomass gasifier in Oregon. The gas can be burned to generate $27,250 \mathrm{Mg} / \mathrm{h}(60,000 \mathrm{lb} / \mathrm{h})$ of $3.2 \mathrm{MPa}(450 \mathrm{psig}) / 440^{\circ} \mathrm{C}\left(825^{\circ} \mathrm{F}\right)$ steam. In $1985 \mathrm{a}$ $100,000 \mathrm{MJ} / \mathrm{h}\left(94 \times 10^{6} \mathrm{Btu} / \mathrm{h}\right)$ heat-release gasifier started up in Bloomfield, Missouri. It generates a lowheat-content fuel gas for a rotary kiln and fuel dryer. Finally, a $205-\mathrm{Mg} / \mathrm{h}(45,000-\mathrm{lb} / \mathrm{h})$ boiler fueled by low-heat-content gas from biomass was installed in 1982 as part of the State of California's central heating plant in Sacramento

Because there have recently been changes in the economics of wood waste supply since their installation, the gasification units are not presently operating. However, there were no unusual or severe operating problems observed when the gasification units were on-line.

\section{Project Development Posture}

EPI's current efforts are primarily those of an equipment vendor. They offer a guaranteed hardware and process system, including fuel handling and burning, heat recovery, and air pollution control, but not the civil engineering "wrap-around"-buildings, foundations, road, and utility services, for example-nor energy conversion or other electrical and mechanical facilities. As in the case of Tacoma and LaCrosse, EPI is pleased to work with A\&E engineering firms to develop a specific project. 
Table 3.9 Typical Fuel Heat Release Rates inTacoma Facility

\begin{tabular}{|c|c|c|c|c|c|}
\hline \multirow{2}{*}{ Fuel } & \multirow{2}{*}{$\begin{array}{c}\text { Percentage } \\
\text { Heat Release }\end{array}$} & \multicolumn{2}{|c|}{ Mass Rate } & \multicolumn{2}{c|}{ Heat Release Rate } \\
\cline { 3 - 6 } & & $\mathbf{( k g / h )}$ & $(\mathbf{l b} / \mathbf{h})$ & $(\mathbf{M J} / \mathbf{h})$ & $(\mathbf{1 0}$ Btu/h) \\
\hline \hline Coal & 50 & 17.25 & 38,000 & 387 & 367 \\
\hline Wood & 35 & 34.10 & 75,000 & 286 & 257 \\
\hline RDF & 15 & 12.70 & 28,000 & 116 & 110 \\
\hline
\end{tabular}

In the special case of the DuPont system, EPI provided the complete hardware train on a turnkey basis. They also provided operating staff for the first several years of plant operation. The operations contract for the DuPont operation was sold off by EPI in 1993.

\section{H. INTERVIEWS}

In the course of evaluating the EPI technology, CDM engineers met with EPI personnel, visited the DuPont facility in Brevard, North Carolina, and visited the site in Brooklyn, New York, where one of the EPI gasification-mode beds has been relocated and is being reactivated. Those interviewed were:

- Ms. Joyce M. Ferris, Director of Business Development

EPI, Philadelphia, Pennsylvania

- Mr. Thomas H. Daniels, Technical Director

EPI, Coeur d'Alene, Idaho

- Mr. Dennis E. Haddock, Alternate Fuels Boiler Plant Manager

Precision Energy Services, Inc., Brevard, North Carolina

(re: DuPont facility)

- Mr. Thomas Polsinelli, Vice President

Atlas, Inc., Brooklyn, New York

(re: Reconstruction of gasifier) 


\section{Section 4}

\section{TPS TERMISKA PROCESSER AB (TPS) TECHNOLOGY}

\section{A. SUMMARY}

TPS Termiska Processer (Thermal Processes), or TPS, is a small, independent, Swedish company with about 50 employees, working in the specialized field of energy and environmental process research and technology development. The main TPS office is near Nyköping, Sweden. Between 1991 and 1995, TSP focused on process development for small- to medium-scale electricity production plants using biomass and refuse-derived fuel (RDF) as feedstocks. Their technology involves starved-air gasification of RDF in a combined bubbling- and circulating-type fluid bed. Following the gasification bed, they insert a second, circulating-bed "cracker." In the second bed, ground dolomite (mixed magnesium-calcium carbonate) is injected as the catalyst for the conversion of high-molecular-weight gasification by-products ("tars") into much lower molecular-weight compounds. This conversion allows reduction of the gas temperature using heat-recovery boiler tube surfaces, without losing a significant fraction of the gas heating value from condensation of the high-molecular-weight compounds. Scrubbers are used by TPS before combustion of the fuel gas in a gas engine or gas turbine energy conversion system.

The product of the TPS effort is a well-developed and demonstrated technology for gasification of RDF with subsequent conversion to electricity. The technology offered by TPS is presently close to the point of commercial availability. Fuel gas generated at the plant is either burned in a boiler to generate electricity or used as a fuel in an adjacent lime kiln operation.

\section{B. FINANCIAL AND BUSINESS ASPECTS}

\section{Projected Capital and Operating Cost}

Data on the capital cost of a TPS facility are based on estimates by TPS for the fluid bed vessels and their support equipment. The capital cost of a two-line TPS system burning prepared, but unpelletized, $\mathrm{RDF}$ is shown in Table 4.1. The vessels generate a fuel gas with an estimated higher heating value (HHV) of $7.5 \mathrm{MJ} / \mathrm{Nm}^{3}\left(224 \mathrm{Btu} / \mathrm{sft}^{3}\right)$. Each furnace, running at capacity, produces gas at the rate of $249,350 \mathrm{MJ} / \mathrm{h}$ $\left(236.510^{6} \mathrm{Btu} / \mathrm{h}\right)$. The fuel gas is subsequently converted to electricity using a gas turbine-based, combined-cycle system. Additional electricity is generated from steam derived from several gas cooling steps.

Table 4.2 presents operating cost estimates for such a plant. Internal electrical use is based on TPS estimates (12.4 MW or 16.7 percent of the gross generation of $74.5 \mathrm{MW})$. The net cost for waste disposal is $\$ 38.91 / \mathrm{Mg}(\$ 35.37 / \mathrm{t})$ raw MSW. No credits for any recovered materials have been assumed. 
Table 4.1 Capital Cost: Termiska Processer Thermal Processing System

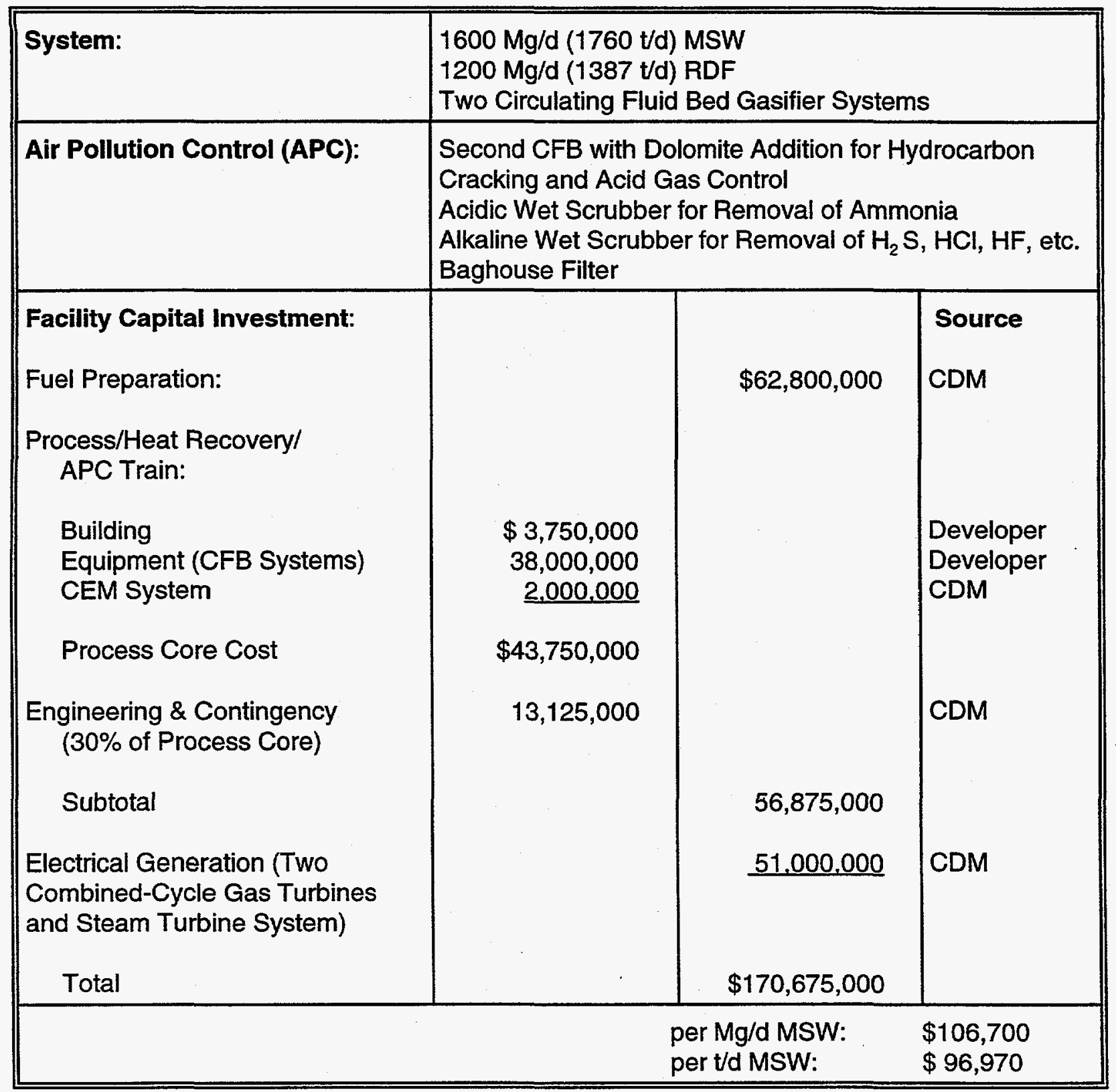


Table 4.2 Operating Costs for TPS Thermal Processing System

\begin{tabular}{|c|c|c|c|c|c|}
\hline Cost Element & No./Shift & Basis & Unit Cost & $\begin{array}{c}\text { Annual Cost } \\
(000)\end{array}$ & Source \\
\hline \multicolumn{6}{|l|}{ Labor } \\
\hline Superintendent & - & 1 & $\$ 45.00 / \mathrm{h}$ & $\$ 99$ & CDM \\
\hline Operator (Op.) & 2 & 8 & $\$ 32.00 / \mathrm{h}$ & $\$ 561$ & CDM \\
\hline Auxiliary Op. & 1 & 4 & $\$ 30.00 / \mathrm{h}$ & $\$ 263$ & $\mathrm{CDM}$ \\
\hline Feed System Op. & 2 & 8 & $\$ 30.00 / \mathrm{h}$ & $\$ 526$ & $\mathrm{CDM}$ \\
\hline Plant Attendant & 2 & 8 & $\$ 25.00 / \mathrm{h}$ & $\$ 438$ & CDM \\
\hline Elect./Inst Maintenance & 2 & 8 & $\$ 35.00 / \mathrm{h}$ & $\$ 613$ & CDM \\
\hline Mechanical Maintenance & 1 & 4 & $\$ 35.00 / \mathrm{h}$ & $\$ 307$ & $\operatorname{CDM}$ \\
\hline Nat. Gas $\left(10^{6} \mathrm{Btu} / \mathrm{y}\right)$ & & 0 & $\$ 4.00 / 10^{6} \mathrm{Btu}$ & $\$ 0$ & Developer \\
\hline Lime (t/yr) & & 0 & $\$ 85 / t$ & $\$ 0$ & Developer \\
\hline Dolomite (t/y) & & 17,100 & $\$ 30 / t$ & $\$ 513$ & Developer \\
\hline Liq. $\mathrm{NH}_{3}(\mathrm{t} / \mathrm{y})$ & & 0 & $\$ 292 / t$ & $\$ 0$ & Developer \\
\hline Carbon $(t / y)$ & & 0 & $\$ 1,000 / t$ & $\$ 0$ & Developer \\
\hline Maint.- Supplies & $\$ 56,875,000$ & Allowance & $1.5 \%$ of Capital & $\$ 853$ & CDM \\
\hline Maintenance & $\$ 56,875,000$ & Allowance & $3 \%$ of Capital & $\$ 1,706$ & CDM \\
\hline Insurance & $\$ 56,875,000$ & Allowance & $1 \%$ of Capital & $\$ 569$ & CDM \\
\hline Compliance Testing & & Allowance & & $\$ 300$ & $\mathrm{CDM}$ \\
\hline \multirow[t]{2}{*}{ Residue Landfill } & & $130,200 t / y$ & $\$ 40 / t$ & $\$ 5,208$ & $\mathrm{CDM}$ \\
\hline & \multicolumn{3}{|c|}{ Total Cost for Process Core } & $\$ 11,955$ & \\
\hline Contingency & \multicolumn{3}{|c|}{$10 \%$ of Process Core Cost } & $\$ 1,195$ & $\mathrm{CDM}$ \\
\hline Debt Service & $\$ 170,675,000$ & & $10.19 \%$ of Capital & $\$ 17,392$ & CDM \\
\hline RDF Operations & N/A & $546 \times 10^{6} / y$ & $\$ 7.85 / \mathrm{t}$ & $\$ 4,286$ & CDM \\
\hline Electric Gen. Operations. & N/A & $473 \times 10^{6} \mathrm{Btu} / \mathrm{h}$ & & $\$ 2,160$ & CDM \\
\hline & & & Total Gross Cost & $\$ 35,661$ & \\
\hline \multicolumn{6}{|c|}{ Electrical Revenue } \\
\hline Gross Generation (MWh/y) & $473 \times 10^{6} \mathrm{Btu} / \mathrm{h}$ & 501,900 & & & Developer \\
\hline RDF Power Use (MWh/y) & & $(9,425)$ & & & $\mathrm{CDM}$ \\
\hline Internal Use (MWh/y) & $16.70 \%$ & $(83,817)$ & & & Developer \\
\hline \multirow[t]{4}{*}{ Net to Export (MWh/y) } & & 408,658 & $\$ 0.04 / \mathrm{kWh}$ & $(\$ 16,346)$ & \\
\hline & & & Net Annual Cost & $\$ 19,315$ & \\
\hline & & & Unit Cost $\$ / t$ & $\$ 35.37$ & \\
\hline & & & Unit Cost $\$ / M g$ & $\$ 38.91$ & \\
\hline
\end{tabular}




\section{Business Aspects}

TPS is an offshoot of Studsvik, a public-sector organization established in the 1940s as a semiprivate research company for the development of nuclear energy. During the 1970s, Studsvik ventured into the areas of energy use and production development. The Thermal Engineering Laboratory assumed primary activity in this technical area. TPS was separated from the Thermal Engineering Laboratory and established as an independent, private company in 1992.

The focus of the company's operation is basic and applied research, process and product development, and process design within the heat and power generation sector, with special emphasis on the environment. Commercialization of the new techniques developed by TPS normally progresses through demonstration plants to commercial operating plants. In this case, however, their path has been technology licensing or joint venture activities. Between 1991 and 1995, TPS has focused on process development for small- to medium-scale electricity production plants using biomass and RDF as feedstocks. During that period, exclusive worldwide licenses for circulating fluid bed combustors (CFBCs) were granted to Babcock \& Wilcox, USA.

As of late 1995, TPS had not pursued the municipal solid waste market in the U.S.-either by themselves or through their licensee. TPS was selected to construct a 30-MWe wood-fueled Circulating Fluid Bed Gasifier (CFBG) combined-cycle plant for installation in Brazil (start-up in 1999). A second unit, fueled with biomass harvested during short-rotation forestry (clear-cutting of rapid-growth species on a 3-year cycle) is expected to enter start-up in the United Kingdom in 1998.

In late 1995, the firm's main office address and communications numbers were:

TPS Termiska Processer AB

Studsvik

S-611 82 Nyköping, Sweden.
Tel: $011-46-155-22-13-00$

Fax: 011-46-155-26-30-52

\section{IMPLEMENTATION FEASIBLITY}

Ansaldo Aerimpianti SpA (Italy) constructed twin, 15-MW each $\left[54,000-\mathrm{MJ} / \mathrm{h}\left(51 \times 10^{6} \mathrm{Btu} / \mathrm{h}\right)\right] \mathrm{CFB}$ gasification units according to TPS specifications for operation in Grève-en-Chianti, Italy. The gasifiers were commissioned in 1992 to gasify pelletized RDF or biomass. The resultant fuel gas can be passed to an adjacent cement plant kiln or burned in a boiler to generate steam. Present economics favor electrical generation. Limited RDF availability since early 1995 has led to the use of biomass (hogged wood or agricultural wastes) from time to time. New RDF facilities near Florence, Italy, constructed to serve the Grève facility are expected on-stream in mid-1996.

The manufacturing methods for the TPS-designed systems, the long-term operating reliability of their beds with acceptable management of bed solids, the projected emissions control performance, the feeders, etc., have all been tested in MSW-based RDF service. Therefore, in matters of technical maturity and commercial verification, the TPS system should be considered as highly implementable with only moderate technological risk. 


\section{Process Issues and Problem Areas}

The primary area remaining for process development relates to the gas cleaning train following the dolomite cracker and preceding a gas engine or gas turbine. The equipment installed at Grève did not include gas refining with, for example, a dolomite cracker bed or a scrubber. The next step after the gasification bed was direct firing in the boiler to generate steam. If an engine or turbine energy-conversion option is to be used in future commercial applications, a scheme for gas clean-up will be required. The successful achievement of this development is likely, and the time frame should be short.

TPS should also confirm that their feeding devices and the CFB reactor itself can accommodate nonpelletized RDF. To date, all RDF experience has involved material that was pelletized to facilitate transport and storage. However, if material in pellet form is actually required for the TPS process, the process would be economically encumbered with another capital and operating cost increment for the pelletizing equipment.

\section{Operating Issues and Problem Areas}

At the Grève plant, where the raw gas is burned directly in a boiler, a problem has been experienced with slag accumulation on the boiler tubes. The problem has been severe enough to cause a plant shutdown and longer-than-acceptable outages for boiler cleaning and rework. However, the Grève plant boiler was somewhat undersized and was not well-configured for burning a high-ash fuel. In any future plant designed according to the flowsheet illustrated in Figure 4.1, a boiler must be designed to avoid this problem. A possible solution is to custom-design the boiler to provide greater gas cooling before to the tube banks so that the slag particles are cold and dry when they hit the tubes.

\section{Remaining Research and Development Needs}

Data are needed on the characteristics of the TPS process residue. The mechanism to obtain such data is the Toxicity Characteristics Leaching Procedure (TCLP) leaching tests. Although no particular problems are foreseen, such information is needed to allow proper planning for residue disposal.

Further, the dioxin compound data collected at Grève should be augmented with similar data from the area following the dolomite cracker. To facilitate evaluations in the U.S., the results should be reported on a "total dioxin and furans" basis as well as in the Toxic Equivalents (TEQs) used to date.

\section{PROCESS DESCRIPTION}

\section{General}

A bubbling fluid bed reactor has a cylindrical or rectangular chamber containing coarse sand or a similar bed material. A gas passes through the bed at a rate that causes the sand bed to expand and bubble, much like a liquid. Contact between gas and solids is intimate, facilitating solids drying and reduction by solids attrition. The large mass of sand ("thermal inertia") in comparison with the gas stabilizes the bed temperature. The bed can be designed and operated by setting the feed rate high relative to the air supply, so that the air rate is lower than the theoretical oxygen quantity needed for full feed material oxidation attrition. Under these conditions, the product gas and solids leaving the bed contain unreleased fuel 


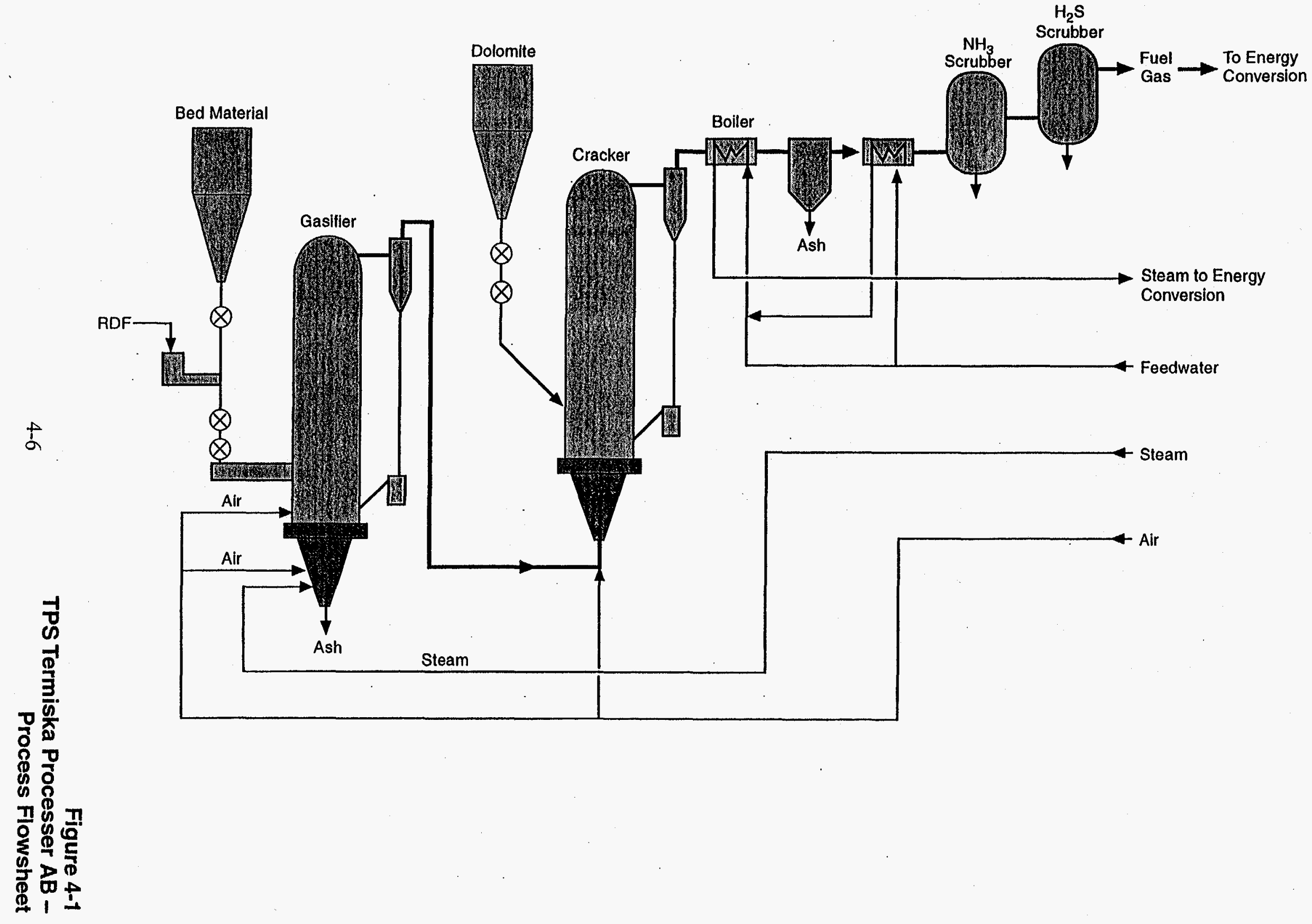


value. The heating value of the gases and the char increases as the air setting decreases relative to the theoretical oxygen demand. This is the gasification mode of operation.

As the gas velocity increases, the bed of solids continues to expand, and an increasing fraction of the particles is blown out of the bed. If a medium- to low-efficiency particulate collector is interposed, perhaps one collecting 100 percent of particles with greater than a 30-micron aerodynamic diameter, the larger particles can be captured and returned to the bed. This embodiment of the suspended-combustion concept is called a circulating fluid bed.

The fluid bed concept was originally developed as a solids-to-gas contacting device for catalytic operations in the petroleum field. The principles of fluidization were soon extended to drying, ore processing, and ultimately, to combustion. Early interest in the fluid bed as a combustor focused mainly on the combustion of sludge. In that application, the thermal inertia of the bed, its tolerance for highmoisture-content feeds, and its effective and flexible response to changing feed characteristics made a fluid bed combustor especially useful. The fluid bed can present problems when burning refuse-based materials because massive nonburnables (stones, pieces of metal, etc.) tend to accumulate in the bed. Thus the development of effective and reliable bed-cleansing techniques was an important catalyst to the use of fluid beds for refuse applications.

As the bed temperature rises, the system can approach the state of bed defluidization-bed temperature approaches the fusion point and sand becomes sticky. Operation in the gasification mode has the advantage that the operating temperature for satisfactory gasification is considerably below that where RDF ash fusion is likely.

Circulating fluid bed technology to gasify prepared refuse, RDF, has been adopted in several plants in Europe. With this operating concept, the overall bed air-to-fuel ratio can be dropped below the stoichiometric point (reducing conditions), lowering the bed temperature. Under these conditions, a very large fraction of organic refuse components and biomass materials (e.g., wood) breaks down into volatile components. The remainder is found as a solid char. A cyclone or other device in the exit gas captures and returns the solids so that an acceptable level of carbon burnout is achieved.

The feasibility of the CFB as a gasifier is greatly enhanced by the large fraction of the organic material present as volatile matter. This quality of the RDF is reported in a proximate analysis and reflects the fraction of the waste that is distilled upon heating. This favorable circumstance is not the case for most coals, where the dominant product with bed heating would be fixed carbon. If the volatile fraction is low, steam is often added to the fluidizing medium to enhance gasification of the carbon via the water gas reaction:

$$
\mathrm{C}+\mathrm{H}_{2} \mathrm{O} \rightarrow \mathrm{CO}+\mathrm{H}_{2}
$$


The volatilized organic matter can appear in the reactor gas in various forms. For convenience, they can be categorized as:

- Basic reactor gas-carbon monoxide and hydrogen

- Low- to medium-molecular-weight hydrocarbons-those with boiling points at or below $100^{\circ} \mathrm{C}\left(212^{\circ} \mathrm{F}\right)$

- High-molecular-weight hydrocarbons-sometimes called tar.

The combination of heating values of these gases and tar-like compounds constitutes the fuel value of the resultant gas. Another energy form found in the CFB reactor gas is the heat associated with gas temperature or enthalpy.

The overall heat balance of the bed and reactor gas suggests a relationship between gas temperature, waste moisture content, and the reactor gas heating value. When any one of the three quantities increases, it is detrimental to the others. For example, if the moisture content of the waste increases, either the gas temperature or the heating value, or both to some lesser extent, must fall. Note also that the reactor gas is diluted with the nitrogen brought in with the combustion air. Therefore, a shift to oxygen-enriched air or pure oxygen will increase reactor gas heat content-at the price of increased operating cost.

The tar-like material in the reactor gas can be a problem. If the gas is cleaned with a water scrubber, the tars condense and their heating value is lost. In addition, a portion of the sensible heat will be lost if a boiler is not installed between the CFB and the scrubber. The combustion of the tar-like compounds may be less complete than that of the lower-molecular-weight hydrocarbons and reactor gas components, possibly leading to soot formation. Once soot has formed, relatively severe combustion conditiontemperature, and residence time-may be required for adequate burnout. Finally, the tars are quite odorous and believed by some to be potentially carcinogenic.

Because of these problems, TPS has added a second CFB and cyclone to their configuration, following the CFB gasifier. The second bed is fed with crushed dolomite, a naturally occurring mixed calcium and magnesium carbonate, which acts as a catalyst at about $900^{\circ} \mathrm{C}\left(1650^{\circ} \mathrm{F}\right)$ to crack the tars to lower-molecular-weight hydrocarbons. A small fraction of the cracking products remains in heavier molecules such as benzene, toluene, and naphthalene. Only an unimportant portion of the heating value of the tar-like organic compounds is lost in the dolomite gas cleaning/reforming processes. In the course of catalyzing the cracking reactions, the dolomite also scavenges the flue gases for acidic components such as hydrochloric acid $(\mathrm{HCl})$ and sulfur oxides $\left(\mathrm{SO}_{2}\right.$ and $\left.\mathrm{SO}_{3}\right)$.

\section{TPS Termiska Circulating Fluid Bed Gasifier System}

The TPS gasifier comprises a bubbling fluid bed into which RDF or RDF pellets are fed. The addition of secondary air part way up the furnace transforms the bed aerodynamic balance so that smaller, lighter particles are blown from the circulating bed. Heavy, still-burning "chunks" remain in the dense, bubbling fluid bed until they are consumed. Dolomite can be added in a second bed to catalyze breakdown of high-molecular-weight hydrocarbons into lighter products. The product gas can be cleaned to generate a fuel gas suitable for use in a gas engine or turbine or can be burned directly in a boiler or process furnace. 


\section{a. RDF Preparation}

TPS does not normally supply fuel preparation. However, the quality and characteristics of the fuel are clearly important to the process. The RDF fed to the fluid bed is produced through a sequence of mechanical processes-horizontal-shaft hammermill or shear shredder-type primary shredding, secondary hammermill shredding, magnetic separation, air classification, and disc screening of the fines to remove glass and grit. For the TPS system at Grève and in the TPS pilot plant, pelletized RDF has been used to date. If pellets were required, another processing step would be added to RDF preparation. Considering the high degree of mechanical abuse in the Grève handling system, engineers at TPS believe that the actual RDF material fed to the gasifiers has degraded to a pelletized, "fluff" state. This degradation will be investigated during future testing.

The pelletized RDF feed specifications for the Grève system are:

$\begin{array}{lll}\text { - } & \text { Diameter } & 10 \text { to } 15 \mathrm{~mm}(0.4 \text { to } 0.6 \mathrm{in} .) \\ \text { - } & \text { Length } & 50 \text { to } 150 \mathrm{~mm}(2 \text { to } 6 \mathrm{in} .) \\ \text { - Nulk Density } & 500 \text { to } 700 \mathrm{~kg} / \mathrm{m}^{3}\left(31 \text { to } 42 \mathrm{lb} / \mathrm{ft}^{3}\right) \\ \text { - Mot Calorific Value } & 17.2 \mathrm{MJ} / \mathrm{kg}(7380 \mathrm{Btu} / \mathrm{lb}) \\ \text { - Volatile Matter } & 6.5 \text { percent } \\ \text { - Fixed Carbon } & 71.1 \text { percent } \\ \text { - Sulfur } & 11.4 \text { percent } \\ \text { - Chlorine } & 0.5 \text { percent } \\ \text { - Total noncombustibles } & 0.4 \text { to } 0.6 \text { percent }\end{array}$

\section{b. Intermediate RDF Storage}

RDF processing facilities are generally operated for only one or two shifts daily, a reflection of the often high processing capacity and a provision to protect the operation if there is a prolonged outage caused by explosions or the need for major maintenance or an outage that is the result of a need to access equipment for routine maintenance. Thus it is common to incorporate some kind of intermediate RDF storage as a buffer between RDF preparation and the combustion facility. In some urban locations, the intermediate storage is a covered, live-bottom bin-type system that lessens the opportunity for the processed RDF to compact, knit together, and resist subsequent reclaim. When space permits, a floor dump with reclaim from the top has proved low in cost and reliable. At the Grève facility, there are four 80-Mg (88-t) steel silos.

\section{c. RDF Reclaiming and Feeding}

RDF is reclaimed from storage, moved to a small feed hopper, and then fed to the gasifier. The Grève plant recovers the RDF or biomass from their storage silos using a twin-screw reclaimer that "digs" the waste from the silos and deposits it into a bucket conveyor. From the bucket elevator, the RDF is 
moved by a screw conveyor that runs the length of the building, discharging into the feed hopper. RDF fuel is removed from the hopper with a twin-screw auger/reclaimer; it passes through a rotary valve and is sent by chute into the gasifier.

\section{d. Fluid Bed Gasifier}

The heart of the TPS process is the fluid bed gasifier. A cylindrical, bubbling-bed type, the system operates at about atmospheric pressure. Feed is distributed across the lower "dense bed" and begins to volatilize. The temperature in this zone is approximately 700 to $800^{\circ} \mathrm{C}\left(1300\right.$ to $\left.1500^{\circ} \mathrm{F}\right)$. Residence time for larger particles in the dense bed can be quite long. As the particles are reduced, they are lifted up and out of the dense, bubbling-bed zone. Steam can be added to the dense bed if required to facilitate gasification of carbon in wastes with a high fixed-carbon content. Above the dense-bed zone, secondary air is injected. The combination of heat release (i.e., temperature increase and density reduction) and greater mass flow raises the velocity of the gas flowing upward and facilitates carbon oxidation. The temperature rises to about 850 to $900^{\circ} \mathrm{C}\left(1560\right.$ to $\left.1650^{\circ} \mathrm{F}\right)$ in the bubbling-bed zone, described by TPS as the "fast bed." In beds firing fuels with a limited moisture content, steam must be added to the fluidizing gas flow. Water is an oxidizer to gasify carbon to $\mathrm{CO}$ and hydrogen.

The gases leaving the bed pass to large-diameter refractory-lined cyclones for particulate recovery. They then pass to a large-diameter, refractory-lined cyclone, where additional particulate recovery occurs. The solids streams from the cyclone hoppers accumulate in a vertical pipe, forming an air seal or plug. At the very bottom of the accumulation pipe, a small amount of nitrogen is introduced to fluidize the lower mass of solids. Then, by gravity, the fluidized solids flow from the pipe and are reintroduced into the dense-phase bubbling fluidized bed. Oxygen-free gas is used as the fluidizing medium to avoid the high temperatures that would occur if air (with oxygen) were used to move the stillhot, ignitable char solids.

The off-gas from the cyclone is, then, a fuel gas comprising a mixture of product gas, hydrocarbons, and tars, with some residual particulate matter. The typical composition and heating value of the gas derived from RDF and the gas composition data from the Grève facility are shown in Table 4.3.

For combustors incorporating additional air pollution control systems, such as rotary cement or lightweight aggregate kilns or process furnaces, the gas can be used directly as a medium-heat-content fuel gas. Or, if this is not the choice, it can be burned in a boiler. A subsequent air pollution control train would be required to remove acid gases, particulates, etc.

Alternatively, the fuel gas can be cleaned to the degree required for combustion in a gas engine or gas turbine for the direct generation of electricity. Optimum electrical generation is found in the combined-cycle mode, where the exhaust gases from the engine or turbine pass through a boiler to generate steam for about one-third more power generation. The latter choice may result in the loss of the sensible heat of the fuel gas unless a dolomite-cracker circulating bed with an associated cyclone is appended to the gasifier. With such a cracker, loss of fuel gas heating value through condensation in water scrubbers is avoided. Almost all of the tar is converted into lower-molecular-weight compounds and a small amount of benzene, toluene, and naphthalene. Nitrogen-containing compounds and hydrogen cyanide decompose into either nitrogen gas or ammonia. Carbon-containing dust is gasified by the residual oxidizing gases (e.g., $\mathrm{H}_{2} \mathrm{O}$ and $\mathrm{CO}_{2}$ ) at the higher temperatures of the cracker bed. 
Table 4.3 Typical Reactor-Gas Composition at Grève

\begin{tabular}{|c|c|c|c|}
\hline \multirow{2}{*}{ Component } & \multicolumn{2}{|c|}{ Vol\% } & \multirow{2}{*}{$\begin{array}{l}\text { Percentage of } \\
\text { Heating Value }\end{array}$} \\
\hline & Grève Data & "Typical" Data* & \\
\hline $\mathrm{CO}_{2}$ & 15.65 & 10 & None \\
\hline $\mathrm{N}_{2}+\mathrm{Ar}$ & 45.83 & 40 & None \\
\hline $\mathrm{co}$ & 8.79 & 22 & 34.9 \\
\hline $\mathrm{H}_{2}$ & 8.61 & 14 & 22.5 \\
\hline Methane & 6.51 & 4 & 12.8 \\
\hline $\mathrm{C}_{x} \mathrm{H}_{\mathrm{y}}$ & 4.88 & 2 & 29.7 \\
\hline $\mathrm{H}_{2} \mathrm{~S}$ & $48.61(\mathrm{ppm})$ & 0.02 & 0.06 \\
\hline $\mathrm{H}_{2} \mathrm{O}$ & 9.48 & 8 & None \\
\hline Other & 0.14 & - & $N / A$ \\
\hline Total & 100.00 & - & $\begin{array}{l}7.53 \mathrm{MJ} / \mathrm{Nm}^{3} \\
\left(202 \mathrm{Btu} / \mathrm{sft}^{3}\right)\end{array}$ \\
\hline
\end{tabular}

*For typical reactor gases at tar cracker discharge.

\section{e. Air Pollution Control}

Following the cracker, a waste-heat boiler can be installed to. bring the temperature down to about $200^{\circ} \mathrm{C}\left(400^{\circ} \mathrm{F}\right)$, where a fabric filter system can remove particulate matter. The particulates, consisting mainly of calcined dolomite and fine soot, are not abrasive.

Demonstrated sulfur oxides removal is over 70 percent. Carbon injection can be provided for mercury control, although the Grève data suggest that acceptable mercury emissions may be achievable without this feature. TPS offers a wet scrubber system when there is a need for enhanced ammonia, tar, acid gas $\left(\mathrm{H}_{2} \mathrm{~S}, \mathrm{HCl}\right)$, and condensible vapor removal. At this point, the fuel gas is of a quality that can be burned in a boiler without further clean-up to generate steam or it can be cleaned for use as a fuel in a gas engine or turbine combustor for the generation of electricity.

\section{f. Typical Plant Configurations and Performance}

TPS can provide their fluid bed equipment in two styles of fuel generator to produce a fuel gas for firing a boiler or a process furnace or for use in a gas engine or turbine. Combined-cycle design for the latter alternative offers optimum energy conversion. 


\section{E. ENVIRONMENTAL ASPECTS}

\section{Process Emissions Characteristics (Air, Water, Solids)}

\section{a. Air Emissions}

Data are available from stack tests of the Grève system. Data from tests made when the plant was burning RDF are listed in Table 4.4. Heavy metal data from Grève are given in Table 4.5. The complete TPS system, including tar cracker, baghouse filters, and scrubbers, appears able to meet all European and U.S. emissions standards.

\section{b. Wastewater Emissions}

Other than boiler and cooling tower blowdown streams, there are no major wastewater streams from the TPS process. Wastewater is produced in the scrubber systems. Pilot test data suggest that these streams can be treated in a biological system or in activated carbon filters.

\section{c. Residue Characteristics}

Data on the leaching characteristics of TPS process residues are not available.

\section{Potential for Regulatory Compliance}

The TPS system has emissions data and ash characteristics from a full-size facility burning RDF materials on which to base permitting submissions. In addition, there is a large body of data from the $20-\mathrm{Mg} / \mathrm{d}(22-\mathrm{t} / \mathrm{d})$ pilot facility in Nyköping, Sweden. These data demonstrate compliance with all of the present requirements of the U.S. EPA New Source Performance Standards (NSPS) for municipal waste combustors.

\section{F. FLOWSHEET}

\section{Heat and Material Balances}

Figure 4.2 is the process flowsheet for a single, combustion-mode TPS furnace system receiving $388-\mathrm{Mg} / \mathrm{d}(427-\mathrm{t} / \mathrm{d}) \mathrm{RDF}$. This size corresponds to a plant receiving approximately $554-\mathrm{Mg} / \mathrm{d}(610-\mathrm{t} / \mathrm{d})$ MSW. TPS system heat and material balances, Figure 4.3, shows the system from the feed subsystem to the combustor, the heat-recovery boiler, and the air pollution control system.

\section{2. $\quad$ End Product}

Because of the high dilution with nitrogen from the air, it is unlikely that the TPS gasifier product would be refined as a chemical feedstock. Rather, it would be burned as a process heating fuel or in a boiler or gas turbine for power generation. Gas cleaning before combustion is an option because of the high cost of particulate and acid gas control on the larger volume of burned gases. However, when the fluid bed fuel gas is cooled and cleaned, up to 25 percent of the net heat content is lost. Net heat content is defined as the combination of sensible heat and fuel energy in the gas and particulate carbon. 
Table 4.4 Air Emissions Data: Grève-en Chianti Plant

\begin{tabular}{|c|c|c|c|c|}
\hline \multirow{2}{*}{ Pollutant } & \multicolumn{2}{|c|}{ Measured Emission Rates } & \multicolumn{2}{|c|}{ Grève Regulatory Limits } \\
\hline & $11 \% \mathrm{O}_{2}$ & $7 \% \mathrm{O}_{2}$ & $11 \% \mathrm{O}_{2}$ & $7 \% \mathrm{O}_{2}$ \\
\hline $\mathrm{CO}, \mathrm{mg} / \mathrm{Nm}^{3}$ & $2.5-5$ & $1.8-3.6$ & 50 & 35 \\
\hline Particulates, $\mathrm{mg} / \mathrm{Nm}^{3}$ & $3-7$ & $2-5$ & 10 & 7 \\
\hline $\mathrm{HCl}, \mathrm{mg} / \mathrm{Nm}^{3}$ & $0.5-2$ & $0.4-1.4$ & 30 & 21 \\
\hline $\mathrm{HF}+\mathrm{HBr}, \mathrm{mg} / \mathrm{Nm}^{3}$ & $<0.1$ & $<0.1$ & 2 & 1.4 \\
\hline $\mathrm{SO}_{2}, \mathrm{mg} / \mathrm{Nm}^{3}$ & $5-15$ & $3.6-10$ & 100 & 71 \\
\hline Heavy Metals, $\mathrm{mg} / \mathrm{Nm}^{3}$ & 2.2 & 1.6 & * & * \\
\hline $\mathrm{NO}_{\mathrm{x}}, \mathrm{mg} / \mathrm{Nm}^{3}$ & $200-300$ & $140-214$ & 300 & 214 \\
\hline $\mathrm{PCB}, \mathrm{ng} / \mathrm{Nm}^{3}$ & 163.0 & 116 & 0.1 & $<0.1$ \\
\hline PCDD/PCDF, ng/ $\mathrm{Nm}^{3}$ & 13.1 & 9.3 & 2860 & 2040 \\
\hline
\end{tabular}

* Refer to Table 4.5.

Table 4.5 Heavy Metals Emission Data for the Grève-en Chianti Plant

\begin{tabular}{|l|c|c|}
\hline \multicolumn{1}{|c|}{ Metal } & $\begin{array}{c}\text { Measured Value } \\
\left(\mathbf{m g} / \mathbf{N m}^{\mathbf{3}}\right)\end{array}$ & $\begin{array}{c}\text { Italian Regulatory } \\
\text { Limit }\left(\mathbf{m g} / \mathbf{N m}^{\mathbf{3}}\right)\end{array}$ \\
\hline \hline Lead $(\mathrm{Pb})$ & $\max 0.005$ & 3 \\
\hline Cadmium $(\mathrm{Cd})$ & $<0.0004$ & 0.1 \\
\hline Mercury $(\mathrm{Hg})$ & $0.008-0.05$ & 0.1 \\
\hline
\end{tabular}




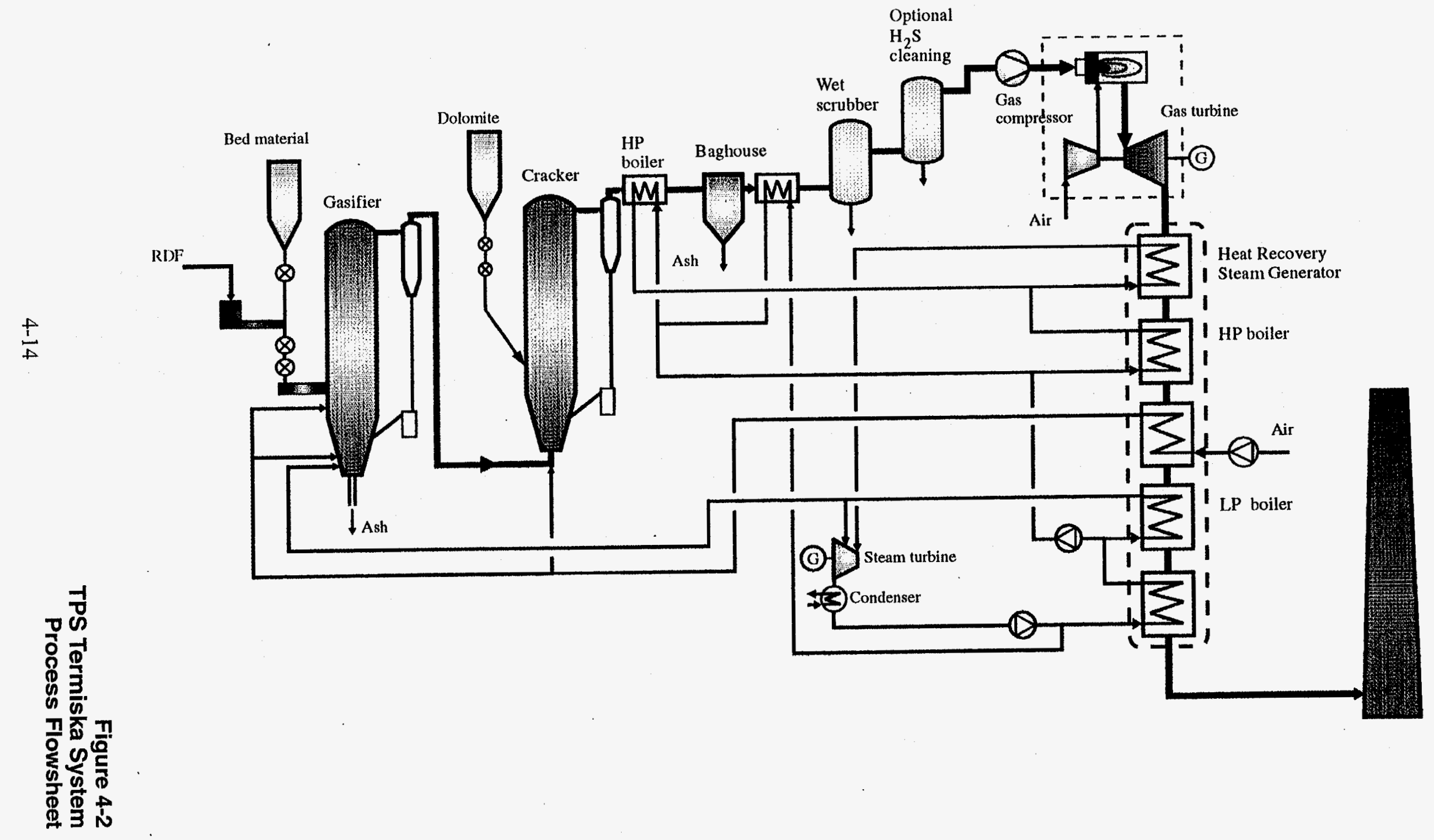




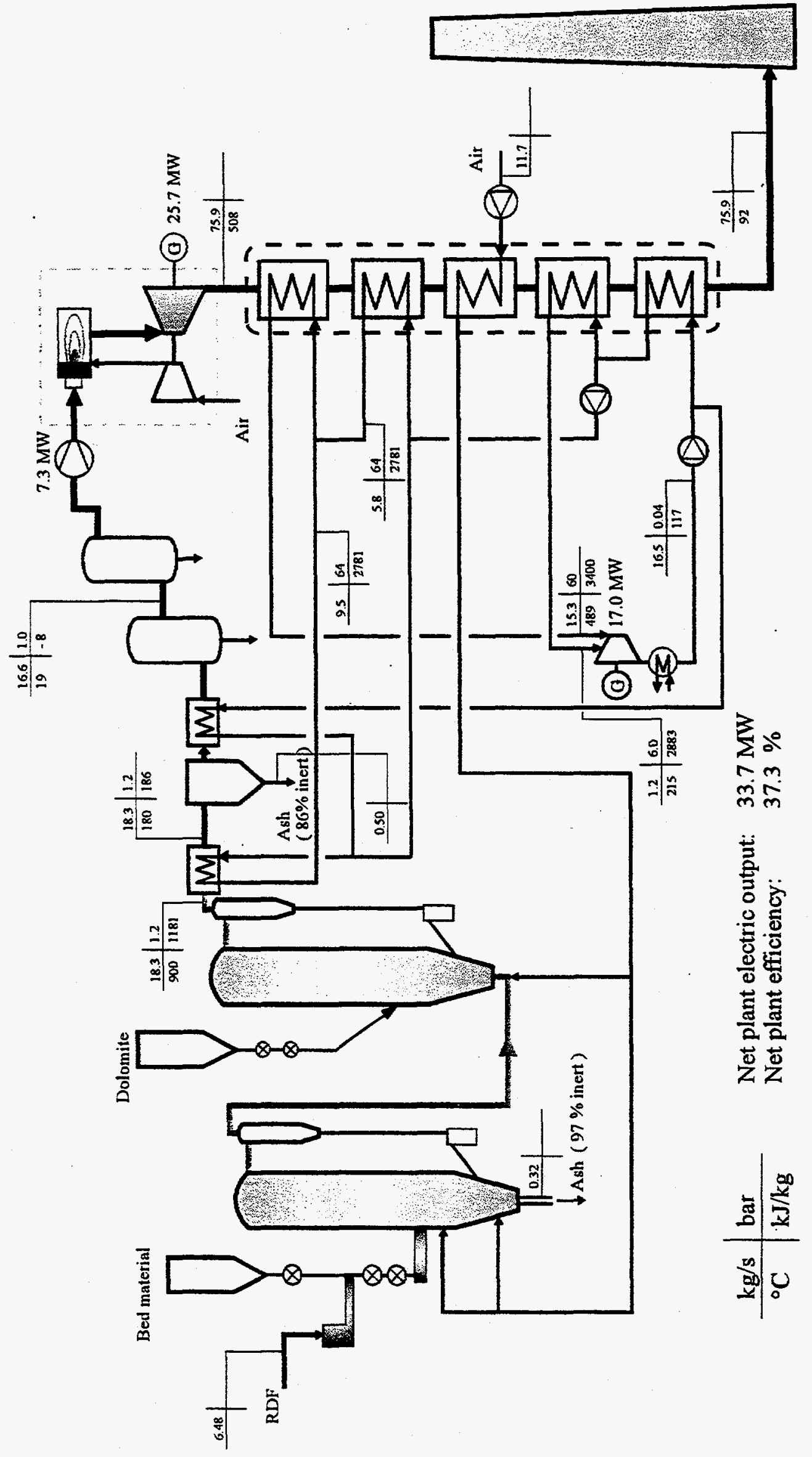

Figure 4-3

TPS Termiska System Heat 


\section{G. DEVELOPMENT HISTORY}

\section{Laboratory/Bench-Scale Studies}

In 1978 TPS began its studies of the circulating fluid bed (CFB) gasification process using a small, plexiglass model. Between 1979 and 1980 , subsequent test work was conducted in a $900-\mathrm{MJ} / \mathrm{h}$ $(853,000 \mathrm{Btu} / \mathrm{h}) \mathrm{CFB}$ reactor. This work included tests in an air-blown, atmospheric pressure CDF process fed with wood chips, sawdust, shale, and propane. These tests and subsequent work supported and complemented the design of a $7.2-\mathrm{MJ} / \mathrm{h}(6800-\mathrm{Btu} / \mathrm{h})$ CFB prototype at their facility in Studsvik, Sweden, where further development work is being conducted.

\section{Pilot Plant Studies}

Pilot work with the 7.2-MJ/h (6800-Btu/h) prototype began in 1986. Since then, hundreds of hours of testing has been conducted with wood, industrial waste, and prepared RDF pellets. The pilot facility was expanded in 1988 to include a dolomite cracker and a modified, 500-kW shaft power, turbocharged, eight-cylinder, dual-fuel diesel engine. Filtered and scrubbed off-gases from wood chips and wood pellets were burned in the diesel in campaigns totaling 1300 hours overall, with 750 engine hours. Tar cracking produced a gas with sufficiently low tar content for satisfactory operation of a fabric filter downstream of the cracker. Pilot tests with RDF were conducted in 1990 and 1991 to develop a "clean-gas concept" for RDF feedstocks.

\section{H. INTERVIEWS}

In the course of evaluating the TPS technology, CDM engineers inspected the facilities in Grève-enChianti, Italy, and visited the TPS engineering offices in Nyköping, Sweden. Those interviewed were:

- Grève-en-Chianti, Italy (Facility Inspection)

- Giancarlo Polzinetti, Plant Manager

S.A.F.I. SpA, Localita Testi

- Dott. Ing. Gianluca Barducci, Direttore Techico

Tavolini, S.R.L.

- Dott. Ing. Raffaello Cellai Rustici, Sales Director IDC snc (Industrial Design Consultants)

- Nyköping (TPS Termiska Processer AB Headquarters)

- Michael Morris, Licensing Manager

- Lars Waldheim, Manager, Gasification

- William H. Blackadder, Manager, Laboratory Services

- Eva Olsson, Project Engineer 


\section{Section 5}

\section{PROLER INTERNATIONAL CORPORATION}

\section{A. SUMMARY}

The PROLER SynGas Process is a patented technology that reforms hydrocarbon-containing wastes into a reactor gas. The process is being demonstrated in a $1.8-\mathrm{Mg} / \mathrm{h}(2-\mathrm{t} / \mathrm{h})$ plant in Houston, Texas. Although the process was originally developed for the gasification of automobile shredder residue (ASR), limited runs have demonstrated its suitability for gasifying municipal solid waste (MSW). The process accepts preshredded material and produces a fuel gas suitable for power generation. The residue is discharged in the form of commercially useful vitrified by-products as well as wastes acceptable for landfills.

\section{B. FINANCIAL AND BUSINESS ASPECTS}

\section{Projected Capital and Operating Costs}

Capital and operating costs have been placed on a common basis according to the procedure described in Section 2. Capital costs for a projected two-line facility processing $1247-\mathrm{Mg} / \mathrm{d}$ (1370-t/d) raw waste are shown in Table 5.1. The costs for the required refuse-derived fuel (RDF) preparation plant, as well as a gas turbine combined-cycle power plant, are included.

Projected operating costs for the two-line facility are shown in Table 5.2. They include labor, maintenance, and oxygen and gas use for both the preprocessing facility and the power plant. The yearly total cost is $\$ 38.3$ million gross, with a revenue stream from export power of $\$ 15.3$ million. The net operating costs are $\$ 23$ million-equivalent to $\$ 59.47 / \mathrm{Mg}(\$ 54.06 / \mathrm{t}) \mathrm{MSW}$. Proler says that the ultimate, vitrified "ash" residue can be marketed at zero cost or with a modest income, and that the residue landfill cost may be greatly reduced or eliminated.

Proler believes that their process can tolerate very coarse RDF. Consequently, they believe that the capital and operating costs shown in Tables 5.1 and 5.2 for RDF preparation are higher than ultimately achievable.

\section{Financial and Business Aspects}

Proler International is a $\$ 100$ million a year public company, with its stock traded on the New York Stock exchange. The company, through its joint operations on the East and West Coasts, states that it is the world's largest exporter of scrap steel. It is now the intention of the company to design, build, and finance complete waste gasification facilities while, at the same time, assuming the risk of guaranteeing the performance of the system. 
Table 5.1 Capital Cost: Proler International Corporation Thermal Processing System

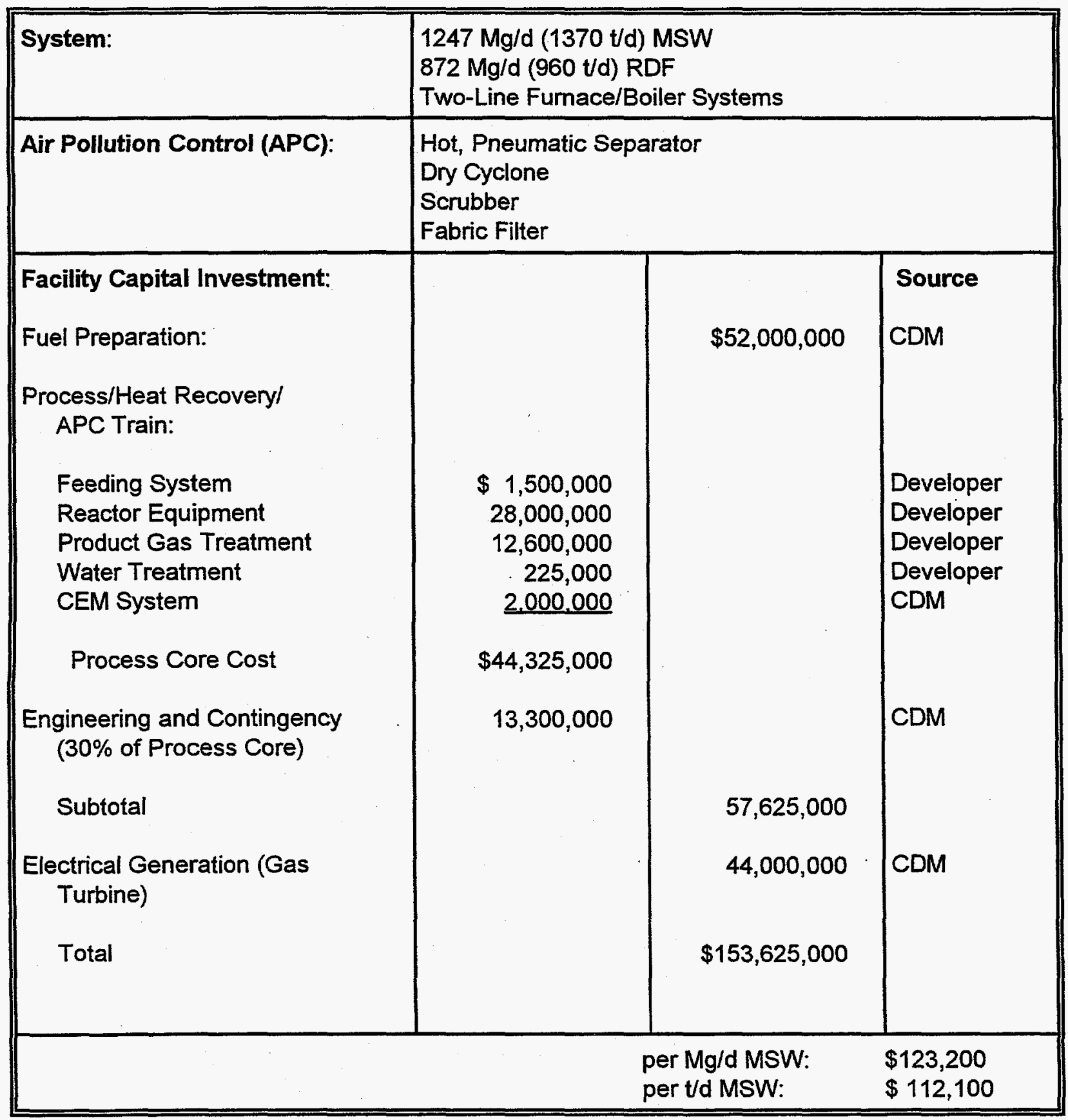


Table 5.2 Operating Costs for Proler International Corporation

\begin{tabular}{|c|c|c|c|c|c|}
\hline Cost Element & No./Shift & Basis & Unit Cost & $\begin{array}{c}\text { Annual Cost } \\
(000)\end{array}$ & Source \\
\hline \multicolumn{6}{|l|}{ Labor } \\
\hline Superintendent & - & 1 & $\$ 45.00 / \mathrm{h}$ & $\$ 99$ & Developer \\
\hline Operator (Op.) & $1+$ & 5 & $\$ 32.00 / \mathrm{h}$ & $\$ 350$ & Developer \\
\hline Aluxiliary Op. & $1+$ & 5 & $\$ 30.00 / \mathrm{h}$ & $\$ 329$ & Developer \\
\hline Feed System Op. & $1+$ & 5 & $\$ 30.00 / \mathrm{h}$ & $\$ 329$ & Developer \\
\hline Plant Attendant & $1+$ & 5 & $\$ 25.00 / \mathrm{h}$ & $\$ 274$ & Developer \\
\hline Elect./nst Maintenance & - & 3 & $\$ 35.00 / \mathrm{h}$ & $\$ 230$ & Developer \\
\hline Mechanical Maintenance & - & 3 & $\$ 35.00 / \mathrm{h}$ & $\$ 230$ & Developer \\
\hline Accountant & 1 & 1 & $\$ 30.00 / \mathrm{h}$ & $\$ 66$ & Developer \\
\hline Clerk & 1 & 1 & $\$ 25.00 / \mathrm{h}$ & $\$ 55$ & Developer \\
\hline Nat. Gas $\left(10^{6} \mathrm{Btu} / \mathrm{y}\right)$ & & 175,000 & $\$ 4.00 / 10^{6}$ & $\$ 700$ & Developer \\
\hline Oxygen (ty) & & 70,000 & $\$ 7.00 / t$ & $\$ 490$ & Developer \\
\hline Consumables (chem., water) & & Allowance & $\$ 2,220$ & $\$ 2,220$ & Developer \\
\hline Maintenance Supplies & $\$ 57,625,000$ & Allowance & $1.5 \%$ of & $\$ 864$ & Developer \\
\hline Maintenance & $\$ 57,625,000$ & Allowance & $3 \%$ of & $\$ 1,729$ & Developer \\
\hline Insurance & $\$ 57,625,000$ & Allowance & $1 \%$ of & $\$ 576$ & CDM \\
\hline Compliance Testing & & Allowance & & $\$ 300$ & CDM \\
\hline \multirow[t]{2}{*}{ Residue Landfill } & & 127,500 & $\$ 40 / t$ & $\$ 5,100$ & $\mathrm{CDM}$ \\
\hline & & \multicolumn{2}{|c|}{ Total Cost for Process Core } & $\$ 13,939$ & \\
\hline Contingency & & \multicolumn{2}{|c|}{$10 \%$ of Process Core Cost } & $\$ 1,394$ & $\mathrm{CDM}$ \\
\hline Debt Service & $\$ 172,700$ & & $10.19 \%$ of & $\$ 17,598$ & CDM \\
\hline RDF Operations & N/A & $425 \times 10^{3} \mathrm{t} / \mathrm{y}$ & $\$ 7.70 / t$ & $\$ 3,273$ & CDM \\
\hline \multirow[t]{2}{*}{ Electric Gen. Operations. } & N/A & $393 \times 10^{6} \mathrm{Btu} / \mathrm{h}$ & & $\$ 2,100$ & CDM \\
\hline & & & Total Gross & $\$ 38,304$ & \\
\hline \multicolumn{6}{|c|}{ Electrical Revenue } \\
\hline Gross Generation (MWh/y) & $393 \times 10^{6} \mathrm{Btu} / \mathrm{h}$ & 450,000 & & & CDM \\
\hline RDF Power Use (MWh/y) & & $(10,625)$ & & & CDM \\
\hline Internal Use (MWh/y) & $12.50 \%$ & $(56,250)$ & & & Developer \\
\hline \multirow[t]{4}{*}{ Net to Export (MWh/y) } & & 383,125 & $\$ 0.04 / \mathrm{kWh}$ & $(\$ 15,325)$ & \\
\hline & & & Net Annual & $\$ 22,979$ & \\
\hline & & & Unit Cost $t$ & $\$ 54.06$ & \\
\hline & & & Unit Cost & $\$ 59.47$ & \\
\hline
\end{tabular}


As of late 1995, the firm's Main Office address and communications numbers were:

Proler International

4265 San Felipe, Suite 900

Houston, Texas 77027
Tel: (713) $963-5940$

Fax: (713) 627-2737

\section{IMPLEMENTATION FEASIBILITY}

The developer states that full-scale facilities for the processing of ASR and MSW are being negotiated with customers in Europe, Canada, and the U.S. However, a number of issues apparently must be addressed before successful commercialization for MSW in the U.S. can be achieved.

\section{Remaining Development Needs}

Proler states that preliminary design work has been completed for a full-scale $900-\mathrm{Mg} / \mathrm{d}(1000-\mathrm{t} / \mathrm{d})$ commercial facility using MSW as feedstock and consisting of two process lines at $18 \mathrm{Mg} / \mathrm{h}(20 \mathrm{t} / \mathrm{h})$ each. Major technical problems appear to be:

- Although the demonstration plant is processing RDF at a top size of $5.8 \mathrm{~cm}(2 \mathrm{in}$.), the commercial plant is expected to be able to accept shredded material with a top size of $15.24 \mathrm{~cm}$ ( 6 in.). However, only $18-\mathrm{Mg}(20-\mathrm{t})$ coarse material have been tested. The material and energy balances for a full-scale facility will also need to be confirmed.

- The demonstration plant has operated with shredded MSW on a limited basis only. An extended campaign of operation appears essential to evaluate potential problems with refractory degradation, slag problems, and control of tramp air when there is seal deterioration.

- The reliability and performance of the vitrifier and the integration of this equipment with the existing gasifier is yet to be proved. The mechanism and rate of heat transfer from the vitrifier to the incoming feed must be demonstrated. The introduction of natural gas at the discharge end of the reactor is regarded solely as a source of auxiliary heat, while relying on the heat from the vitrifier as the main source.

- The planned commercial size at $36-\mathrm{Mg} / \mathrm{h}(40-\mathrm{t} / \mathrm{h}) \mathrm{MSW}$ represents a scale-up of 11:1 over the demonstration plant or 5.5:1 on a per-line basis. Experience during municipal waste combustor (MWC) development efforts by several other firms would suggest that such a substantial step carries a high risk factor for systems processing MSW.

Further testing with MSW to resolve these issues seems desirable.

\section{PROCESS DESCRIPTION}

\section{General}

The Proler demonstration waste processing facility, located on the outskirts of Houston, Texas, was visited on October 30, 1995. The system, referred to as the Proler SynGas Process, is designed to produce recyclable solid by-products together with a clean fuel gas from ASR and other wastes, including MSW. It 
was developed and patented by Proler International Corporation's wholly owned subsidiary-Proler Environmental Services, Inc. The demonstration unit has a capacity of $1.9-\mathrm{Mg} / \mathrm{h}(2.0-\mathrm{t} / \mathrm{h})$ shredded $\mathrm{MSW}$, equivalent to $2.6-\mathrm{Mg} / \mathrm{h}(2.9-\mathrm{t} / \mathrm{h})$ raw $\mathrm{MSW}$. The unit includes a feeding system; a horizontal, rotary reactor; a gas-cleaning train; and a compressor that supplies cleaned fuel gas to a dual-fuel-fired engine/ generator. At the time of CDM's visit, shredded MSW was being processed, and the complete system was operating.

\section{a. Detailed Description}

Figure 5.1 is a schematic of the gasification process as it now exists, with the exception of the "Cyclonic Vitrifier," which is not yet installed but is scheduled for early in 1996 (see Section c, Reactor Gas Characteristics, which follows). The RDF feed consists of waste material shredded to a top size of $15 \mathrm{~cm}$ ( $6 \mathrm{in}$.) after removal of the larger ferrous and nonferrous metal pieces for re-use.

The remaining, coarsely shredded "fluff" is delivered by truck from a Proler-owned shredding facility located off-site and is conveyed by a belt conveyor to a dual-ram feeder that pushes the waste into the reactor. An air-tight plug of feed forms a seal between the feed hopper and the reactor. The latter is a Proler-designed refractory-lined horizontal vessel, rotating between 1 and $2 \mathrm{rpm}$. Sealing air at both ends of the chamber, at a rate of $0.13 \mathrm{~m}^{3} / \mathrm{h}\left(4.5 \mathrm{ft}^{3} / \mathrm{h}\right)$, finds its way into the chamber itself. Natural gas and oxygen are fired through oxyfuel burners to maintain a temperature of 650 to $850^{\circ} \mathrm{C}\left(1200\right.$ tol600 $\left.{ }^{\circ} \mathrm{F}\right)$ in a reducing atmosphere. As the material is being heated and gasified, the raw gas and solids exit at the discharge end into the Hot Pneumatic Separator (HPS). This unit contains a series of baffles that, by reversing the gas flow several times, drop out the larger solid constituents. The dirty gas is then cleaned in a "Hot Cyclone," followed by a baghouse and a wet scrubber. A Roots blower compresses the cleaned gas to $101 \mathrm{kPa}\left(30\right.$ in. $\left.\mathrm{H}_{2} \mathrm{O}\right)$ and supplies it to a $186-\mathrm{kW}(250-\mathrm{hp})$ reciprocating Diesel engine. For stable ignition, the engine uses auxiliary fuel at the rate of 10 -percent heat input. A flare burns off any excess gas.

The large solids removed by the HPS contain recyclable metals-iron and copper, for example - which may have a commercial value. The remainder, as well as the fines separated by the scrubber and baghouse, is presently sent to a landfill. In the future the fines will be vitrified in the planned high-temperature vitrifier (Figure 5.1).

\section{b. Vitrifier}

Proler has obtained an exclusive, worldwide license to use TRW's cyclonic vitrification technology in recycling applications. TRW's vitrifier will be integrated into the existing plant by mid-1996. Tests are presently being run on these units with ASR fines mixed with electric-arc furnace residues. The plan for the ultimate system calls for recycling the fines collected in the baghouse into the vitrifier and firing it with gas/oxygen at $1350^{\circ} \mathrm{C}\left(3100^{\circ} \mathrm{F}\right)$. This heat will be the major source of process heat, with the

off-gases passed from the vitrifier into the discharge end of the reactor. The granulated, nonleaching, glassy 


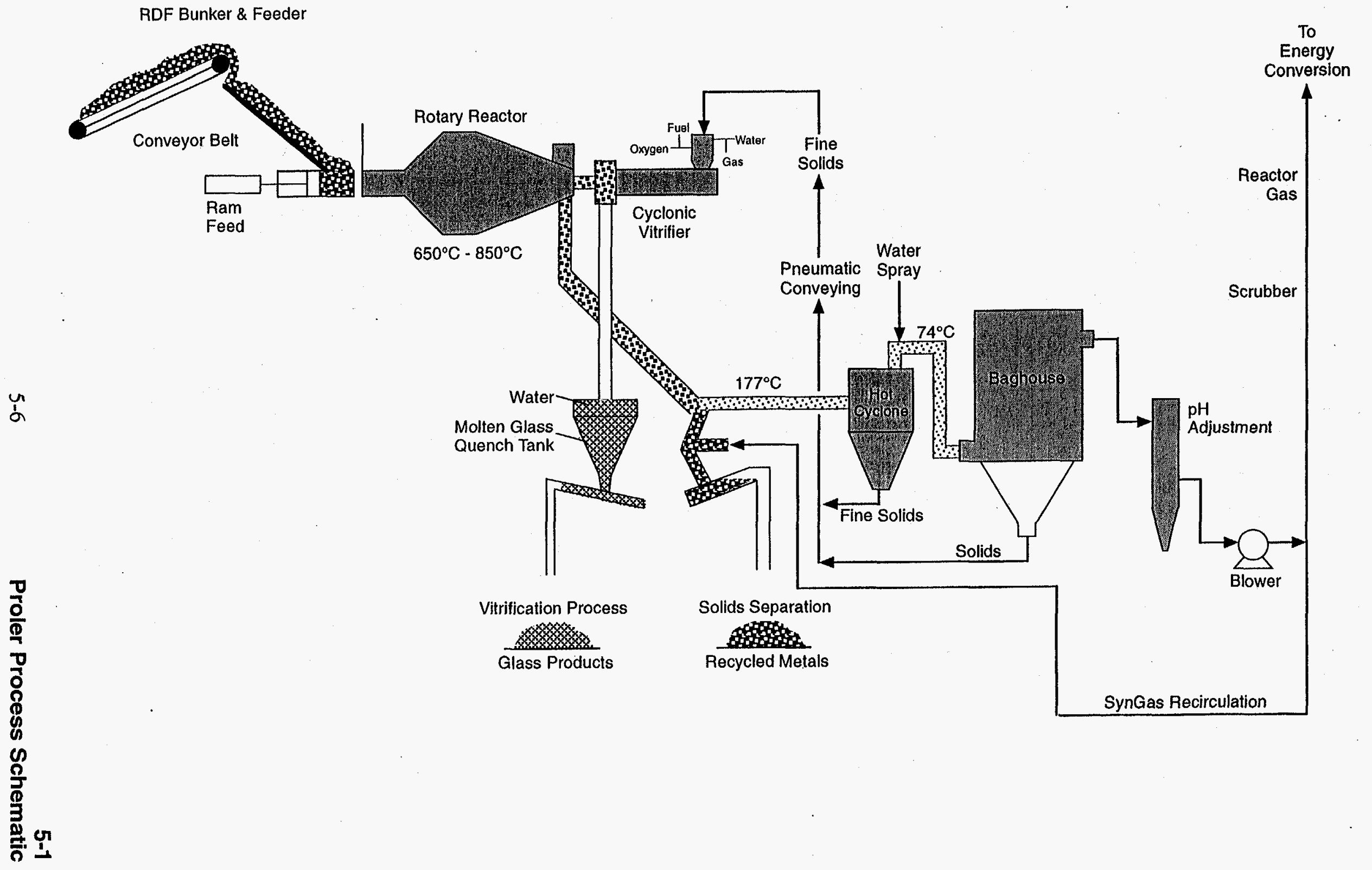


material produced from the vitrifier is believed to be a by-product of value to the ceramics industry in such applications as tile manufacturing.

\section{c. Reactor Gas Characteristics}

Table 5.3 presented an analysis of the fuel gas currently produced without the vitrifier in operation. According to the energy balances, the value of the fuel gas appears to be independent of the use of the vitrifier. The heating value has been calculated at $11.3 \mathrm{MJ} / \mathrm{Nm}^{3}\left(302 \mathrm{Btu} / \mathrm{sft}^{3}\right)$, dry, with a theoretical flame temperature of $1775^{\circ} \mathrm{C}\left(3227^{\circ} \mathrm{F}\right)$. The contaminants in the fuel gas are listed in Table 5.4.

\section{E. ENVIRONMENTAL ASPECTS}

Environmental emissions were obtained from the exhaust gas leaving the existing dual-fuel-fired Diesel engine. Table 5.5 lists the tested contaminants normalized to 7-percent oxygen. The emissions are all below EPA's December 1995 Maximum Achievable Control Technology (MACT) limits and the New Source Performance Standards (NSPS). The second column shows the developer's projected values for an optimized system with "upstream ultrafiltration." With the addition of the vitrifier, Proler claims that the solids effluent is a usable by-product with superior leaching characteristics. Table 5.6 presents the heavy metals

content of the vitirfied glass material and the associated Toxicity Leaching Characteristics Procedure (TCLP) results. The TCLP results are well below EPA limits.

Table 5.3 Reactor Gas Analysis

\begin{tabular}{|l|c|}
\hline Components & Vol\% \\
\hline \hline Hydrogen & 30.8 \\
\hline Nitrogen & 4.6 \\
\hline Carbon Monoxide & 31.2 \\
\hline Methane & 5.7 \\
\hline Carbon Dioxide & 17.8 \\
\hline Ethylene & 1.7 \\
\hline Ethane & 0.1 \\
\hline Acetylene & 0.5 \\
\hline Water & 7.1 \\
\hline Benzene & 0.5 \\
\hline
\end{tabular}


Table 5.4 Cleaned Reactor Gas Contaminants

\begin{tabular}{||l|c|l|}
\hline \multicolumn{1}{|c|}{ Contaminant } & Value & \multicolumn{1}{c|}{ Units } \\
\hline \hline Fly Ash and Tar & $0.04-0.216$ & gr/dsft $^{3}$ \\
\hline Chlorides $/ \mathrm{HCl}$ & $20-100$ & ppm(v) \\
\hline $\mathrm{H}_{2} \mathrm{~S}$ & $1-5$ & ppm(v) \\
\hline $\mathrm{NH}_{3}$ & $90-120$ & ppm(v) \\
\hline $\mathrm{K}, \mathrm{Na}, \mathrm{Ca}$, Salts & $1-2$ & $\mathrm{ppm}$ \\
\hline
\end{tabular}

Table 5.5 Environmental Emissions Data

\begin{tabular}{||l|l|l||}
\hline \multicolumn{1}{|c|}{ Parameter } & \multicolumn{1}{c|}{ Corrected Values } & Estimated Values \\
\hline \hline Particulates & $\begin{array}{c}4.6-9.2 \mathrm{mg} / \mathrm{Nm}^{3} \\
\left(0.002-0.004 \mathrm{gr} / \mathrm{stt}^{3}\right)\end{array}$ & $\begin{array}{c}2.3 \mathrm{mg} / \mathrm{Nm}^{3} \\
\left(<0.001 \mathrm{~g} / \mathrm{stt}^{3)}\right.\end{array}$ \\
\hline $\mathrm{HCl}$ & $5-10 \mathrm{ppm}(\mathrm{v})$ & $3 \mathrm{ppm}$ \\
\hline Fluorides & $3-4 \mathrm{ppm}(\mathrm{v})$ & $1 \mathrm{ppm}(\mathrm{v})$ \\
\hline $\mathrm{CO}$ & $75-100 \mathrm{ppm}(\mathrm{v})$ & $25 \mathrm{ppm}(\mathrm{v})$ \\
\hline Organic Compounds (as C) & $3-5 \mathrm{ppm}(\mathrm{v})$ & $0.065 \mathrm{ppm}(\mathrm{v})$ \\
\hline Sulfur Oxides (as SO, $)$ & $4-5 \mathrm{ppm}(\mathrm{v})$ & $2 \mathrm{ppm}(\mathrm{v})$ \\
\hline Nitrogen Oxides & $100-150 \mathrm{ppm}(\mathrm{v})$ & $40 \mathrm{ppm}(\mathrm{v})$ \\
\hline $\begin{array}{l}\text { Metals: Sb, } \mathrm{Pb}, \mathrm{Cr}, \mathrm{Cu}, \mathrm{Mn}, \\
\mathrm{V}, \mathrm{Sn}, \mathrm{As}, \mathrm{Co}, \mathrm{Ni}, \mathrm{Se} \mathrm{T}^{4}, \mathrm{Te}\end{array}$ & $0.2-0.4 \mathrm{ppm}(\mathrm{v})$ & $0.2 \mathrm{ppm}$ \\
\hline $\mathrm{Cd}$ & $0.02-.03 \mathrm{ppm}$ & $0.01 \mathrm{ppm}$ \\
\hline $\mathrm{Hg}$ & $<.01 \mathrm{ppm}(\mathrm{v})$ & $<0.01 \mathrm{ppm}(\mathrm{v})$ \\
\hline $\begin{array}{l}\text { Dioxins and Furans } \\
\text { (total mass emissions) }\end{array}$ & $<10 \mathrm{ng} / \mathrm{dNm}$ & $<3.5 \mathrm{ng} / \mathrm{dNm}^{3}$ \\
\hline
\end{tabular}

* Data for dual-fuel reciprocating internal combustion engine exhaust normalized to 7-percent oxygen. 
** Estimates for an optimized combustion system with up-stream ultra-filtration to remove a greater amount of submicron particles at 7 percent oxygen.

Table 5.6 Heavy Metal Content in Vitrified Glass Product

\begin{tabular}{|l|c|c|}
\hline \multicolumn{1}{|c|}{ Element } & $\begin{array}{c}\text { Elemental } \\
\text { (ppm) }\end{array}$ & $\begin{array}{c}\text { TCLP Leachability } \\
\text { (ppm) }\end{array}$ \\
\hline \hline Lead & 1100 & 0.05 \\
\hline Chromium & 34 & 0.01 \\
\hline Copper & 1500 & 0.15 \\
\hline Zinc & 400 & 0.02 \\
\hline Nickel & 200 & 0.01 \\
\hline Cadmium & 8 & 0.01 \\
\hline Mercury & 3 & 0.002 \\
\hline
\end{tabular}

\section{F. FLOWSHEETS}

Figures 5.2 and 5.3 show the mass and energy balances for the gasification system as currently constituted and as planned respectively. As stated earlier the difference arises out of the addition of the vitrifier to the final system.

Both figures summarize the major streams in and out of the process for both the existing and planned systems. An analysis of the data, together with the mass/energy balances, reveals that the existing demonstration plant produces approximately $1000-\mathrm{Nm}^{3} / \mathrm{t}\left(33,000-\mathrm{ft}^{3} / \mathrm{t}\right)$ fuel gas from shredded MSW. This amount is expected to increase to $1100 \mathrm{Nm}^{3} / \mathrm{t}\left(35,000 \mathrm{ft}^{3} / \mathrm{t}\right)$ after adding the vitrifier. The heating value of the gas in both cases remains at $10.35 \mathrm{MJ} / \mathrm{m}^{3}\left(278 \mathrm{Btu} / \mathrm{sft}^{3}\right)$, wet.

The explanation for the increase in fuel gas output is explained by the gasification of carbon and volatiles with the vitrifier. Without the vitrifier, these benefits were lost in the solid waste streams from the existing plant. In confirmation of this projection, the vitrifier is expected to reduce the solids discharges from 400 to $280 \mathrm{~kg} / \mathrm{t}$ ( 800 to $560 \mathrm{lb} / \mathrm{t}$ ), the difference being accounted for by the organics content in the solids. As further evidence, Proler expects the overall thermal efficiency of the process to rise from 74 percent to 85 percent with the addition of the vitrifier.

Although there is no substantial change to the rate of oxygen use [about $240 \mathrm{~kg} / \mathrm{Mg}$ (460 lb/t)], natural gas consumption is expected to drop from 49.2 to $17.5 \mathrm{~m}^{3} / \mathrm{Mg}$ (1565 to $\left.612 \mathrm{ft}^{3} / \mathrm{t}\right)$, or 60 percent. Both cases produce an aqueous effluent of 33 and $37 \mathrm{l} / \mathrm{t}(8.8$ and $9.8 \mathrm{gal} / \mathrm{t})$ respectively. After treatment, this effluent can be discharged to a sewer. 


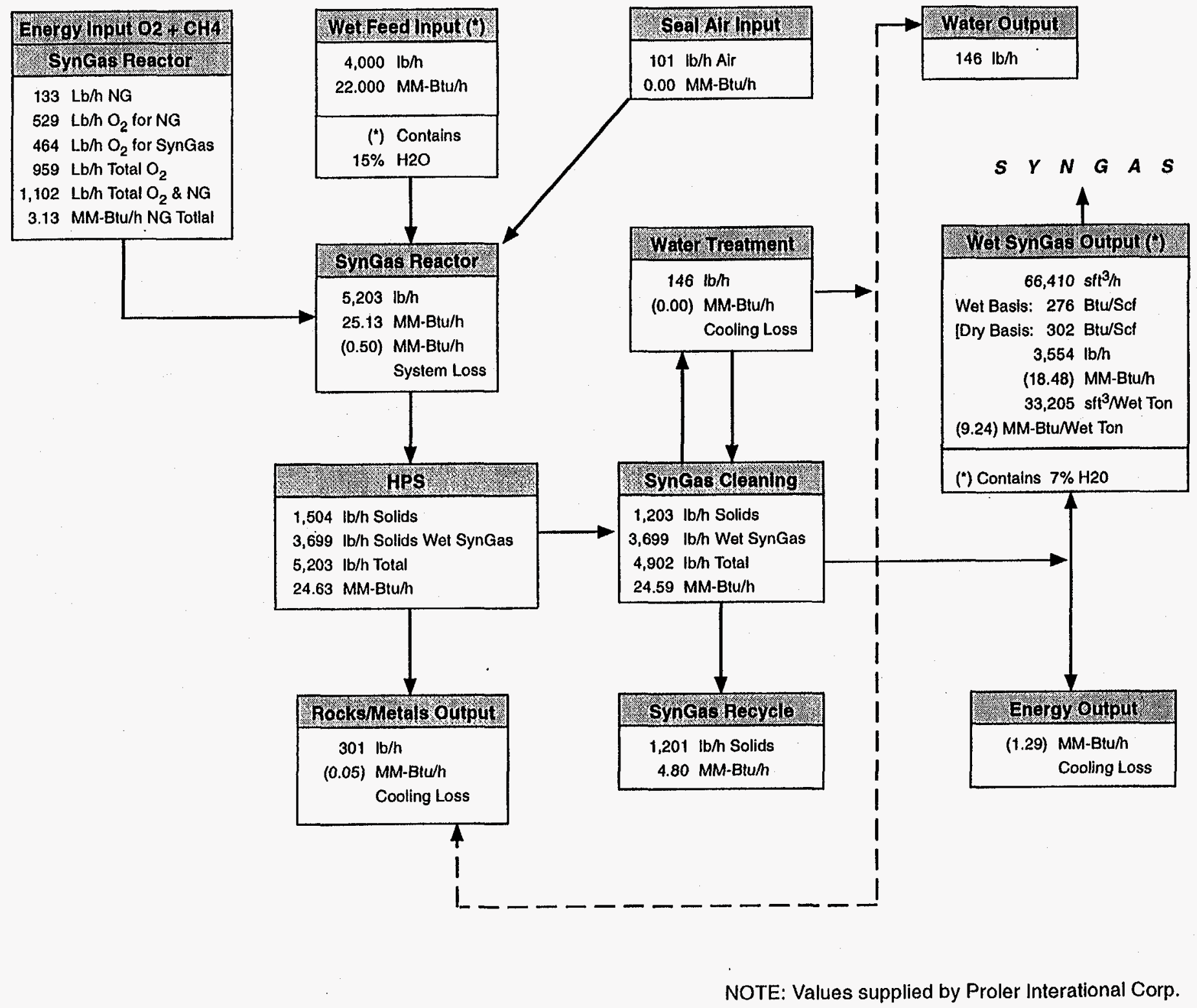

NOTE: Values supplied by Proler Interational Corp. 


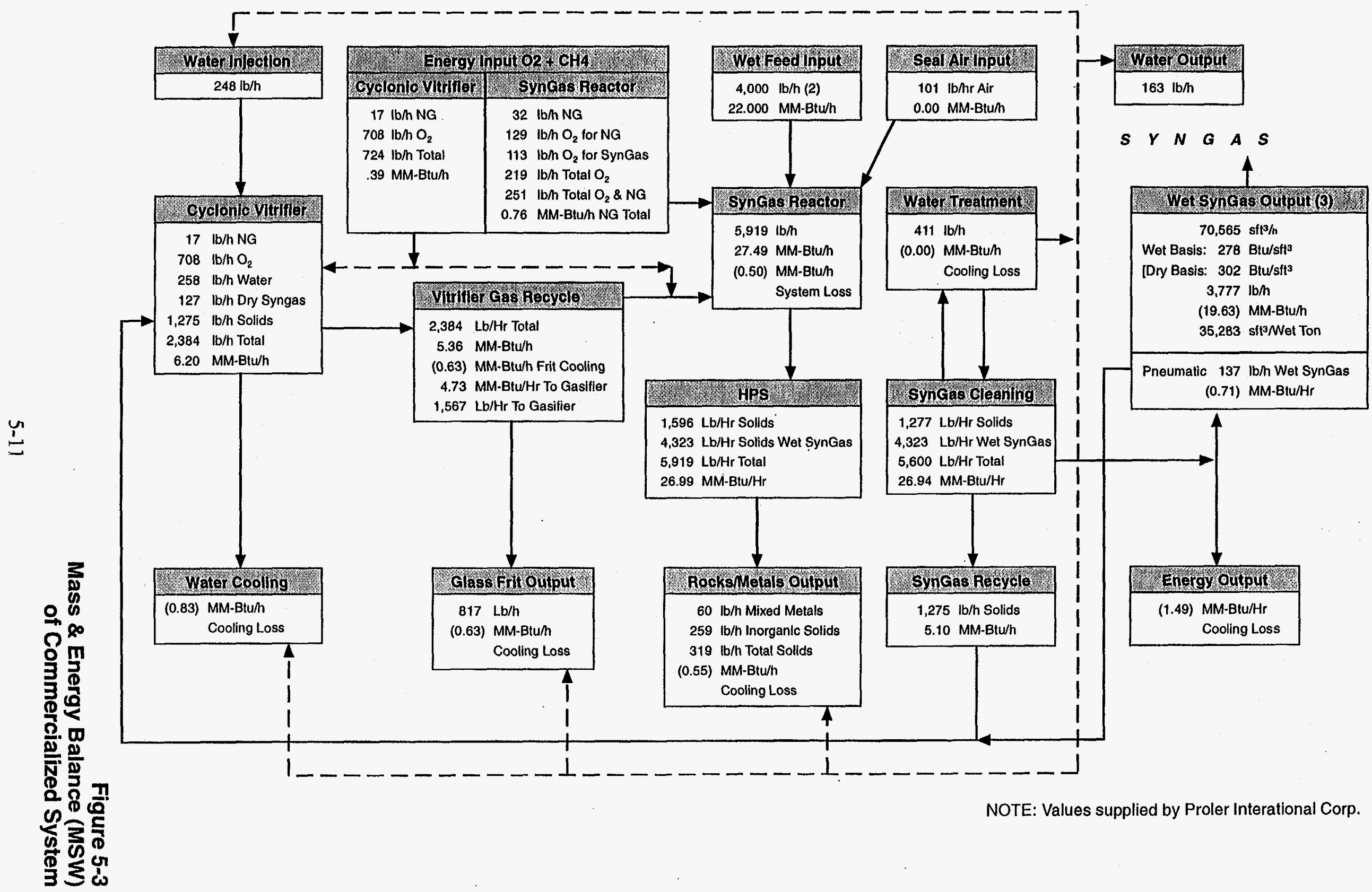


The complete, integrated system at $36 \mathrm{Mg} / \mathrm{h}$ (40 t/h) RDF will process $864 \mathrm{Mg} / \mathrm{d}(1000 \mathrm{t} / \mathrm{d})$ or $270,000 \mathrm{Mg} / \mathrm{y}(300,00 \mathrm{t} / \mathrm{y})$ at 85 -percent availability. Output of energy, in the form of fuel gas, is expected to be $411,000 \mathrm{MJ} / \mathrm{h}\left(390 \times 10^{6} \mathrm{Btu} / \mathrm{h}\right)$. A plant of this capacity would warrant combined-cycle power generation - (gas turbine/steam turbine combination) - with an estimated capacity of $60 \mathrm{MW}$.

\section{G. DEVELOPMENTAL HISTORY}

Proler began development of this gasification technology in 1989, primarily for the processing of ASR. The Project Team member visited a demonstration unit that was said to represent the fifth generation and that had been in operation for 4 years. The technology was originally developed to solve the problems associated with recycling the nonmetallic components found in automobiles. In the past this material had been disposed of in a landfill. Although initially developed to solve an internal solid-residue recycling problem, Proler is now involved in discussions with companies throughout the world about applications of its proprietary technology.

In operation since June 1991, the current demonstration plant without the vitrifier has a design capacity of $1.8-\mathrm{Mg} / \mathrm{h}(2.0-\mathrm{t} / \mathrm{h})$ prepared RDF. Proler claims that "the system has gasified over 136-Mg (150-t) MSW, $36-\mathrm{Mg}(40-\mathrm{t})$ paper processing waste, $9-\mathrm{Mg}(10-\mathrm{t})$ tire chips, and over $1200-\mathrm{Mg}(1300-\mathrm{t}) \mathrm{ASR}$." The longest extended run has been approximately 100 hours, with unscheduled downtimes of 3 percent and 17 percent caused by "materials conveying problems." The facility normally operates for 2 to 3 days a week. For a total plant operating time of over 4000 hours, 320 runs have been made, according to Proler.

Almost 100 percent of the pilot experience to date used RDF shredded to less than a 5-cm (2-in.) top size. In a short-duration trial run (10 hours maximum), $18-\mathrm{Mg}(20-\mathrm{t})$ coarser [15-cm x 15-cm (6-in. x 6-in.)] RDF was processed without difficulty. Further tests are needed to qualify this system for coarse feed.

The fuel gas is tested on-line with a chromatograph. Additional tests have been conducted in the past by outside commercial laboratories. Proler stated that "independent outside analysis has shown that the fuel gas is also suitable for being fired in boilers and in gas turbines, or for producing either methanol or ammonia."

\section{H. INTERVIEWS}

In the course of evaluating the Proler technology, meetings were held with Proler personnel in the Houston area, site of the Proler pilot plant. Those interviewed were:

- Steven F. Gilliland, President and CEO

- Dennis L. Caputo, Vice President, Environmental and Safety Compliance

- Harold B. Burnham, Vice President, Business Development

- Norman Bishop, Vice President (originator of the gasification process)

- Donald Gene Taylor, Consultant 


\section{Section 6}

\section{Thermoselect Inc.}

\section{A. SUMMARY}

The Thermoselect process embodies a fully developed method of gasifying municipal solid waste (MSW) and industrial raw wastes without apparent adverse impact on the environment. The residue is converted into what are described as commercially useful by-products. A standard design has been developed for a two-line nominal, $480-\mathrm{Mg} / \mathrm{d}(528-\mathrm{t} / \mathrm{d})$ system housed in an attractive industrial building. Larger capacity systems are offered by adding multiples of the "standard" modules.

\section{B. FINANCIAL AND BUSINESS ASPECTS}

\section{Projected Capital and Operating Costs}

Capital and operating costs have been normalized to a common basis, according to the procedure described in the "Introduction." Capital costs for a six-line facility, including gas-turbine gas-engine electric power generation, are shown in Table 6.1. The developer points out that the installed costs will decrease as additional modules are added. The gas purification equipment, oxygen plant, power plant, and others will be shared by the process lines.

Yearly operating costs, estimated at $\$ 55.06$ million (Table 6.2), cover a staff of 122 operators and administration personnel. With revenue from export power of over $\$ 12.6$ million, net yearly owning and operating costs are about $\$ 42.41$ million-equivalent to a break-even tipping fee of $\$ 94.92 / \mathrm{Mg}(\$ 86.29 / \mathrm{t})$. The developer believes that the granulated slag produced by the process should be considered a product that can be hauled away at no cost or sold. Thus the actual operating cost would be lower than shown in Table 6.2. However, the market for their slag has not yet been demonstrated in the United States.

\section{Business Aspects}

Thermoselect SA is a privately held Swiss company created to commercialize the Thermoselect process, for which over 31 patents have been issued. In January 1995 the German utility Badenwerke AG joined the company as a 25 -percent owner. Thermoselect is not currently interested in selling the technology; they want to license it to plant owners. They are prepared to enter into the following arrangements:

- Provide a licensed facility to an owner on a turnkey basis

- Enter into a joint operating venture with an owner

- Work with a developer, community, finance group, or technology provider. 
Table 6.1 Capital Cost: Thermoselect Six-Line Standard System

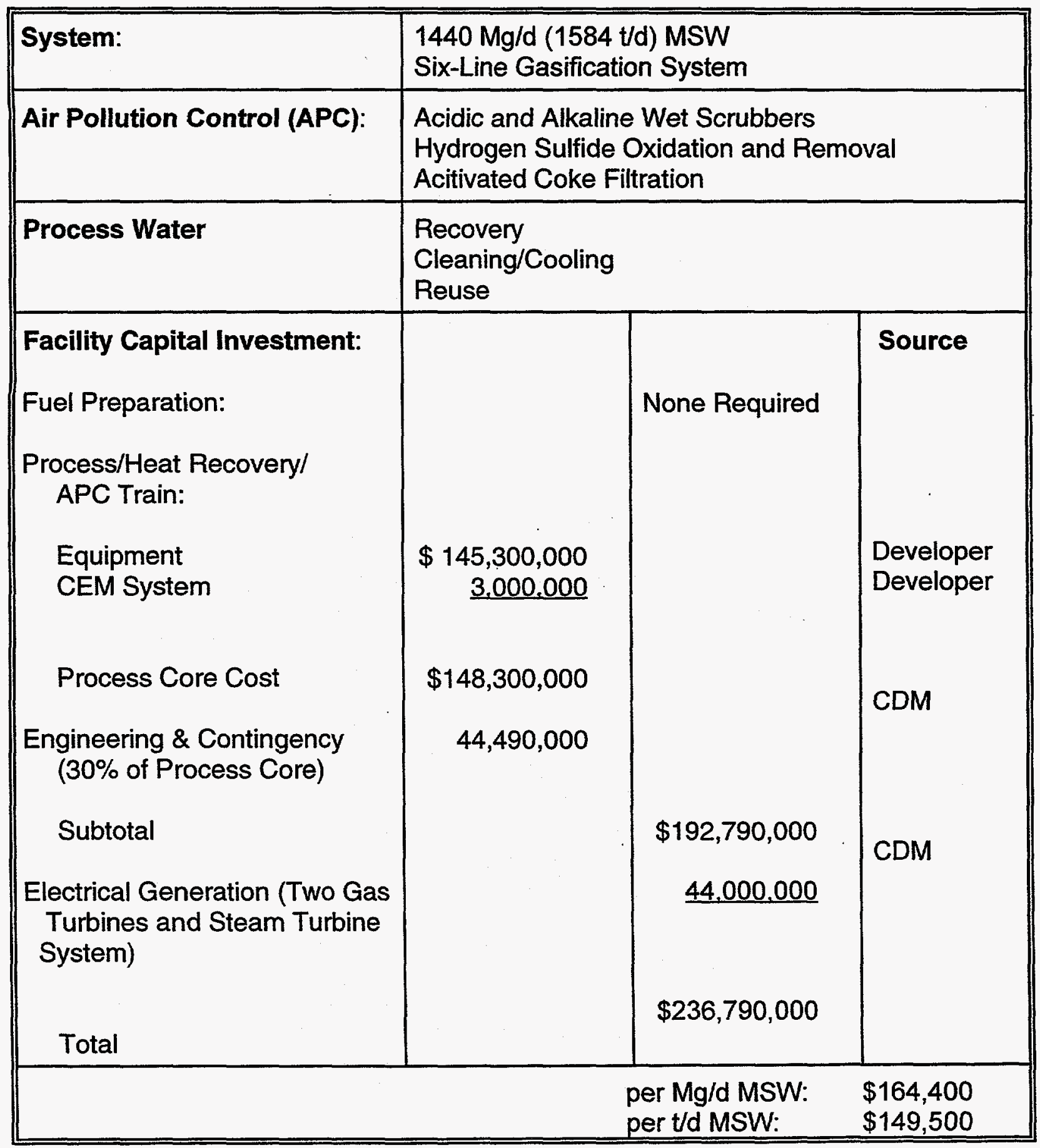


Table 6.2 Operating Costs for Six-Line Thermoselect System

\begin{tabular}{|c|c|c|c|c|c|}
\hline Cost Element & No./Shift & Basis & Unit Cost & $\begin{array}{l}\text { Annual Cost } \\
(000)\end{array}$ & Source \\
\hline \multicolumn{6}{|l|}{ Labor } \\
\hline Superintendent & --- & 1 & $\$ 45.00 / \mathrm{h}$ & $\$ 99$ & CDM \\
\hline Clerk & & 1 & $\$ 25.00 / \mathrm{h}$ & $\$ 55$ & CDM \\
\hline Operator (Op.) & 3 & 12 & $\$ 32.00 / \mathrm{h}$ & $\$ 841$ & CDM \\
\hline Auxiliary Op. & 6 & 24 & $\$ 30.00 / \mathrm{h}$ & $\$ 1,577$ & CDM \\
\hline Feed System Op. & 3 & 12 & $\$ 30.00 / \mathrm{h}$ & $\$ 788$ & CDM \\
\hline Plant Attendant & 6 & 24 & $\$ 25.00 / \mathrm{h}$ & $\$ 1,314$ & CDM \\
\hline Elect./nst Maintenance & 6 & 24 & $\$ 35.00 / \mathrm{h}$ & $\$ 1,840$ & CDM \\
\hline Mechanical Maintenance & 6 & 24 & $\$ 35.00 / \mathrm{h}$ & $\$ 1,840$ & CDM \\
\hline Nat. Gas $\left(10^{6} \mathrm{Btu} / \mathrm{y}\right)$ & & 496,500 & $\$ 4.00 / 10^{6} \mathrm{Btu}$ & $\$ 1,986$ & Developer \\
\hline Chemicals and Reactants & & & Allowance & $\$ 3,000$ & Developer \\
\hline Oxygen (On-Site Plant) & & N/A & $\$ 0$ & $\$ 0$ & Developer \\
\hline Heavy Metal Sludge Disposal & & & Allowance & $\$ 150$ & Developer \\
\hline Maintenance & $\$ 192,790,000$ & & Allowance & $3 \%$ of Capital & $\$ 5,784$ Deve \\
\hline Insurance & $\$ 192,790,000$ & Allowance & $1 \%$ of Capital & $\$ 1,928$ & Developer \\
\hline Compliance Testing & & Allowance & & $\$ 300$ & Developer \\
\hline \multirow[t]{2}{*}{ Residue Landfill } & & 124,500 & $\$ 40 / t$ & $\$ 4980$ & CDM \\
\hline & & \multicolumn{2}{|c|}{ Total Cost for Process Core } & $\$ 26,480$ & \\
\hline Contingency & & \multicolumn{2}{|c|}{$10 \%$ of Process Core Cost } & $\$ 2,648$ & CDM \\
\hline Debt Service & $\$ 236,790,000$ & & $10.19 \%$ of Capital & $\$ 24,129$ & CDM Mt'y \\
\hline \multirow[t]{2}{*}{ Electric Gen. Operations. } & N/A & $390 \times 10^{6}$ Btu/h & & $\$ 1,800$ & CDM \\
\hline & & & Total Gross Cost & $\$ 55,057$ & \\
\hline \multicolumn{6}{|l|}{ Electrical Revenue } \\
\hline Gross Generation (MWh/y) & $390 \times 10^{6} \mathrm{Btu} / \mathrm{h}$ & 440,000 & & & CDM \\
\hline Internal Use (MWh/y) & & $(123,750)$ & & & Developer \\
\hline \multirow[t]{4}{*}{ Net to Export (MWh/y) } & & 316,250 & $\$ 0.04 / \mathrm{kWh}$ & $(\$ 12,650)$ & \\
\hline & & & Net Annual Cost & $\$ 42,407$ & \\
\hline & & & Unit Cost $\$ / t$ & $\$ 86.29$ & \\
\hline & & & Unit Cost $\$ / M g$ & $\$ 94.92$ & \\
\hline
\end{tabular}


Thermoselect has stated that the proper funding and backing are in place for commercializing their process.

The addresses and communications numbers for Thermoselect as of late 1995 are:

US Main Office:

Thermoselect, Inc.

201 West Big Beaver Road, Suite 230

Troy, Michigan 48084

Tel: $\quad$ (810) 689-3060

Fax: $\quad(810) 689-2878$
Corporate Office:

Thermoselect S.A.

Plaza Pedrazzini,11

CH-6600 Locarno, Switzerland

Tel: $011-093-31.67 .92$

Fax: 011-093-32.23.70

\section{IMPLEMENTATION FEASIBILITY}

Development of this process is practically at the commercialization stage, as evidenced by the $100-\mathrm{Mg} / \mathrm{d}$ (106-t/d) demonstration facility in Italy. As of October 1995, several orders for full-scale standard plants had apparently been placed by European customers and were going though the permitting process.

The anticipated performance of Thermoselect technology relative to environmental emissions is expected to be very good. Stringent control and a high degree of detoxification of all effluent streams are consistent goals in the firm's development philosophy.

\section{Current Status and Remaining Development Needs}

According to Thermoselect, the demonstration plant has gone through 20,000 hours of operation and now operates continuously for 5 days a week, processing unshredded municipal and industrial wastes. The plant uses product gas to drive an engine generator and to heat the degasification channel. Since not all available gas is used, any excess is burned in a combustion chamber and discharged through the stack together with the products of combustion from the degasification chamber annulus.

Major unresolved areas appear to be:

- Optimization of energy use: An 1.8-MW engine being installed for further testing.

- Use of reactor gas on gas turbines: Being investigated.

- Commercial plant design: Replacement of natural gas with the reactor gas envisioned

- Waste heat recovery from gas engine off-gases and process waters: Planned for commercial systems to improve overall plant thermal efficiency.

- Continuity and reliability of operation: Demonstration plant has only been operated on a 5-day/ week cycle. Continuous round-the-clock operation is yet to be demonstrated.

Experience in other development programs has shown the importance of demonstrating that the process can run successfully under the stresses and limitations of nonstop operation. 
- Scale-up: Although the current demonstration plant is reported to have a "nominal capacity of $4 \mathrm{Mg} / \mathrm{h}$ " $(4.4 \mathrm{t} / \mathrm{h})$, experience to date shows that the unit appears to operate at an actual throughout of only $3.8 \mathrm{Mg} / \mathrm{h}(4.2 \mathrm{t} / \mathrm{h}$ ). The Standard design (Table 6.3) has a line capacity of $10 \mathrm{Mg} / \mathrm{h}(11.0 \mathrm{t} / \mathrm{h})$ per line; therefore it represents a scale-up factor over that indicated by Thermoselect of about 2.7:1 based on actual operating experience. The attainment of design capacity in scale-up situations is never certain because the relationships between the scale of operation (e.g., feed rate) and key process variables, such as the rate of heat transfer into the compressed "plug" of waste, are complex. Although the success of the planned commercialsize facility is yet to be proved, the extensive positive experience in the demonstration plant to date increases confidence in a successful outcome.

\section{PROCESS DESCRIPTION}

\section{General Description}

The Thermoselect system processes commingled MSW and "selected" industrial waste and converts them into what they state are environmentally safe products, including a cleaned product, vitrified solid granules, elemental sulfur, and sodium salts. No liquid effluents are discharged into the environment. Process water is treated and recycled. In addition, the process is intended to minimize both the formation and emission of particulates, nitrogen oxides, and other pollutants.

Gasification is achieved at a high temperature. The products of gasification are then held at high temperatures for more than 4 seconds - a relatively long residence time. Data indicate that this combination of time and temperature destroys the complex organic compounds produced in the gasification process and yields a product gas that, substantially, has reached chemical equilibrium. The raw gas is cleaned in an air pollution control/gas purification system, removing acid gases, hydrogen sulfide, particulates, and volatile heavy metals. Air emissions result solely from the combustion of the cleaned gas during the production of heat in boilers or other means for the generation of electric power.

The Thermoselect demonstration facility is located at Fondotoce, Italy, near Lago Maggiore, a picturesque tourist area in the southern foothills of the Alps. The plant was in normal operation during CDM's visit on October 8, 1995. The equipment, consisting of one process line with a nominal capacity of $4 \mathrm{Mg} / \mathrm{h}(4.4 \mathrm{t} / \mathrm{h})$, is housed in an attractive low-level building with two relatively short stacks. Normal operation was in progress during the visit, with the delivery of municipal and bagged industrial wastes by truck. No odor or noise was observed either inside or outside the plant.

\section{Process Description}

\section{a. Schematic and Flowsheet}

Figure 6.1 is a schematic of the Thermoselect ${ }^{\circledR}$ gasification system; Figure 6.2 is a flowsheet showing the components of the process. The various stages of this process are described in the following subsections. 
Table 6.3 Scale Up: Thermoselect Process

\begin{tabular}{|c|c|c|c|c|c|c|}
\hline \multicolumn{2}{|c|}{ Category } & Units & $\begin{array}{l}\text { Prior } \\
\text { Work }\end{array}$ & & $\begin{array}{l}\text { Fondotoc } \\
\text { e Facility }\end{array}$ & $\begin{array}{c}\text { Standard } \\
\text { Plant }\end{array}$ \\
\hline \multirow[t]{2}{*}{ Line } & capacity & $\mathrm{Mg} / \mathrm{h}$. & 1.00 & & 3.8 & 10.00 \\
\hline & factor capacity & & & & 4.20 & 2.38 \\
\hline \multirow[t]{3}{*}{$\begin{array}{l}\text { Press } \\
\text { (Compactor) }\end{array}$} & $\begin{array}{l}\text { maximum } \\
\text { capacity }\end{array}$ & $\mathrm{Mg} / \mathrm{h}$ & 1.50 & & 6.00 & 16.00 \\
\hline & capacity & $\mathrm{kg} / \mathrm{cycle}$ & 80.00 & & 280.00 & 600.00 \\
\hline & cycles & $1 / \mathrm{h}$ & 12.50 & & 15.00 & 16.67 \\
\hline \multirow{8}{*}{$\begin{array}{l}\text { Degassing } \\
\text { Channel }\end{array}$} & length & $\mathrm{m}$ & 20.00 & 13.00 & 13.00 & 14.00 \\
\hline & height & $\mathrm{m}$ & 0.25 & 0.25 & 0.35 & 0.50 \\
\hline & width & $\mathrm{m}$ & 0.90 & 0.90 & 1.50 & 1.80 \\
\hline & section area & $m^{2}$ & 0.23 & 0.23 & 0.53 & 0.90 \\
\hline & surface factor & & & & 2.33 & 1.71 \\
\hline & volume & $\mathrm{m}^{3}$ & 4.50 & 2.93 & 6.83 & 12.60 \\
\hline & capacity & $\mathrm{Mg}$ & 7.20 & 4.68 & 10.92 & 20.16 \\
\hline & residence time & $\mathrm{h}$ & 7.20 & 4.68 & 2.60 & 2.02 \\
\hline \multirow{7}{*}{$\begin{array}{l}\text { High- } \\
\text { Temperature } \\
\text { Chamber }\end{array}$} & $\begin{array}{l}\text { diameter lower } \\
\text { section }\end{array}$ & $\mathrm{m}$ & 2.10 & & 2.10 & 2.60 \\
\hline & $\begin{array}{l}\text { height solid } \\
\text { bed }\end{array}$ & $\mathrm{m}$ & 0.90 & & 1.60 & 3.20 \\
\hline & $\begin{array}{l}\text { volume lower } \\
\text { section }\end{array}$ & $m^{3}$ & 3.12 & & 5.54 & 16.99 \\
\hline & $\begin{array}{l}\text { capacity lower } \\
\text { section }\end{array}$ & $\mathrm{Mg}$ & 6.23 & & 11.08 & 33.97 \\
\hline & capacity factor & & & & 1.78 & 3.07 \\
\hline & energy input & MW & & & $\begin{array}{c}\text { propor- } \\
\text { tional }\end{array}$ & $\begin{array}{l}\text { propor- } \\
\text { tional }\end{array}$ \\
\hline & $\begin{array}{l}\text { residence } \\
\text { time, top } \\
\text { section }\end{array}$ & second & $\sim 2$ & & $>2.5$ & $>2.5$ \\
\hline $\begin{array}{l}\text { Homogenization } \\
\text { Chamber }\end{array}$ & $\begin{array}{l}\text { length } \mathrm{x} \text { width } \\
\text { factor }\end{array}$ & & & & $\sim 2.5$ & $\sim 2.5$ \\
\hline
\end{tabular}




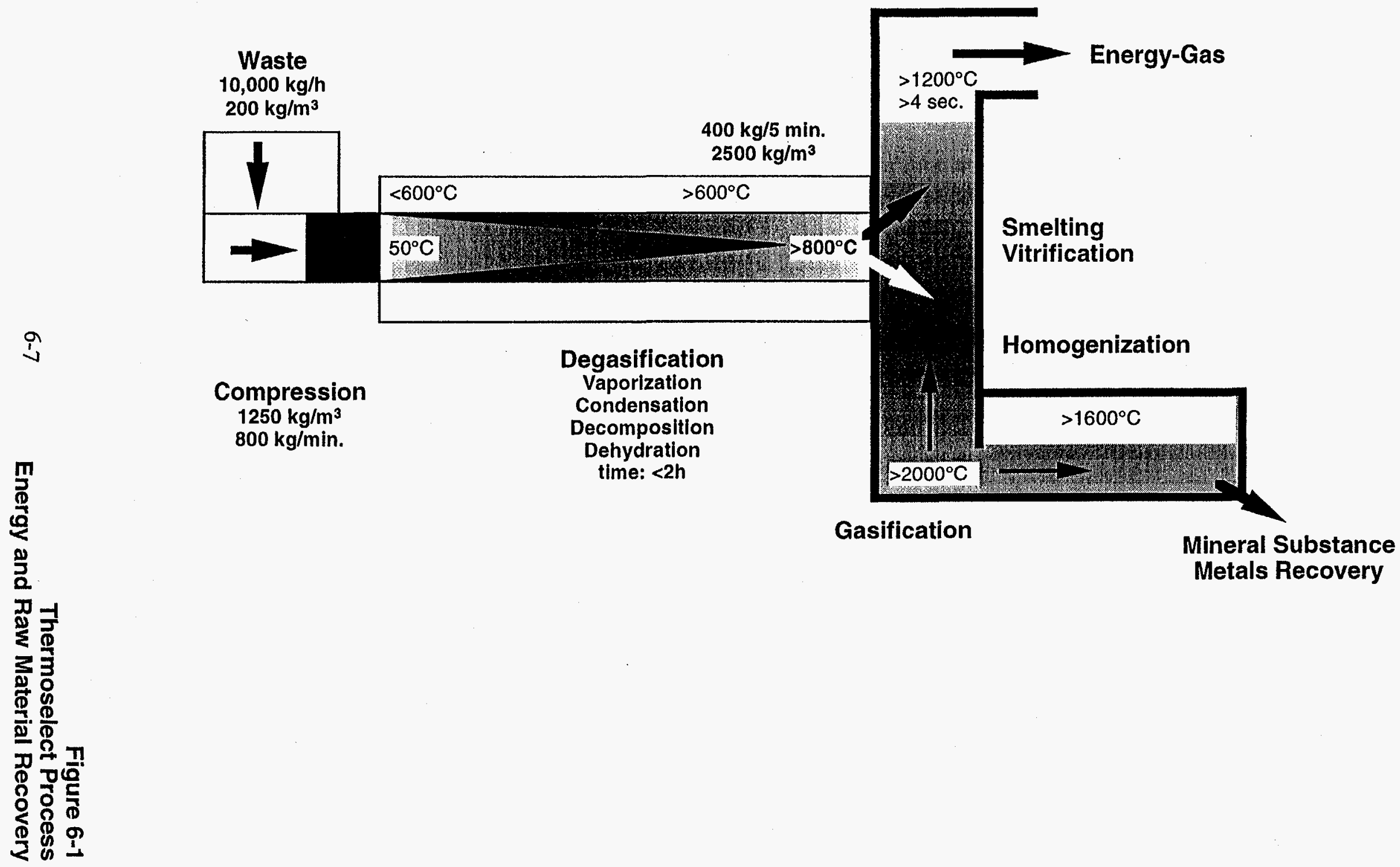




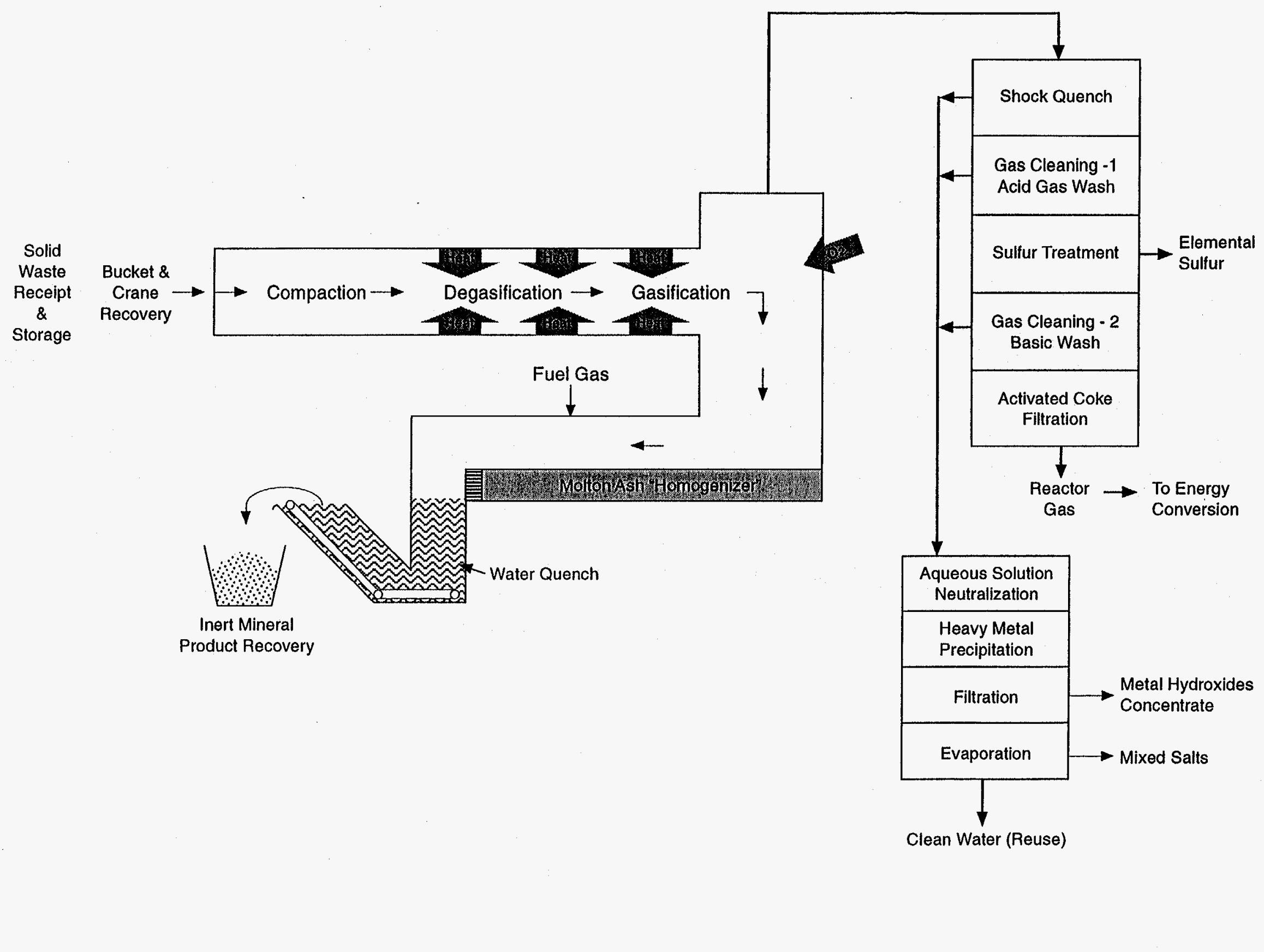

Clean Water (Reuse) 


\section{b. Compaction}

An industrial scrap-metal compactor is used to pack commingled waste to less than 10 percent of its original volume, thereby removing the air contained in the original loose material. The raw waste is dropped by grapple from the waste pit into the housing of the compactor, which presses the loose material against a heavy metal gate to a density of $1.25 \mathrm{Mg} / \mathrm{m}^{3}\left(78.5 \mathrm{lb} / \mathrm{ft}^{3}\right)$. As the process calls for feed, the gate opens, and the compactor moves the plug of waste though an unheated transition section into the degassing channel.

\section{c. Degassing/Pyrolysis of the Organic Fraction of the Waste}

The degassing channel containing compacted material is externally heated with a portion of the process generated gas to $600^{\circ} \mathrm{C}\left(1112^{\circ} \mathrm{F}\right)$. The reactor gas is burned with forced air in an annulus surrounding the degassing channel. As the compacted waste plug heats, volatile components (VOCs) contained in the waste vaporize and move the waste forward to the next stage. The heated vapors include the water common to solid wastes as steam. The waste plugs are pushed down the degassing channel; as they approach the transition to the next in-line state, they receive radiant heat from the next stage. The temperature in this area is $800^{\circ} \mathrm{C}\left(1472^{\circ} \mathrm{F}\right)$. At this transition point between the degassing channel and the next stage, identified as the high-temperature chamber (HTC), the waste plugs are much smaller because they have lost volatile components (water and VOC); the nonvolatile organic portion has been carbonized to a high degree, and the inorganic portion of the waste has remained virtually unaffected as part of the carbon matrix.

During this degassing stage, the conditions and ingredients that allow a water-gas reaction are present $\left(\mathrm{C}+\mathrm{H}_{2} \mathrm{O}=\mathrm{CO}+\mathrm{H}_{2}\right)$. Hydrogen and carbon monoxide thus move with the vaporized VOCs from the degassing channel into the upper section of the $\mathrm{HTC}$, which is maintained at $1200^{\circ} \mathrm{C}\left(2192^{\circ} \mathrm{F}\right)$.

Upon reaching the transition point with the HTC, the carbon matrix breaks apart and falls into the lower section of the HTC. The travel time through the degassing channel is normally less than 2 hours.

\section{d. High-Temperature Gasification (maximum pressure: $1.3 \mathrm{~atm}$ )}

The matrix of carbon and inorganic material fills the lower section of the HTC, where oxygen is introduced. The reaction of oxygen with carbon produces a temperature of $2000^{\circ} \mathrm{C}\left(3632^{\circ} \mathrm{F}\right)$. This controlled exothermic temperature provides the heat necessary to melt the inorganic fractions-composed primarily of glass products and various metals - contained in the carbon matrix. In effect, this lower section performs as a smelter. The inorganic molten mass of mineral and liquid metals flows from the lower HTC into the homogenization stage, where it is prepared for removal from the process.

In the lower section of the HTC, the equilibrium reaction $\left(\mathrm{C}+\mathrm{O}_{2} \rightarrow \mathrm{CO}_{2}\right)$ between carbon and oxygen produces the gas - carbon dioxide $\left(\mathrm{CO}_{2}\right)$. By shifting the equilibrium in the presence of $\mathrm{CO}_{2}$ $\left(\mathrm{C}+\mathrm{CO}_{2} \rightarrow 2 \mathrm{CO}\right.$ ), a high-volume percentage of the energy carrier-carbon monoxide ( $\mathrm{CO}$--is formed. Both these gases, the $\mathrm{CO}$ and a reduced volume of $\mathrm{CO}_{2}$, flow to the upper section of the HTC, which is maintained at $1200^{\circ} \mathrm{C}\left(2192^{\circ} \mathrm{F}\right)$, and join the other gaseous products received from the degassing channel of the process.

In the upper chamber of the HTC, the addition of oxygen maintains the temperature at $1200^{\circ} \mathrm{C}$ $\left(2192^{\circ} \mathrm{F}\right)$. This upper chamber is the collection point for all process gases. The temperature provided in 
this section through a proprietary oxygen introduction technique, combined with a residence period approaching 4 seconds and turbulence, is adequate to destroy the most complex organic compounds.

The resultant hot gases at $1200^{\circ} \mathrm{C}\left(2192^{\circ} \mathrm{F}\right)$ exit the $\mathrm{HTC}$ and are immediately water quenched in a spray chamber to below $70^{\circ} \mathrm{C}\left(158^{\circ} \mathrm{F}\right)$. Section g., Process By-Products, has a further discussion of the process.

\section{e. Homogenization Chamber}

The metal and mineral flow from the lower HTC enter this stage, where additional oxygen is introduced to react with any remaining carbon particles in the mineral/ metal melt flow. As all remaining carbon is depleted, additional heat is required to maintain the melt. Natural gas burners provide this heat at $23 \mathrm{~kg} / \mathrm{Mg}(46.6 \mathrm{lb} / \mathrm{t})$ or $31.15 \mathrm{~m}^{3} / \mathrm{Mg}\left(1000 \mathrm{ft}^{3} / \mathrm{t}\right)$. The combined molten metal and mineral melt streams are quenched in a water bath. The vitrified mineral stream cools and forms a vitrified mineral granulate, and the metal mix freezes, forming metal alloy pellets, as the flow enters the water bath. The resultant mix of granulate and metal pellets is recovered using a drag chain conveyor. The developers have stated that the vitrified mineral granulate meets EPA Toxicity Characteristics Leaching Procedure (TCLP) standards, as shown in Table 6.4. Such compliance may make possible the use of this glass-like mineral product for:

- Raw material components for making clinker brick

- A cement substitute analogous to the use of anthracite fly ash

- A concrete additive

- A filler for bituminous mixtures

- A filler and antifrost layer in underground engineering

- Mineral fiber and heat insulation fibers

- Decorative pavers and blocks for the building industry.

The redox processes occurring above $1800^{\circ} \mathrm{C}\left(3272^{\circ} \mathrm{F}\right)$ reduce the metal oxides and cause typical alloy-forming metals such as nickel, chromium, and copper to pass into an iron-rich metal melt. Since this melt has a very low concentration of high-vapor-pressure components such as mercury, zinc, cadmium, lead, and arsenic, it can be used directly for metallurgical purposes.

Because of the severe duty imposed on the Homogenizer Section, it must be replaced periodically. The developer includes a "spare" Homogenizer in the basic plant capitalization to ensure that an exchange with a spare section can be performed with minimum line outage. The replacement period is 6 months, and Thermoselect has stated that cooling and removal of the spent unit, positioning of the refreshed unit, and restart can be accomplished over a weekend-a seemingly optimistic estimate.

\section{f. Gas Cooling and Gas Separation from Process Water}

The hot gases contained in the upper section of the HTC exit are rapidly water quenched to below $70^{\circ} \mathrm{C}\left(158^{\circ} \mathrm{F}\right)$. The reactor gases and sulfur gases $\left(\mathrm{H}_{2} \mathrm{~S}\right)$ are separated from the quench water and passed through successive scrubbers: acid wash at $\sim 60^{\circ} \mathrm{C}\left(\sim 140^{\circ} \mathrm{F}\right)$, desulfurization, and base wash at 
Table 6.4 Vitreous Mineral Product: Elution Testing

\begin{tabular}{|l|l|c|c||}
\hline \multicolumn{1}{|c|}{ Analysis } & Result & Unit & $\begin{array}{c}\text { EPA Regulatory } \\
\text { Limit }\end{array}$ \\
\hline \hline Ignition & $>200$ & ${ }^{\circ} \mathrm{F}$ & $<140$ \\
\hline Corrosivity & 6.9 & $\mathrm{pH}$ & $<2,>12.5$ \\
\hline As Cyanide & $<0.10$ & $\mathrm{mg} / \mathrm{kg}$ & variable \\
\hline As Sulfide & $<0.50$ & $\mathrm{mg} / \mathrm{kg}$ & variable \\
\hline Arsenic, TCLP & $<0.40$ & $\mathrm{mg} / /$ & 5.0 \\
\hline Barium, TCLP & 0.07 & $\mathrm{mg} / /$ & 100.0 \\
\hline Cadmium, TCLP & $<0.01$ & $\mathrm{mg} / /$ & 1.0 \\
\hline Chromium, TCLP & 0.04 & $\mathrm{mg} / 1$ & 5.0 \\
\hline Copper, TCLP & 0.11 & $\mathrm{mg} / /$ & 100.0 \\
\hline Lead, TCLP & $<0.10$ & $\mathrm{mg} / /$ & 5.0 \\
\hline Mercury, TCLP & $<0.0025$ & $\mathrm{mg} / /$ & 0.2 \\
\hline Selenium, TCLP & $<1.0$ & $\mathrm{mg} / /$ & 1.0 \\
\hline Silver, TCLP & 0.03 & $\mathrm{mg} / /$ & 5.0 \\
\hline Zinc, TCLP & 0.22 & $\mathrm{mg} / /$ & 500.0 \\
\hline \hline
\end{tabular}

$40^{\circ} \mathrm{C}\left(104^{\circ} \mathrm{F}\right)$. They are cooled to $5^{\circ} \mathrm{C}\left(41^{\circ} \mathrm{F}\right)$ to remove water vapor and are then passed through a coke filter and warmed to ambient temperature before use.

When a waste feed containing $50 \%$ organic matter $/ 25 \%$ organics $/ 25 \%$ water at $10.4 \mathrm{MJ} / \mathrm{kg}$ $(4472 \mathrm{Btu} / \mathrm{lb})$ is processed, an $8.3-\mathrm{MJ} / \mathrm{Nm}^{3}\left(224-\mathrm{Btu} / \mathrm{ft}^{3}\right)$ reactor gas with the following average composition results:

$\begin{array}{lc}\text { Average Reactor Gas Composition } & \text { Vol \% } \\ \text { Carbon Monoxide }(\mathrm{CO}) & 34-39 \\ \text { Hydrogen }\left(\mathrm{H}_{2}\right) & 32-35 \\ \text { Carbon Dioxide }\left(\mathrm{CO}_{2}\right) & 22-27 \\ \text { Nitrogen }\left(\mathrm{N}_{2}\right) & 3-4 \\ \text { Methane }\left(\mathrm{CH}_{4}\right) & <0.1 \\ \text { Other } & <0.6\end{array}$


These values appear close to those predicted by the assumption of thermodynamic equilibrium at $1200^{\circ} \mathrm{C}$ $\left(2192^{\circ} \mathrm{F}\right)$, which suggests there is adequate retention time. The small amounts of methane, as well as larger proportions of $\mathrm{CO}$, are indicative of the decomposition of higher-molecular-weight substances.

The cleaned reactor gas is an energy source for the production of electricity or as a fuel to a steam boiler. The energy conversion plant is included as part of the scope of supply by the developer. The reactor gas can also be a chemical feedstock for methanol or benzene formation.

Air emissions from all sources are significantly below EPA NSPS for large MSW combustors, as shown in Table 6.5 .

The high-volume water quench of the hot process gases quickly lowers the temperature of the gases; the water serves as a sink for particulates, heavy metals, and water-soluble acid gases such as $\mathrm{Cl}_{2}$ and $\mathrm{F}_{2}$, which form $\mathrm{HCl}$ and $\mathrm{HF}$ respectively.

The sulfur-removal system converts hydrogen sulfide $\left(\mathrm{H}_{2} \mathrm{~S}\right)$ to sulfur using an iron III complex via a well-proven, proprietary process. The resultant iron III complex, proportionately formed, is regenerated in an adjoining stage using air oxygen. The removal of elemental sulfur (S), compared with the removal as gypsum $\left(\mathrm{CaSO}_{4}\right)$-common to most thermal processes-reduces the sulfur solids end product by a factor of more than four.

\section{g. Process By-Products}

The processing-water solutions generated from the gas-cleaning sections are subject to conventional chemical material separation processes. After removal of the heavy metal hydroxides as a solid concentrate and other insoluble portions of the process water, the combined streams pass through a reverse osmosis membrane, removing much of the remaining salts (sodium chloride). This step is followed by evaporation of the water to remove any soluble residuals. The cleaned water is used in the processwater loops and cooling towers. Since the process recovers the water contained in the original waste input, there is additional water recovered as part of the process; it is sprayed on hybrid cooling towers and evaporated. No process water need be diverted to a sewer.

The following by-products are collected in addition to the product gas, vitrified mineral product, and metal alloy pellets:

- Industrial-grade sodium chloride (salt)

- Elemental sulfur

- Concentrate containing heavy metal hydroxides.

The metal and vitrified mineral granulates collected from the Homogenization Chamber can be density separated when in molten form, but they are more easily handled in granulate and metal-pellet form. These pellets can then be separated by a magnet into vitrified mineral product and metal alloy pellets. The metal pellets consist of iron alloy $(>90 \%)$, with considerable amounts of copper ( 3 to $5 \%$ ), nickel $(0.6 \%)$, chromium $(0.3 \%)$, tin $(0.4 \%)$, and phosphorus $(0.1 \%)$. Concentrations of heavy metals that find their way into these by-products are at acceptable levels. 
Table 6.5 Comparison of Air Emissions

\begin{tabular}{||l|l|l|c|c||}
\hline \multicolumn{1}{|c|}{ Component } & \multicolumn{1}{c|}{ Units } & \multicolumn{2}{|c|}{ U.S. EPA* } & Thermoselect \\
\hline \hline $\mathrm{HCl}$ & $\mathrm{ppm}(\mathrm{v})$ & 25.0 & (or 95\% removal) & 0.5 \\
\hline $\mathrm{SO}_{2}$ & $\mathrm{ppm}(\mathrm{v})$ & 30.0 & (or $80 \%$ removal) & 2.0 \\
\hline $\mathrm{NO}_{x}$ & $\mathrm{ppm}(\mathrm{v})$ & & & $<80.0^{\S}$ \\
\hline First Year & & 180.0 & & \\
\hline Subsequent Years & & 150.0 & & \\
\hline $\mathrm{CO}$ & $\mathrm{ppm}(\mathrm{v})$ & 1 & & 30.0 \\
\hline Dust & $\mathrm{mg} / \mathrm{Nm}^{3}$ & 24.0 & & 9.0 \\
\hline Cd and $\mathrm{TI}$ & $\mathrm{mg} / \mathrm{Nm}^{3}$ & 0.020 & & $<0.01$ \\
\hline $\mathrm{Hg}$ & $\mathrm{mg} / \mathrm{Nm}^{3}$ & 0.08 & (or $85 \%$ removal) & 0.03 \\
\hline $\mathrm{Pb}$ & $\mathrm{mg} / \mathrm{Nm}^{3}$ & 0.20 & & 0.01 \\
\hline PCDD \& PCDF & & & & \\
\hline Total & $\mathrm{ng} / \mathrm{Nm}^{3}$ & 13.0 & & \\
\hline TEQ & $\mathrm{ng} / \mathrm{Nm}^{3}$ & 0.20 & & \\
\hline
\end{tabular}

* Final U.S. EPA standards. NSPS for New MWCs: Federal Register, December 19, 1995 - 40 CFR Part 60

$\dagger$ Represents average daily values

$\S$ This value is dependent on the method used to convert synthesis gas into an energy form.

II Depends on EPA interpretation of combustor class.

** $\mathrm{Pb}$ plus all remaining heavy metals: $<0.07 \mathrm{mg} / \mathrm{Nm}^{3}$.

$\Sigma: \mathrm{Sb}, \mathrm{As}, \mathrm{Pb}, \mathrm{Cr}, \mathrm{Co}, \mathrm{Cu}, \mathrm{Mn}, \mathrm{Ni}, \mathrm{V}, \mathrm{Sn}$. 
The residual aqueous solution from the wastewater purification system flows to a distillation tower to concentrate the residual sodium salt and recover high-quality water for recycle to the process. Thermoselect claims that the concentrate contains only minimal amounts of contaminants.

\section{E. ENVIRONMENTAL ASPECTS}

\section{Process Emissions Characteristics}

An extensive testing program was conducted between June and September 1994 by ten institutions from Germany, Switzerland, and Italy. Some of the participants were:

- RWTÜ-Essen

- Badenwerke AG-Karlsruhe
- TÜ Energy \& Environment GMBH

- Filderstadt and Steiger Environmental Technology AG-Lista

Emissions data from the gases exhausted when heating the Degasification Channel (Table 6.5) indicate emissions well below the EPA NSPS for new MWCs.

Further, test results indicate less than $0.1 \%$ free oxygen in the gas and only minute traces of organic compounds. No chlorinated aromatic hydrocarbons, other than PCDD+PCDF, were detected. No aromatic amines, carbonyl-sulfide, carbon sulfide, or phosgene could be detected. The data indicate that this system will comply with US environmental regulations.

\section{Aesthetics}

The demonstration plant, as well as the standard plant design, includes an attractive low-rise architec- turally designed building that should blend in well in a commercial environment, such as a modern industrial park. What remains to be seen, however, is whether the short stacks presently included in the design will be acceptable to US regulatory agencies.

\section{F. MATERIAL AND HEAT BALANCES}

\section{Mass Balance}

The values of the mass and energy balances shown are derived from the experience and test data obtained at the demonstration facility. They have been recalculated for the six-gasifier representation of Thermoselect's standard $10-\mathrm{Mg} / \mathrm{h}(11-\mathrm{t} / \mathrm{h})$ units.

The mass balance is presented in graphic form in Figure 6.3 at a total feed rate of $60 \mathrm{Mg} / \mathrm{h}(66 \mathrm{t} / \mathrm{h})$. The balance shows the flow-through of materials, including the outflows of product gas and various byproducts of the process. Although natural gas is presently used in the Homogenizer, Thermoselect anticipates that future commercial facilities will be able to use the product gas for this purpose. 


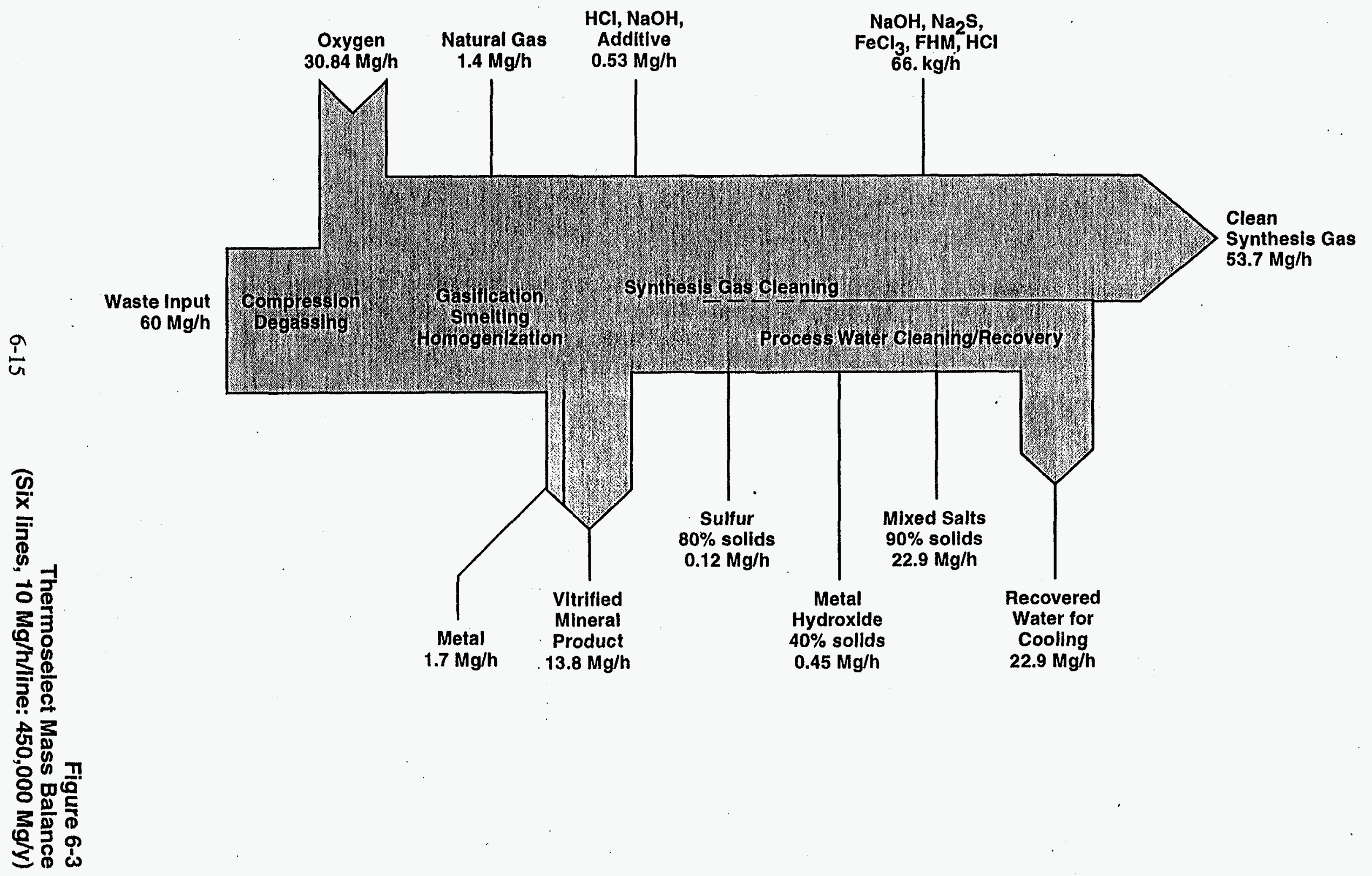


The process consumes oxygen at a rate of $0.514 \mathrm{Mg}(1028 \mathrm{lb} / \mathrm{t}) / \mathrm{Mg}(\mathrm{t})$ waste plus natural gas at $15.4 \mathrm{Nm}^{3} / \mathrm{mg}\left(1000 \mathrm{ft}^{3} / \mathrm{t}\right)$. The process produces about $830 \mathrm{Nm}^{3}\left(26,500 \mathrm{ft}^{3} / \mathrm{t}\right) / \mathrm{Mg}(\mathrm{t})$ gas for each ton of waste. A six-unit facility is expected to produce the following quantities of by-products:

$\begin{array}{llll}\text { Metal } & 1.74 \mathrm{Mg} / \mathrm{h} & = & 12,900 \mathrm{t} / \mathrm{y} \\ \text { Vitrified granulates } & 13.8 \mathrm{Mg} / \mathrm{h} & = & 102,000 \mathrm{t} / \mathrm{y} \\ \text { Sulfur (80-percent solids) } & 120 \mathrm{~kg} / \mathrm{h} & = & 900 \mathrm{t} / \mathrm{y} \\ \text { Mixed salts (90-percent solids) } & 0.72 \mathrm{Mg} / \mathrm{h} & = & 5,400 \mathrm{t} / \mathrm{y} \\ \text { Metal hydroxide (40-percent solids) } & 0.45 \mathrm{Mg} / \mathrm{h} & = & 3,300 \mathrm{t} / \mathrm{y}\end{array}$

Thermoselect believes that a market exists for these products, with the exception of the hydroxide sludge, which may require monofill disposal as a hazardous waste. The metals can be comixed for use in metallurgical furnaces, and the mineral granulates can be raw material for the ceramics industry. Traces of heavy metals in the sludge are said to be securely bonded with mineralizing agents to ensure environmentally stable disposal. Sulfur and industrial mixed salts may find their natural market. However, in the economic analysis of the facility, no credits have been taken for such products. Thus the result of the analysis is conservative.

\section{Energy Balance}

Energy input of $173 \mathrm{MW}\left(590 \times 10^{6} \mathrm{Btu} / \mathrm{h}\right)$ is supplied by the refuse, which has a heat value of $10.4 \mathrm{MJ} / \mathrm{kg}(4472 \mathrm{Btu} / \mathrm{lb})$. An additional energy contribution of about 10 percent is made by natural gas. The energy balance (Figure 6.4) indicates a net thermal energy output in the product gas of $114.8 \mathrm{MW}$ for the $60-\mathrm{Mg} / \mathrm{h}(61.4 \mathrm{t} / \mathrm{h})$ system or $6900 \mathrm{MJ} / \mathrm{Mg}\left(5.9 \times 10^{6} \mathrm{Btu} / \mathrm{t}\right)$ after allowing for the heat energy absorbed in the Degasification channel. This gas is available for the production of energy.

Using the procedure for estimating energy conversion costs described in Section 2, the remaining clean gas generates $240,000 \mathrm{MW}$ annually, or $530 \mathrm{kWh} / \mathrm{Mg}(484 \mathrm{kWh} / \mathrm{t})$ of electrical energy in a gas engine/genererator. The developer's energy balance (Figure 6.4) indicates internal consumption of 16.6 $\mathrm{MW}$ or $123,750 \mathrm{MWh} / \mathrm{y}$, leaving net exportable power at $116,250 \mathrm{MWh} / \mathrm{y}$ or $260 \mathrm{kWh} / \mathrm{Mg}(236 \mathrm{~kW} / \mathrm{t})$. The energy estimates are based on a conversion efficiency of 28 percent. The rejected heat from power generation is identified as recirculated "useful heat."

The six-line, $1440-\mathrm{Mg} / \mathrm{d}(1584-\mathrm{t} / \mathrm{d})$ plant would have an installed electrical capacity of $32.2 \mathrm{MW}$, with a nominal $15.6 \mathrm{MW}$ of export power. Although six, 2-MW spark-ignition gas-engine generators are assumed for the Standard Plant, the actual type of generation equipment is left to user preference. For a 32.2 MW plant, a gas turbine gas-to-electricity conversion strategy may be optimal. The gross heat rate for the facility, before use of internal power, is $18.5 \mathrm{MJ} / \mathrm{kWh}(17,500 \mathrm{Btu} / \mathrm{kWh})$.

\section{G. DEVELOPMENT HISTORY}

The history of the Thermoselect demonstration plant is summarized in Table 6.6. As a demonstration facility for the process, downtimes were scheduled over the years for inspection, equipment modification, and permit application. The plant is presently being run continuously for 5 days a week, with the longest operating period of more than 36 weeks at 5 days a week. 


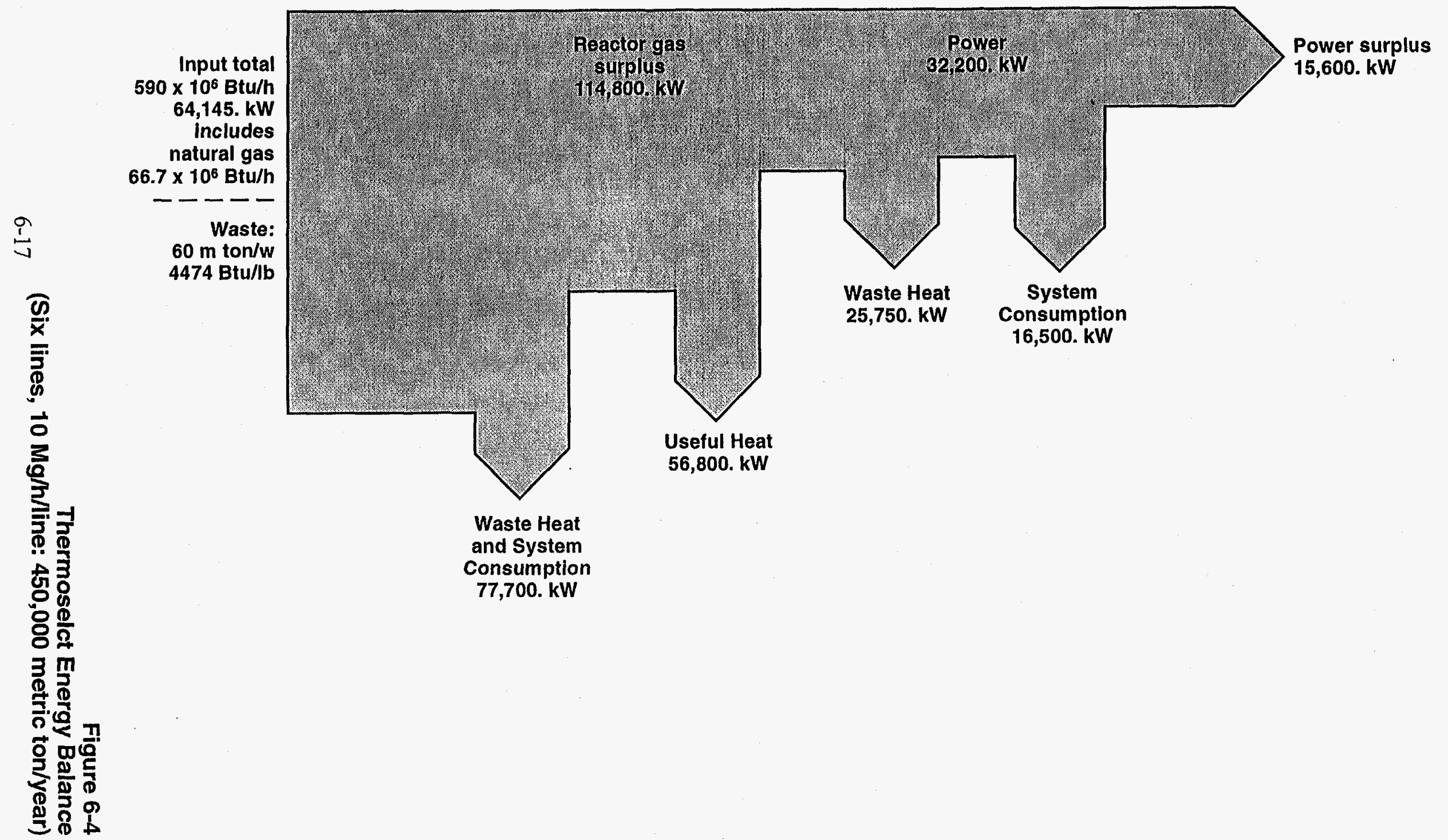


Table 6.6 Sequence Steps in the Development of the Thermoselect Process

\begin{tabular}{|c|c|c|}
\hline Time Frame & Duration & Status \\
\hline 1989 & 2 yrs & $\begin{array}{l}\text { Study of the carbonized process vs. pressure, } \\
\text { temperature, time, and waste properties: } 10 \mathrm{~kg} / \mathrm{h}(22 \mathrm{lb} / \mathrm{h})\end{array}$ \\
\hline 1991 & $1 \mathrm{yr}$ & $\begin{array}{l}\text { Development of the carbonization and degasification pro- } \\
\text { cesses using } 20 \text {-m long, } 0.225 \mathrm{~m}^{3} \text { cross-sectional area; } \\
\text { study of the gasification process and refractory lining } \\
\text { behavior; development of a burner design ensuring both } \\
\text { safety and a quick-change feature; material stability; } \\
\text { measurement methods, and product quality: } 1000 \mathrm{~kg} / \mathrm{h} \\
(2200 \mathrm{lb} / \mathrm{h})\end{array}$ \\
\hline 9/91 & $1 \mathrm{yr}$ & Beginning of plant building construction. \\
\hline $3 / 92$ & 7 months & Installation of major equipment completed. \\
\hline $10 / 92$ & 0 & $\begin{array}{l}\text { Start-up of the complete demonstration plant after } \\
\text { installation of an evaporator assembly. Includes trial } \\
\text { period with tests of a 1.2-MW reactor gas engine. } \\
\text { Plant operation licensed for a processing capacity of } \\
4200 \mathrm{~kg} / \mathrm{h}(9240 \mathrm{lb} / \mathrm{h})\end{array}$ \\
\hline $1 / 93$ & 3 months & $\begin{array}{l}\text { Beginning of an evaluation program by Italian, Swiss, and } \\
\text { German experts. }\end{array}$ \\
\hline $4 / 93$ & 6 months & $\begin{array}{l}\text { Dismantling of major components and inspection by } \\
\text { independent experts mandated to study the stability and } \\
\text { dependability of processing assemblies after } 4000 \text { hours } \\
\text { of operation. }\end{array}$ \\
\hline $11 / 93$ & $\begin{array}{c}13 \\
\text { months }\end{array}$ & $\begin{array}{l}\text { End of a 12-month trial period including tests with a } \\
1.2 \mathrm{MW} \text { reactor gas engine. }\end{array}$ \\
\hline 4/94 & $\begin{array}{c}18 \\
\text { months }\end{array}$ & $\begin{array}{l}\text { Permit received for the continuous operation of a } \\
\text { complete disposal line (Fondotoce plant) at } 100 \mathrm{Mg} / \mathrm{d} \\
(110 \mathrm{t} / \mathrm{d}) \text {. }\end{array}$ \\
\hline $6 / 94$ & $\begin{array}{l}20 \\
\text { months }\end{array}$ & $\begin{array}{l}\text { Comprehensive studies begin of the Fondotoce plant, } \\
\text { including testing of all substance flows and the setting up } \\
\text { of material and energy balances; waste throughput of up } \\
\text { to } 4.4 \mathrm{Mg} / \mathrm{h}(4.8 \mathrm{t} / \mathrm{h}) \text { at waste calorific values of from } 12 \text { to } \\
13 \mathrm{MJ} / \mathrm{kg}(5160 \text { to } 5590 \text { Btu/lb). }\end{array}$ \\
\hline 9/94 & 2 yrs & $\begin{array}{l}\text { Completion of testing and confirmation of the design for } \\
\text { the standard plant. }\end{array}$ \\
\hline
\end{tabular}

* For start-up of demonstration plant 
The table also shows the various upgrading steps undertaken during the history of this development; Figure 6.5 illustrates the dimensional changes (shown to scale) made when upgrading from laboratory scale to the proposed Standard Line.

The plant was subjected to thermal cycling during the early years to "identify stress areas." Engineering teardown assessments was made in 1993 after 4000 hours. In December 1994, the plant was shut down after 7500 hours of operation for another assessment of the equipment. The evaluation did not show any unusual or unexpected wear or corrosion problems. Subsequently, the plant was restarted and, apart from weekend shutdowns, is now in continuous commercial operation. Certified TUV reports are available that summarized the findings for the 1994 shutdown.

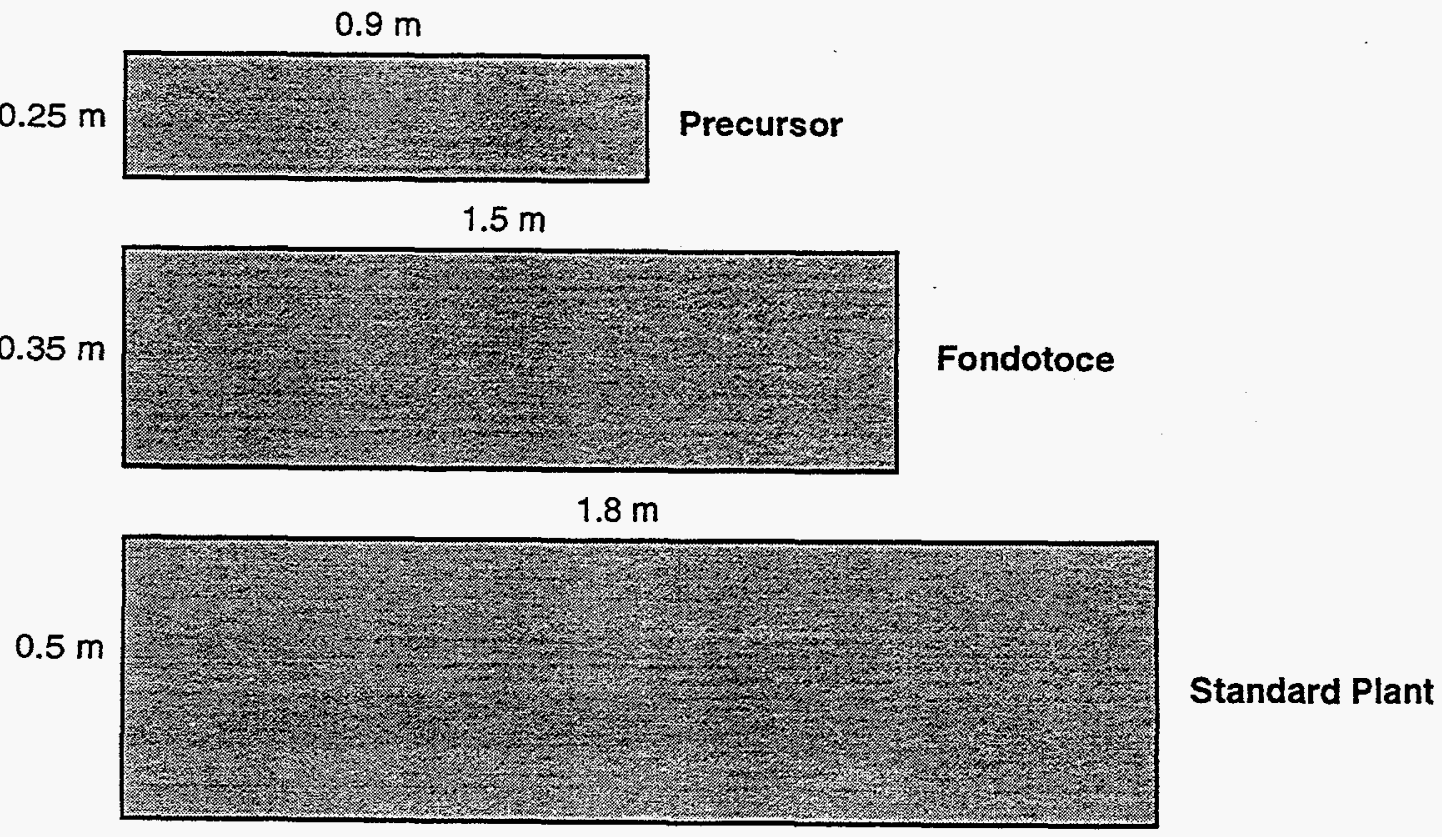




\section{H. INTERVIEWS}

In the course of evaluating the Thermoselect technology, CDM engineers inspected the facilities in Fondotoce and met with staff from the U.S. operations. Those interviewed were:

Fondotoce

- Dr. Jurgen Riegel, President

- Professor Dr. Rudi Stahlberg, Technical director

- Dr. Bernd Calaminus, Technical Associate, Chemical Engineer

- Dr. Uwe Feuerriegel, Technical Associate, Chemical Engineer

- Dr. Franz Steiger, Consulting Environmental Engineer

- Mr. Frederico Rei, Consulting Engineer

U.S. Operations (Troy, Michigan)

- David Runyon, Executive Vice President

- Gayle E. Koch, Consultant

\section{BIBLIOGRAPHY}

1. Response dated June 6, 1995 to Camp Dresser \& McKee"s Questionnaire of May 30, 1995.

2. Response dated September 14,1995 to Camp Dresser \& McKee Questionnaire of August 10, 1995.

3. R. Stahlberg and D. J. Runyon, "Part 1: Energy and Raw Material Recovery Through Thermal Chemical Transformation in a Closed-Loop System," 16th Biennial ASME National Waste Processing Conference, Boston, June 1994 .

4. R. Stahlberg and U. Fenerriegel, "Part 2: Performance of the Thermoselect Demonstration Plant at Fondotoce, Italy: Product Quality and Distribution of Chemical Elements in the Material Flow," Waste Management Association International Conference, Washington, DC, April 19, 1995.

5. R. Stahlberg, et al., "Part 3: Mass and Energy Balances of the Thermoselect Demonstration Plant," ASME ASTHMA Solid Waste Processing Division, 17th Biennial ASME National Solid Waste Processing Conference, Atlantic City, NJ, April 1996.

6. Technical Specifications, Thermoselect STANDARD PLANT, Rev.2, January 10, 1995 (Confidential and Proprietary Document)

7. G. Hessler, "Der Neue Weg, Rostmüll umweltgerecht zu behandeln" (The new environmentally safe way to process waste), Verlag Karl Goerner, 1995. 


\title{
Section 7
}

\author{
Battelle
}

\section{A. Summary}

The Battelle High Throughput Gasification System (BHTGS) is an indirectly heated, two-stage process that uses circulating fluidized bed (CFB) reactors. In a high-throughput gasifier, refuse-derived fuel (RDF) or other biomass feedstocks is gasified in a CFB to a medium-heating-value gas [18.6 to $22.4 \mathrm{Nm}^{3}$ (500 to $\left.600 \mathrm{Btu} / \mathrm{sft}^{3}\right)$ ], using steam without oxygen as the fluidizing medium. Residual char is consumed in an associated CFB combustor. A circulating-sand phase is the method for heat transfer between the separate reactors.

The BHTGS is said to produce gaseous emissions from the combustor that comply with EPA's New Source Performance Standards (NSPS) for Municipal Waste Combustors (MWCs). Wastewater from the process contains only trace quantities of organic materials. At Battelle's test site, the outlet of a simple, industrial treatment system-a sand filter followed by a simple charcoal filter-showed wastewater to be within EPA's drinking water standards.

Experimental data have been generated in Battelle's process research units (PRUs) in 1.5- and 2.5-dm (6and $10-$ in) gasifiers with throughputs of $0.22-$ and $9.1-\mathrm{Mg} / \mathrm{d}(0.24-$ and $10-\mathrm{t} / \mathrm{d})$ dry RDF respectively. Data from these units showed that extremely high throughputs, over $19.5 \mathrm{Mg} / \mathrm{h} \cdot \mathrm{m}^{2}\left(1,400 \mathrm{lb} / \mathrm{hr} \bullet \mathrm{ft}^{2}\right)$, could be achieved. A wide range of feed materials, including $\mathrm{RDF}$, has been tested in the system.

Battelle's development efforts began in 1977. Detailed process development activities were begun in 1980 with the construction of the PRU. These PRU investigations were conducted during the mid-1980s. The tests demonstrated the technical feasibility of the gasification process and provided the basis for generating a detailed process conceptual design. Based on this design, capital and operating costs estimates were also calculated. Testing of a highly prepared RDF was conducted in 1989 in a $2.5-\mathrm{dm}$ (10-in.) ID, 6.9-m (22.7-ft)-high gasifier and a 1.0-m (40-in.), 3.5-m (11.5-ft)-high combustor. Throughput was $0.65 \mathrm{Mg} / \mathrm{d}$ $(0.72 \mathrm{t} / \mathrm{d}){ }^{1,2}$ The PRU has logged over 10,000 operating hours on a variety of feedstocks. The longest continuous operating run was approximately 100 hours at $9.1-\mathrm{Mg} / \mathrm{d}(10-\mathrm{t} / \mathrm{d}) \mathrm{dry} \mathrm{RDF}$. A $200-\mathrm{kW}$ gas turbine has been installed on the PRU and operated with wood for about 60 hours as an integrated gasifier/ turbine system. The major issues requiring further work are feedstock preparation and gas cleanup.

Battelle has licensed its BHTGS for the North American market to Future Energy Resources Corporation (FERCO) in Atlanta, Georgia. A commercial-scale demonstration is under way at Burlington Electric's McNeil Generating Station in Burlington, Vermont, using whole tree wood chips. 


\section{B. FINANCIAL AND BUSINESS ASPECTS}

\section{Projected Capital and Operating Costs}

Battelle has developed a process heat and material model to predict commercial-scale production with $\mathrm{RDF}$ as the feedstock. A copy of the computer printout for a $908-\mathrm{Mg} / \mathrm{d}(1000-\mathrm{t} / \mathrm{d})$ dry $\mathrm{RDF}$ plant is shown in Figure 7.1. Battelle used this model to estimate the capital costs for a plant processing 908$\mathrm{Mg} / \mathrm{d}(1000-\mathrm{t} / \mathrm{d})$ dry RDF. The cost of the gasifier plant was $\$ 19.2$ million. The RDF Preparation Plant was estimated by Battelle at $\$ 25$ million, based on published data for the National Ecology Plant in Baltimore, Maryland. The energy recovery was a combined cycle, and comparison with a conventional massburn waste-to-energy plant was quite favorable. ${ }^{1}$ No estimates were made of operating and maintenance costs.

Even though the intent of this study was not to rank various technologies, a plant throughput at a lower rate was deemed more appropriate in this case. Battelle indicated the costs could be proportionate by ratio to the 0.6 power. This system and the ThermoChem system-another indirect system-are similar. Thus the ThermoChem referenced throughput of $479-\mathrm{Mg} / \mathrm{d}(528-\mathrm{t} / \mathrm{d})$ dry RDF was assumed. This throughput converts to $595-\mathrm{Mg} / \mathrm{d}(655-\mathrm{t} / \mathrm{d})$ wet RDF or $849-\mathrm{Mg} / \mathrm{d}(935-\mathrm{t} / \mathrm{d}) \mathrm{MSW}$. The original Battelle costing was done for a combined cycle. The same assumptions were made for this study, based on the fact that the BHTGS would be the same system, with a duty of $249,000 \mathrm{MJ} / \mathrm{h}\left(237 \times 10^{6} \mathrm{Btu} / \mathrm{h}\right)$. Capital costs are shown in Table 7.1.

\section{Alternative Revenue Streams}

In a study for DOE, K\&M Engineering \& Consulting Corporation designed an RDF plant that was connected to a gasifier plant. They analyzed resource recovery from the RDF preparation plant. The study also investigated various energy recovery systems. ${ }^{3}$

\section{Business Aspects}

Although Battelle has done only pilot plant testing with RDF, they have developed the gasifier system to the demonstration stage for wood chips. FERCO, Battelle's licensee, is commercializing Battelle's technology. FERCO chose not to participate in this study; they are actively pursuing the wood chip gasification market.

The main office address and communications numbers for Battelle, as of late 1995, are:

Battelle

505 King Avenue

Columbus, Ohio 43201
Tel: (614) 424-4958

Fax: (614) 424-3321

\section{IMPLEMENTATION FEASIBLITY}

Battelle's gasifier lends itself to a variety of applications-from gas distribution to energy recovery. In a recent study for DOE, K\&M Engineering and Consulting Corporation analyzed implementation options. The energy recovery systems included combined cycle, Rankine cycle, methanol synthesis, and hot-water generation. ${ }^{3}$ The BHTGS could be used for similar energy-recovery systems. 
Table 7.1 Capital Cost: Battelle High Throughput Gasification System (BHTGS)

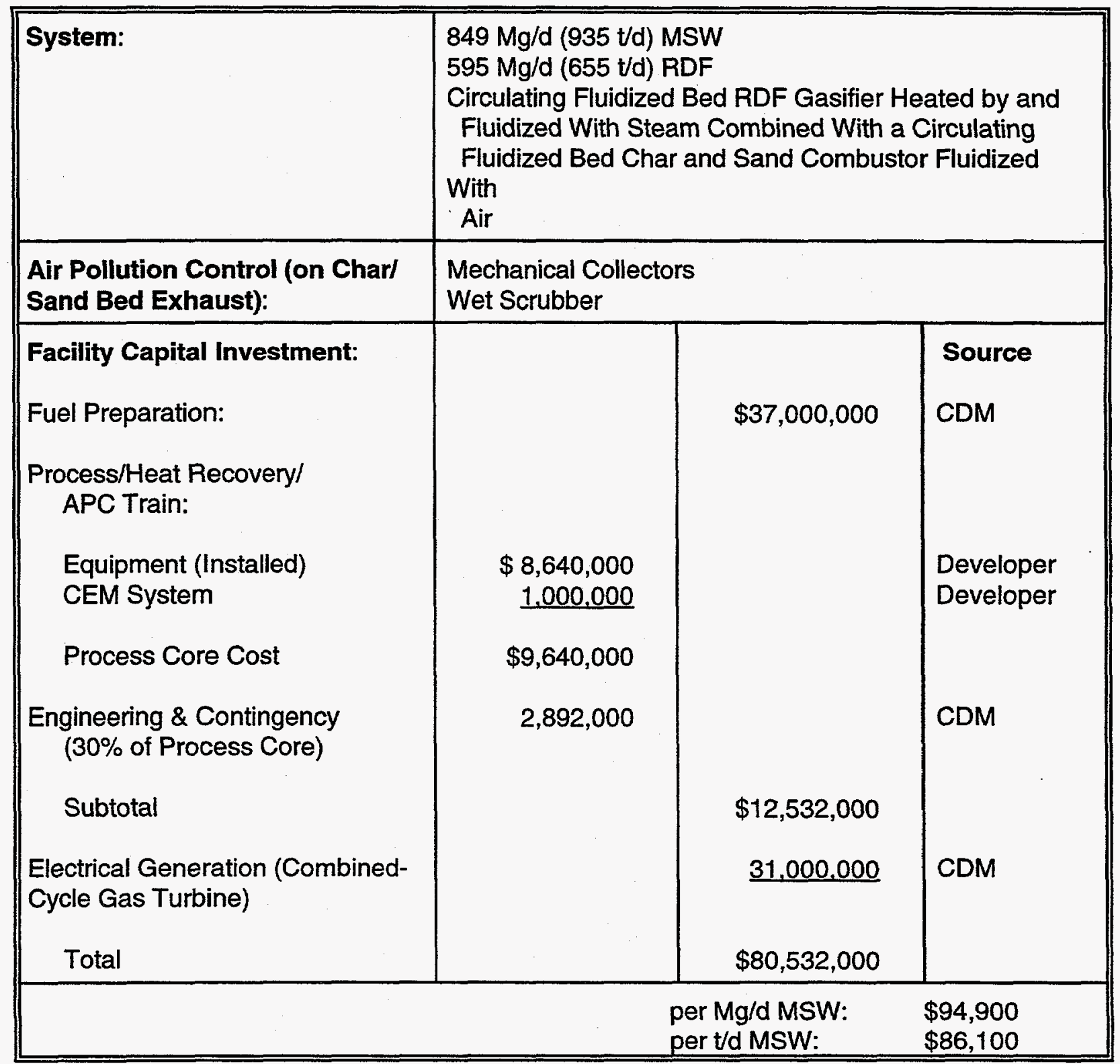


Battelle did not provide estimates of operating costs. The operating costs follow the guidelines mentioned previously for this study. The labor costs were based on the costs as generated for the ThermoChem system. The operating costs are shown in Table 7.2.

The wood-chip project in Burlington, Vermont, will be conducted in two phases. In the first phase, construction and operation of a $182-\mathrm{Mg} / \mathrm{d}(200-\mathrm{t} / \mathrm{d})$ gasifier began at the site in 1995 . The product gas will be burned in the existing boilers. In the second phase, a gas turbine will be installed to accept the product gas from the gasifier as part of a combined-cycle system planned for operation in 1997.,5

\section{Process Issues and Problem Areas}

The primary process issue relates to fuel preparation. The specific level of fuel preparation necessary for the process has not yet been determined. In this case, preparation refers to the removal of low-meltingpoint inorganic materials, such as glass and aluminum, from the incoming waste. It does not encompass a requirement for fine shredding of the feedstock or for extensive preparation such as pelletizing. Feed size. range will be dictated by the feed system requirements.

\section{Operating Issues and Problem Areas}

The primary operating issue when processing MSW in the system is ash agglomeration. The melting characteristics of the inorganic portion of the MSW feed material are directly related to the removal of glass and aluminum from that material.

\section{Remaining Research and Development Needs}

The primary research need is to determine the degree of preparation of the incoming MSW necessary for successful operation. A secondary need, but also important, is product gas cleanup (tar cracking and particulate removal). Additional operation at PRU scale is necessary to confirm the preliminary results obtained during the 1989 study at Battelle. Some preliminary data have been generated relative to the fate of chlorine in the process; these data should be confirmed before the design of a commercial facility. ${ }^{7}$

\section{PROCESS DESCRIPTION}

\section{Overview}

The BHTGS employs a CFB gasifier to provide high throughputs of biomass material. Heat necessary for the gasification reactions is provided from a stream of circulating sand which passes between the gasifier and an associated combustion reactor. The process is shown schematically in Figure 7.2. A small amount of char is produced as a result of the gasification reactions (typically 20 percent of the feed material). This char provides the fuel for reheating the circulating sand in the combustor. Like the gasifier, the combustor is a CFB reactor; it is also is capable of high throughputs. 
Table 7.2 Operating Costs for Battelle Incineration System

\begin{tabular}{|c|c|c|c|c|c|}
\hline Cost Element & No.IShift & Basis & Unit Cost & $\begin{array}{c}\text { Annual Cost } \\
(000)\end{array}$ & Source \\
\hline \multicolumn{6}{|l|}{ Labor } \\
\hline Superintendent & - & 1 & $\$ 45.00 / \mathrm{h}$ & $\$ 99$ & CDM \\
\hline Operator (Op.) & 1 & 4 & $\$ 32.00 / \mathrm{h}$ & $\$ 280$ & CDM \\
\hline Auxiliary Op. & 1 & 4 & $\$ 30.00 / \mathrm{h}$ & $\$ 263$ & CDM \\
\hline Feed System Op. & 1 & 4 & $\$ 30.00 / \mathrm{h}$ & $\$ 263$ & CDM \\
\hline Plant Attendant & 1 & 4 & $\$ 25.00 / \mathrm{h}$ & $\$ 219$ & CDM \\
\hline Elect./Inst Maintenance & 1 & 4 & $\$ 35.00 / \mathrm{h}$ & $\$ 307$ & CDM \\
\hline Mechanical Maintenance & 1 & 4 & $\$ 35.00 / \mathrm{h}$ & $\$ 307$ & CDM \\
\hline Inert Gas (t/y) & & 609 & $\$ 35 / t$ & $\$ 21$ & Developer \\
\hline Maintenance & $\$ 12,532,000$ & Allowance & $3 \%$ of Capital & $\$ 376$ & $\mathrm{CDM}$ \\
\hline Insurance & $\$ 12,532,000$ & Allowance & $1 \%$ of Capital & $\$ 125$ & $\mathrm{CDM}$ \\
\hline Compliance Testing & & Allowance & & $\$ 300$ & CDM \\
\hline \multirow[t]{2}{*}{ Residue Landfill } & & 129,343 & $\$ 40 / t$ & $\$ 5,174$ & CDM \\
\hline & & \multicolumn{2}{|c|}{ Total Cost for Process Core } & $\$ 7,734$ & \\
\hline Contingency & & \multicolumn{2}{|c|}{$10 \%$ of Process Core Cost } & $\$ 773$ & CDM \\
\hline Debt Service & $\$ 80,532,000$ & & $10.19 \%$ of Capital & $\$ 8,206$ & $\mathrm{CDM}$ \\
\hline RDF Operations & N/A & $290 \times 10^{6} \mathrm{t} / \mathrm{y}$ & $\$ 8.50 / t$ & $\$ 2,465$ & CDM \\
\hline Electric Gen. Operations & N/A & $237 \times 10^{6} \mathrm{Btu} / \mathrm{h}$ & & $\$ 1,700$ & CDM \\
\hline 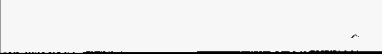 & & & Total Gross Cost & $\$ 20,878$ & \\
\hline \multicolumn{6}{|c|}{ Electrical Revenue } \\
\hline Gross Generation (MWh/y) & $237 \times 10^{6} \mathrm{Btu} / \mathrm{h}$ & 240,000 & & & CDM \\
\hline RDF Power Use (MWh/y) & & $(7,250)$ & & & $\mathrm{CDM}$ \\
\hline Internal Use (MWh/y) & & $(24,000)$ & & & $\mathrm{CDM}$ \\
\hline \multirow[t]{4}{*}{ Net to Export (MWh/y) } & & 208,750 & $\$ 0.04 / \mathrm{kWh}$ & $(\$ 8,350)$ & \\
\hline & & . & Net Annual Cost & $\$ 12,528$ & \\
\hline & & & Unit Cost \$/Ton & $\$ 43.20$ & \\
\hline & & & Unit Cost \$/Mg & $\$ 47.63$ & \\
\hline
\end{tabular}




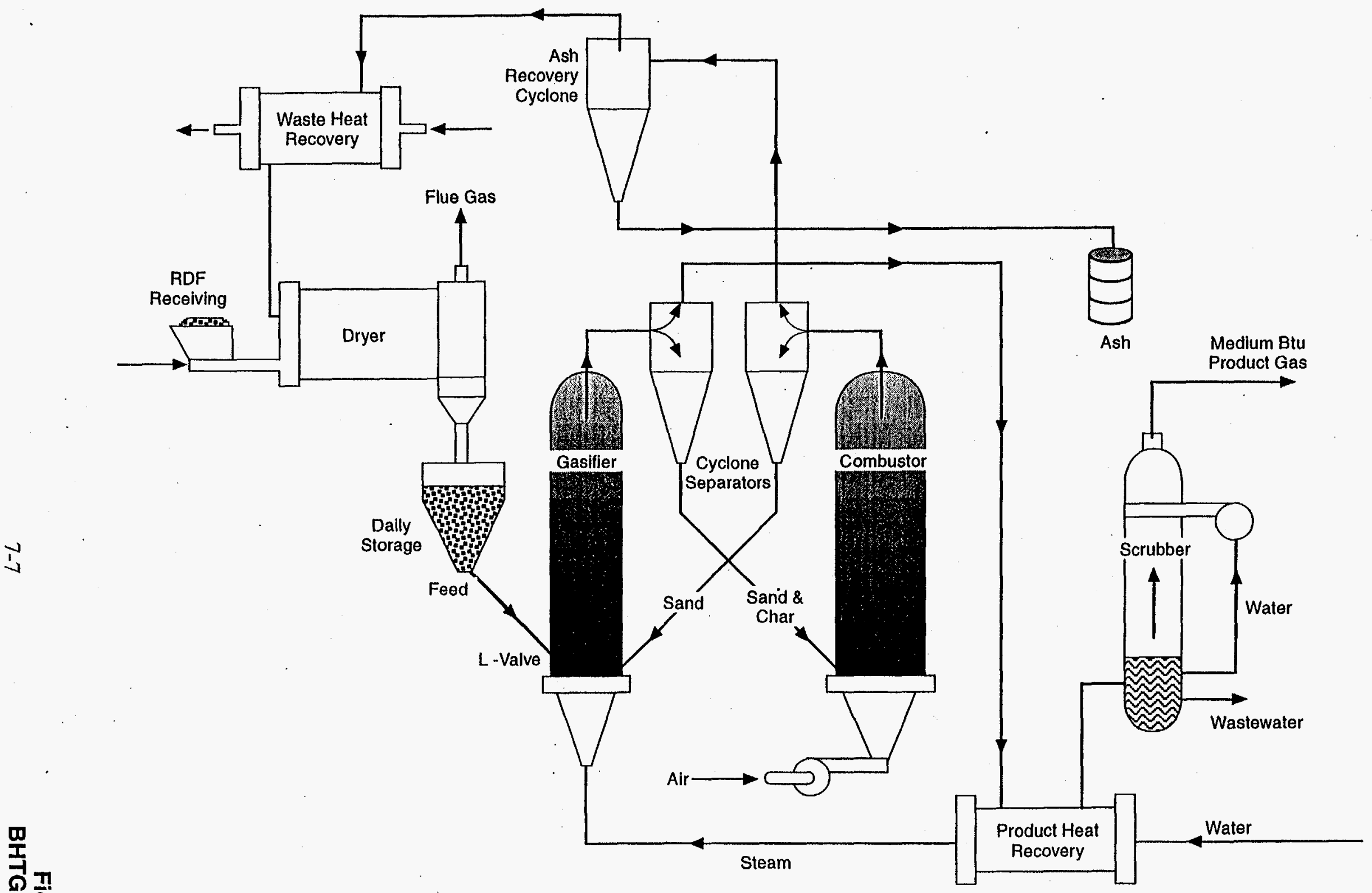




\section{a. Basic Concept}

The Battelle biomass gasification process produces a medium-Btu product gas without the need for an oxygen plant. The process schematic in Figure 7.2 shows the two reactors and their integration into the overall gasification process. This process uses two physically separate reactors:

- A gasification reactor in which the biomass is converted into a medium-heating-level gas and residual char

- A combustion reactor that burns the residual char to provide heat for gasification.

Heat transfer between the reactors is accomplished by circulating sand between the gasifier and the combustor.

The Battelle process provides a cooled, clean, $18.6-$ to $22.4-\mathrm{MJ} / \mathrm{Nm}^{3}\left(500-\right.$ to $\left.600-\mathrm{Btu} / \mathrm{sft}^{3}\right)$ product gas. Waste heat in the flue gas from the combustor can be used to preheat incoming air and then to dry the incoming feedstock. Although these unit operations are not required, they provide a means of increasing product yield by returning waste heat to the process. The condensed, organic phase scrubbed from the product gas is separated from the water, in which it is insoluble, and injected into the combustor. As Figure 7.2 indicates, the products from the process are the cooled, cleaned product gas; ash; and treated wastewater.

Table 7.3 shows the chemical similarity of wood and RDF. Wood has been successfully tested and a commercial plant being constructed. The analysis shown is typical for RDF produced by National Ecology in Baltimore, Maryland. This same RDF was used during the Battelle PRU tests. The chemical similarity of the two materials suggested that RDF might behave in a similar manner to wood in the Battelle process. The PRU tests conducted in 1989 verified this expectation and demonstrated the potential of the process for providing an economical alternative to current RDF-based MSW systems.

The medium-heating-value gas generated can readily be used in conventional natural-gas-fired combustion equipment. Steam boilers, gas turbines, industrial heat treating furnaces, and process heaters are examples of potential users of the gas.

As Shown in Figure 7.2, fluidizing gases enter the gasifier at a level below the RDF feed entry port and an L-valve sand recycle entry. The sand, char, and product gas are conveyed from the top of the gasifier into the cyclone mounted atop the combustor; the cyclone disengages the sand and char and allows them to flow back into the combustor bed. After separation of the sand and char in the cyclone, the product gas passes through an additional cyclone, product heat recovery, and a scrubber.

The combustor, a bubbling fluidized bed with a refractory lining, is designed to minimize heat losses. Sand enters the combustor through a closed chute line from the gasifier cyclone. This line enters through the top of the combustor and extends downward into the fluidized bed. The sand bed is returned to the gasifier from the combustor by an L-valve. The L-valve provides the necessary seal between the combustor and gasifier environments.

Exhaust gases from the combustor pass through a cyclone separator, which discharges the fine, separated particles directly back into the fluidized bed. The flue gases then are further cleaned and cooled by a waste-heat recovery system and RDF dryer before being exhausted to the atmosphere. 
Table 7.3 Comparison of Wood and RDF Analyses

\begin{tabular}{|c|c|c|}
\hline \multirow{2}{*}{ Description } & \multicolumn{2}{|c|}{$\%$ Dry Basis } \\
\hline & Wood & RDF \\
\hline Proximate Analysis: & & \\
\hline Volatile Matter & 83.89 & 77.76 \\
\hline Fixed Carbon & 15.78 & 11.23 \\
\hline Ash & 0.33 & 11.01 \\
\hline Total & 100.00 & 100.00 \\
\hline Ultimate Analysis: & & \\
\hline $\begin{array}{l}\mathrm{C} \\
\mathrm{H} \\
\mathrm{O} \\
\mathrm{N} \\
\mathrm{S} \\
\mathrm{Cl}\end{array}$ & $\begin{array}{r}52.37 \\
6.04 \\
41.30 \\
0.02 \\
0.25 \\
\underline{0.02} \\
\end{array}$ & $\begin{array}{r}47.31 \\
6.16 \\
45.71 \\
0.68 \\
0.14 \\
-\end{array}$ \\
\hline Total & 100.00 & 100.00 \\
\hline $\begin{array}{l}\text { Heating Value, MJ/kg } \\
\text { (Btu/lb) (dry) }\end{array}$ & $\begin{array}{c}9.22 \\
(8739) \\
\end{array}$ & $\begin{array}{l}8.53 \\
(8082) \\
\end{array}$ \\
\hline
\end{tabular}

\section{b. Commercial Plant}

Battelle estimated that a plant processing $1816-\mathrm{Mg} / \mathrm{d}(2000-\mathrm{t} / \mathrm{d})$ dry RDF would require a

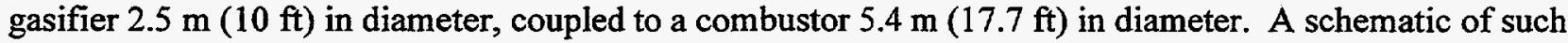
a plant is shown in Figure 7.3.

\section{E. ENVIRONMENTAL ASPECTS \\ 1. Process Emission Characteristics}

Low by-product production results in simple environmental systems. During the limited test program with RDF, lower concentrations of condensed organic materials were generated than in tests with wood. Battelle indicated a much more extensive evaluation would be necessary to confirm and quantify these results. Wastewater contained a mixture of hydrocarbons that were relatively insoluble in water, thus greatly simplifying projected wastewater cleanup requirements. Inorganics exit the BHTGS as part of the ash stream. Although sufficient RDF operating data have not been developed to provide complete mass- 


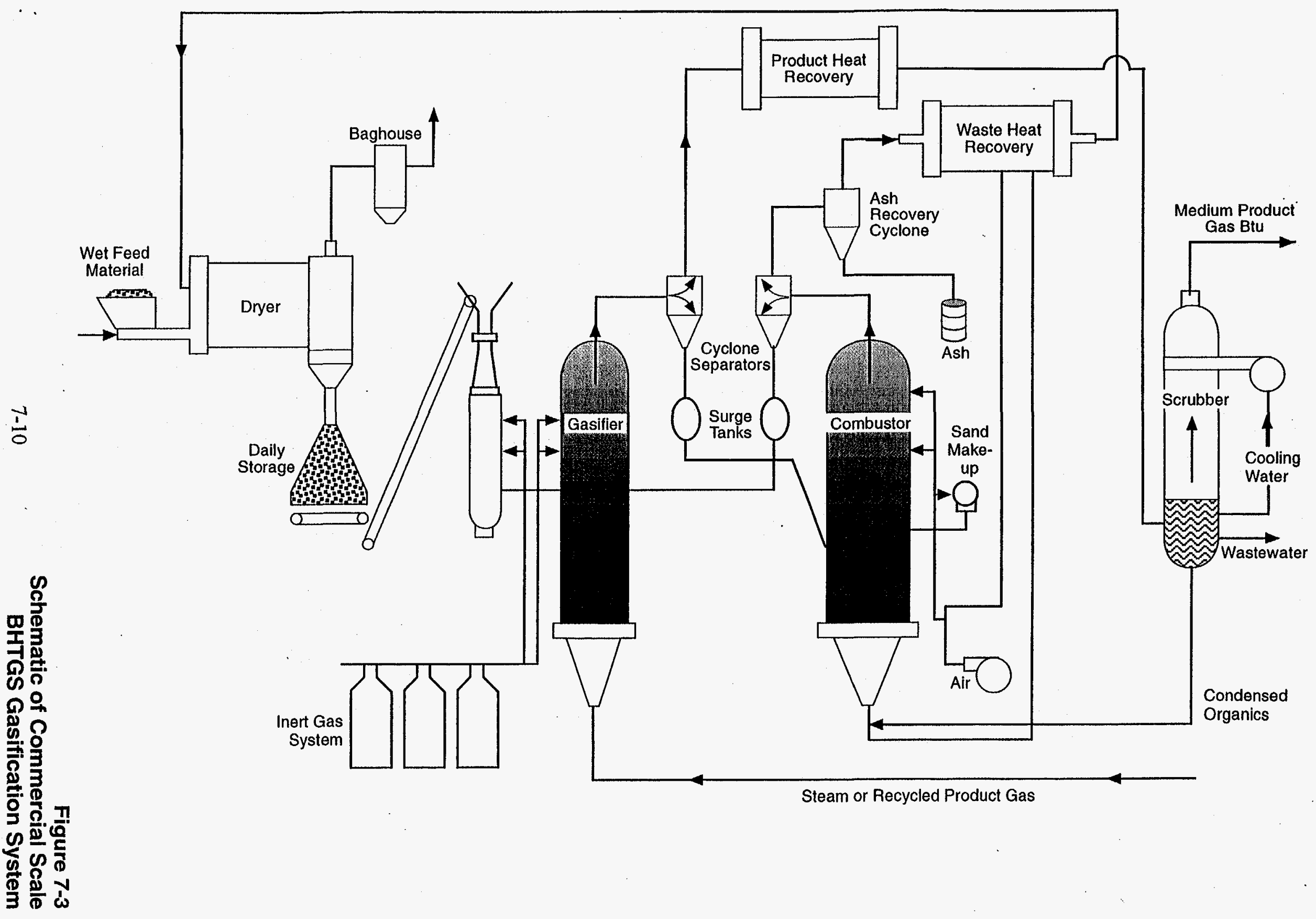


balance results for all inorganic species, Battelle's experience with other forms of biomass suggests that inorganics tend to be removed from the combustor as fine fly-ash material.

Glass and aluminum, like other low-melting-point species, have the potential for causing operating difficulties if they become part of the circulating phase. The BHTGS; because of its CFB (entrained-flow through the reactors) tends to remove larger tramp material, such as glass and aluminum, from the bottom of the reactor.

The BHTGS includes a wet scrubber in the process loop. Battelle has suggested that this scrubber will significantly reduce the particulate matter concentration in the fuel gas stream, simplifying the end use of the gas for power-plant fuel applications. One concern, however, is whether the quality will be sufficient for use in gas engines and, particularly, gas turbines without secondary gas cleanup.

Chlorine was not measured during the RDF testing. However, subsequent proprietary Battelle data indicate that chlorine in the waste stream is converted completely to $\mathrm{HCl}$ in the gasifier and not to chlorinated organic materials such as dioxins and furans. There is a small concentration of $\mathrm{HCl}$ present in the gas, most of which is removed by the scrubber. ${ }^{6}$

\section{Potential for Regulatory Compliance}

The estimated emissions are expected to comply with EPA regulations for MSW incineration plants.

\section{F. FLOWSHEET}

\section{Material Balances}

Data generated during Battelle's test program were incorporated into a Battelle process heat and material balance model to predict commercial-scale production rates. Table 7.4 is a summary mass and energy balance based on the schematic flowsheet shown in Figure 7.4.

\section{Heat Balance}

The heat balance is shown in Table 7.4. The basis for the mass and energy balances is the computer model output shown in Figure 7.1. The cold-gas efficiency is 69.2 percent.

\section{End Product}

The results of testing with RDF are the end product data shown in Tables 7.5 and 7.6. 
Table 7.4 BHTGS Mass and Energy Balance: Plant at $908 \mathrm{Mg} / \mathrm{d}$ (1000 t/d) dry RDF

\begin{tabular}{|c|c|c|c|c|c|c|c|}
\hline \multirow[b]{3}{*}{ Component } & \multicolumn{7}{|c|}{ Stream No. } \\
\hline & 1 & 2 & 3 & 4 & 5 & 6 & 7 \\
\hline & $\begin{array}{l}\text { RDF to } \\
\text { Gasifier } \\
\text { (lb/h) }\end{array}$ & $\begin{array}{l}\text { Feed- } \\
\text { water } \\
\text { (lb/h) }\end{array}$ & $\begin{array}{c}\text { Air to } \\
\text { Combustor } \\
\text { (lb/h) }\end{array}$ & $\begin{array}{c}\text { Product } \\
\text { Gas } \\
(\mathbf{l b} / \mathbf{h})\end{array}$ & $\begin{array}{l}\text { Flue Gas } \\
(\mathrm{Ib} / \mathrm{h})\end{array}$ & $\begin{array}{c}\text { Ash } \\
\text { (lb/h) }\end{array}$ & $\begin{array}{c}\text { Waste- } \\
\text { waterl } \\
\text { Con- } \\
\text { densibles } \\
\text { (lb/h) }\end{array}$ \\
\hline RDF (dry) & 83,333 & & & & & & \\
\hline $\mathrm{H}_{2} \mathrm{O}$ (liquid) & 24,194 & 25,984 & & & & 15,684 & 22,178 \\
\hline Ash & & & 144,617 & 22 & 5,022 & & \\
\hline $\mathrm{N}_{2}$ & & & 38,442 & 616 & 100,616 & & 63 \\
\hline $\mathrm{O}_{2}$ & & & & & 3,800 & & \\
\hline $\mathrm{CH}_{4}$ & & & & 6,354 & & & \\
\hline $\mathrm{C}_{2} \mathrm{H}_{4}$ & & & & 6,496 & & & \\
\hline $\mathrm{C}_{2} \mathrm{H}_{6}$ & & & & 390 & & & \\
\hline CO & & & & 25,452 & & & \\
\hline $\mathrm{CO}_{2}$ & & & & 10,296 & 49,984 & & \\
\hline $\mathrm{H}_{2}$ & & & & 810 & & 267 & 39 \\
\hline $\mathrm{H}_{2} \mathrm{O}$ (vapor) & & & & 61,920 & 2,286 & & \\
\hline $\mathrm{NH}_{3}$ & & & & & & & \\
\hline $\mathrm{H}_{2} \mathrm{~S}$ & . & & & & & & \\
\hline c & & & & & & 13,629 & 315 \\
\hline Subtotal, Ib/h & 107,836 & 25,984 & 183,059 & 112,334 & 196,726 & 29,580 & 22,595 \\
\hline Total, lb/h & & & 316,879 & & & & 316,879 \\
\hline $\begin{array}{l}\text { Temperature, } \\
{ }^{\circ} \mathrm{F}\end{array}$ & 70 & 120 & 70 & & & & \\
\hline $\begin{array}{l}\text { Duty, } \\
10^{6} \mathrm{Btu} / \mathrm{h}\end{array}$ & 649 & 36 & 31 & 592 & 93 & 3 & 7 \\
\hline Subtotal & & & 716 & & & & 693 \\
\hline Losses & & & 0 & & & & 21 \\
\hline Grand Total & & & 716 & & & & 716 \\
\hline
\end{tabular}




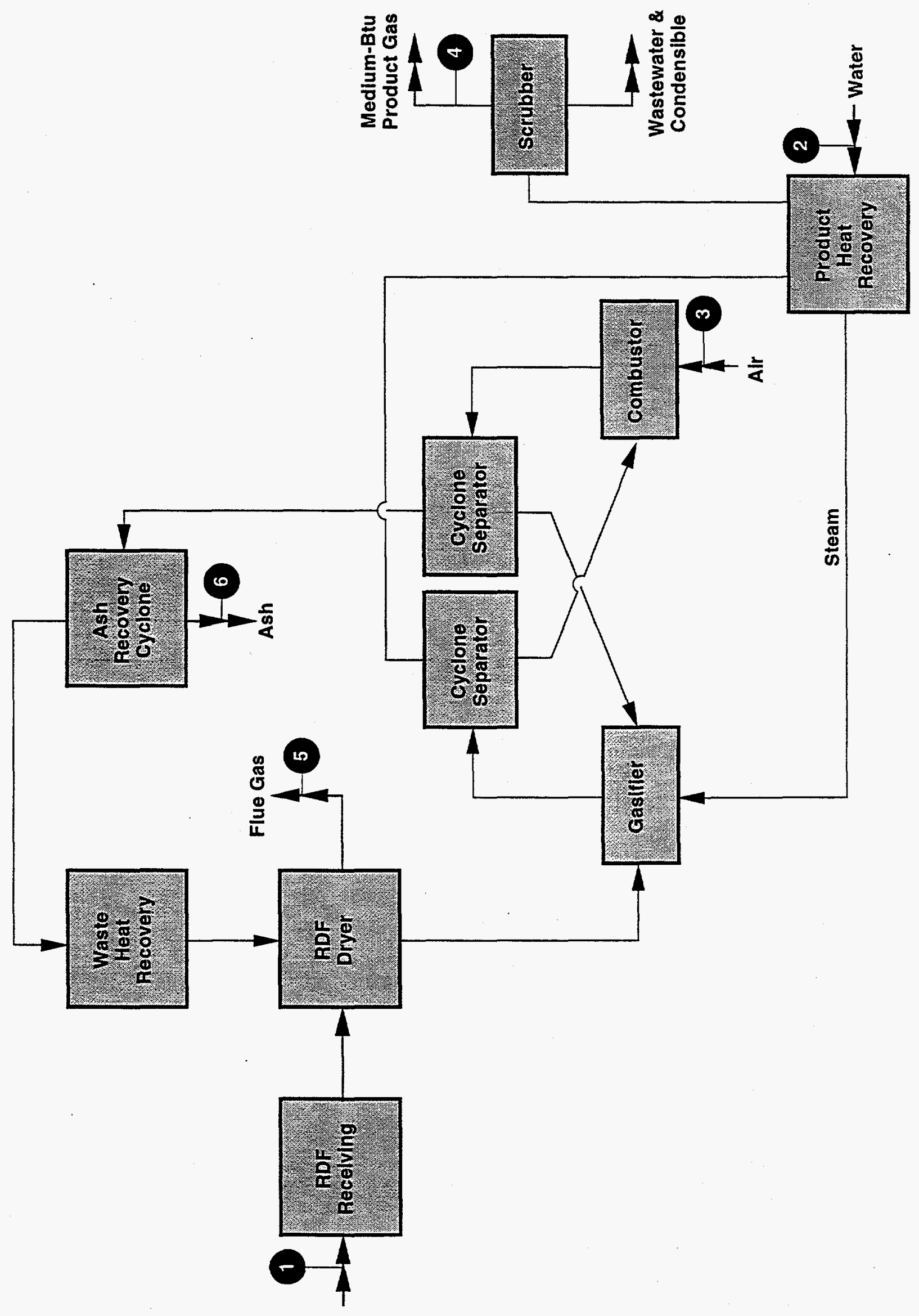

Figure 7-4

Battelle's System Schematic Flowsheet 


\section{Table 7.5 End Product Data}

\begin{tabular}{|c|c|}
\hline Gasifier Operating Temperature, ${ }^{\circ} \mathrm{C}\left({ }^{\circ} \mathrm{F}\right)$ & $660-840$ \\
\hline Carbon Gasified, \% & $41-69$ \\
\hline Product Gas Heating Value, $\mathrm{J} / \mathrm{Nm}^{3}\left(\mathrm{Btu} / \mathrm{sft}^{3}\right)$ & $20.2-23.3(541-627)$ \\
\hline $\begin{array}{l}\text { Product Gas Yield, } \mathrm{stt}^{3} / \mathrm{lb} \text { MAF Feed per RDF on MAF basis, } \\
\mathrm{Nm}^{3} / \mathrm{kg}\left(\mathrm{stt}^{3} / \mathrm{b}\right)\end{array}$ & $0.43-0.75(7-12)$ \\
\hline $\begin{array}{l}\text { Heating Value of Gas Produced, per RDF on MAF basis, } \\
\mathrm{MJ} / \mathrm{kg} \text { (Btu/lb) }\end{array}$ & $8.52-15.3(3662-6578)$ \\
\hline
\end{tabular}

Table 7.6 Product Gas Composition (vol\%)

\begin{tabular}{||l|l|}
\hline $\mathrm{H}_{2}$ & 15.7 \\
\hline $\mathrm{CO}_{2}$ & 11.1 \\
\hline $\mathrm{CO}$ & 43.9 \\
\hline $\mathrm{CH}_{4}$ & 16.3 \\
\hline $\mathrm{C}_{2} \mathrm{H}_{4}$ & 11.2 \\
\hline
\end{tabular}

\section{Proposed Interface}

Battelle has made studies that focus on power generation for a combined cycle using gas and steam turbines. According to Battelle's model, a $908-\mathrm{Mg} / \mathrm{d}(1000-\mathrm{t} / \mathrm{d})$ dry RDF gasification plant will produce $947,000 \mathrm{MJ} / \mathrm{h}\left(898 \times 10^{6} \mathrm{Btu} / \mathrm{h}\right)$ medium product gas, and thus about $112 \mathrm{MW}$ of power. A similar quantity of MSW in a mass-burn plant with a Rankine cycle will produce only $60 \mathrm{MW}$.

\section{G. DEVELOPMENT HISTORY}

\section{Laboratory/Bench Studies}

Development efforts on the BHTGS were begun in 1977. Initial tests were conducted in a 5-cm (2-in.) unit that could be used to screen different types of RDF. 


\section{Pilot Plant Studies}

Detailed process development activities were begun in 1980 with the construction and start-up of a PRU at Battelle's West Jefferson Laboratory. The PRU was designed so that the inherently high reactivity of biomass feedstocks could be exploited. These PRU investigations, conducted during the mid-1980s, demonstrated the technical feasibility of the gasification process and provided the basis for generating a detailed process conceptual design.

Experimental data have been generated in Battelle's PRUs in 1.5-dm (6-in.) and 2.5-dm (10-in.) diameter gasifiers with throughputs of 0.22 and $9.1 \mathrm{Mg} / \mathrm{d}(0.24$ and $10 \mathrm{t} / \mathrm{d}) \mathrm{dry}$ RDF respectively. Data from these tests showed that extremely high throughputs-over $19.5 \mathrm{Mg} / \mathrm{h} \cdot \mathrm{m}^{2}\left(4000 \mathrm{lb} / \mathrm{hr} \cdot \mathrm{ft}^{2}\right)$ could be achieved. A wide range of feed materials has been tested in the system including:

- RDF

- Hardwood and Softwood Chips

- Shredded Bark
- Sawdust

- Whole Tree Chips

- Shredded Stump Material

Testing in the PRU demonstrated the flexibility of the system to handle a variety of biomass forms with little or no preparation. This flexibility in feedstock acceptance was also apparent with the use of RDF as a feedstock for the process. The product gas heating value was consistent regardless of the moisture or ash content of the feed material tested.

\section{Semiworks Plant Studies}

None were planned or built.

\section{Current Status}

Using whole-tree wood chips, a commercial-scale demonstration is under way in Burlington, Vermont, at Burlington Electric's McNeil Generating Station.

\section{H. INTERVIEWS}

CDM engineers met with the Battelle Team involved with BHTGS development. Those interviewed were:

- Mark A. Paisley, P.E., Projects Manager

Phone: (614) 424-4958

- Dr. Robert D. Giammar, Department Manager

Process Engineering Department

Phone: (614) 424-7701

Fax: (614) $424-3321$ 


\section{REFERENCES}

1. M. A. Paisley, et al., "Gasification of Refuse Derived Fuel in the Battelle High Throughput Gasification System," prepared for Pacific Northwest Laboratory, U.S. Department of Energy Contract DE-ACX06-76RLO 1830 under Agreement 007069-A-H6, Battelle Columbus Division, July 1989.

2. M. A. Paisley, et al., "Gasification of Refuse Derived Fuel in a High Throughput Gasification System," Energy from Biomass and Wastes XIV, Lake Buena Vista, Florida, January 29 February 2, 1990.

3. K\&M Engineering and Consulting Corporation, "Minimizing Landfilling Through Pulse Enhanced Steam Reforming of Municipal Solid Waste, Final Report," prepared for the U.S. Department of Energy, Morgantown Energy Research Center, under Contract DE-AC21-90MC27346, Washington, DC, September 1995.

4. M. A. Paisley and G. Farris, "Development and Commercialization of a Biomass Gasification/Power Generation System," Second Biomass Conference of the Americas, Portland, Oregon, August 21-24, 1995.

5. "Burlington Electric Plans Wood Gasification Project to Reduce Costs and to Meet Environmental Requirements," Battelle brochure, June 1995.

6. Letter from M. A. Paisley to R. E. Sommerlad, November 6, 1995.

7. Letter from M. A. Paisley to R.E. Sommerlad, December 11, 1995. 


\section{Section 8}

\section{Pedco Incorporated}

\section{A. SUMMARY}

The Pedco Rotary Cascading Bed Combustor (RCBC) is, in essence, a robust solid-fuel burner and heatrecovery system. Among other solid fuels (coal and wood chips, for example), it can burn prepared municipal solid waste (MSW). Pedco's basic business is the design of combustion systems using the RCBC concept. Although their corporate experience favors applications providing steam for industry, they also have an interest in solid-waste management projects.

Pedco has two furnaces operating in the U.S.-a development unit at North American Rayon Corporation and a specialized unit used by a commercial hazardous waste management firm in the Houston, Texas area. The plants are reported to have shown good reliability, environmental emissions, and basic operability and maintainability characteristics.

\section{B. FINANCIAL AND BUSINESS ASPECTS}

\section{Projected Capital and Operating Cost}

The projected capital investment for implementation of the RCBC technology is based on capital and operating cost estimates prepared by Pedco for a proposed plant to be located at a North American Rayon Corporation's production facility in Elizabethton, Tennessee. Pedco's detailed cost estimate was based on a development plan that began with two RCBC furnaces and provided for progressive expansion of RCBC capacity over time.

The plant concept evaluated during this project includes four $\mathrm{RCBCs}$ that receive $800-\mathrm{Mg} / \mathrm{d}(880-\mathrm{t} / \mathrm{d})$ raw waste. This waste input results in $560-\mathrm{Mg} / \mathrm{d}$ (616 t/d) prepared RDF. At capacity, each of the boilers generates $22,100 \mathrm{~kg} / \mathrm{h}(48,600 \mathrm{lb} / \mathrm{h})$ steam. At peak load, the four boilers generate $24.8-\mathrm{MW}$ electricity. The investment estimate uses the reference costs developed under this program for RDF preparation and energy conversion. Similar to recent experience in the permitting of new refuse-burning facilities, the Pedco boilers are equipped with spray/dryer absorbers (one absorber serving two Pedco boilers) and are equipped for carbon addition. Selective noncatalytic reduction (SNCR) in the boilers reduces $N_{x}$. The capital cost of a complete Pedco system burning prepared, 5-cm (2-in.) top size, refuse-derived fuel (RDF) and generating electricity is shown in Table 8.1.

Table 8.2 presents operating cost estimates by Pedco for this plant. The costs incorporate estimates for RDF preparation and for energy conversion and revenues. For the energy generation calculations, the boilers were assumed to operate at 130-percent excess air (the average of Pedco's five pilot tests with RDF). Limestone, added as coarse, $1.0-\mathrm{cm}(3 / 8-\mathrm{in}$.) screenings, corresponds to a $\mathrm{Ca} /(\mathrm{S}+0.5 \mathrm{Cl})$ molar ratio of 
Table 8.1 Capital Cost: Pedco Thermal Processing System

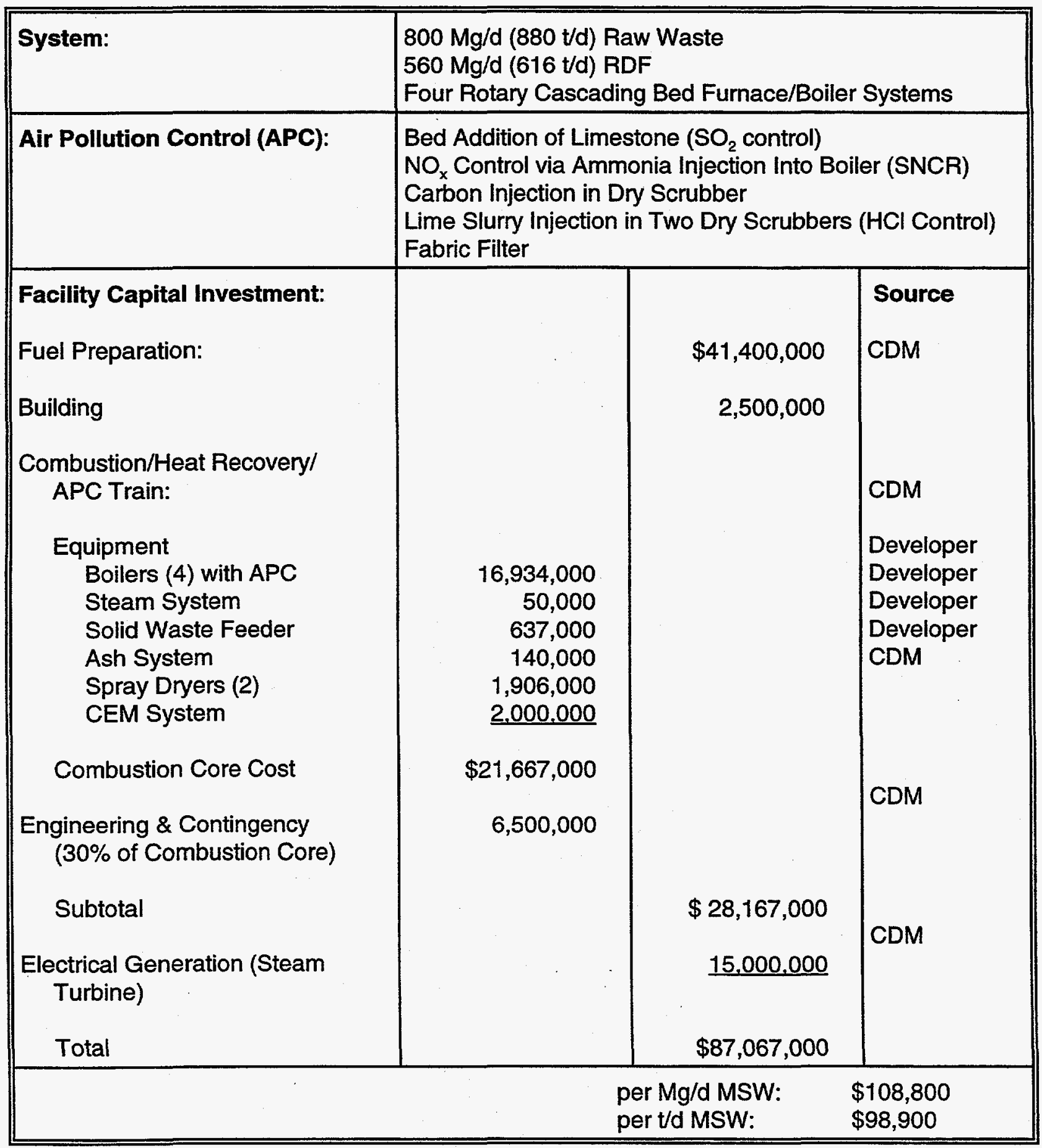


Table 8.2 Operating Costs for Pedco Incineration System

\begin{tabular}{|c|c|c|c|c|c|}
\hline Cost Element & No.JShift & Basis & Unit Cost & $\begin{array}{c}\text { Annual Cost } \\
(000)\end{array}$ & Source \\
\hline \multicolumn{6}{|l|}{ Labor } \\
\hline Superintendent & - & 1 & $\$ 45.00 / \mathrm{h}$ & $\$ 99$ & CDM \\
\hline Operator (Op.) & 2 & 8 & $\$ 32.00 / \mathrm{h}$ & $\$ 561$ & $\mathrm{CDM}$ \\
\hline Auxiliary Op. & 1 & 4 & $\$ 30.00 / \mathrm{h}$ & $\$ 263$ & CDM \\
\hline Feed System Op. & 1 & 4 & $\$ 30.00 / \mathrm{h}$ & $\$ 263$ & CDM \\
\hline Plant Attendant & 2 & 8 & $\$ 25.00 / \mathrm{h}$ & $\$ 438$ & CDM \\
\hline Elect./nst Maintenance & 2 & 8 & $\$ 35.00 / \mathrm{h}$ & $\$ 613$ & CDM \\
\hline Mechanical Maintenance & 1.5 & 6 & $\$ 35.00 / \mathrm{h}$ & $\$ 460$ & $\mathrm{CDM}$ \\
\hline Nat. Gas $\left(10^{6} \mathrm{Btu} / \mathrm{y}\right)$ & & 0 & $\$ 4.00 / 10^{6} \mathrm{Btu}$ & $\$ 0$ & CDM \\
\hline Lime (t/y) & & 1,510 & $\$ 85 / t$ & $\$ 128$ & CDM \\
\hline Limestone Screenings (t/y) & & 3,020 & $\$ 9 / t$ & $\$ 27$ & CDM \\
\hline Liq. $\mathrm{NH}_{3}(\mathrm{t} / \mathrm{y})$ & & 490 & $\$ 292 / t$ & $\$ 143$ & CDM \\
\hline Carbon (t/y) & & 160 & $\$ 1,000 / t$ & $\$ 160$ & CDM \\
\hline Maintenance-Supplies & $\$ 28,167,000$ & Allowance & $1.5 \%$ of Capital & $\$ 423$ & CDM \\
\hline Maintenance & $\$ 28,167,000$ & Allowance & $3 \%$ of Capital & $\$ 845$ & CDM \\
\hline Insurance & $\$ 28,167,000$ & Allowance & $1 \%$ of Capital & $\$ 282$ & CDM \\
\hline Compliance Testing & & Allowance & & $\$ 300$ & $\mathrm{CDM}$ \\
\hline \multirow[t]{2}{*}{ Residue Landfill } & & 118,300 & $\$ 40 / t$ & $\$ 4,732$ & CDM \\
\hline & & \multicolumn{2}{|c|}{ Total Cost for Combustion Core } & $\$ 9,736$ & \\
\hline Contingency & & \multicolumn{2}{|c|}{$10 \%$ of Combustion Core Cost } & $\$ 974$ & CDM \\
\hline Debt Service & $\$ 87,067,000$ & & $10.19 \%$ of Capital & $\$ 8,872$ & CDM \\
\hline RDF Operations & N/A & $325 \times 10^{3} \mathrm{t} / \mathrm{y}$ & $\$ 8.40 / t$ & $\$ 2,730$ & CDM \\
\hline \multirow[t]{2}{*}{ Electric Gen. Operations. } & N/A & $328 \times 10^{6} \mathrm{Btu} / \mathrm{h}$ & & $\$ 940$ & CDM \\
\hline & & & Total Gross Cost & $\$ 23,251.00$ & \\
\hline \multicolumn{6}{|c|}{ Electrical Revenue } \\
\hline Gross Generation ( MWh/y & $328 \times 10^{6} \mathrm{Btu} / \mathrm{h}$ & 240,000 & & & CDM \\
\hline RDF Power Use (MWh/y) & & $(8,125)$ & & & $\mathrm{CDM}$ \\
\hline Internal Use (MWh/y) & & $(36,000)$ & & & CDM \\
\hline \multirow[t]{4}{*}{ Net to Export (MWh/y) } & & 195,875 & $\$ 0.04 / \mathrm{kWh}$ & $(\$ 7,835)$ & \\
\hline & & & Net Annual Cost & $\$ 15,416$ & \\
\hline & & & $\$ / t$ & $\$ 47.43$ & \\
\hline & & & $\$ / M g$ & $\$ 52.29$ & \\
\hline
\end{tabular}


1.75:1, matching Pedco pilot plant experience with acid gas control. On this basis, the net costs per ton of raw waste are $\$ 60.41 / \mathrm{Mg}(\$ 54,921 / \mathrm{t})$. No credits for recovered materials have been assumed.

\section{Business Aspects}

Pedco Incorporated (Pedco) has headquarters in Cincinnati, Ohio. Originally formed in 1967, Pedco has gone through several stages of organizational growth and subsidiary spin-off since. The present firm was organized in 1984 to pursue, among other interests, the development and commercialization of an innovative solid-fuel combustor. Pedco is an engineering firm with experience in the design, modification, construction, and operation of industrial plants. Following its 1984 reorganization, Pedco concentrated its entire effort on the development and commercialization of its proprietary technology: the Pedco Rotary Cascading Bed Combustion System (RCBC). The RCBC has been granted U.S. Patents 4,583,468 and $4,724,777$; patents for the RCBC technology have also been issued elsewhere.

Pedco operates to supply the technology of RCBC systems based on their proprietary designs. Their responsibility generally focuses on fuel feeding; the rotating device including its internal boiler, air supply, ash recirculation, and other ash management systems; and the overall combustion control system. Their scope of supply includes all applicable process controls and systems for data collection and archiving. The boiler and all other aspects of energy recovery and conversion; air pollution control; the RDF preparation facilities; and the buildings, foundations, roads, and other civil works are normally designed and furnished by others.

As of late 1995, Pedco's address and communications numbers were:

Pedco Incorporated

214 East Ninth Street, 2nd Floor

Cincinnati, Ohio 45202
Tel: (513) 361-8643

Fax: (513) 351-8646

\section{IMPLEMENTATION FEASIBILITY}

The technology offered by Pedco is presently short of confident, commercial availability for MSW management. Other than in a specialized hazardous-waste burning configuration, Pedco has installed only one RCBC furnace/boiler in the U.S. That unit, originally installed at the Hudepohl Brewery in Cincinnati, was subsequently upgraded and relocated to the North American Rayon Corporation plant in Elizabethton, Tennessee. The unit has a capacity of $4550 \mathrm{~kg} / \mathrm{h}(10,000 \mathrm{lb} / \mathrm{h})$ steam and is set up to burn a variety of fuels, including coal and coal-mine wastes, chopped tires, wood wastes, and an RDF fuel. The circumstances of the facility are such that it did not routinely practice 100-percent MSW-derived RDF firing. Pedco's total operating experience with RDF was only about 225 operating hours as of December 1995 . They have explored coal and coal wastes much more thoroughly, with over 3500 operating hours for testing and design, in addition to time burning conventional fuels. Test burns of up to several hours in duration have also been made with a variety of industrial residues; shredded tires; and various solid, liquid, and sludge wastes.

Consequently, there is much to learn about a wide variety of process and operating features and problems in a "real" facility operating under inflexible requirements for process availability, operating costs, energy recovery etc. Thus the Pedco system, while attractive, presents a significant risk to prospective users. There are aspects of the process, such as boiler-tube bundle and internal ash chute plugging/fouling and corrosion/erosion throughout the system where the limited data and lack of sufficient operating experience 
present a prospective owner with considerable uncertainty. The lack of dioxin emissions data introduces another element of process uncertainty. Although the process does not appear to be especially problematic regarding dioxin generation, the high profile of this pollutant and its impact on the time and difficulty of facility permitting make such data omission an impediment to implementation.

The issue of risk is compounded by Pedco's present inability to fully guarantee the successful implementation of an RCBC system. Although this constraint may be relieved if a partner with substantial capital resources is found, it may present a problem to prospective owners.

\section{Process Issues and Problem Areas}

The primary process issue relates to the need for Pedco to develop and adopt a front-end wasteprocessing concept and, ultimately, a hardware system that can produce a 5-cm (2-in.) top-size RDF feed for the RCBC system. Development of an RDF flowsheet should not generally be a problem. However, at almost all RDF facilities, extensive redesign and reconstruction have been needed to bring the RDF processing elements of their system to an acceptable level of reliability and performance.

\section{Operating Issues and Problem Areas}

The primary Pedco need is to relate operating experience in all aspects of RDF burning to the RCBC system. Although the data and experience gathered to date appear to show very basic proof of principle, a firm offering a waste management concept must understand the design and operational issues of:

- Waste receipt

- RDF preparation and storage

- RDF recovery and firing

- Furnace behavior under long-term RDF firing conditions

- Ash characteristics and handling issues

- Associated air pollution control and residue-processing systems.

A few hours' operation of a robust combustor with RDF, however successful, does not constitute an adequate basis for facility design, process and emissions guarantees, air pollution and other permit submissions, and long-term operating contracts.

\section{Remaining Research and Development (R\&D) Needs}

The primary $R \& D$ areas for Pedco include the following:

- Operating time on RDF. The development work to date has focused on the combustion of coal and coal-derived wastes. To gain acceptance of the process for solid-waste applications, there must be a greater level of experience in burning waste, including a more expansive data base on air emissions-especially for dioxins, $\mathrm{CO}$, and acid gases. Additional data are also needed on residue quality, which includes the unburned carbon content in the ash. Data in these areas are needed both to assist in air pollution control concept selection and design and to facilitate permitting. 
- $R C B C$ Performance on $R D F$. The high degree of materials handling within the Pedco combustor and the frequently problematic history of materials handling for solid waste systems suggest that much more operating experience is needed to ensure compatibility of the basic RCBC concept with an RDF feed. Of particular importance are:

- Fouling and plugging of the ash-handling chutes with wire and oversized noncombustibles

- Similar fouling problems for the boiler tube bundle

- Abrasion and corrosion problems.

These problems could result in frequent equipment outages, affecting both plant throughput and electrical revenue, and in high maintenance expense.

- Boiler Development. Experience to date with the cluster of boiler tubes inserted into the RCBC device has been limited to relatively low-pressure saturated steam. To achieve maximum power production, higher pressures and superheated conditions are greatly preferred. Higher skin temperatures on the tubes may affect their erosion and corrosion sensitivity and should be evaluated before commitment to a full-scale facility.

- Other Issues. The working environment of a solid-waste processing facility is very abusive and unfriendly. The material being handled and fired, the flue gases, the slags, the residue, and the plant air itself range from relatively benign to aggressively destructive. The development of a total facility concept that works with the reliability and availability sought by most municipal clients is neither trivial nor easy. There are hundreds of design decisions to be made relative to pumps, fans, vehicle tires, cranes, shredders, etc. Often such design decisions are blocked by the uncertain balance between cost and the desire to install high-quality, rugged, heavy-duty equipment that will confidently overcome the aggressive working environment. With only limited RDF and RDF-firing experience, many of these decisions may be wrong. If, after startup, Pedco's cost for correcting the design is low, the consequences may not be great. If, however, the corrective actions are costly, the consequences could result in economic failure of the project. This risk is borne by the community.

\section{PROCESS DESCRIPTION}

The Pedco RCBC technology has been in use since 1981. In essence, the RCBC was designed to function as a robust, fuel-insensitive solid-fuel combustion system. An underlying marketing assumption by Pedco was that the burner would be mated to a waste-heat boiler serving industrial steam users. Alternatively, the $\mathrm{RCBC}$ burner could discharge into a boiler making superheated steam for electrical generation. As a fuelflexible burner, the RCBC system is intended to burn coals, coal waste, wood, chipped tires, RDF, and a variety of other fuels having the common denominator of low cost. Figure 8.1 is a flowsheet of a typical Pedco steam generation operation.

The RCBC burner comprises a horizontal, cylindrical combustion chamber, as shown in Figure 8.2. A nonrotating bundle of boiler tubes projects into one end of the chamber, cantilevered from external supports. The rotating speed of the chamber is high enough to keep a substantial fraction of the bed material continually airborne, producing an environment similar to that of a fluid bed, but a mechanically fluidized 


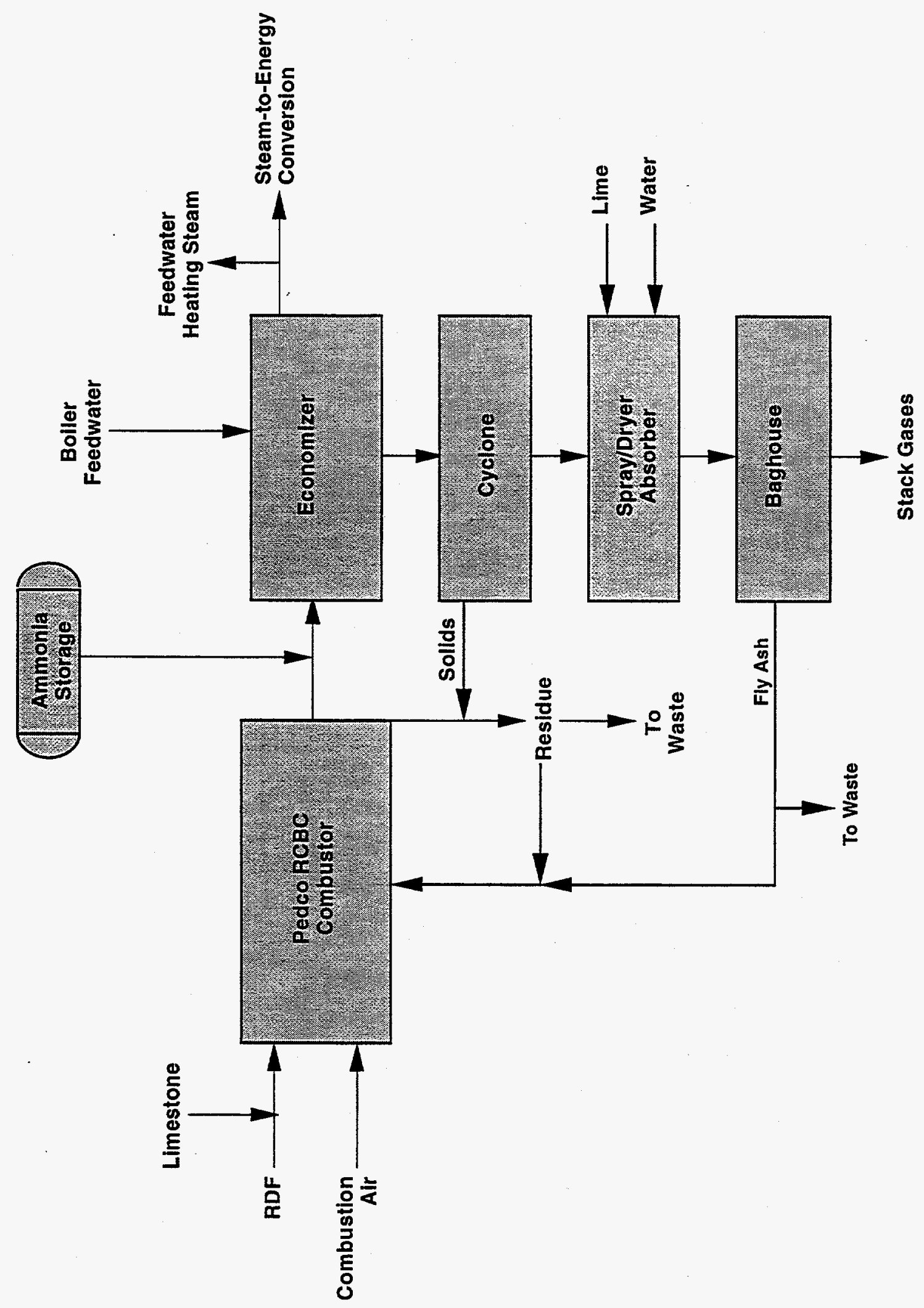

Figure 8-1 


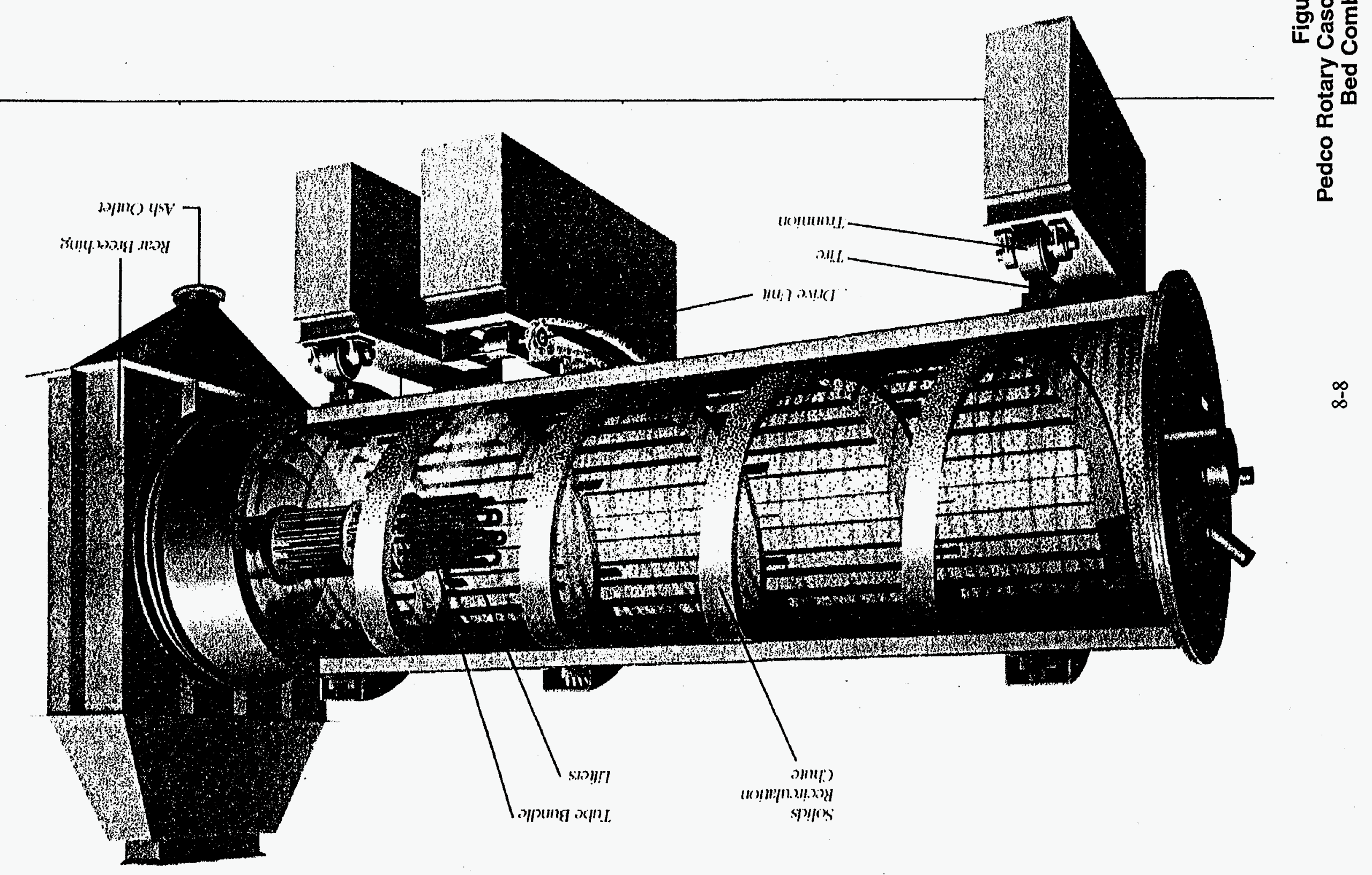


bed. The hot falling solids cascade across the whole diameter so that the boiler tubes are submerged in hot fuel and bed material. The bed material exchanges a portion of its heat to the boiler tubes and is then recycled to the feed end of the combustion chamber at a rate of 40 to 100 times the fuel feed rate. The hot solids recycle preheats and ignites the incoming fuel and the combustion air. This operating concept results in behavior much like a fluid bed-lower average temperatures than are seen in grate-burning systems and a high degree of temperature uniformity.

Pedco continues developing its RCBC technology at the North American Rayon Corporation facility in Elizabethton, Tennessee, in a system generating up to $4.55-\mathrm{Mg} / \mathrm{h}(10,000 \mathrm{lb} / \mathrm{h}) \mathrm{steam}$. The key elements of the system when burning MSW will have to include the RDF preparation system, the intermediate RDF storage system, the RDF reclaiming and feeding system, the RCBC burner and associated boiler, and the air pollution control system.

\section{a. RDF Preparation}

Although fuel preparation facilities are not normally supplied by Pedco, they have proposed an RDF preparation system consisting of a horizontal shaft hammermill or shear shredder-type primary shredding; secondary, hammermill shredding; magnetic separation; air classification; and disc screening of the fines for removal of glass and grit. The RDF feed specifications for the RCBC system may require a 5$\mathrm{cm}$ (2-in.) top size. Additional test data are required to confirm the most acceptable top size.

\section{b. Intermediate RDF Storage and Reclaiming}

Generally, RDF processing facilities are operated only one or two shifts per day. Pedco is proposing to incorporate some kind of intermediate RDF storage as a buffer between RDF preparation and the combustion facility. In some urban locations, the intermediate storage is a covered, live-bottom bin-type system to minimize the opportunity for the processed RDF to compact, knit together, and resist subsequent reclaim. When space permits, a floor dump with reclaim from the top has proved low in cost and reliable.

\section{c. RCBC Burner and Boiler}

The heart of the Pedco process is their RCBC burner and associated boiler. The system is "atmospheric," operating at a pressure only slightly below 1 atma. Limestone can be added to the bed as a means of absorbing $\mathrm{SO}_{2}$ and $\mathrm{HCl}$ from the $\mathrm{RDF}$ or from coal or other "high-sulfur" fuels. The high solids recycle reduces the net unburned carbon losses and maintains the combustion zone temperature to only about 920 to $950^{\circ} \mathrm{C}\left(1600\right.$ to $\left.1650^{\circ} \mathrm{F}\right)$. The RCBC can operate over a wide heat-release range. The "thermal inertia" of the large mass of recirculating ash acts as a thermal flywheel to stabilize bed temperature. Keeping a low mean temperature in the combustion chamber reduces thermal $\mathrm{NO}_{x}$ formation, minimizes the effects of high-temperature corrosion, and protects against bed agglomeration associated with local melting and "stickiness" of the ash particles.

The bed is fitted with a tube bundle cantilevered into the RCBC cavity on the discharge end. Using boiler water, the tube bundle is equipped for forced-flow cooling to maintain bed temperature in the target range. The hot, recirculating ash is an important means for energy transfer, exchanging heat between the combustion process and the boiler tube bundle. At the normal combustion zone temperature, $\mathrm{SO}_{2}$ absorption is at its maximum, and $\mathrm{NO}_{\mathrm{x}}$ generation is minimal. A feature of this temperature profile is that high-sulfur coals (4- to 6-percent sulfur) can be handled by the RCBC system without appreciable $\mathrm{SO}_{2}$ emissions. The RCBC operates at from 100- to 120-percent excess air in refuse service, with typical RDF 
heat content and in-bed tubes for temperature control. This operation compares with the 90 - to 110-percent excess air typical of mass-burning units.

In the $2.27-\mathrm{Mg} / \mathrm{h}(5000 \mathrm{lb} / \mathrm{h})$ burner used at the Hudepohl Brewing Company, the system characteristics were:

$\begin{array}{lll}\text { - Internal Diameter } & 1.66 \mathrm{~m}(5.5 \mathrm{ft}) \\ \text { - } & \text { Length (Overall) } & 7.57 \mathrm{~m}(25 . \mathrm{ft}) \\ \text { - } & \text { Maximum Temperature } & 950^{\circ} \mathrm{C}\left(1650^{\circ} \mathrm{F}\right) \\ \text { - } & \text { Rotation (maximum) } & 16(23) \mathrm{rpm} \\ \text { - } & \text { Heat-Transfer Area } & 34.5 \mathrm{~m}^{2}\left(375 \mathrm{ft}^{2}\right) \\ \text { - Steam Pressure } & 1 \mathrm{MPa}\left(150 \mathrm{lb} / \mathrm{in}^{2}\right) \\ \text { - } & \mathrm{SO}_{2} \text { Control } & 90 \mathrm{percent}(\mathrm{at} \mathrm{Ca:S} \text { ratio of } 1.2 \text { for coals }) \\ \text { - } & \text { Particulate Control Fabric } \\ & \text { Filter }\end{array}$

Unlike the $1100^{\circ} \mathrm{C}\left(2000^{\circ} \mathrm{F}\right)$ combustion temperatures found in the diffusion flame above the bed in conventional mass-burn systems, $\mathrm{RCBC}$ bed combustion temperatures are relatively low. At these temperatures, furnace absorption of $\mathrm{SO}_{2}$ and $\mathrm{HCl}$ is effective, and thermal $\mathrm{NO}_{x}$ generation is low.

One of the most important and proprietary features of the Pedco RCBC design is the bed ash management system. The system allows bed media to flow through a spiral chute buried in the refractory kiln liner and laid inside the outer shell. The solid bed material is collected by gravity as it flows into the chute at the discharge end of the chamber and is "pumped" by the kiln rotation to the feed end.

\section{d. Air Pollution Control}

In addition to the acid gas control achieved through in-bed lime addition, Pedco proposes to equip the combustion train with fabric filters for particulate reduction. Because of the low working temperatures, $\mathrm{NO}_{\mathrm{x}}$ control may not be required. Carbon injection downstream of the boiler economizer can be provided for mercury control, although there is no operating experience available at Pedco to characterize the likely performance. Pedco could supply a conventional spray/ dryer absorber and fabric filter combination when there is a need for enhanced acid-gas and condensible-vapor removal.

\section{e. Typical Plant Configurations and Performance}

Pedco prefers to provide their RCBC system as a factory-assembled RCBC burner with a wasteheat boiler configuration sized to make shipping by truck or rail feasible. The design heat-release rate of the prospective Pedco "catalogue" RCBC system is approximately $233,000 \mathrm{MJ} / \mathrm{h}\left(100 \times 10^{6} \mathrm{Btu} / \mathrm{h}\right)$, corresponding to daily RDF rates of $168 \mathrm{Mg} / \mathrm{d}(185 \mathrm{t} / \mathrm{d})$. Air pollution control efforts, beyond the addition of low-cost, coarse limestone screenings to the bed for acid gas control, would normally involve a fabric filter unit. Pedco believes that their in-bed limestone addition and consequent acid gas absorption eliminates the necessity for the spray/dryer absorber used in many mass-burn plants. However, there is a lack of data in refuse applications and the needed function of the spray dryer (with carbon addition). In order to cool the 
gases and achieve acceptable dioxin and mercury removal, a spray dryer unit servicing two Pedco furnaces has been incorporated into the flowsheets and economic analyses in this report.

\section{E. ENVIRONMENTAL ASPECTS}

\section{Process Emissions Characteristics (Air, Water, Solids)}

\section{a. Air Emissions}

Data are available from the $\mathrm{RDF}$ tests for $\mathrm{SO}_{2}, \mathrm{NO}_{\mathrm{x}}$ opacity (continuous), and $\mathrm{CO}$. No particulate or dioxin data were taken during these runs. The data in Table 8.3 describe tests during which RDF from three different sources was burned. In all cases, limestone was added for a portion of the test period to control $\mathrm{SO}_{2}$ and $\mathrm{HCl}$. The $\mathrm{HCl}$ stack emissions data are very limited. The project team reviewed only one set of data from three tests that used EPA Method 25. When burning the semidensified RDF from the Robertson County Recycling Center in Tennessee, the $\mathrm{HCl}$ concentration was reported to be less than 20 $\mu \mathrm{g} / \mathrm{ft}^{3}$.

\section{b. Wastewater Emissions}

Other than boiler and cooling tower blowdown streams, there are no wastewater streams from the Pedco process.

\section{c. Residue Characteristics}

Table 8.4 shows Toxicity Characteristics Leaching Procedure (TCLP) data for heavy metals in the Pedco fly ash. The tests were conducted by the Tennessee Technological University Water Center Laboratory in support of the Pedco semiworks testing program. These results would suggest that, for the waste material burned in the test, the ash does not trigger the metal limits corresponding to a "hazardous waste." Without additional data, it is impossible to extend this conclusion to ashes from other waste sources.

\section{Potential for Regulatory Compliance}

As described in the previous section on general process implementation, the Pedco system has only limited emissions and ash characteristics data. These data have been taken in the course of relatively short operating runs with RDF feeds. This limited data base can be expected to present some problems in preparing and defending permit submissions.

Ash inlet loading can be expected to be high, but not higher than fluid bed systems with very high particulate concentrations at the furnace outlet and those that meet code requirements. Acid gas control is, to a degree, effected by limestone addition to the bed. However, more data are needed to be confident that the regulatory limits can be met by this approach (without secondary control devices). $\mathrm{NO}_{\mathrm{x}}$ is especially low for the Pedco RCBC. CO emissions patterns are not well characterized in Pedco's limited test data base for RDF combustion. Often, significant emissions of $\mathrm{CO}$ are observed; excursions of several thousand ppm, lasting several minutes, have been routinely observed. 
Table 8.3 Measured Air Emissions from Pedco System

\begin{tabular}{|c|c|l|l|}
\hline \multirow{2}{*}{ Pollutant } & \multicolumn{3}{|c|}{ Measured Emissions Rate $\left(\mathbf{l b} / 10^{6} \mathrm{Btu}\right)$} \\
\cline { 2 - 4 } & Test T-11 & Test T-16 & Test T-22 \\
\hline \hline Limestone Ca/S Ratio & $3.7-4.3$ & 2.35 & None added \\
\hline $\mathrm{SO}_{2}$ & $0.07-0.98$ & $0.08-0.71$ & $0.02-0.03$ \\
\hline $\mathrm{NO}_{x}$ & $0.02-0.12$ & $0.05-0.08$ & $0.06-0.10$ \\
\hline $\mathrm{CO}$ & $0.10-0.12$ & $0.42-0.66$ & $0.22-1.09$ \\
\hline
\end{tabular}

Table 8.4 Measured TCLP Leaching Data (mg/l) for Pedco Fly Ash

\begin{tabular}{||l|c|c|c||}
\hline Metal & $\begin{array}{c}\text { Measured Value } \\
\text { Test T-11 }\end{array}$ & $\begin{array}{c}\text { Measured Value } \\
\text { Test T-16 }\end{array}$ & Regulatory Limit \\
\hline \hline Arsenic & 0.007 & $<0.005$ & 5.0 \\
\hline Barium & 0.367 & 1.970 & 100.0 \\
\hline Cadmium & $<0.005$ & $<0.005$ & 1.0 \\
\hline Chromium & $<0.005$ & $<0.005$ & 5.0 \\
\hline Lead & 0.010 & $<0.005$ & 5.0 \\
\hline Mercury & $<0.001$ & $<0.001$ & 0.2 \\
\hline Selenium & $<0.005$ & $<0.005$ & 1.0 \\
\hline Silver & $<0.005$ & $<0.005$ & 5.0 \\
\hline pH, Lab & 11.7 & 12.3 & N/A \\
\hline
\end{tabular}


Emissions of dioxins and other organic species are uncertain. No emissions data for this pollutant sector are available. The low combustion temperature in the RCBC and the high degree of ash/carbon carryover would suggest that the uncontrolled emissions rates of these pollutants may be high. Current analysis of the dioxin emissions problem has suggested that dioxins are formed through chlorination reactions on graphitic carbon in fly ash. Data from Pedco show from 2.9- to 7.7-percent carbon in the ash. This result suggests that the potential for high dioxin formation exists. At present, however, there are no experimental data to either confirm or refute this hypothesis.

\section{F. FLOWSHEET}

\section{Heat and Material Balances}

Figure 8.3 presents the process flowsheet for a single Pedco furnace system burning $167 \mathrm{Mg} / \mathrm{d}(184 \mathrm{t} / \mathrm{d})$ RDF. This rate would correspond to a plant receiving approximately $240 \mathrm{Mg} / \mathrm{d}(262 \mathrm{t} / \mathrm{d}) \mathrm{raw}$ waste. Material balances for this Pedco system are shown in Tables $8.5 \mathrm{a}$ and $8.5 \mathrm{~b}$, in metric and English units respectively. The balances represent the system from the feed system of prepared waste through the combustor, heatrecovery boiler, and air pollution control system to the steam header shown in Figure 8.3.

\section{End Product (Fuel type and Characteristics)}

The Pedco RCBC boiler system generates steam for process or electrical generation. Units can be constructed to generate either saturated or superheated steam.

\section{Proposed Interface With Other Processes (Boiler, Methanol Plant, etc.)}

The Pedco burner system is designed to be connected to a waste-heat boiler for the generation of steam. Although Pedco foresees opportunities in the application of their combustor to the supply of steam for industrial operations, electrical generation (a 100-percent reliable energy market) was assumed for the purposes of the NREL assignment.

\section{G. DEVELOPMENT HISTORY}

\section{Laboratory/Bench Studies}

The early work with the RCBC began in 1981 . This initial phase of development involved use of a small incinerator to evaluate basic RCBC principles and, importantly, to collect data on the capture of sulfur dioxide and hydrochloric acid by adding limestone to the bed. The latter characteristic is particularly important if low-cost high-sulfur coals are used either as a supplemental fuel or as the main fuel in an industrial steam-raising operation. 


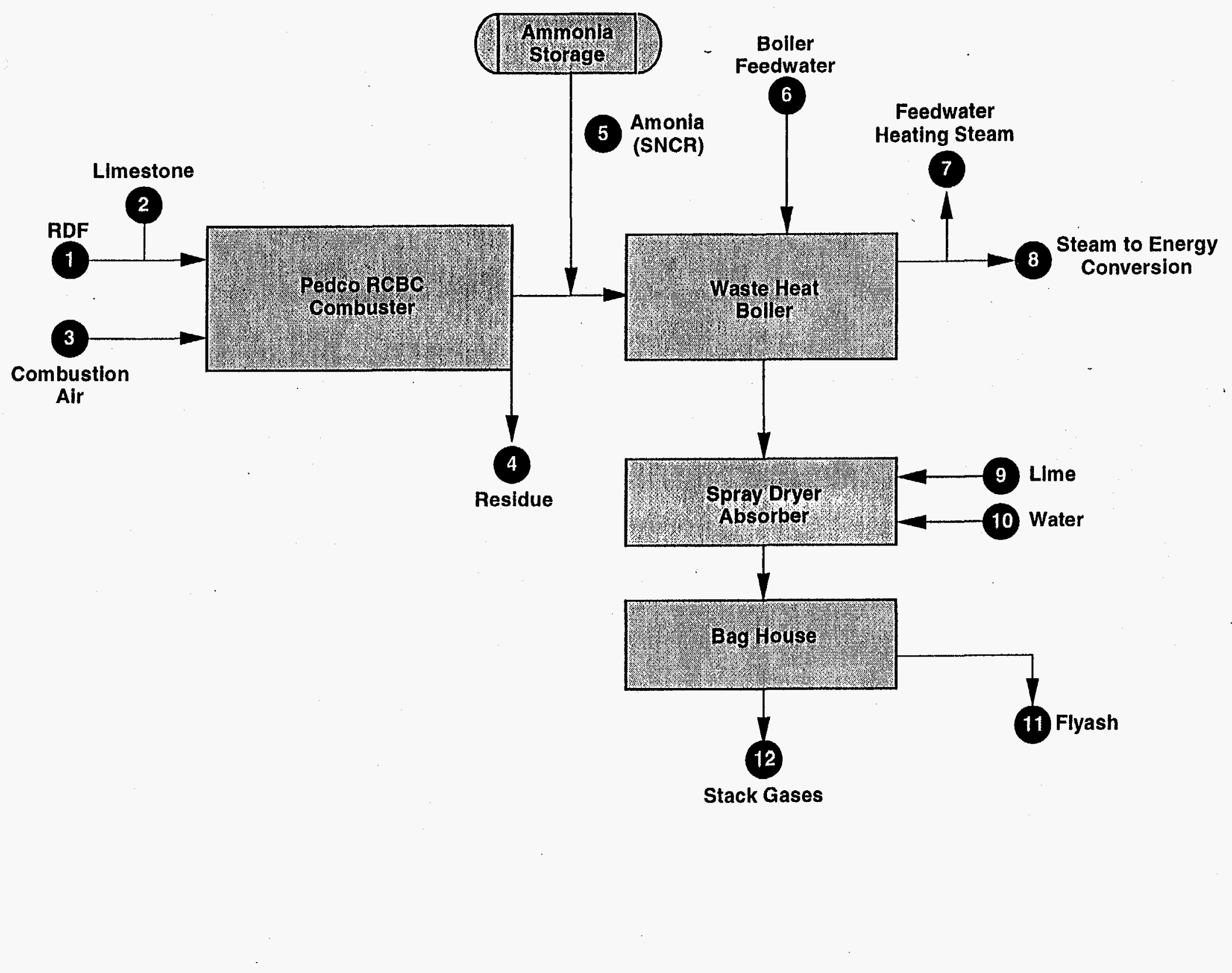

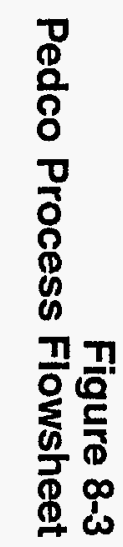


Table 8.5a Material Balance for Pedco Furnace (Metric Units)

\begin{tabular}{|c|c|c|c|}
\hline Location & Material & Characteristics & Mass Rate $(\mathrm{kg} / \mathrm{h}$ \\
\hline 1 & RDF & $\begin{array}{c}\text { Proximate Analysis: } 83.55 \% \text { Combustibles } \\
9.12 \% \text { Ash } \\
7.33 \% \text { Moisture } \\
7.47 \mathrm{MJ} / \mathrm{kg} \text { (dry basis) }\end{array}$ & 6,955 \\
\hline 2 & $\begin{array}{l}\text { Limestone } \\
\text { Screenings }\end{array}$ & $100 \% \mathrm{CaCO}_{3}$ & 64 \\
\hline 3 & Combustion Air & $15^{\circ} \mathrm{C}$ & 74,350 \\
\hline 4 & Residue & Dry weight & 635 \\
\hline 5 & Ammonia & Anhydrous & 13 \\
\hline 6 & Feedwater & $115.5^{\circ} \mathrm{C}$ (saturated) & 27,325 \\
\hline 7 & $\begin{array}{l}\text { Feedwater } \\
\text { Heating Steam }\end{array}$ & $5.86 \mathrm{MPa} / 440^{\circ} \mathrm{C}$ & 880 \\
\hline 8 & Product Steam & $5.86 \mathrm{MPa} / 440^{\circ} \mathrm{C}$ & 26,440 \\
\hline 9 & Lime & $90 \% \mathrm{CaO}$ & 32 \\
\hline 10 & Water & Approximately $5 \%$ solids in feed slurry & 1,225 \\
\hline 11 & Fly Ash & $\begin{array}{l}\text { Dry weight } \\
\text { Estimated as } 10 \% \text { of input ash + limestone, } \\
\text { lime etc. }\end{array}$ & 73 \\
\hline 12 & Stack Gas & $\begin{array}{l}143^{\circ} \mathrm{C} \\
1396 \mathrm{Nm}^{3}\end{array}$ & 83,115 \\
\hline
\end{tabular}


Table 8.5b Material Balance for Pedco Furnace (English Units)

\begin{tabular}{|c|c|c|c|}
\hline Location & Material & Characteristics & Mass Rate (lb/h) \\
\hline 1 & RDF & $\begin{array}{c}\text { Proximate Analysis: } 83.55 \% \text { Combustible } \\
9.12 \% \text { Ash } \\
7.33 \% \text { Moisture } \\
7,081 \text { Btu/lb (dry basis) }\end{array}$ & 15,300 \\
\hline 2 & $\begin{array}{l}\text { Limestone } \\
\text { Screenings }\end{array}$ & $100 \% \mathrm{CaCO}_{3}$ & 142 \\
\hline 3 & Combustion Air & $60^{\circ} \mathrm{F}$ & 163,569 \\
\hline 4 & Residue & Dry weight & 1,397 \\
\hline 5 & Ammonia & Anhydrous & 28 \\
\hline 6 & Feedwater & $240^{\circ} \mathrm{F}$ (saturated) & 60,114 \\
\hline 7 & $\begin{array}{l}\text { Feedwater } \\
\text { Heating Steam }\end{array}$ & $850 \mathrm{lb} / \mathrm{in}^{2} / 825^{\circ} \mathrm{F}$ & 1,935 \\
\hline 8 & Product Steam & $850 \mathrm{lb} / \mathrm{in}^{2} / 825^{\circ} \mathrm{F}$ & 58,178 \\
\hline 9 & Lime & $90 \% \mathrm{CaO}$ & 71 \\
\hline 10 & Water & Approximately $2.6 \%$ solids in feed slurry & 2,695 \\
\hline 11 & Fly Ash & $\begin{array}{l}\text { Dry. weight } \\
\text { Estimated as } 10 \% \text { of input ash + } \\
\text { limestone, lime etc. }\end{array}$ & 160 \\
\hline 12 & Stack Gas & $\begin{array}{l}290^{\circ} \mathrm{F} \\
58,970 \mathrm{ft}^{3} \text { (actual) }\end{array}$ & 182,850 \\
\hline
\end{tabular}




\section{Pilot Plant Studies}

The second phase of work began in 1985, when the Ohio Coal Development Office executed a cooperative grant with Pedco for the design, fabrication, installation, and testing of an RCBC combustor/boiler sized to generate $2.27 \mathrm{Mg} / \mathrm{h}(5000 \mathrm{lb} / \mathrm{h})$ of $1 \mathrm{MPa}\left(150 \mathrm{lb} / \mathrm{in}^{2}\right)$ steam. The system was located at the Hudepohl Brewing Company in Cincinnati, Ohio. The primary function of the boiler was the generation of process steam for use in the brewery. Thus the RCBC, operated by the regular Hudepohl boiler operators, functioned as a working boiler. It was serviced by the regular maintenance staff.

Hudepohl gave Pedco the freedom to burn test fuels, modify the system, and otherwise to explore the capabilities of the unit. Over the operating period from June 1986 through 1988, Pedco tested the unit with a wide variety of alternative fuels - alternative coals, wood waste, anthracite culm, shredded tires, and RDF, for example-although coal was the primary fuel. Over the period the unit was operated about 1400 hours.

The generally high level of success of the pilot testing led to the design and construction of a specialized RCBC system for burning hazardous wastes. The system has been operating since 1988 . The unit is located in Texas and burns a variety of waste streams. The hazardous waste incineration unit is unique in both operating character and feed but, to the knowledge of the Pedco developers, is still in operation and is reported to have presented few operating problems.

\section{Semiworks Plant Studies}

When Hudepohl was acquired and their operations terminated, Pedco made arrangements to upgrade and relocate the boiler to the North American Rayon Corporation plant in Elizabethton, Tennessee. The upgrades increased the steam generation capacity of the system to $4.55 \mathrm{Mg} / \mathrm{h}(10,000 \mathrm{lb} / \mathrm{h})$ and added a superheater with steam temperatures to $271^{\circ} \mathrm{C}\left(520^{\circ} \mathrm{F}\right)$. The physical dimensions of the combustor were unchanged, although the heat-transfer area was enlarged from 34.5 to $45.8 \mathrm{~m}^{2}$ ( 376 to $500 \mathrm{ft}^{2}$ ) and the mean rotational speed was increased to $18 \mathrm{rpm}$. Once operational at North American Rayon, Pedco ran the facility from December 1990 through January 1992. They evaluated combustion and air emissions for several fuels; of importance was the RDF generated in the region. However, only about 160 hours of RDF operation were logged.

The series of tests showed the ability of the RCBC to burn a wide variety of wastes. The tests were of limited duration for any one fuel and in total; but within the test period, zero to very small degrees of erosion, corrosion, bed defluidization, or other problems were observed. Although the results were encouraging, longterm operation extending over several years and much more data on equipment performance may be needed to demonstrate, convincingly, that no problems exist that threaten the underlying technical acceptability of the process.

Pedco is attempting to secure financial support for a project to extend the development at the North American Rayon plant to include a facility with two, $27.3-\mathrm{Mg} / \mathrm{h}(60,000-\mathrm{lb} / \mathrm{h}) \mathrm{RCBC}$ boilers. Boiler No. 1 would routinely be fired with RDF from Johnson City and Washington County, Tennessee. Boiler No. 2 would normally burn coal and other fossil- and waste-derived fuels. It would be equipped with RDF feeding systems, offering availability as a backup to Boiler No. 1. Pedco envisions that these boilers will have an

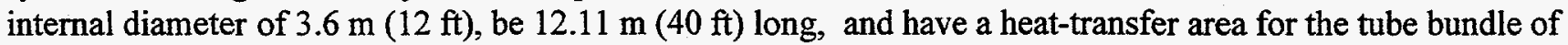
$220 \mathrm{~m}^{2}\left(2400 \mathrm{ft}^{2}\right)$. The rotation rate is expected to be $12 \mathrm{rpm}$. The steam pressure/temperature would be $5.86 \mathrm{MPa}\left(850 \mathrm{lb} / \mathrm{in}^{2}\right) / 440^{\circ} \mathrm{C}\left(825^{\circ} \mathrm{F}\right)$ to integrate with the North American Rayon steam system. 


\section{Current Status}

Pedco claims that their testing program has adequately evaluated the major technical issues affecting the basic technical feasibility of their RCBC process. This may be true. However, the credibility of their process concept for MSW applications would be greatly enhanced if data were available from extended operating campaigns, where corrosion, erosion, plugging, wear, unexpected events, and other real-world process stresses had the opportunity to emerge and show their effects. The impact of such stresses can be significant. Untoward consequences can adversely affect on-time availability; increase maintenance expense and frequency; decrease power generation reliability, affecting the price that can be charged for the energy product; and engender other effects that erode the utility of the technology.

One can have confidence that these problem areas will be acceptable to an owner or will be tractable to modest engineering improvements or operating "work-arounds." However, the prospective owner of a new process that has had very limited operating experience must recognize that there is a risk that the process will fail to achieve its full potential. Total failure is unlikely, but additional capital investment for equipment modifications, higher maintenance costs, etc. may erode the economic and operational benefits that were expected.

\section{H. INTERVIEWS}

In the course of evaluating the Pedco technology, CDM engineers visited the Pedco Incorporated engineering offices in Cincinnati, Ohio. Those interviewed were:

- Mr. Gene McCracken, President

a Mr. William H. Long, Vice President

- Mr. Leland M. Reed, Ph.D., Vice President 


\section{Section 9}

\section{ThermoChem}

\section{A. SUMMARY}

The Manufacturing and Technology Conversion International, Inc. (MTCI) Steam Reforming Process is an indirectly heated fluidized bed reactor using steam as the fluidizing medium. Under license from MTCI, ThermoChem, Inc. (TC) has the exclusive rights to apply its PulseEnhanced ${ }^{\mathrm{TM}}$ heater and steam-reforming technology to a variety of applications. These applications include industrial and municipal wastes and sludges-paper mill rejects, agricultural wastes, and refuse-derived fuels (RDF) and biomass fuels. The result is a clean, hydrogen-rich medium-heating-value, 13.9 to $16.7 \mathrm{MJ} / \mathrm{Nm}^{3}\left(374\right.$ to $448 \mathrm{Btu} / \mathrm{st}^{3}$ ) gas. PulseEnhanced ${ }^{\mathrm{TM}}$ indirect heating combined with a fluid bed and steam reforming provides a process for converting organics to fuel gas while separating the inorganics without oxidation or melting. The heart of the process is the Pulsed Enhanced ${ }^{\mathrm{TM}}$ heater, which is immersed in the fluidized bed. This pulsed heater, with unique aerovalves, generates an oscillating flow in a bundle of heat-transfer tubes that pass through the fluidized bed gasifier. The pulsed combustion phenomenon results in turbulent mixing and significantly enhanced heat transfer between the gases in the tube and the RDF. Part of the product gas is used in the pulsed heater as the energy source. The exhaust from the heater never enters the fluid-bed steam reformer and does not dilute the product gas. The organic waste fed to the fluid-bed steam reformer reacts solely with the steam in a reducing atmosphere, producing the fuel gas.

Based on $6.8-\mathrm{kg} / \mathrm{h}(15-\mathrm{lb} / \mathrm{h})$ pilot plant tests, the TC Process emits gaseous emissions from the combustor that are likely to comply with EPA's New Source Performance Standards (NSPS) for municipal waste combustors (MWCs). Using a gas cleanup system, the fuel gas is cleaned of acid gases that might be generated from impurities in the feed. The mineral matter contained in the feed collects in the fluid bed and drains from the bed. The residue meets EPA leachability criteria for landfill disposal as a nonhazardous waste. Wastewater contains only trace amounts of organic materials. Test data showed high steam-to-biomass ratios, especially with Municipal Solid Waste (MSW.) and RDF. A wide range of materials has been tested in the pilot system.

MTCI's development efforts were started in 1984. Experimental data have been generated from different scales of reactors [ 9.1 to $2722 \mathrm{~kg} / \mathrm{h}(20$ to $6,000 \mathrm{lb} / \mathrm{h})$ ] using various biomass and waste feedstocks. In 1990 tests were conducted in an 20.32-cm (8-in.) reactor using RDF as the feed material at a throughput of $6.8 \mathrm{~kg} / \mathrm{h}(15 \mathrm{lb} / \mathrm{h}) .{ }^{1,2}$ In 1991 and 1992 , a $13.6-\mathrm{Mg} / \mathrm{d}(15-\mathrm{t} / \mathrm{d})$ demonstration unit was operated using rejects from a cardboard recycle paper mill in Ontario, California. This same unit, relocated to TC's test facility in Baltimore, has since processed coal, wood chips, and straw., 2

At a pulp mill in New Bern, North Carolina, MTCI and TC have built a five-heater fluid-bed steam reformer that can process $109 \mathrm{Mg} / \mathrm{d}(120 \mathrm{t} / \mathrm{d})$ black liquor. A unit of similar size has been built in India to process organic solids from several food industries. Under the DOE Clean Coal Technology Program, TC received an an award for a $454-\mathrm{Mg} / \mathrm{d}(500-\mathrm{t} / \mathrm{d})$ coal gasifier or $871-\mathrm{Mg} / \mathrm{d}(960-\mathrm{t} / \mathrm{d})$ char production facility. Plans for a commercial plant to handle up to $528-\mathrm{Mg} / \mathrm{d}(655-\mathrm{t} / \mathrm{d}) \mathrm{RDF}$ at a landfill site in South Carolina have reached the design stage. ${ }^{3}$ 


\section{B. FINANCIAL AND BUSINESS ASPECTS}

\section{Projected Capital and Operating Costs}

In a recent engineering study, TC developed several cases for an RDF gasifier and applied them to five options for energy recovery. The gasifier cases were for $227-$ and $595-\mathrm{Mg} / \mathrm{d}(250-$ and $655-\mathrm{t} / \mathrm{d}) \mathrm{RDF}$ facilities; 300- and 726-Mg/d (330- and 800-t/d) MSW equivalents were based on TC's waste. The major components for the steam reformer consisted of:

- Fluidized bed reformer, including pulsed heaters to supply the heat required to dry the RDF

- Waste-heat recovery steam generator in the product gas stream to generate steam for fluidization

- Feedstock dryer using heat recovered from the product gas

- Quench system to cool the gas and remove entrained particulates

- Char handling system

- Steam superheater and an air heater installed on the pulse combustor flue gas

The dryer and air heater were not used in all configurations. Cases $1 \mathrm{~A}, 1 \mathrm{~B}, 2 \mathrm{~A}$, and $2 \mathrm{~B}$ of the ThermoChem study were based on a steam reformer operated at $816^{\circ} \mathrm{C}\left(1500^{\circ} \mathrm{F}\right)$ and processing $227 \mathrm{Mg} / \mathrm{d}$ $(250 \mathrm{t} / \mathrm{d})$ wet $\mathrm{RDF}$. At $649^{\circ} \mathrm{C}\left(1200^{\circ} \mathrm{F}\right)$, these reformers can process $595-\mathrm{Mg} / \mathrm{d}(655-\mathrm{t} / \mathrm{d})$ wet $\mathrm{RDF}$. Cases $3 \mathrm{~A}$ and $3 \mathrm{~B}$ were based on processing $595 \mathrm{Mg} / \mathrm{d}(655 \mathrm{t} / \mathrm{d})$ at $816^{\circ} \mathrm{C}\left(1500^{\circ} \mathrm{F}\right)$. The Cases denoted " $\mathrm{A}$ " did not include a feed dryer or an air heater and, as a consequence, showed a lower cold-gas efficiency-54 percent vs. 65 percent of the RDF heat content appeared as fuel value in the product gas. The cold-gas efficiency is higher for the " $\mathrm{B}$ " Cases, where a feed dryer and air heater are used. The overall thermal efficiency is over 78 percent for the " $A$ " Cases and about 87 percent for the "B" Cases. Associated plant capital and operating costs are given on pp. 45 through 57 of a K \& M report. ${ }^{3}$

The reformer that included the dryer and air heater that processes $595 \mathrm{Mg} / \mathrm{d}(655 \mathrm{t} / \mathrm{d})$ at $816^{\circ} \mathrm{C}$ $\left(1500^{\circ} \mathrm{F}\right)$ processes 2.6 times the RDF as the lower-temperature, $649^{\circ} \mathrm{C}\left(1200^{\circ} \mathrm{F}\right)$ unit, and with a capital cost only about 40 percent greater. The costs for the dryer and air preheater are offset by decreased pulse heater costs. Cases $3 \mathrm{~A}$ and $3 \mathrm{~B}$, the high-temperature, high-throughput $[595 \mathrm{Mg} / \mathrm{d}$ $(655 \mathrm{t} / \mathrm{d})]$ scenarios at about $\$ 15.5$ million, would cost about 35 percent more than the low-temperature, high-throughput case and about 90 percent more than the $231-\mathrm{Mg} / \mathrm{d}(255-\mathrm{t} / \mathrm{d})$ high-temperature case.

The operating and maintenance costs are estimated to be $\$ 21.25 / \mathrm{Mg}(\$ 19.32 / \mathrm{t}) \mathrm{RDF}$ for Cases $1 \mathrm{~A}$ and $1 \mathrm{~B}, \$ 10.95 / \mathrm{Mg}(\$ 9.95 / \mathrm{t})$ for Cases $2 \mathrm{~A}$ and $2 \mathrm{~B}$, and $\$ 10.01 / \mathrm{Mg}(\$ 9.10 / \mathrm{t})$ for Cases $3 \mathrm{~A}$ and $3 \mathrm{~B}$. Additional analyses were made for revenue from product gas alone at various gas prices. The cost analyses were also applied to various energy-recovery options. ${ }^{3}$

For this study, the project costing protocols described previously were applied. The throughput used was the same as in a recent TC study-479-Mg/d (528-t/d) dry RDF [595-Mg/d (655-t/d) wet RDF or 849$\mathrm{Mg} / \mathrm{d}(935-\mathrm{t} / \mathrm{d}) \mathrm{MSW}$-for a combined-cycle gas turbine. A gasifier temperature of $816^{\circ} \mathrm{C}\left(1500^{\circ} \mathrm{F}\right)$ with a duty of $264,000 \mathrm{MJ} / \mathrm{h}\left(250 \times 10^{6} \mathrm{Btu} / \mathrm{h}\right)$ was assumed. The capital costs are shown in Table 9.1. Operating costs are shown in Table 9.2. 
Table 9.1 Capital Cost: ThermoChem Steam Reforming Processing System

\begin{tabular}{|c|c|c|c|}
\hline System: & \multicolumn{3}{|c|}{$\begin{array}{l}849 \mathrm{Mg} / \mathrm{d}(935 \mathrm{t} / \mathrm{d}) \\
595 \mathrm{Mg} / \mathrm{d}(655 \mathrm{t} / \mathrm{d}) \mathrm{RDF} \\
\text { Bubbling Fluid Bed Furnace Indirectly Heated by Using } \\
\text { Steam as the Fluidizing Medium } \\
\text { PulseEnhanced } \\
\text { TM Heater }\end{array}$} \\
\hline Air Pollution Control (APC): & \multicolumn{3}{|l|}{ Wet Scrubber } \\
\hline $\begin{array}{l}\text { Facility Capital Investment: } \\
\text { Fuel Preparation: } \\
\text { Process/Heat Recovery/APC } \\
\text { Train } \\
\text { Equipment (Installed) } \\
\text { CEM System } \\
\text { Process Core Cost } \\
\text { Engineering \& Contingency } \\
\text { (30\% of Process Core) } \\
\text { Subtotal } \\
\text { Electrical Generation (Steam } \\
\text { Turbine) } \\
\text { Total }\end{array}$ & $\begin{array}{r}\$ 15,141,000 \\
1,000,000 \\
\$ 16,141,000\end{array}$ & $\$ 37,000,000$ & $\begin{array}{l}\text { Source } \\
\text { CDM } \\
\text { Developer } \\
\text { CDM } \\
\text { CDM }\end{array}$ \\
\hline & & $\begin{array}{l}\mathrm{Mg} / \mathrm{d} \text { MSW: } \\
\mathrm{Vd} \text { MSW: }\end{array}$ & $\begin{array}{l}\$ 108,000 \\
\$ 98,100\end{array}$ \\
\hline
\end{tabular}


Table 9.2 Operating Costs for ThermoChem

\begin{tabular}{|c|c|c|c|c|c|}
\hline Cost Element & No./Shift & Basis & Unit Cost & $\begin{array}{c}\text { Annual Cost } \\
(000)\end{array}$ & Source \\
\hline \multicolumn{6}{|l|}{ Labor } \\
\hline Superintendent & - & 1 & $\$ 45.00 / \mathrm{h}$ & $\$ 99$ & CDM \\
\hline Operator (Op.) & 1 & 4 & $\$ 32.00 / \mathrm{h}$ & $\$ 280$ & CDM \\
\hline Auxiliary Op. & 1 & 4 & $\$ 30.00 / \mathrm{h}$ & $\$ 263$ & CDM \\
\hline Feed System Op. & 1 & 4 & $\$ 30.00 / \mathrm{h}$ & $\$ 263$ & CDM \\
\hline Plant Attendant & 1 & 4 & $\$ 25.00 / \mathrm{h}$ & $\$ 219$ & CDM \\
\hline Elect./Inst Maintenance & 1 & 3 & $\$ 35.00 / \mathrm{h}$ & $\$ 230$ & CDM \\
\hline Mechanical Maintenance & 1 & 3 & $\$ 35.00 / \mathrm{h}$ & $\$ 230$ & CDM \\
\hline Maint.- Supplies & & Allowance & & $\$ 52$ & Developer \\
\hline Maintenance & $\$ 20,983$ & Allowance & $3 \%$ of Capital & $\$ 629$ & CDM \\
\hline Insurance & $\$ 20,983$ & Allowance & $1 \%$ of Capital & $\$ 210$ & CDM \\
\hline Compliance Testing & & Allowance & & $\$ 300$ & CDM \\
\hline \multirow[t]{2}{*}{ Residue Landfill } & & 110,077 & $\$ 40 / t$ & $\$ 4,403$ & CDM \\
\hline & & \multicolumn{2}{|c|}{ Total Cost for Process Core } & $\$ 7,079$ & \\
\hline Contingency & & \multicolumn{2}{|c|}{$10 \%$ of Process Core Cost } & $\$ 708$ & CDM \\
\hline Debt Service & $\$ 91,733$ & & $10.19 \%$ of Capital & $\$ 9,348$ & CDM \\
\hline RDF Operations & NA & $290 \times 10^{3}$ ty & $\$ 8.50 / t$ & $\$ 2,465$ & CDM \\
\hline \multirow[t]{2}{*}{ Electric Gen. Operations. } & N/A & $264 \times 10^{6} \mathrm{Btu} / \mathrm{h}$ & & $\$ 1,750$ & CDM \\
\hline & & & Total Gross Cost & $\$ 21,350$ & \\
\hline \multicolumn{6}{|c|}{ Electrical Revenue } \\
\hline Gross Generation (MWh/y) & $264 \times 10^{6} \mathrm{Btu} / \mathrm{h}$ & 275,500 & & & CDM \\
\hline RDF Power Use (MWh/y) & & $(7,250)$ & & & CDM \\
\hline Internal Use (MWh/y) & & $(27,550)$ & & & \\
\hline \multirow[t]{4}{*}{ Net to Export (MWh/y) } & & 240,700 & $\$ 0.04 / \mathrm{kWh}$ & $(\$ 9,628)$ & \\
\hline & & & Net Annual Cost & $\$ 11,722$ & \\
\hline & & & Unit Cost $\$ / t$ & $\$ 40.42$ & \\
\hline & & & Unit Cost $\$ / M g$ & $\$ 44.50$ & \\
\hline
\end{tabular}




\section{Alternative Revenue Streams}

As part of the study for DOE, K\&M analyzed resource recovery from the RDF preparation plant. As mentioned previously, various energy recovery systems were also investigated. ${ }^{3}$

\section{Business Aspects}

Although TC has done only pilot plant testing with RDF, they have developed the gasifier system to the demonstration stage for sludge and black liquor.

The main address and communications numbers of the firm as of late 1995 are:

ThermoChem, Inc.

10220-H Old Columbia Road

Columbia, Maryland 21046
Tel: $(410) 312-6300$

Fax: (410) 312-6303

\section{IMPLEMENTATION FEASIBILITY}

TC's gasifier lends itself to a variety of applications, ranging from gas distribution to energy recovery. In a recent study for the Department of Energy (DOE), conducted in collaboration with K\&M Engineering and Consulting Corporation, implementation options were analyzed. The energy-recovery systems included combined cycle, Rankine cycle, methanol synthesis, and hot water generation. ${ }^{3}$

As discussed in the sections that follow, it is clear that considerable demonstration work is needed to address remaining uncertainties regarding air emissions, residue quality, and tubesheet plugging with refuse-derived wire, metals, and rocks, for example. These uncertainties translate into risks for prospective owners.

\section{Process Issues and Problem Areas}

$\mathrm{TC}$ envisions no problem areas with $\mathrm{RDF}$, and they dispute the potential for in-bed tube plugging and erosion/corrosion. However, experience in other RDF-based technologies strongly suggests that until full-scale trials over an extended period are complete, the risks and potential costs of these problems should not be ignored. Also, other development experiences suggest that there are issues with the engineering aspects of presorting and reliability of undensified RDF material-handling systems that must be learned and mastered by the developer. The cyclones are subject to plugging, just as they are in conventional atmospheric fluid beds.

\section{Operating Issues and Problem Areas}

Over 500 hours of operation on reject fiber and black liquor tends to give confidence to long-term operation. TC prefers sand to limestone as the bed material. However, they might consider limestone for chlorine sorption. TC believes all the technical problems can be solved, but they recognize that problems will become apparent when large-scale units become operational and that these problems can only be addressed in long-term operation. 


\section{Remaining Research and Development Needs}

Many problems have been resolved. As with most fuel substitution technologies, commercialization is dependent on energy prices.

\section{PROCESS DESCRIPTION}

\section{Overview}

In the PulseEnhanced ${ }^{\mathrm{TM}}$ steam reformer, the organics react with steam, and the external heat is obtained by combustion of residual char from the reformer and part of the product fuel gas. The product gas from the indirectly heated processes does not contain combustion products or atmospheric nitrogen and is not as constrained with respect to potential end uses, such as for the production of methanol. Product gas quality from indirect systems is highly insensitive to feedstock moisture content, and this insensitivity provides a flexibility for the use of a broad range of high-moisture feedstocks for which predrying is impractical or uneconomical.

In the TC PulseEnhanced ${ }^{\mathrm{TC}}$ steam reformer shown in Figure 9.1, a multiple-resonance tube-pulse combustor is employed. Using the resonance tubes as a firetube bundle raises the rate of heat transfer almost fivefold. Such high rates of heat transfer greatly improve energy efficiency and reduce the size of the reformer unit. These benefits significantly improve the economic competiveness of the process.

Combustion persists down the resonance tubes (firetubes) for a significant length in an environment of an oscillating flow field. Radiant heat transfer continues along the length of the firetube. Pulsing from pressure fluctuations is on the order of 175 to $180 \mathrm{~dB}$ in sound pressure level. This net pressure boost is employed to overcome pressure drop in the system. Pulse combustors also regulate their own air-fuel ratio within their range of firing without the need for extensive controls. Pulse-enhanced steam reformers have the potential for using different bed materials which can also act as catalysts and absorbents for the sulfur and chlorine species released in the process. In-situ capture of chlorine is expected to inhibit the production of dioxins and furans. Steam reforming occurs in an oxygen-free environment, which would preclude $\mathrm{SO}_{\mathrm{x}}$ formation, with the $\mathrm{H}_{2} \mathrm{~S}$ formed easily and effectively scrubbed from the product gas.

The primary advantages of pulse combustion technology are:

- Enhanced heat-release rates and uniform temperature profile

- Enhanced heat transfer and reaction rates

- Combustion-air aspiration and flue-gas pressure boost

- Low capital, operating, and maintenance costs

- Modularity. ${ }^{1}$

A simplified process schematic is shown in Figure 9.2. Heat is recovered from the fuel gas, and then the gas cleaned in a scrubber. Part of the clean fuel gas is used in the pulse heater as the energy source. The exhaust from the pulsed heater never enters the fluid bed steam reformer and does not dilute the product gas. The pulsed heater is a low-emissions device with low $\mathrm{NO}_{\mathrm{x}}$ emissions. The organic waste fed to the fluid bed reformer reacts solely with steam in a reducing atmosphere, producing hydrogen, 


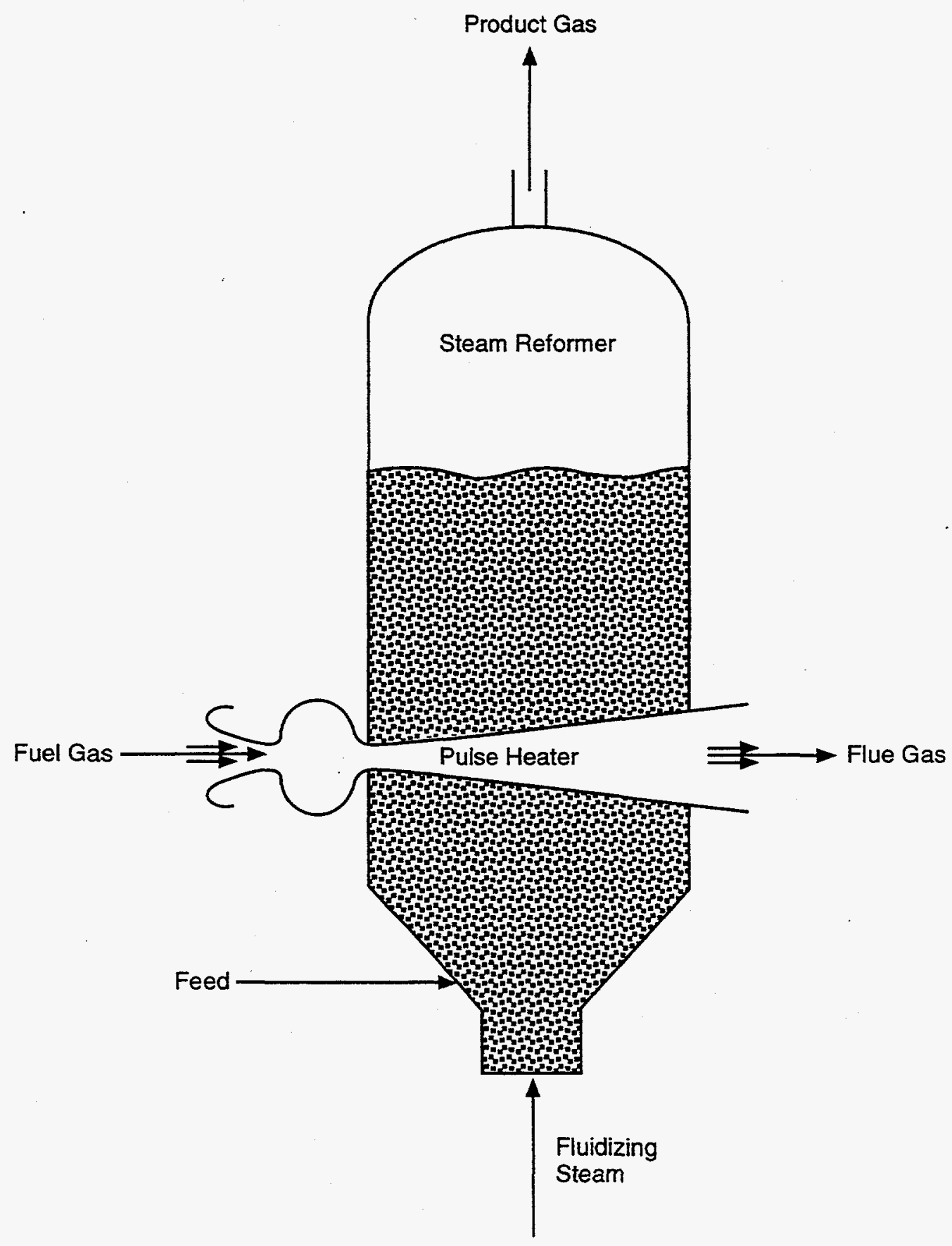

Figure 9-1 


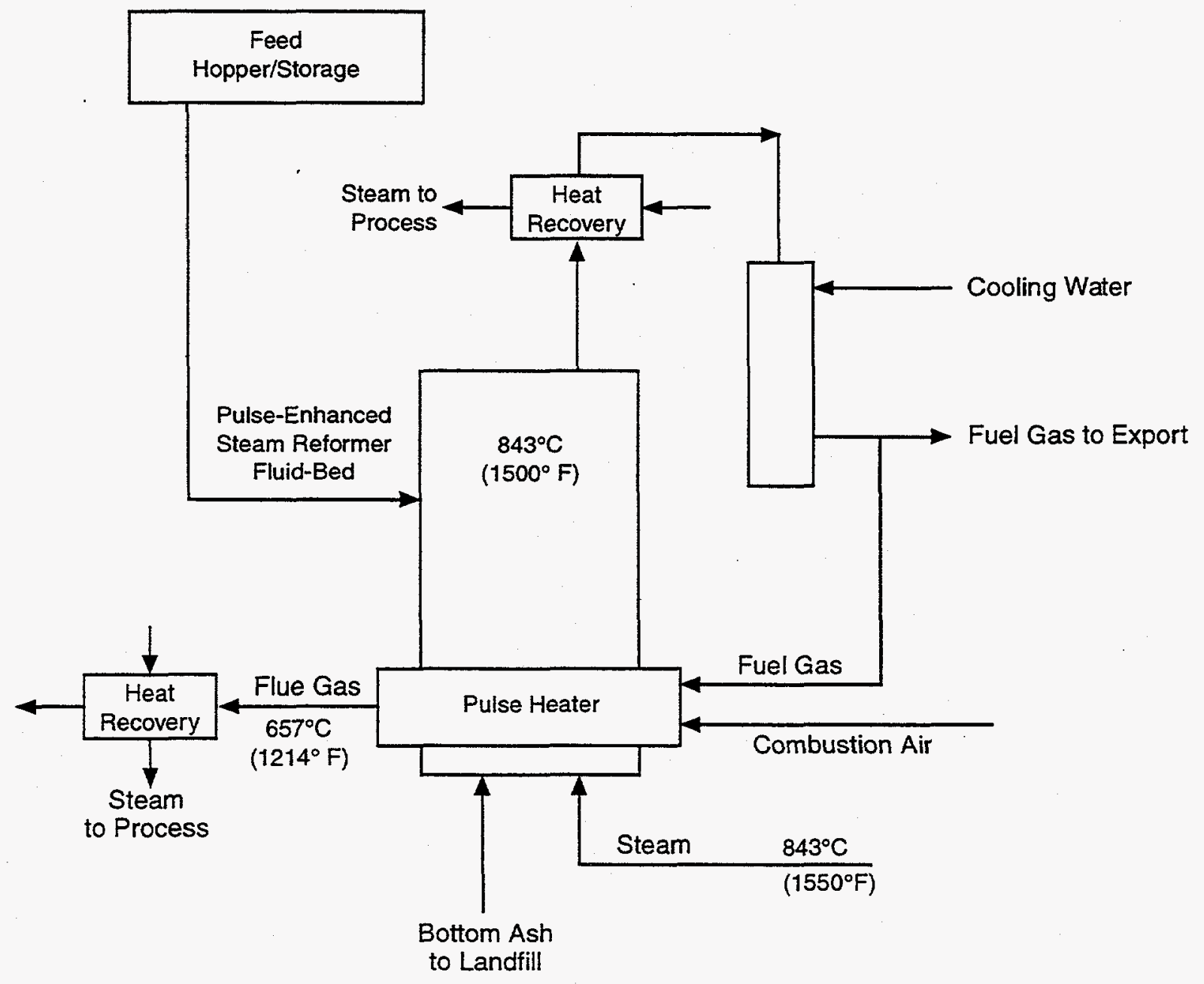

Figure 9-2 
carbon monoxide, carbon dioxide, and small amounts of light hydrocarbons. The product gas is cleaned of acid gases in the air pollution control (APC) system. The mineral matter contained in the feed collects in the fluid bed and is removed from the bed. The residue meets the leachability criteria set by EPA for disposal as a nonhazardous material. Two waste-heat-recovery boilers generate steam for the process by cooling the fuel gas and the flue gas.

Some systems have a dryer and an air heater. The dryer uses sensible heat from the fuel gas in between the boiler and scrubber. The air heater recovers sensible heat from the pulse heater flue gas.

The PulseEnhanced ${ }^{\mathrm{TM}}$ steam reformer is flexible and can trade off higher throughput by accepting a slightly higher char yield. In one design study, an increase of 162 percent in throughput resulted in a char residue that rose from 12 to 20 percent. The fluid bed can be operated at $816^{\circ} \mathrm{C}\left(1500^{\circ} \mathrm{F}\right)$. At this

temperature, production of fuel gas is at its maximum and ash output is at its minimum. It can also be operated at a lower temperature, $649^{\circ} \mathrm{C}\left(1200^{\circ} \mathrm{F}\right)$, for example. At this temperature MSW (RDF) throughput is at its maximum, but more residue (char) is generated.

\section{E. ENVIRONMENTAL ASPECTS}

\section{Process Emissions Characteristics}

Indirectly fired systems have the advantage of minimizing product gas contamination as a result of the absence of combustion products in the product gas. Low temperatures and an oxygen-free reactor do not favor $\mathrm{NO}_{\mathrm{x}}$ production. Likewise, low-temperature operation in the range of 600 to $810^{\circ} \mathrm{C}(1110$ to $1490^{\circ} \mathrm{F}$ ) results in low PCDD/PCDF in fly ash and flue gas. Operation at low temperature and an oxygendeficient environment minimize the vaporization of toxic metals.

Limited Toxicity Characteristics Leaching Procedure (TCLP) leach testing indicated that the char is not hazardous, according to the TCLP threshold guidelines. Only barium and selenium were detected, but they were well below the allowable EPA maximum concentration of contaminants specifications, as shown in Table 9.3. ${ }^{1}$

Tests for polychlorinated dibenzo p-dioxin (PCDD) and polychlorinated dibenzo furan (PCDF) were conducted on RDF and char/ash samples. Both the feedstock and the char/ash contained very small amounts of dioxin and furan, as shown in Table 9.4..$^{2}$ These data suggest that the dioxin and furan compounds are substantially burned out. Such a conclusion is, however, very tentative. Data on actual flue gas discharge concentration are needed for comparison with EPA Maximum Achievable Control Technology (MACT) limits.

\section{Potential for Regulatory Compliance}

The estimated emissions are expected to be in compliance with regulations for MSW combustors. However, there are no data to support this expectation. 
Table 9.3 ThermoChem TCLP Metal Concentrations From Cyclone Ash of RDF Test- November 7, 1990

\begin{tabular}{||l|c|c|c|}
\hline \multirow{2}{*}{ Metal } & \multicolumn{3}{|c|}{ Concentration (mg/n) } \\
\cline { 2 - 4 } & Detection Limit & Test Result & MCOC $^{*}$ \\
\hline \hline Arsenic & 0.0125 & ND $^{\dagger}$ & 5.0 \\
\hline Barium & 0.1 & 1.3 & 100 \\
\hline Cadmium & 0.1 & ND & 1.0 \\
\hline Chromium & 0.1 & ND & 5.0 \\
\hline Lead & 0.1 & ND & 5.0 \\
\hline Mercury & 0.0025 & ND & 0.2 \\
\hline Selenium & 0.0125 & 0.021 & 1.0 \\
\hline Silver & 0.1 & ND & 5.0 \\
\hline
\end{tabular}

${ }^{*} \mathrm{MCOC}=$ Maximum Concentration of Contaminants $\quad$ TND $=$ Not detected, below detection limit.

Table 9.4 PCDD/PCDF Analysis of RDF Feedstock and Cyclone Ash in RDF Test (Concentration ng/g)-December 7, 1990

\begin{tabular}{||l|c|c|c|c||}
\hline \multirow{2}{*}{ Component } & \multicolumn{2}{|c|}{ RDF Feedstock } & \multicolumn{2}{c||}{ Cyclone Ash } \\
\cline { 2 - 5 } & Detection Limit & Concentration & Detection Limit & Concentration \\
\hline \hline \multicolumn{3}{|c|}{ Dioxins } \\
\hline Total TCDD & 0.56 & ND & 0.089 & ND \\
\hline Total PeCDD & 0.76 & ND & 0.13 & ND \\
\hline Total HxCDD & 0.11 & ND & 0.091 & ND \\
\hline Total HpCDD & Not Supplied & 0.27 & 0.23 & ND \\
\hline & Not Supplied & 1.7 & 0.21 & ND \\
\hline Total TCDF & & Furans & & ND \\
\hline Total PeCDF & 0.30 & ND & 0.29 & ND \\
\hline Total HxCDF & 0.22 & ND & 0.13 & ND \\
\hline Total HpCDF & 0.3 & ND & 0.20 & ND \\
\hline Total OCDF & 0.23 & ND & 0.21 & ND \\
\hline \hline
\end{tabular}




\section{F. FLOWSHEET}

\section{Material Balances}

Data generated during TC's test program were incorporated into a process heat and material balance model to predict commercial-scale production rates. Table 9.5 is a summary mass and heat balance based on the schematic flowsheet shown in Figure 9.3.

\section{Heat Balance}

The mass and energy balance is summarized in Table 9.5 and presented in detail in Table 9.6. The basis for the mass and energy balances is TC's flowsheet shown in Figure 9.3. These results indicate that 72 percent of the refuse fuel energy has been converted to fuel value in the gas-a high cold-gas efficiency when compared with that from an air-blown gasifier.

Steam distribution to the base of the gasifier is accomplished by means of pipes (sparger tubes) discharge into the bed. Waste feedstock is introduced directly into the fluid bed using a water-cooled injection screw.

The hot product gases exit the gasifier to a recycle cyclone, where the entrained particulates are captured for return to the bed. A second cyclone, in series, removes much of the remaining particulates in the product gases.

The pulse combustor module, mounted at the base of the gasifier, has a normal firing rate of approximately $211 \mathrm{MJ} / \mathrm{h}(200,000 \mathrm{Btu} / \mathrm{h})$. It is connected to two, independent firetubes immersed in the fluid bed. The firetubes indirectly transfer heat to the bed to support the endothermic gasification reactions, thus minimizing $\mathrm{NO}_{\mathrm{x}}$ production. Likewise, low-temperature operation in the range of 600 to $810^{\circ} \mathrm{C}\left(1110\right.$ to $\left.1490^{\circ} \mathrm{F}\right)$ results in low PCDD/PCDF in fly ash and flue gas. Operation at a low temperature and in an oxygen-deficient environment minimizes the vaporization of toxic metals.

\section{End Product}

Testing with RDF resulted in the end product data shown in Tables 9.7 and $9.8 .^{3}$

\section{Proposed Interface}

In a recent study in collaboration with $\mathrm{K} \& \mathrm{M}$ Engineering and Consulting Corporation, $\mathrm{TC}$ conducted an assessment of the feasibility of an integrated facility combining MSW processing in the amount of $726 \mathrm{Mg} / \mathrm{d}(800 \mathrm{t} / \mathrm{d})$, using the PulseEnhanced ${ }^{\mathrm{TM}}$ heater and steam-reforming technology with the following four options: ${ }^{3}$

- Combined-cycle plant for the production of electricity

- Boiler and steam turbine for the production of electricity

- Methanol production plant

- Hot water production for industrial use. 
Table 9.5 Mass and Energy Balance Summary-595 Mg/d (665 t/d) RDF-High-Temperature Case

\begin{tabular}{|c|c|c|c|c|c|c|c|}
\hline Stream & Incoming & From & $\begin{array}{l}\text { Pressure } \\
\left(\mathrm{lb} / \mathrm{in}^{2}-\mathrm{g}\right)\end{array}$ & $\begin{array}{l}\text { Tempera- } \\
\text { ture }\left({ }^{\circ} \mathrm{F}\right)\end{array}$ & $\begin{array}{c}\text { Mass Flow } \\
\left(10^{3} \mathrm{lb} / \mathrm{h}\right)\end{array}$ & $\begin{array}{l}\text { Enthalpy } \\
\left(10^{3} \mathrm{Btiu} / \mathrm{h}\right)\end{array}$ & $\begin{array}{c}\text { Total } \\
\text { Energy } \\
\left(10^{3} \mathrm{Btu} / \mathrm{h}\right) \\
\end{array}$ \\
\hline 25 & RDF & Feed Prep & 0 & 77 & 54,583 & 0 & 356,734 \\
\hline 5 & Boiler Feedwater & Water Treatment & 200 & 77 & 18,991 & 0 & 0 \\
\hline 16 & Combustion Air & Atmosphere & 0 & 77 & 97,978 & 0 & 0 \\
\hline \multicolumn{5}{|r|}{ Total } & 171,552 & 0 & 356,734 \\
\hline Stream & Outgoing & From & $\begin{array}{l}\text { Pressure } \\
\left(\mathrm{Ib} / \mathrm{in}^{2}-\mathrm{g}\right)\end{array}$ & $\begin{array}{l}\text { Tempera- } \\
\text { ture }\left({ }^{\circ} \mathrm{F}\right)\end{array}$ & $\begin{array}{l}\text { Mass Flow } \\
\left(10^{3}(\mathrm{~b} / \mathrm{h})\right.\end{array}$ & $\begin{array}{l}\text { Enthalpy } \\
\left(10^{3} \mathrm{Btu} / \mathrm{h}\right)\end{array}$ & $\begin{array}{c}\text { Total } \\
\text { Energy } \\
\left(10^{3} \mathrm{Btu} / \mathrm{h}\right) \\
\end{array}$ \\
\hline 8 & Char to Disposal & Char Cooler & 8 & 200 & 6,503 & 176 & 16,934 \\
\hline 14 & Water to Discharge & & 60 & 125 & 10,512 & 495 & 3,146 \\
\hline 26 & Hot Flue Gas & Air Heater & 1 & 1184 & 116,168 & 50,801 & 50,801 \\
\hline 20 & Product Gas & & 3 & 125 & 37,997 & 7,075 & 264,071 \\
\hline & & & & Total & 171,180 & 60,519 & 334,952 \\
\hline
\end{tabular}


Table 9.6 Mass and Energy Balance (655 t/d)

\begin{tabular}{|c|c|c|c|c|c|c|c|c|c|}
\hline \multirow[b]{2}{*}{ Component } & \multicolumn{9}{|c|}{ Stream No./Description } \\
\hline & $\begin{array}{c}1 \\
\text { RDF to } \\
\text { Gasifier }\end{array}$ & $\begin{array}{c}2 \\
\text { Steam to } \\
\text { Gasifier }\end{array}$ & $\begin{array}{c}3 \\
\text { Product } \\
\text { Gas to } \\
\text { Boiler }\end{array}$ & $\begin{array}{c}4 \\
\text { Product Gas } \\
\text { to Dryer }\end{array}$ & $\begin{array}{c}5 \\
\text { Water to } \\
\text { Boller }\end{array}$ & $\begin{array}{c}6 \\
\text { Boller } \\
\text { Blowdown }\end{array}$ & $\stackrel{7}{\text { Char to Cooler }}$ & $\begin{array}{c}8 \\
\text { Char to } \\
\text { Disposal }\end{array}$ & $\begin{array}{c}9 \\
\text { Water to } \\
\text { Cooler }\end{array}$ \\
\hline $\mathrm{CH}_{4}$ & & & 5,294 & 5,294 & & & & & \\
\hline $\mathrm{co}$ & & $\therefore$ & 24,666 & 24,666 & & & & & \\
\hline $\mathrm{CO}_{2}$ & & & 14,983 & 14,983 & & & & & \\
\hline $\mathrm{H}_{2}$ & & & 2,395 & 2,395 & & . & & & \\
\hline $\mathrm{H}_{2} \mathrm{O}$ (vapor) & & 18,619 & 8,437 & 8,437 & & & & & \\
\hline $\mathrm{NH}_{3}$ & & & 106 & 106 & & & & & \\
\hline $\mathrm{H}_{2} \mathrm{~S}$ & & & 231 & 231 & & & & & \\
\hline c & & & & & & & 1,189 & 1,189 & \\
\hline Ash & 5,314 & & & & & & 5,314 & 5,314 & \\
\hline MAF Feed & 38,243 & & & & & & & & \\
\hline $\mathrm{H}_{2} \mathrm{O}$ (liquid) & 440 & & & & 18,991 & 372 & & & 25,414 \\
\hline \multicolumn{10}{|l|}{$\mathrm{N}_{2}$} \\
\hline \multicolumn{10}{|l|}{$\mathrm{O}_{2}$} \\
\hline \multicolumn{10}{|l|}{$\mathrm{SO}_{2}$} \\
\hline \multicolumn{10}{|l|}{$\mathrm{CaO}$} \\
\hline \multicolumn{10}{|l|}{$\mathrm{CaCO}_{3}$} \\
\hline \multicolumn{10}{|l|}{$\mathrm{CaSO}_{4}$} \\
\hline Total Mass, $10^{3} \mathrm{lb} / \mathrm{h}$ & 43.997 & 18,619 & 56,113 & 56,113 & 18,991 & 372 & 6,503 & 6,503 & 25,414 \\
\hline Temp. ${ }^{\circ} \mathrm{F}$ & 220 & 1550 & 1550 & 947 & 77 & 375 & 1500 & 200 & 77 \\
\hline Energy, $10^{3} \mathrm{Btu} / \mathrm{h}$ & 356,734 & 0 & 382,673 & 382,673 & 0 & 0 & 16,758 & 16,758 & 0 \\
\hline Enthalpy, $10^{3} \mathrm{Btu} / \mathrm{h}$ & 1,434 & 33.362 & 48,435 & 31,800 & 0 & 113 & 2,036 & 176 & 0 \\
\hline Total Heat, $10^{3} \mathrm{Btu} / \mathrm{h}$ & 358,168 & 33,362 & 431,108 & 414,473 & 0 & 113 & 18,794 & 16,934 & 0 \\
\hline Pressure, $1 \mathrm{~b} / \mathrm{in}^{2} \cdot \mathrm{g}$ & 0 & 10 & 5 & 4 & 200 & 10 & 0 & 0 & 60 \\
\hline
\end{tabular}


Table 9.6 (Cont) Mass and Energy Balance (655 t/d)

\begin{tabular}{|c|c|c|c|c|c|c|c|c|c|}
\hline \multirow[b]{2}{*}{ Component } & \multicolumn{8}{|c|}{ Stream No./Description } & \multirow{2}{*}{$\begin{array}{c}18 \\
\text { Steam to } \\
\text { Superheater }\end{array}$} \\
\hline & $\begin{array}{c}10 \\
\text { Water to } \\
\text { Discharge }\end{array}$ & $\begin{array}{c}11 \\
\text { Product Gas } \\
\text { From Quench }\end{array}$ & $\begin{array}{c}12 \\
\text { Water to } \\
\text { Quench } \\
\end{array}$ & $\begin{array}{c}13 \\
\text { Water From } \\
\text { Quench }\end{array}$ & $\begin{array}{c}14 \\
\text { Water to } \\
\text { Discharge }\end{array}$ & $\begin{array}{c}15 \\
\text { Fuel Gas to } \\
\text { Combustor } \\
\end{array}$ & Air to Combustor & $\begin{array}{c}17 \\
\text { Flue Gas to } \\
\text { Superheater }\end{array}$ & \\
\hline $\mathrm{CH}_{4}$ & & 5,294 & & & & 1.714 & & & \\
\hline co & & 24,666 & & & & 7,985 & & & \\
\hline $\mathrm{CO}_{2}$ & & 14,983 & & & & 4,851 & & 22,099 & \\
\hline $\mathrm{H}_{2}$ & & 2,395 & & & & 775 & & & \\
\hline $\mathrm{H}_{2} \mathrm{O}$ (vapor) & & 8,445 & & & & 2,864 & & 13,644 & 18,619 \\
\hline $\mathrm{NH}_{3}$ & & 0 & 6,646 & 6,752 & 106 & 0 & & & \\
\hline $\mathrm{H}_{2} \mathrm{~S}$ & & 2 & 14,380 & 14,609 & 229 & 1 & & & \\
\hline \multicolumn{10}{|l|}{ c } \\
\hline \multicolumn{10}{|l|}{ Ash } \\
\hline \multicolumn{10}{|l|}{ MAF Feed } \\
\hline $\mathrm{H}_{2} \mathrm{O}$ (liquid) & 25,414 & & 638,617 & 648,794 & 10,177 & & & & \\
\hline $\mathrm{N}_{2}$ & & & & & & & 75,157 & 75,157 & \\
\hline $\mathrm{O}_{2}$ & & & & & & & 22,821 & 5,266 & \\
\hline $\mathrm{SO}_{2}$ & & & & & & & & 1 & \\
\hline \multicolumn{10}{|l|}{$\mathrm{CaO}$} \\
\hline \multicolumn{10}{|l|}{$\mathrm{CaCO}_{3}$} \\
\hline \multicolumn{10}{|l|}{$\mathrm{CaSO}_{4}$} \\
\hline Total Mass, $10^{3} \mathrm{lb} / \mathrm{h}$ & 25,414 & 56,187 & 659,643 & 670,156 & 10,512 & 18,190 & 97,978 & 116,168 & 18,619 \\
\hline Temp. ${ }^{\circ} \mathbf{F}$ & 150 & 125 & 95 & 125 & 125 & 125 & 400 & 1700 & 375 \\
\hline Energy, $10^{3} \mathrm{Btu} / \mathrm{h}$ & 0 & 380,022 & 166,354 & 169,005 & 2,651 & 123,026 & 0 & 0 & 0 \\
\hline Enthalpy, $10^{3} 8$ tu/h & 1,860 & 10,462 & 11,627 & 31,532 & 495 & 3,387 & 7,714 & 69,755 & 22,123 \\
\hline Total Heat, $10^{3} \mathrm{Btu} / \mathrm{h}$ & 1,860 & 390,483 & 177,981 & 200,537 & 3,146 & 126,413 & 7,714 & 69,755 & 22,123 \\
\hline Pressure, Ib/in' $-\mathrm{g}$ & 60 & 3 & 20 & 60 & 60 & 1 & 1 & 0.6 & 50 \\
\hline
\end{tabular}


Table 9.6 (Cont) Mass and Energy Balance (655 t/d)

\begin{tabular}{|c|c|c|c|c|c|c|c|c|}
\hline \multirow[b]{2}{*}{ Component } & \multicolumn{8}{|c|}{ Stream No./Description } \\
\hline & $\begin{array}{c}19 \\
\text { Flue Gas } \\
\text { to Alr } \\
\text { Heater } \\
\end{array}$ & $\begin{array}{c}20 \\
\text { Product } \\
\text { Gas to } \\
\text { Export } \\
\end{array}$ & $\begin{array}{c}21 \\
\text { Steam } \\
\text { From Heat } \\
\text { Recovery } \\
\end{array}$ & $\begin{array}{c}22 \\
\substack{\text { Steam From } \\
\text { Boiler }}\end{array}$ & $\begin{array}{c}23 \\
\text { Steam From } \\
\text { PC Cooler }\end{array}$ & $\begin{array}{c}24 \\
\text { Product Gas } \\
\text { to Quench }\end{array}$ & $\begin{array}{c}25 \\
\text { RDF to Dryer }\end{array}$ & $\begin{array}{c}26 \\
\text { Flue Gas to } \\
\text { Heat } \\
\text { Recovery } \\
\end{array}$ \\
\hline $\mathrm{CH}_{4}$ & & 3,580 & & & & 5,294 & & \\
\hline $\mathrm{co}$ & & 16,681 & & & & 24,666 & & \\
\hline $\mathrm{CO}_{2}$ & 22,099 & 10,133 & & & & 14,983 & & 22,099 \\
\hline $\mathrm{H}_{2}$ & & 1,620 & & & & 2,395 & & \\
\hline $\mathrm{H}_{2} \mathrm{O}$ (vapor) & 13,644 & 5,982 & 18,619 & 13,906 & 4,713 & 19,023 & & 13,644 \\
\hline $\mathrm{NH}_{3}$ & & 0 & & & & 106 & & \\
\hline $\mathrm{H}_{2} \mathrm{~S}$ & & 2 & & & & 231 & & \\
\hline \multicolumn{9}{|l|}{ c } \\
\hline Ash & & & & & & & 5,314 & \\
\hline MAF Feed & & & & & & & 38,243 & \\
\hline $\mathrm{H}_{2} \mathrm{O}$ (liquid) & & & & & & & 11,026 & \\
\hline $\mathbf{N}_{2}$ & 75,157 & & & & & 75,157 & & 75,157 \\
\hline$\overline{\mathrm{O}_{2}}$ & 5,266 & & & & & 22,821 & & 5,266 \\
\hline $\mathrm{SO}_{2}$ & 1 & & & & & & & 1 \\
\hline \multicolumn{9}{|l|}{$\mathrm{CaO}$} \\
\hline \multicolumn{9}{|l|}{$\mathrm{CaCO}_{3}$} \\
\hline \multicolumn{9}{|l|}{$\mathrm{CaSO}_{4}$} \\
\hline Total Mass, $10^{3} \mathrm{lb} / \mathrm{h}$ & 116,168 & 37,997 & 18,619 & 13,906 & 4,713 & 66,699 & 54,583 & 116,168 \\
\hline Temp. ${ }^{\circ} \mathbf{F}$ & 1398 & 125 & 375 & 375 & 375 & 424 & 77 & 1184 \\
\hline Energy, $10^{3} \mathrm{Btu} / \mathrm{h}$ & 0 & 256,996 & 0 & 0 & 0 & 382,673 & 356,734 & 0 \\
\hline Enthalpy, $10^{3} \mathrm{Btu} / \mathrm{h}$ & 58,515 & 7,075 & 22,123 & 16,523 & 5,600 & 30,366 & 0 & 50,801 \\
\hline Total Heat, $10^{3} \mathrm{Btu} / \mathrm{h}$ & 58,515 & 264,071 & 22,123 & 16,523 & 35,600 & 413,039 & 356,734 & 50,081 \\
\hline Pressure, $\mathrm{b} b / \mathrm{in}^{2}-\mathrm{g}$ & 0.2 & 3 & 200 & 200 & 200 & 3 & 4 & 0.2 \\
\hline
\end{tabular}


Table 9.7 End-Product Data

[for operations at $798^{\circ} \mathrm{C}\left(1450^{\circ} \mathrm{F}\right)$ ]

\begin{tabular}{|l|l|}
\hline Carbon Gasified, \% & 83 \\
Product Gas Heating Value, MJ/Nm ${ }^{3}$ (Btu/sft' $)$ & $15.6(418)$ \\
$\begin{array}{l}\text { Product Gas Yield, per RDF on MAF basis, } \\
\mathrm{Nm}^{3} / \mathrm{kg}\left(\mathrm{st}^{3} / \mathrm{lb}\right)\end{array}$ & $1.24(19.85)$ \\
$\begin{array}{l}\text { Heating Value of Gas Produced, per RDF on MAF } \\
\text { basis, MJ/kg (Btu/lb) }\end{array}$ & $19.3(8320$ \\
\hline
\end{tabular}

Table 9.8 Product Gas Composition

\begin{tabular}{|l|c|}
\hline \multicolumn{1}{|c|}{ Compound } & Vol\% \\
\hline \hline $\mathrm{H}_{2}$ & 45.4 \\
\hline $\mathrm{CO}_{2}$ & 25.2 \\
\hline $\mathrm{CO}$ & 14.5 \\
\hline $\mathrm{CH}_{4}$ & 4.4 \\
\hline $\mathrm{C}_{2} \mathrm{H}_{4}$ & 0.6 \\
\hline $\mathrm{C}_{2} \mathrm{H}_{6}$ & 0 \\
\hline Other & 9.9 \\
\hline Total & 100.0 \\
\hline
\end{tabular}

The primary objective of the TC study was to minimize the volume of waste that had to be send to a landfill, while incurring the lowest possible cost. The PulseEnhanced ${ }^{\mathrm{TM}}$ heater and steam-reforming technology was an alternative to the landfill option for the MSW and for currently available waste-to-energy systems. The results indicated that the combined cycle will produce about $278,000-\mathrm{MJ} / \mathrm{h}\left(264 \times 10^{6}-\mathrm{Btu} / \mathrm{h}\right)$ medium-heating-value gas, generating about $36.5 \mathrm{MW}$. A similar quantity of RDF with a Rankine (steam only) cycle will generate 20.6 MW. In terms of the MSW characteristics used in TC's study, the combined-cycle energy conversion efficiency (heat rate) is $1206 \mathrm{kWh} / \mathrm{Mg}(1095 \mathrm{kWh} / \mathrm{t})$. The Rankine cycle heat rate is $680 \mathrm{kWh} / \mathrm{Mg}(618$ $\mathrm{kWh} / \mathrm{t})$ for $13.1 \mathrm{Mpa}-\mathrm{g} / 510^{\circ} \mathrm{C}\left(1900 \mathrm{lb} / \mathrm{in}^{2}-\mathrm{g} / 950^{\circ} \mathrm{F}\right)$ steam conditions. A mass-burn plant with a Rankine Cycle can achieve a heat rate of about 804 to $826 \mathrm{kWh} / \mathrm{Mg}(730$ to $750 \mathrm{kWh} / \mathrm{t})$. 


\section{G. DEVELOPMENTAL HISTORY}

\section{Laboratory/Bench Studies}

MTCI (ThermoChem's licensor) operated a bench-scale gasification system at its former laboratory in Santa Fe Springs, California. The equipment is presently being relocated to TC's Baltimore laboratory. The 7$\mathrm{kg} / \mathrm{h}(15-\mathrm{lb} / \mathrm{h})$ unit includes a gasifier, scrubber, filters, incinerator, and gas analysis instruments. The gasifier hot section consisted of the gasifier shell, steam-distributor nozzles, pulse-combustor module with integral immersed firetubes, recirculation cyclone, and polishing cyclone. The gasifier shell consists of a $10-\mathrm{cm}(8$-in.) lower portion and a 30-cm (12-in.) upper (freeboard) section. The expanded fluid bed height is approximately $1.8 \mathrm{~m}(6 \mathrm{ft})$. A schematic is shown in Figure 9.4.

\section{Pilot Plant Studies} liquor:

ThermoChem has several pilot units in the U.S. and abroad that have been used for sludges and black

- $\quad 11.3-\mathrm{kg} / \mathrm{h}(25-\mathrm{lb} / \mathrm{h})$ small pilot plants in Santa Fe Springs, California (currently being moved to Baltimore, Maryland) and in Zaragosa, Spain

- 544-kg/h $(1200-\mathrm{lb} / \mathrm{h})$ process development units in Baltimore, Maryland, and in Erode, Tamil $\mathrm{Nadu}$, India.

\section{Semiworks Plant Studies}

In New Bern, North Carolina, and in Pennadam, Tamil Nadu, India, 68-Mg/d (75-t/d) commercial feasibility demonstration units were operated. The former was used in a DOE Clean Coal Technology demonstration at a Weyerhaeuser plant to gasify black liquor. The plant is currently being relocated to another Weyerhaeuser plant.

\section{Current Status}

TC is focusing its efforts to the gasification of black liquor and sludges. A recent study with K\&M Engineering and Consulting Corporation under DOE funding provided an opportunity to perform detailed technical and economic evaluations of gasifying RDF for several applications. ${ }^{3}$ (Section 6 contains a discussion.)

Testing of RDF has been done on a $7-\mathrm{kg} / \mathrm{h}(15-\mathrm{lb} / \mathrm{h})$ unit only. ${ }^{3}$ Although they have achieved remarkable progress in scaling-up their system for black liquor, RDF is an extremely difficult material to handle and process. Scale-up from their pilot plant to larger size would be prudent before this system can be expected to be commercial. 


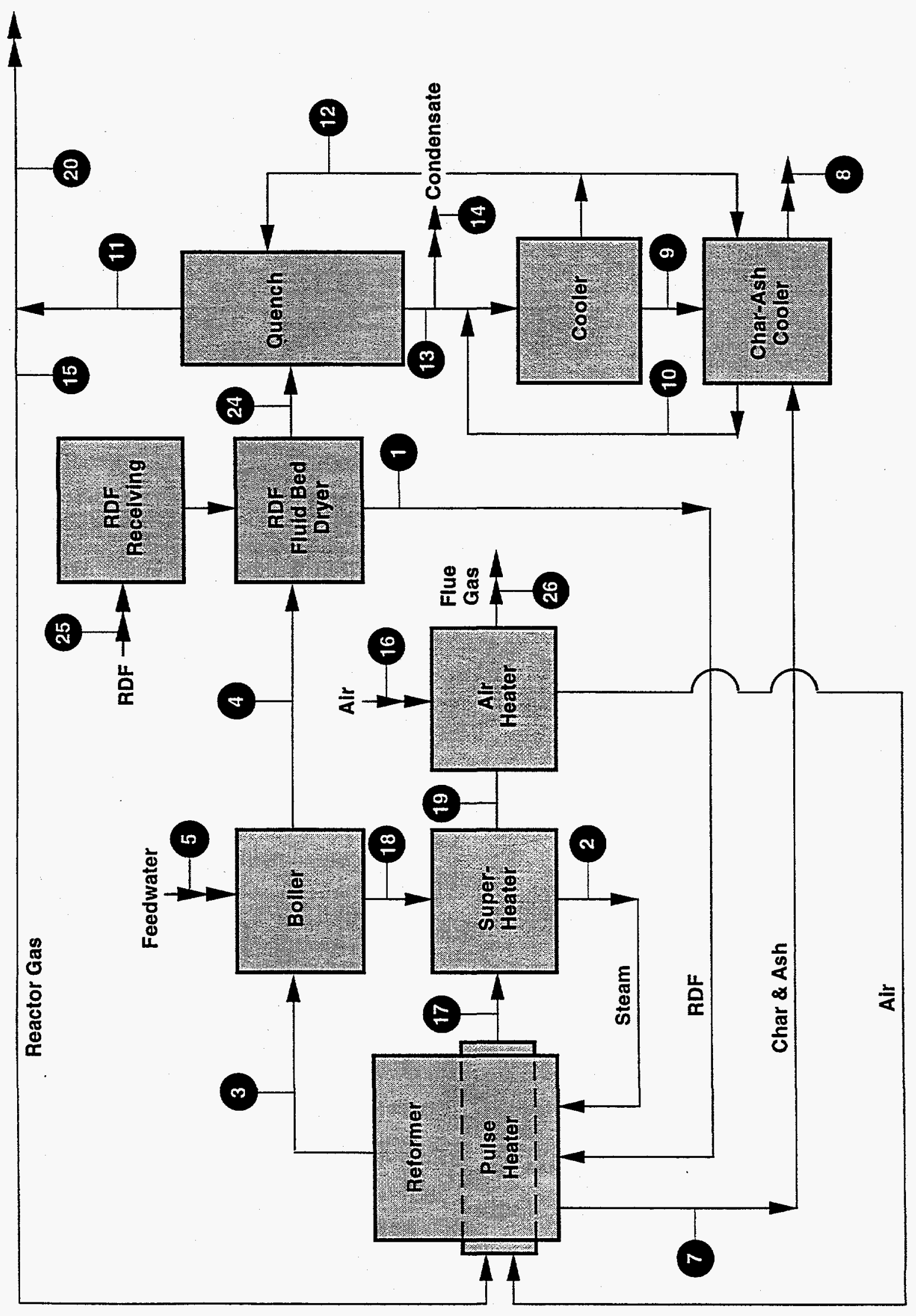

Figure 9-3 


\section{H. INTERVIEWS}

In the course of evaluating the TC technology, CDM engineers met with TC personnel in their Maryland offices. Those interviewed were:

- Gary Voelker, Chief Operating Officer

Tel: (410) 312-6300

Fax: (410) 312-6303

- William G. Steedman, Senior Systems Engineer

\section{REFERENCES}

1. "Steam Reforming of Municipal Wastewater Sludge, Phase 1 Final Report," prepared for the U.S. Environmental Protection Agency under EPA/SBIR Contract No. 68D00046 by Manufacturing and Technology Conversion International, Inc., 1990.

2. G. Voelker and K. Durai-Swamy, "MTCI Steam Reforming Process for Solid Waste Disposal - A New Technology," presented at the Solid Waste Management - Thermal Treatment \& Waste-toEnergy Technologies, Washington, DC, April 18-21, 1995.

3. "Minimizing Landfilling Through Pulse Enhanced Steam Reforming of Municipal Solid Waste, Final Report," Prepared for the U.S. Department of Energy, Morgantown Energy Research Center, Contract DE-AC21-90MC27346 by K\&M Engineering and Consulting Corporation, Washington, DC, September 1995. 


\section{Section 10}

\section{Refuse Gasification and Novel Thermal Processing Technologies in 1995 -A Summary Overview-}

Refuse is a difficult fuel. The chemical, physical, and thermal properties of waste are heterogeneous and constantly changing. Compounding the effect of the variability is the fact that many refuse characteristics cause problems in high-temperature operation-ash fusion temperatures that are too low and heavy metal and chlorine concentrations that are too high, for example.

Yet with these problems comes an irrefutable fact-refuse is a material that cities and counties must manage. Unlike a fossil fuel that can be left in the ground if it commands no market, waste is generated daily in the course of human activity, and we must develop reliable methods for coping with it. Society has accepted the reality that the management of wastes is not free. So, again unlike the fossil fuels, sufficient value can be assigned to the disposal of wastes that one can consider subsidizing processes that accomplish the task or even substantially reduce the wastes themselves. Other than by supporting the goal of cost-effective disposal, most U.S. cities and towns also assign value to two other dimensions of waste management:

- Recovery of the greatest amount of material from waste (recycling) before destructive processing or disposal

- Recovery of useful energy from the waste.

The proper management of solid waste remains an important element of municipal sanitation and a major line item in municipal budgets. In years past, these realities, combined with energy conservation policies and anticipated increases in U.S. energy costs, created a significant opportunity for thermal processing and associated energy recovery from MSW. In recent years, however, several significant market developments have sharply curtailed the thermal processing market:

- Inability to ensure a reliable supply of waste

- Changing social attitudes

- Changing strategies for obtaining capital

- Lower prices for fossil-fuel prices and thus of energy revenue.

The supply problem is best comprehended from the view of a prospective owner. To ensure a successful endeavor, the owner of a capital-intensive waste management system must be able to support capital borrowing with firm, long-term contracts for waste disposal. More than one municipality or county is usually needed to secure such contracts, and wastes must be drawn from a relatively large area to take full advantage of the costly combustion facilities. The collection of waste has frequently been the purview of private-sector firms. And indeed, during the growth years of waste-to-energy technology, between 1970 and 1985 , cities and counties directed these haulers to use a proposed waste management facility. For a time, this practice was acceptable, and it was supported by numerous State statutes, which aided in the formation of waste management districts and similar collectives. However, recent U.S. Supreme Court 
decisions have restricted the right of such districts to direct waste, calling the practice an unfair restraint of trade. Therefore, unless there is redress of the Court finding by act of the Federal Congress, the basic mechanism for raising capital for waste processing facilities will be greatly weakened or lost. Without such help, a prospective owner faces a greater financial risk during project development, and there is a concomitant effect on bonding costs to the communities and counties.

Environmental issues, especially air emissions, have also had an impact on municipal waste combustion. Initially, pressure focused on visible emissions - the smoking stacks from plants of the 1940s and 1950s were no longer acceptable. The Clean Air Act and its amendments drove the industry away from simple refractory enclosures to waterwall boiler designs. With cooled, air-tight waterwalls, low-excess-air operation was possible. The resultant decrease in flue gas volume made air pollution control economically feasible. This evolutionary change in equipment selection had the beneficial effect of bringing the technical sophistication and systems view of the commercial boiler and combustion industry into the MSW combustion market.

In 1977 the pollutant "dioxin" emerged as one new focus of concern. Dioxin has become the umbrella word for a mix of compounds that includes the several isomers and congeners of polychlorinated dibenzo-pdioxin and polychlorinated dibenzofuran. Also in the spotlight are emissions of the acid gases $\left[\mathrm{HCl}, \mathrm{SO}_{2}\right.$, and nitrogen oxides $\left(\mathrm{NO}_{\mathrm{x}}\right)$ ] and of the toxic elements (mercury, cadmium, lead, nickel, chromium, and arsenic, for example). Ash material has also been targeted. In the case of ash, interest has been directed toward both dioxin compounds and toxic elements. Although worry about the environment has not driven thermal processing programs out of business, it has resulted in significantly higher costs, more complex systems, and long delays in moving projects through the public review and regulatory-approval process.

The significance of these impediments to thermal processing is revealed by these observations:

- There have been few new starts of major WTE facilities in the U.S. for several years.

- Companies with owner/operator waste-to-energy plants are aggressively seeking new areas of business for the future.

Adding to these difficulties, there is a generally high level of stress within communities to keep expenditures as low as possible and to constrain borrowing. These cost-control measures are coupled with the "politically correct" pressures for recycling and cutting waste, which are at present dominant forces in the selection of new waste-management facilities in many areas of the U.S. However, these pressures and their consequences are most likely insufficient barriers to thermal processing as a viable option in solid waste management.

One has only to look to Europe, where waste-to-energy is in a commanding position and where environmental regulations are exceedingly strict. In Germany, France, and The Netherlands, recent legislation mandating the cessation of raw waste landfilling will further emphasize the role of thermal processing in solid waste management. Such market expansion in Europe will respond to air-pollutionbased environmental concerns through shifts in basic thermal processing technology and the installation of enhanced "back-end control" devices. Although a duplication of this regulatory pattern in the U.S. is unlikely, there is activity in the U.S. Congress to address, and perhaps resolve, the supply reliability problem.

In response to the issues that have been raised, several new or enhanced technologies have emerged to thermally process solid wastes. The most common system is the mass-burn incinerator, which burns raw 
waste properties through the generation of a refuse-derived-fuel (RDF). A variation burns RDF, but it is combined with other fossil fuels to take advantage of existing combustion equipment, labor forces, energyconversion systems, etc. One fact worth noting relates to RDF. If that fuel contributes less than 30 percent of the fuel weight input of an existing boiler, the federal air permit for that boiler is not affected.

Beyond these well-established combustion processes with energy recovery, a second class of technology has emerged-refuse gasification. Using this technology, usually after recycling and processing to an RDF, the organic fraction of MSW is heated with limited or no air. A gaseous stream with a substantial heat content is produced. This gas can then be cleaned of metals and other solids and of acidic gases, ammonia, hydrogen sulfide, and other contaminants and burned in a gas engine or gas turbine to generate electricity. Because the cleanup efforts focus on a relatively small gas stream rather than the much larger stream of flue gases from incineration systems, environmental emissions control is substantially less costly. Further, the ultimate combustion process takes place with relatively high-quality fuels rather than being mixed with MSW and its occasionally wet material, combustion-resistant constituents, etc.. Thus very low emission rates of dioxins, acid gases, and other problematic pollutants occur.

Of the seven emerging technologies studied, two-Energy Products of Idaho and Pedco International-use full combustion, but in novel contexts. The others-TPS Termiska AB, Proler International, Thermoselect Incorporated, Battelle, and ThermoChem Incorporated-use gasification methods followed by fuel gas cleanup and use.

The penetration of the thermal processing market by advanced technologies is paced by their environmental, economic, and performance acceptability. From an environmental viewpoint, the seven technologies represent an exceptionally sound response to the regulatory challenges of the revised New Source Performance Standards and the Maximum Achievable Control Technology rules of the U.S. EPA and the equally restrictive regulations within the European community.

Economics has always been a critical and probably pacing factor affecting the penetration of thermal processing technology into U.S. MSW practice. Tables $10.1 \mathrm{a}$ and $10.1 \mathrm{~b}$ summarize the economic data collected and developed in this study. An "apples-to-apples" cost comparison among the seven technologies or between these technologies and conventional mass-burn technologies was not the objective, nor was it appropriate for this assignment. Costs should always be developed in a local context of capacity, construction cost, labor cost, energy revenues, etc. However, as the table shows, the capital costs of many of the processes are comparable to the $\$ 110,000$ per $\mathrm{Mg} / \mathrm{d}(\$ 100,000 \mathrm{per} \mathrm{t} / \mathrm{d})$ typical of contemporary massburn systems-although some of the costs greatly exceed these norms. The proprietary portion of these new-technology plants ranges from a low of 25 percent to over 90 percent-a value generally higher than the 15 to 25 percent typical for mass-burn facilities. Most operating costs are quite comparable or slightly lower than are common for owner-operated mass-burn facilities. One should note that no profits and other charges and costs common to vendor-operated facilities were included in the economic analyses presented in this report. The net costs in Tables $10.1 \mathrm{a}$ and $10.1 \mathrm{~b}$, which may be regarded as the break-even tipping fee, vary widely; but as general numbers, they are mostly in the competitive area when compared with massburn plants. 
Table 10.1a Summary of Statistics for Developing Technologies (per ton quantities relate to raw MSW, metric units)

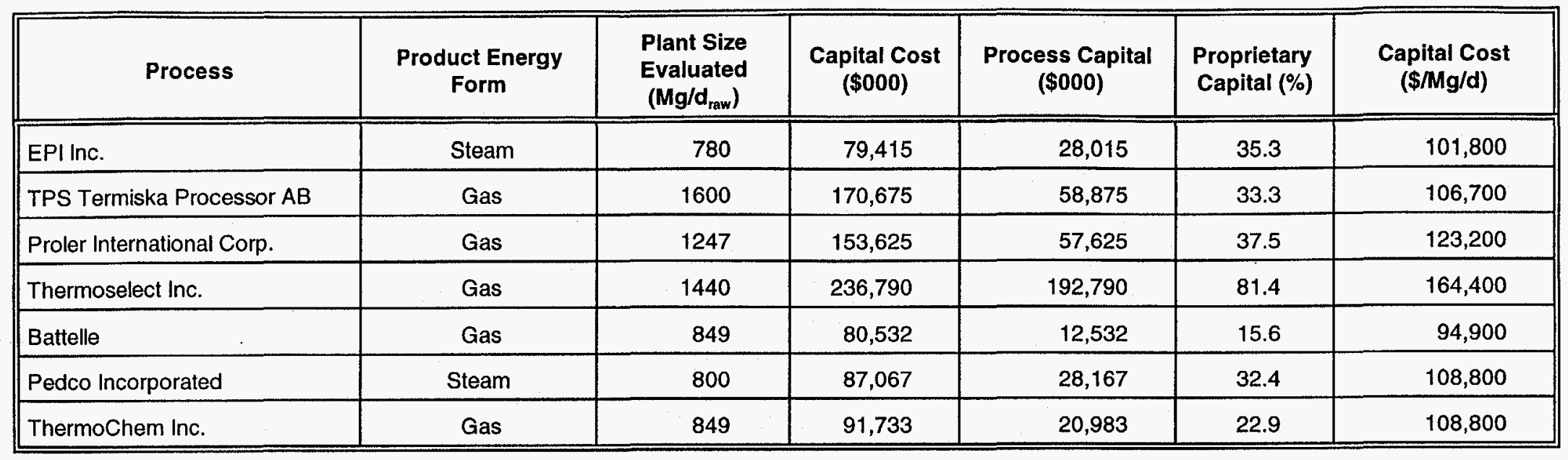

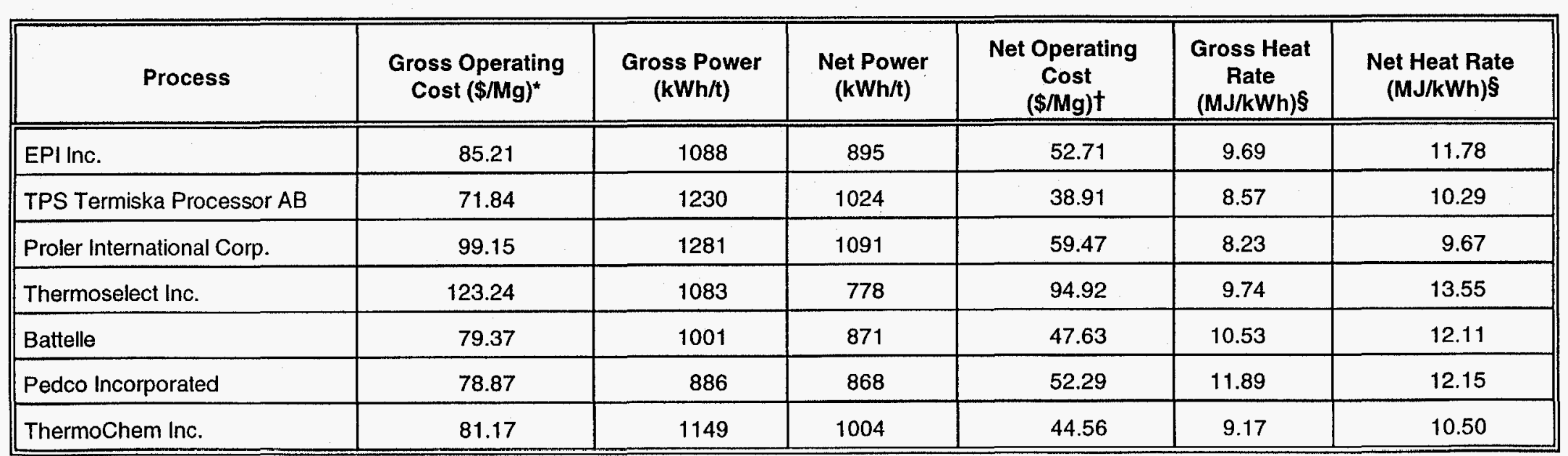

*Gross operating cost/ton raw refuse - total of capital charges, insurance, labor, maintenance, and supplies before energy credits.

†Net operating cost/ton raw refuse-gross operating cost less energy credit.

$\S$ Heat rate-factor relating the fuel value in the raw refuse (assumed at $11.6 \mathrm{MJ} / \mathrm{kg}, 14 \mathrm{MJ} / \mathrm{kg}$ as RDF) to the gross or net generation. 
Table 10.1b Summary of Statistics for Developing Technologies (per ton quantities relate to raw MSW, English units)

\begin{tabular}{|c|c|c|c|c|c|c|}
\hline Process & $\begin{array}{c}\text { Product Energy } \\
\text { Form }\end{array}$ & $\begin{array}{c}\text { Plant Size } \\
\text { Evaluated } \\
\left(\mathbf{t} / d_{\text {raw }}\right)\end{array}$ & $\begin{array}{l}\text { Capital Cost } \\
(\$ 000)\end{array}$ & $\begin{array}{c}\text { Process Capital } \\
(\$ 000)\end{array}$ & $\begin{array}{l}\text { Proprietary } \\
\text { Capital (\%) }\end{array}$ & $\begin{array}{c}\text { Capital Cost } \\
(\$ / t / d)\end{array}$ \\
\hline EPI Inc. & Steam & 860 & 79,415 & 28,015 & 35.3 & 92,343 \\
\hline TPS Termiska Processor AB & Gas & 1760 & 170,675 & 58,875 & 33.3 & 96,974 \\
\hline Proler International Corp. & Gas & 1370 & 153,625 & 57,625 & 37.5 & 112,135 \\
\hline Thermoselect Inc. & Gas & 1585 & 236,790 & 192,790 & 81.4 & 149,394 \\
\hline Battelle & Gas & 935 & 80,532 & 12,532 & 15.6 & 86,130 \\
\hline Pedco Incorporated & Steam & 880 & 87,067 & 28,167 & 32.4 & 98,940 \\
\hline ThermoChem Inc. & Gas & 935 & 91,733 & 20,983 & 22.9 & 98,110 \\
\hline
\end{tabular}

\begin{tabular}{|c|c|c|c|c|c|c|}
\hline Process & $\begin{array}{l}\text { Gross Operating } \\
\text { Cost }(\$ / t)^{*}\end{array}$ & $\begin{array}{c}\text { Gross Power } \\
(\mathbf{k W h} / \mathbf{t})\end{array}$ & $\begin{array}{c}\text { Net Power } \\
(\mathbf{k W h} / \mathrm{t})\end{array}$ & $\begin{array}{c}\text { Net Operating } \\
\text { Cost } \\
(\$ / t) \dagger \\
\end{array}$ & $\begin{array}{l}\text { Gross Heat Rate } \\
(\text { Btu/kWh }) \S\end{array}$ & $\begin{array}{c}\text { Net Heat Rate } \\
\text { (Btu/kWh)\$ }\end{array}$ \\
\hline EPI Inc. & 77.46 & 899 & 740 & 47.88 & 11,117 & 13,522 \\
\hline TPS Termiska Processor AB & 65.31 & 919 & 748 & 35.37 & 10,879 & 13,362 \\
\hline Proler International Corp. & 90.12 & 1059 & 901 & 54.06 & 9,445 & 11,094 \\
\hline Thermoselect Inc. & 112.03 & 895 & 643 & 86.29 & 11,176 & 15,549 \\
\hline Battelle & 71.60 & 827 & 720 & 42.81 & 12,087 & 13,896 \\
\hline Pedco Incorporated & 85.16 & 879 & 717 & 56.47 & 11,376 & 13,938 \\
\hline ThermoChem Inc. & 73.60 & 950 & 830 & 40.41 & 10,529 & 12,052 \\
\hline
\end{tabular}

*Gross operating cost/ton raw refuse-total of capital charges, insurance, labor, maintenance, and supplies before energy credits.

†Net operating cost/ton raw refuse-gross operating cost less energy credit.

$\S$ Heat rate-factor relating the fuel value in the raw refuse (assumed at $5000 \mathrm{Btu} / \mathrm{lb}, 6050 \mathrm{Btu} / \mathrm{lb}$ as RDF) to the gross or net generation. 
The results are less clear concerning "performance." Most of the processes, with the exception of EPI and Thermoselect, require an RDF feed. Landfills are still a necessity for inert materials that cannot be recycled and ash that cannot be used in construction. Historically, most RDF facilities have incurred substantial post-construction rework, capital investment, downrating of capacity, etc. Many of the systems studied have significant development tasks ahead of them. Unfortunately, the catalyst is lacking for the vigorous market activity needed to push this development and to foster risk-taking. Further, many of the systems are quite complex. This complexity presents some problems when attempting to gain acceptance from the client communities, regulatory authorities, and financial and engineering entities involved in concept selection and project implementation.

Finally, most of the processes are still in the developmental stage and have little continuous operating experience under commercial conditions. Thus some risk remains that process or equipment deficiencies or difficulties will appear. Those with knowledge of the waste-to-energy industry are very familiar with the development history of Purox, Landgard, Torrax, Black-Clawson, Melt-Zit, Ecologenics, and many other concepts, which were not successfully commercialized. In the aggressive working environment of waste-management facilities, risk has often meant significant, costly, and politically painful problems.

It would be premature to suggest that gasification technology is the thermal processing strategy of the future. Solid waste is a very difficult fuel. However, in both niche market sectors and the broader market, the gasification technologies studied, and some others, may well emerge as "commercially ready" alternatives, along with mass burning, RDF and fluidized bed technologies, which currently dominate the market.

It is noteworthy to comment that the project team was very impressed with the professionalism, the high technical standards, and the business commitment of most of the companies studied. Further, many of the developers have access to the capital resources that are so important to the challenges of technology demonstration and evolution. Such financial backing augurs well for the ability of many of these developers and others not studied in detail to further their developments and present to the marketplace convincing proof of the ability of their processes to meet the demands of MSW management. 


\section{Appendix A - List of Gasification and Thermal Process Firms \& Processes}

1. Lesley Manufacturing 1207 N 1800 Road

Lawrence, Kansas 66049

Les Blevins

2. Kvaerner EnviroPower, Inc. 10055 Red Run Boulevard

Owings Mills, Maryland 21117

Herbert J. Fruth

3. Global Energy USA

1500 Chiquita Center, 250 East Fifth Street

Cincinnati, Ohio 45202

Harry Graves, President and CEO

4. Proler International Corp.

4265 San Felipe, Suite 900

Houston, Texas 77027

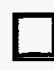

(410) 356-1111

(410) 356-1115 (F)Ext. 41
(913) 842-1943

(913) 842-0341 (F)
(513) 621-0077

alt. (513) 762-7817

(513) 6215947 (F)

alt. (513) $721-4628$ (F)

(713) $963-5944$

or (713) 627-3737

(713) $627-2737$ (F)

Dennis L. Caputo, V.P.

5. Battelle Columbus

$\square \quad$ (614) $424-4958$

505 King Avenue

(614) 424-3321 (F)

Columbus, Ohio 43201-2693

Mark Paisley

6. Themoselect, Inc.

(810) 689-3060

Columbia Center Suite 230

210 W. Big Beaver Road

(810) 689-2878 (F)

Troy, MI 48084

David J. Runyon 
7. Entropic Technologies

4660 South Hagadorn Road

East Lansing, MI 48823

Mark Battaglia

8.Pedco Incorporated

216 East 9th Street, 5th Floor

Cincinati, Ohio 45202

William H. Long

9. Thermogenics, Inc.

3620 Wyoming Blvd. NE - Suite 210

Alburquerque, New Mexico 87111

Stephen Brand

10. Waste Conversion Systems

14590 East Freemont Ave

Englewood, CO 80112

Stan Abrams

11. Institute of Gas Technology

1700 South Mount.Propect Road

Des Plains, Illinios 60018-1804

Ronald H. Carty

12. Bioenergy Development Corp.

220 W. 18th Street - 2nd floor

New York, New York 10011

Earl A. Rogers

EarlA.Rogers
(517) 351-4901

(517) 351-9149 (F)
(513) 784-0033

(513) 241-7958 (F)
(505) 298-4381

(505) 296-4860 (F)
(303) $690-8300$

(303) 690-6336 (F) 
13. Cratech, Inc.

Route 5, 2303 North Second

Tahoka, Texas 79373

Joe D. Craig, President

14. Wright Malta Corporation

Malta Test Station, Plains Road

Ballston Spa, New York 12020

J.A. Coffman

15. PRM Energy Systems, Inc.

504 Windamere Terrace

Hot Springs, AR 71913

Ron Bailey

16. Sur-Lite Corp.

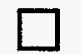

8124 Allport Avenue

Santa Fe Springs, CA 90670

Deward Gjerde, General Manager

17. Morbark Industries

8507 South Winn Road

Winn, MI 48896

$\square$

(517) $866-2381$

(800) 831-0041

(517) $866-2280$ (F)

(501) $767-2100$

(501) $767-6968$ (F)

(310) 693-0796

(310) 693-7564 (F)

(518) $899-4799$ (F)

Run Demlow

18. Ahlstrom - Pyropower (Proflow)

(619) $458-3000$

8925 Rehco Road

(619) $457-1216$ (F)

San Diego, California 92121 
20. Procedyne

$\square \quad(908) 249-8347$

11 Industrial Drive

(908) 249-7220 (F)

New Brunswick, NJ 08901

Thomas Parr, Manager Process Division

21. Wayne Technology Corp. $\quad \square \quad$ (803) 223-4964

625 East Durst Avenue

(803) 229-4382 (F)

Greenwood, SC 29649

Gary Gunderson

23. SRI International

$\square \quad(415) 859-2430$

333 Ravenswood Ave.

(415) 859-3395 (F)

Menlo Park, CA 94025-3493

David Ross

24. KFX Inc.

(303) 293-2992

1999 Broadway Street, Suite 2505

(303) $293-8430$ (F)

Denver, CO 80202

Theodore Venners

25. Molten Metals Technology

51 Sawyer Road

Waltham, Massachusetts 02154

(617) $487-9700$

(617) 487-7870 (F)Ext. 7648

Karen Colette

26. Arizona State University

$\square \quad$ (602) $965-0745$

Center for Energy Research , Box 875806

(602) $965-2896(\mathrm{~F})$

Tempe, Arizona 85257-5806

Dr. Tong 
27. University of Alabama

R I Building , Room E33

Huntsville, Alabama 35899

Dr. Brain Landrum

28. International Technologies, Inc.

1710 West Flecher Street

Chicago, Mlinios 60657

Paul Baskis (Technical), Mike Fink (Business)

29. Destech Energy

2500 City West Blvd., Suite 150

Houston, Texas 77042

Mark Roll

30. EnerTech Environmental, Inc.

430 Tenth Street N.W. Suite N-104

Atlanta, Georgia 30318

Micheal Klosky

31. Energy Product of Idaho

8014 Germantown Road

Philadelphia, PA 19118

Joyce M. Ferris

32. Sofresid

Paris, France

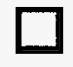

$011+3314818-4160$

$011+331$ 4818-4497 (F)
(312) $472-5006$

(217) $892-8825$

(713) $735-4000$

(713) $735-4059$ (F)
(312) $472-7283$ (F)
(404) $892-9440$

(404) 892-8816 (F)
(215) 248-5244

(215) 248-2381 (F)

Goare Guer 
33. Lurgi Energy

$011+496958083468$

Umwelt Gmbh.

$011+496958082757$ (F)

Lurgi Allee \#5

Frankfort 60295 Germany

Johannes C. Loffler

34. Voest Alphine

$011+4373265928625$

Turmstrasse \#44

$011+4373265922884$ (F)

Linz, Austria

extension

(They will ask for the fax

J. Lehner

and the "answer" is: 2884)

35. ThermoChem, Inc.

(310) $941-2375$

13080 Park Street

Santa Fe Springs, CA 90670

(310) $941-2732(\mathrm{~F})$

K. Durai-Swami SVP-Technology Applications

36. Comprehensive Resources Recovery \& Reuse $\square$

(415) 345-0502

628 Plymouth

(415) 369-4982 (F)

Foster City, CA 94404

Micheal E. Cole

37. HydroMax

257 Water Street, Suite 2E

New York, NY 10038

Marc Kalish (pron. kay-lish)

38. Foster Wheeler Development Corp.

(201) 535-2332

12 Peach Tree Hill Road

Livingston, NJ 07039

(201) $535-2242$ (F)
(212) $385-7560$

(212) $967-3018$ (F) 
48.TPS Termiska Processor AB

011-46-155-22-1385

Studsvik AB S.611 82

011-46-155-26-3052 (F)

Nyköping, Sweden

Erik Rensfelt

50. Lawrence Livermore National Lab.

(510) $423-7053$

(510) 423-0618 (F)

Livermore, CA

(working with Texaco/Montebello/Neil Richter

Firms that could not be contracted or who indicated "no interest"(marked "X")

39. Southern Electric International 900 Ashwood Parway

(404) $261-4700$

Suite 500

(404) $804-9610(\mathrm{~F})$

Atlanta, Georgia 30338

William S. Bulpitt

19. Texaco, Inc., Montbello Research Lab $\square$

(310) 908-7238

329 North Durfee Ave.

(310) $692-4625$ (F)

El Monte, CA 91733

(310) 699-7408 (F-Backup)

Thomas Leininger

22. Interchem Environmental, Inc.

(913) $599-0800$

9135 Barton

(913) $599-2923$ (F)

Oveland Park, Kansas 66214

Lee Derr

40. Halcyon Associates

41. Kellog-Rust -Westinghouse

42. EDP 
43. Xytell Bechtelle

(713) $984-6700$

1400 Brittmore Road

Houston, TX 77043

44. Conrad

45. GM/Lasco Steel

46. SRS

47. PUROX Contact made. Telephone shut off without forwarding address.

49. Ebara 


\section{Camp Dresser \& McKee Inc.}

10 Cambridge Center

Cambridge, $M A 02142$

(617) $252-8357$

Fax: (617) $621-2565$

FAX TRANSMISSION COVER SHEET

Date: $\quad$ August 15, 1996

To: $\quad$ Thermal Processing Developer Mr

Re: $\quad$ National Renewable Energy Laboratory (NERL) Assignment

Sender: $\quad$ Walter R. Niessen

YOU SHOULD RECEIVE 3 PAGE(S), INCLUDING THIS COVER SHEET. IF YOU DO NOT RECEIVE ALL THE PAGES, PLEASE CALL (617) 252-8357.

On May 8, 1995 the National Renewable Energy Laboratory (NREL), an organization formed and reporting to the U.S. Department of Energy, awarded Camp Dresser \& McKee Inc. (CDM) a contract to evaluate a limited number of thermal processing technologies that are (or could be) applicable to municipal solid waste (MSW). Although gasification-based processes have been highlighted by NREL, other advanced or novel thermal methods are of equal interest. We understand that your organization is involved in the development and commercialization of a technology in one of these categories. This letter invites you to consider participation in the NREL project.

The primary objective of the NREL work is to prepare an up-to-date, comprehensive and objective report on the selected processes. Each report will stand on its own: the project does not "pick a winner" or compare technologies. The scope of each report is quite broad and includes the presentation of facts, judgments and analytical results in the following areas:

- Technical - Flowsheets, heat \& material balances, basic principle of operation

- Environmental - Air and water emissions, residue characteristics

- Business - Financial strength and resources

- Cost/Economics - As projected back to MSW waste management costs

- Operations - Reliability, flexibility, maintenance/operational features

- Implementation - Resources and strategy to move into commercialization phase

The activities during the first 30 days of our contract effort fall into two areas: (1) development of a comprehensive Work Plan and (2) selection of the candidates. The Work Plan is the 
blueprint for the report: what information will be sought? how will the information be analyzed and used? and in what form will the work product be presented. I mention this task to illustrate the fact that the detailed framing of our work is still evolving.

The second work area involves selecting the technologies to be evaluated. We have prepared a master list of over 40 candidates including what we trust are the correct addresses, the names of the most appropriate "contact persons", and the telephone/FAX numbers. This FAX marks our first formal contact with your firm. We ask you to fill out a return FAX (attached) to open the dialogue from your end. In the very near future (within a week or thereabouts) we plan to contact you directly by telephone. From these initial exchanges, we will collect sufficient information to produce a "short list" of approximately 20 technologies by May 25th. Following a second round of contacts in late May and early June, we will meet with NREL to select the final technologies that meet the project guidelines. That will mark the beginning of the in-depth data collection and analysis effort.

The ultimate report effort for the seven selected candidates will be comprehensive. It will include an inspection visit by CDM engineers to operating pilot plants or commercial facilities embodying the candidate technologies. Also, we anticipate in-depth discussions and exchanges of information and perspectives with appropriate technical, business and environmental specialists from the candidate firms. From these data and subsequent analysis, we will strive to produce a fair and insightful review of each technology and its potential applicability to MSW management problems. The proposed readership includes, importantly, potential "buyers" of systems as well as consultant organizations, academic researchers and governmental agency/laboratory staff professionals.

The CDM project team looks forward to contacting you within the next 10 days. Again, if you wish to consider participation in the project, please complete and return-FAX the message on the following page.

Very truly yours, CAMP DRESSER \& McKEE INC.

Walter R. Niessen - Principal Investigator Investigation Team: Paul J. Stoller Charles H. Marks

Robert E. Sommerlad 


\section{Appendix B Fax Request for Basic Data}

To: Walter R. Niessen - Camp Dresser \& McKee Inc.

Fax: $\quad(617) 621-2565$

From:

Date: May _, 1995

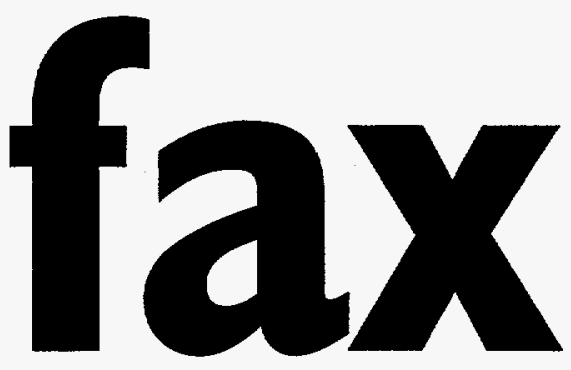
, including cover sheet.

- We are in receipt of your FAX message regarding the NREL project but have no interest in the project at this time. $\square$

- Our firm may have an interest in participation. The correct and complete name of our firm is:

- The contact person you should talk to is:

- The street address (no Box numbers, please) is: Street

City State Zip

- The best telephone/FAX number to use in the next 10 business days is:

Telephone ( ) , $\operatorname{FAX}(\quad)$

- Message: 


\section{Appendix C. Preliminary Request for Data from Seven Processes}

Dear Mr.

As the first step in our project for the National Renewable Energy Laboratory, Camp Dresser \& McKee Inc. (CDM) has completed its preliminary screening of over 50 gasification and advanced thermal processing technologies applicable to municipal solid waste (MSW). As we have described to you and/or others in your firm, our project is intended to prepare a "state-of-the-art" report limited to a maximum of seven processes which best meet the following criterion:

o State of Development - Near to or just at the "commercial stage". All major process issues are to have been researched and resolved by the system provider. Tests should have been conducted at a scale of more than three tons per day and for a cumulative duration of more than 300 hours to demonstrate practical feasibility. At this point in our evaluation, it should appear that the process is technically feasible and potentially recommendable to communities desiring an advanced solid waste processing technology and prepared to accept some (but not excessive) technical risks.

o Business Focus - Clearly targeted on the processing of MSW. The candidate's policy in this matter should be visible both in their present business thrust and in the degree of focus on MSW issues in prior and on-going process development testing. Business planning should "fit" with the U.S. MSW marketplace as it is characterized by the type and quantity of available MSW, energy and materials markets and the nature of typical MSW management contractual agreements.

I am pleased to inform you that your firm and its waste processing process were selected as one of the seven processes to be evaluated. Specifically, I//Mr. Charles E. Marks/Mr. Robert E. Sommerlad will be the project leader for our review and evaluation or your process although others of our core team of senior specialists also will be involved. We expect to begin work in earnest over the next several weeks and have targeted the end of the year for completion of our work and submission of a draft report. In the interim, we hope to become much more familiar with your process and your status in implementation.

The ultimate objective of this project is to produce a public document in the form of a report that includes a comprehensive description of your process (and six others) together with the associated technical, environmental and financial characteristics. It is intended that our report will be made widely available to individuals, to consulting engineers, full-service MSW contractors, researchers and representatives from the various levels of government who have responsibility for solid waste management. Our present concept of our work product is best communicated by indicating the expected "Table of Contents" (see attached).

Specifically, we will seek the following information from you which we hope to replicate in our report: 
- A relatively complete flowsheet showing all major items of process equipment; - A complete heat and material balance tracking all significant mass and energy flows through the system;

- Any available air or water-borne emission data; and information on the economics (capital and operating costs, and any prospective revenue streams).

- General information (such as hours of operation, tons processed etc.) that characterizes the state of development and testing of the key technical features of the process.

We expect that the above information, specifically, will be made available to us free of constraints regarding disclosure to others. However, you may regard some of the details of your process, some of the equipment designs, aspects of operating techniques or conditions/set-points and other matters as proprietary or "company confidential". You will understand that once our report is printed, we lose any control on access and use of the information contained therein.

We recognize that this may produce a conundrum: how can we be exposed to enough information in enough depth to fully understand your process and its technical status while producing a report which protects your investment in technology development? On the other hand, we are not generating a "design manual" nor is our work "comparative" (each process chapter is free-standing). Our report need not include any subtleties of operating technique, set points, intricate discussions of control logic, details of materials of construction selections etc. (excepting, indirectly, as they relate to cost).

In view of these considerations we are willing, if requested, to execute a confidentiality agreement providing for the protection of your proprietary technology when explicitly marked as such, for a reasonable time period (e.g., 5 years) and subject to the conventional releases for information received from third parties or subsequently made public by you.

Please note that our contractual project manager and other members of the project "steering committee" (representing the National Renewable Energy Laboratory, the U.S. EPA, the U.S. Department of Energy and a representative of Southern California Edison) have a strong interest in fully understanding our work and the characteristics of your process. It is desirable if they can have access to as much as possible of the written data on your process without execution of a confidentiality agreement. Thus, please minimize the classification of data if it is not necessary to do so. If you believe it is critical, the steering committee members have indicated that they can execute such an agreement (although with difficulty).

Additionally, at the conclusion of our work when we have prepared a draft of the chapter of the final report relating to your process, we will submit a copy of the chapter for your review. We expect to allow two weeks for your review. At that time you can indicate those elements of the report where (if at all) you believe that proprietary information is revealed and we will edit/delete/mask same to our mutual agreement in the final text of the report. Also, if you disagree with our observations and conclusions or our editorial comments or critiques, you will have the opportunity to (briefly) provide a "rebuttal" which either will be inserted as a footnote or will be accepted and appropriate changes made. We reserve the right to limit the number and 
length of such commentaries.

We trust that this arrangement is satisfactory. If so, please provide a suitable confidentiality agreement (if one is necessary) which will be executed by me on behalf of the NREL project team. If you have remaining concerns or questions, please do not hesitate to call me at (617) 252/8357/Mr. Marks at (617) 784-6374/Mr. Sommerlad at (908) 272-5667. We look forward to working with you and your associates over the next several months.

Very truly yours,

CAMP DRESSER \& McKEE INC.

Walter R. Niessen, P.E.

Senior Vice President

Enc/

cc: C.H. Marks, R.E. Sommerlad, P.J. Stoller 


\section{Appendix D}

\section{WASTE GASIFICATION or NOVEL THERMAL PROCESSING FACILITIES}

Please fill out if applicable. If quantitative answers are requested, please give ranges if appropriate. For our visit we will formulate more detailed questions based on your answers. Please note that the answers will be used for our report, which will be distributed.

1.

\section{BRIEF HISTORY}

Since when has the plant been in operation (month/year)?

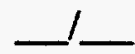

What is the current status of the plant?

demonstration/pilot

_on-line intermittent shut down

commercial on-line intermittent shut down

What is the longest continuous operating period hrs, days?

What was the waste processing rate during that period?

average
maximum
(ton $/$ day, tonnes/day)

Describe briefly the history of laboratory and pilot plant studies. If commercial, what has been the availability of the plant (operable hours per year/8760) since starting operation from year to year (if only shorter periods are applicable. Please indicate)?

1992

$\%$

1993

$\%$

1994

$\%$

1995 $\%$

What has been the unscheduled shut-down time of the plant so far?

1992 _hrs _\%

1993 _hrs _\%

1994 _hrs _\%

1995 _hrs _\% 
Which are the reasons for the unscheduled shut-down time? Problems with any of the following system components (indicate relative importance):

- fuel supply/preparation

- gasifier

- combustion

- gas cleaning

- $\quad$ electricity/heat generation

2. THE PROCESS

Please supply us with a process description and flowsheets of the process including temperatures, mass flows and energy flows, enabling us to present mass and energy balances.

Process Description attached?

Flowsheets attached?

Mass balances attached?

Energy balances attached?

Plant lay-out/plant dimension sheet attached?

What is the maximum capacity of one process-line of the present plant?

(tonnes of waste/day, tons/day)*

How many process lines have been installed for the present plant?

$\begin{array}{ll}-\quad \text { one } \\ - & \text { two }\end{array}$

What is the thermal capacity ( $\mathrm{MW}_{\mathrm{th}}, \mathrm{Btu} / \mathrm{hr}$ ) of one reactor?

$$
\begin{aligned}
& \text { minimum:___ }\left(\mathrm{MW}_{\mathrm{th}}, \mathrm{Btu} / \mathrm{hr}\right) \\
& \text { maximum__ }\left(\mathrm{MW}_{\mathrm{th}}, \mathrm{Btu} / \mathrm{hr}\right)
\end{aligned}
$$

* $\quad$ indicate units as applicable 
What elements of the system (from waste receipt to residue/flue gas treatment) are under test or remain to be tested/developed?
element
$\underline{\text { under test }}$
to be tested

1.

2.

3.

4.

3. WASTE FEED (WASTE) SPECIFICATIONS

Which type of waste is the plant designed for (specification concerns, type, components, composition)?

RDF (please specify):

selected types of waste (please specify)

all types of waste (please specify)

Which type of waste is used currently?

What is the waste configuration required?

pellets (cylindrical)

briquettes

bulky material

"fluff"

What is the type of the waste used currently?

What are the required dimensions of the waste?

What are the dimensions of the waste used currently?

Length $(\mathrm{mm}) \mathrm{x}$ diameter (mm) $\mathrm{x}$ height (mm)

Required bulk density $\left(\mathrm{kg} / \mathrm{m}^{30}, \mathrm{lb} / \mathrm{cft}\right)$ :

Bulk density of the used waste $\left(\mathrm{kg} / \mathrm{m}^{30}, \mathrm{lb} / \mathrm{cft}\right)$ :

What is the required/used waste composition?

Proximate analyses design used

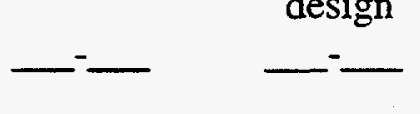


(wet basis, mass\%)

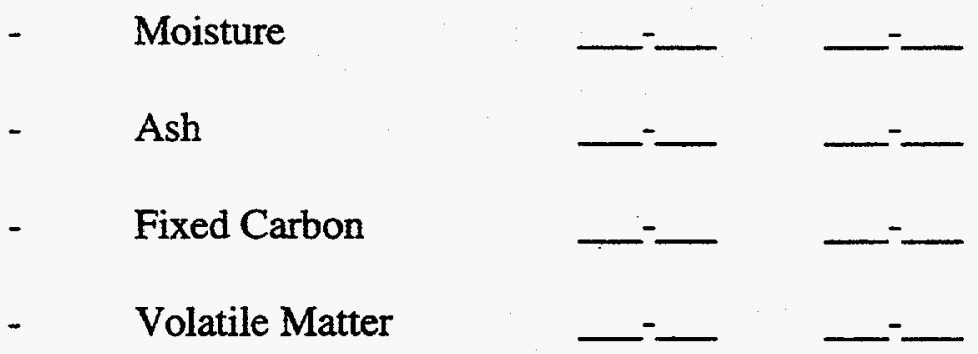

Some components from the ultimate analysis (dry basis, mass\%):

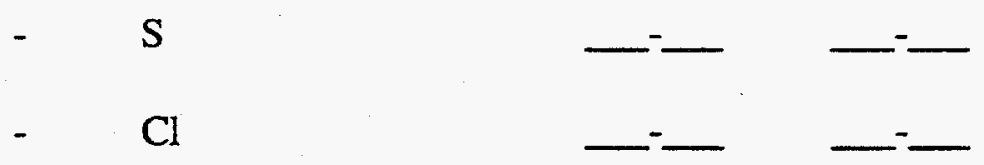

What is the required range of caloric value (LHV or $\mathrm{HHV}_{ـ}$ ) $(\mathrm{MJ} / \mathrm{kg} \mathrm{Btu} / \mathrm{lb})$ ?

What is the actual range caloric value (LHV or HHV ) of the waste (MJ/kg Btu/lb)?

What is the ash melting point/range $\left({ }^{\circ} \mathrm{C} /{ }^{\circ} \mathrm{F}\right)$ ?

Other aspects with respect to waste quality:

Can US waste (specifications attached) be processed in the plant?

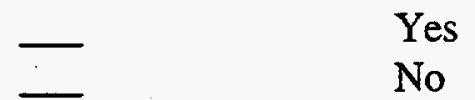

If "Yes", is special pre-treatment required?

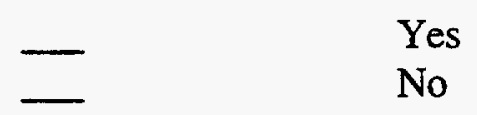

3a. AUXILIARY FUEL

Is auxiliary fuel/energy required?

Yes

No

If so, specify - type

quality (Btu/cft, KWH per ton, $\mathrm{MW}_{\mathrm{th}}$ per tonne) 


\section{PRODUCT/GAS SPECIFICATIONS}

What is the raw gas composition at the reactor outlet (in volume\%)?

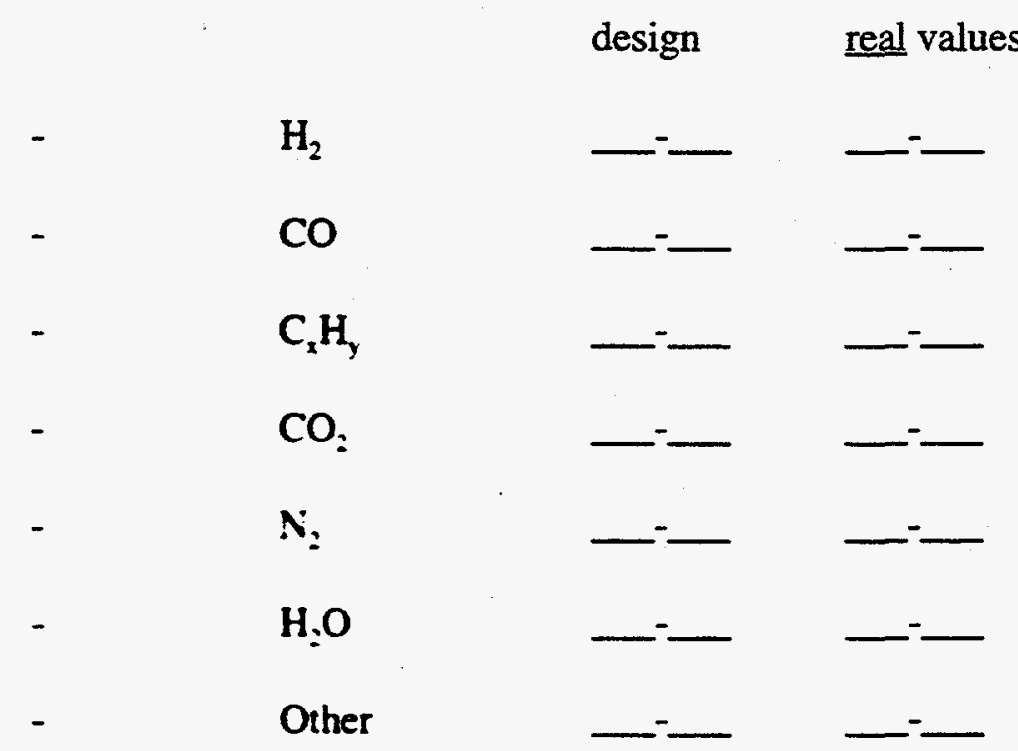

What is the specified concentration of the following components in the product gas at the mentioned locations in the process? (units? corrected to

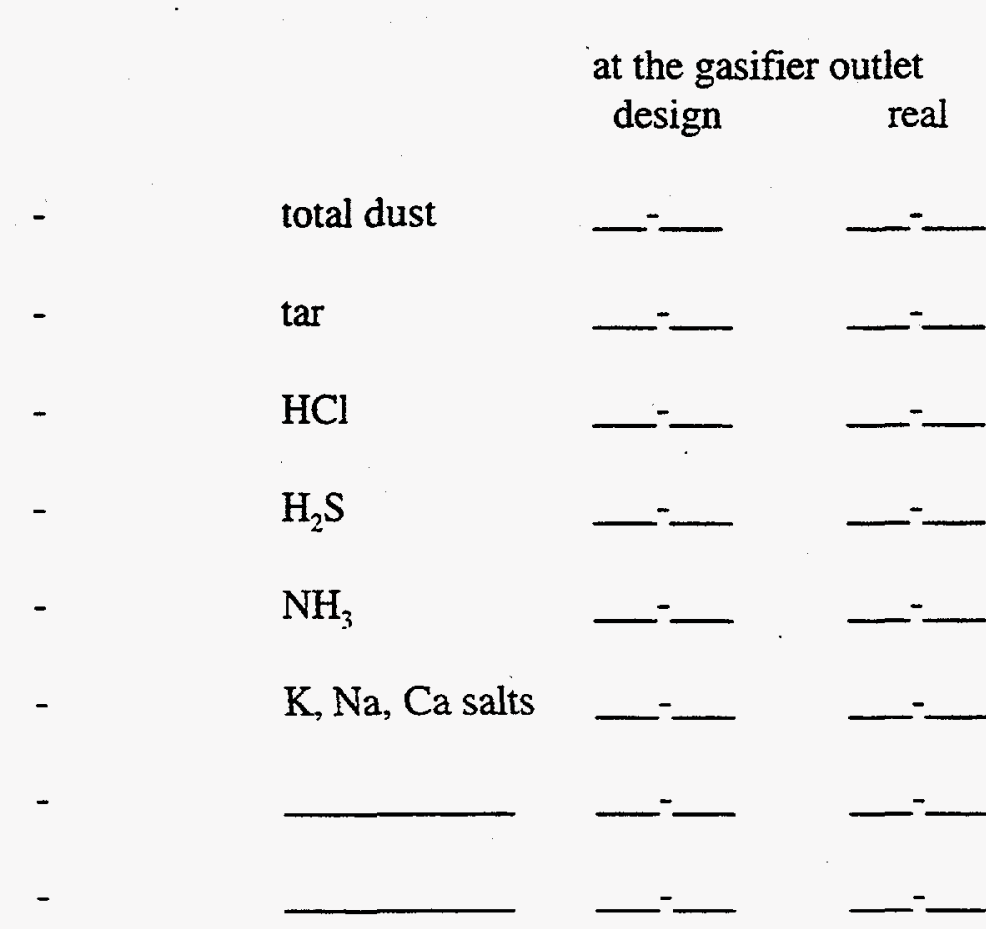
after gas cleaning
design

real 
pressure (bar absolute)

temperature $\left({ }^{\circ} \mathrm{F}\right)$

What is the production rate?

$\left(\mathrm{Nm}^{3} /\right.$ tonne, scft/ton $)$

5.

\section{OPTIMIZATION ${ }^{1}$}

Can the process be optimized with respect to the energy efficiency?

$\begin{array}{ll}- & \text { Yes } \\ - & \text { No }\end{array}$

How much improvement in efficiency do you expect?

Electric efficiency $\quad-\%$
Thermal efficiency
$-\%$

Can the process be optimized with respect to the emissions?

- $\quad$ Yes

Is more energy needed to achieve minimum emissions?

$\begin{array}{ll}- & \text { Yes } \\ - & \text { No }\end{array}$

Please fill out the minimum achievable emissions under "Environmental aspects".

6.

$$
\text { SCALE-UP }{ }^{2}
$$

Where in the process are any limitations in scale-up?

In the reactor sections

In the process train after the reactor sections

What is the expected maximum capacity of one process-line?

With respect to the present plant configuration; concerns optimization by fine tuning etc.

Concerns future plants, which might differ from the present plant. 
tonnes of waste/hr, ton $/ \mathrm{hr}$ of waste

heat input $\left(\mathrm{MW}_{\text {input }}, \mathrm{Btu} / \mathrm{hr}\right)$

7. ENVIRONMENTAL ASPECTS

What are the emissions (in $\mathrm{mg} / \mathrm{m}_{0}{ }^{3}$, gr/cft dry flue gas at $11 \% \mathrm{O}_{2}, 7 \% \mathrm{O}_{2}$ ) of the plant (if you have more data on realized emissions, please specify)? specified realized after optimization

(expected)

total dust

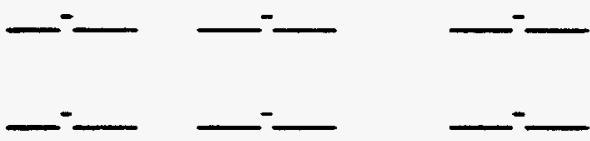

$\mathrm{HCl}$

fluorides

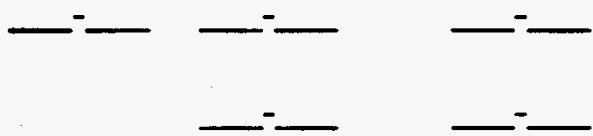

$\mathrm{CO}$

organic compounds (as C)
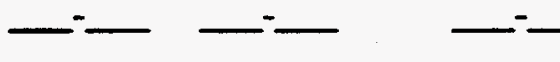

sulphur oxides

(as $\mathrm{SO}_{\mathbf{x}}$ )

nitrogen oxides

(as $\mathrm{NO}_{2}$ )

toxic metals $\mathrm{Sb}+\mathrm{Pb}+\mathrm{Cr}+\mathrm{Cu}+\mathrm{Mn}+\mathrm{V}+\mathrm{Sn}+\mathrm{As}$
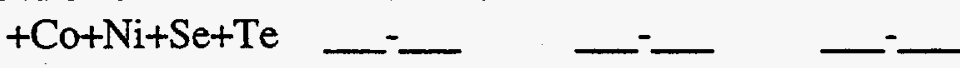

$\mathrm{Cd}$
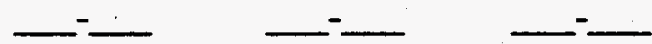

$\mathrm{Hg}$
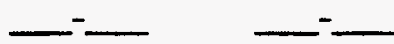

dioxins \& furans

(PCDDs and $\mathrm{PCDFs}$ in $\mathrm{ng} \mathrm{TEQ} / \mathrm{m}_{0}{ }^{3}$ )

What residue and effluent discharge streams are produced and in which quantities (in $\mathrm{kg} /$ tonne, $1 /$ tonne, $\mathrm{lb} / \mathrm{ton}$, gal/ton)? Please describe.

Heavy/toxic metals (mg/kg waste):

$\mathrm{Pb}$ residue

effluent 


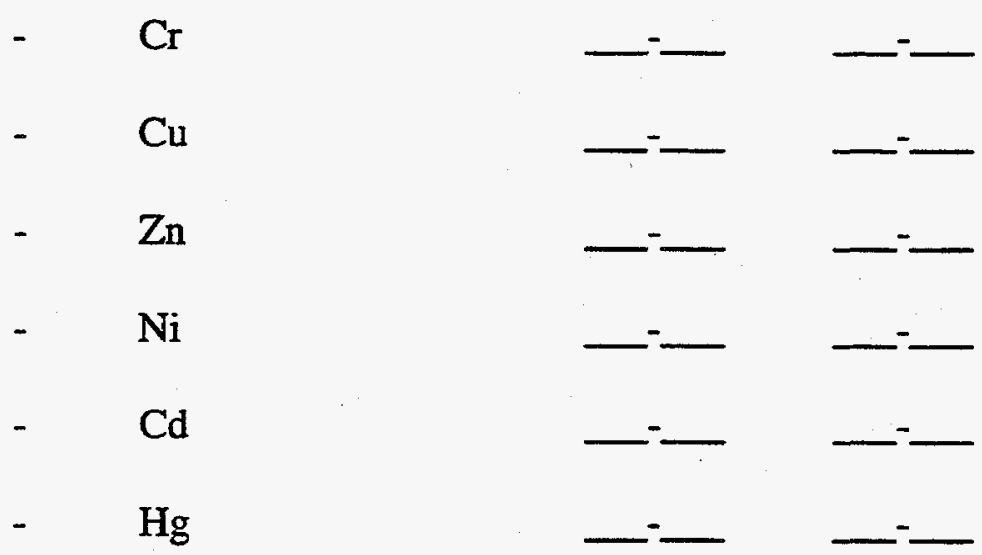

Please supply us with as much information concerning quantity and the characteristics (toxicity, leachability, configuration, composition) and the processing potential of the by-products as possible.

Information attached?

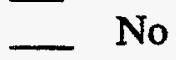

\section{COMPLEXITY AND RELIABILITY}

How many total employees are needed for running the plant?

How many annual manhours are needed for running the plant? manhrs/yr

How many shifts are needed for operation? shifts

How many maintenance (man)hours are needed for the plant annually? manhrs/yr

Are there any fundamental problems in plant operation presently?

- Yes

- No

Are there any problems in plant operation which can be solved in a short term?

- Yes

Is the process sensitive to corrosion/erosion?

- Yes

- No

Are special measures taken/required for safety? e.g. for reducing risk of fire, explosion, etc.?

- Yes

- No 
What?

\section{FINANCIAL ASPECTS}

How many running hours are planned for commercial operation annually? hrs

What is the planned availability of the plant annually?

What is the assessed technical lifetime of the complete plant? $\%$ years

What is the currency in which the amounts are presented?

Italian Lire

German Mark

US Dollar

Other:

Please present requested costs in present values:

What are the investment costs of:

the complete plant:

the process line:
- capacity: tonnes waste/hr capacity: tonnes waste/hr

What are the specific investment costs (per tonne waste) of:

the complete plant (two lines): the process line: capacity:

capacity: tonnes waste/hr tonnes waste/hr

Please fill in the following table:

Main component invest. cost

technical

lifetime of component materials personnel 


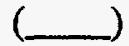

(yr)

Preprocessing

Feeding system

Ash discharge system

Reactor

Flue gas treatment

Product gas treatment

Ash treatment

Water treatment

Heat exchangers

Power generation

What is the accuracy of the afore mentioned investment costs?

within $10 \%$

within $20 \%$

within $30 \%$

other limit:

What are the local operatinging costs of the total plant?

Breakdown:

per year

per tonne waste

$+\quad$ depreciation of investments 
$+1-$

$+$

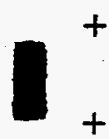

$+1$

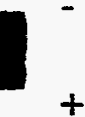

$+$
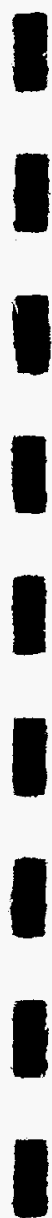

(NREL EVAL/REVISION $1 ; 8 / 10 / 1995)$ fuel costs

operation

maintenance

consumables

by-products

electricity/heat sold

other

TOTAL COSTS
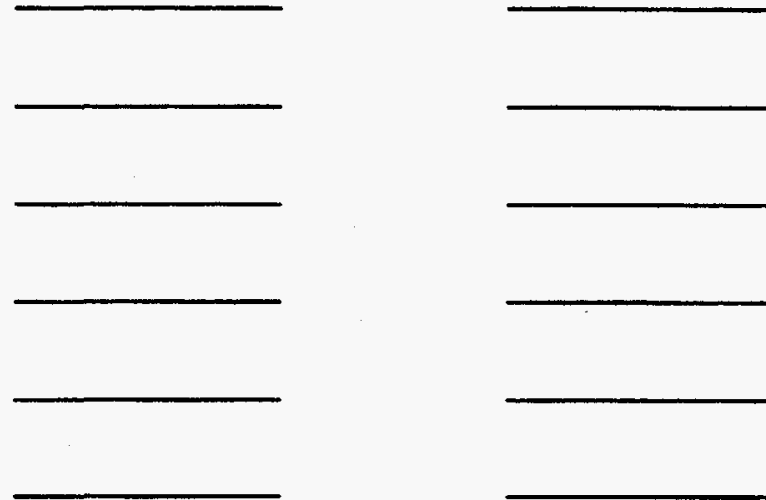
Appendix D

\section{WASTE GASIFICATION or NOVEL THERMAL PROCESSING FACILITIES}

Please fill out if applicable. If quantitative answers are requested, please give ranges if appropriate. For our visit we will formulate more detailed questions based on your answers. Please note that the answers will be used for our report, which will be distributed.

\section{BRIEF HISTORY}

Since when has the plant been in operation (month/year)?

What is the current status of the plant?

demonstration/pilot

_on-line _ intermittent shut down

commercial on-line intermittent shut down

What is the longest continuous operating period hrs, days?

What was the waste processing rate during that period?

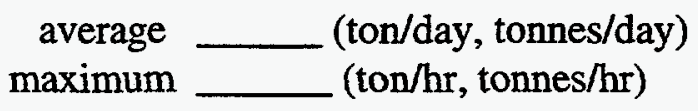

Describe briefly the history of laboratory and pilot plant studies. If commercial, what has been the availability of the plant (operable hours per year/8760) since starting operation from year to year (if only shorter periods are applicable. Please indicate)?

1992

$1993 \ldots \%$

1994

1995

What has been the unscheduled shut-down time of the plant so far?

1992 _hrs _ $\%$

$1993 \ldots$ hrs _ $\%$

$1994 \ldots$ hrs _ $\%$

$1995 \ldots$ hrs _ $\%$ 
Which are the reasons for the unscheduled shut-down time? Problems with any of the following system components (indicate relative importance):

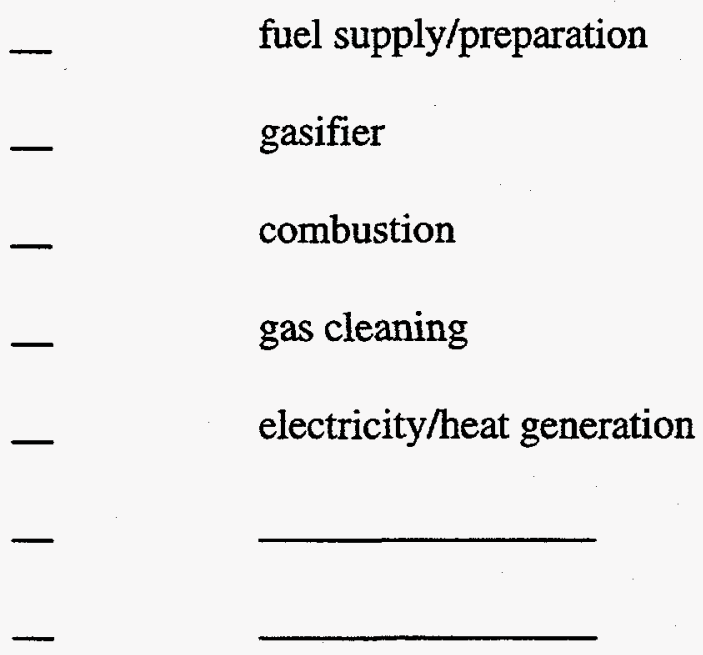

2. THE PROCESS

Please supply us with a process description and flowsheets of the process including temperatures, mass flows and energy flows, enabling us to present mass and energy balances.

Process Description attached?

Flowsheets attached?

Mass balances attached?

Energy balances attached?

Plant lay-out/plant dimension sheet attached?

What is the maximum capacity of one process-line of the present plant?

(tonnes of waste/day, tons/day)*

How many process lines have been installed for the present plant?

$$
\begin{aligned}
& \text { one } \\
& \text { two }
\end{aligned}
$$

What is the thermal capacity (MWth, Btu/hr) of one reactor?

$$
\begin{aligned}
& \operatorname{minimum}: \_\left(\mathrm{MW}_{\mathrm{th}}, \mathrm{Btu} / \mathrm{hr}\right) \\
& \text { maximum } \quad\left(\mathrm{MW}_{\mathrm{th}}, \mathrm{Btu} / \mathrm{hr}\right)
\end{aligned}
$$

$*$

indicate units as applicable 
What elements of the system (from waste receipt to residue/flue gas treatment) are under test or remain to be tested/developed?
element
under test
to be tested

1.

2.

3.

4.

3. WASTE FEED (WASTE) SPECIFICATIONS

Which type of waste is the plant designed for (specification concerns, type, components, composition)?

RDF (please specify):

selected types of waste (please specify)

all types of waste (please specify)

Which type of waste is used currently?

What is the waste configuration required?

pellets (cylindrical)

briquettes

bulky material

"fluff"

What is the type of the waste used currently?

What are the required dimensions of the waste?

What are the dimensions of the waste used currently?

Length $(\mathrm{mm}) \mathrm{x}$ diameter (mm) $\mathrm{x}$ height $(\mathrm{mm})$

Required bulk density $\left(\mathrm{kg} / \mathrm{m}^{30}, \mathrm{lb} / \mathrm{cft}\right)$ :

Bulk density of the used waste $\left(\mathrm{kg} / \mathrm{m}^{30}, \mathrm{lb} / \mathrm{cft}\right)$ :

What is the required/used waste composition?

Proximate analyses design used

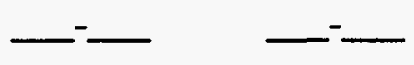


(wet basis, mass\%)

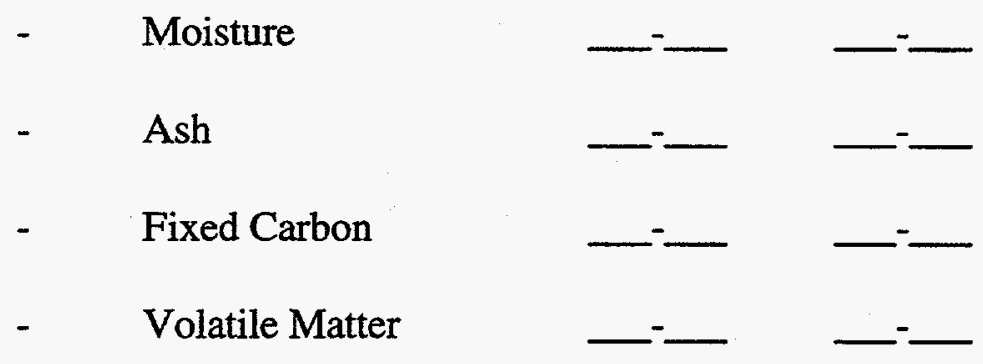

Some components from the ultimate analysis (dry basis, mass\%):

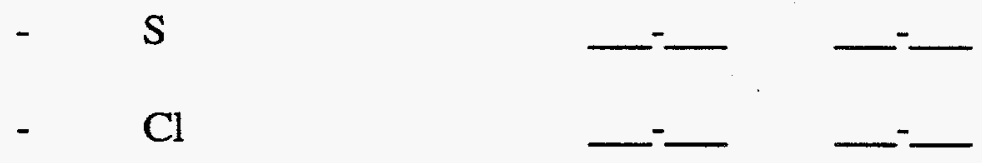

What is the required range of caloric value (LHV or $\mathrm{HHV}_{\longrightarrow}(\mathrm{MJ} / \mathrm{kg} \mathrm{Btu} / \mathrm{lb})$ ?

What is the actual range caloric value ( $\mathrm{LHV}$ or $\mathrm{HHV}_{\text {__ }}$ ) of the waste $(\mathrm{MJ} / \mathrm{kg} \mathrm{Btu} / \mathrm{lb})$ ?

What is the ash melting point/range $\left({ }^{\circ} \mathrm{C} /{ }^{\circ} \mathrm{F}\right)$ ?

Other aspects with respect to waste quality:

Can US waste (specifications attached) be processed in the plant?

$\underset{-}{\square} \quad$ Yes

If "Yes", is special pre-treatment required?

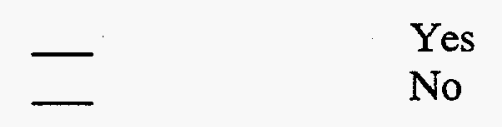

3a. AUXULIARY FUEL

Is auxiliary fuel/energy required?

Yes

- No

If so, specify - type

quality (Btu/cft, KWH per ton, $\mathrm{MW}_{\mathrm{th}}$ per tonne) 


\section{PRODUCT/GAS SPECIFICATIONS}

What is the raw gas composition at the reactor outlet (in volume\%)?

$$
\text { design real values }
$$

$\mathrm{H}_{2}$

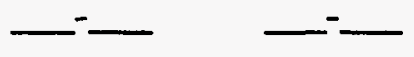

$\mathrm{CO}$

$\mathrm{C}_{\mathrm{x}} \mathrm{H}_{\mathrm{y}}$
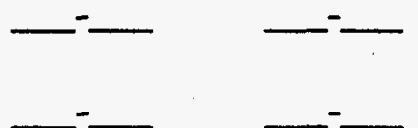

$\mathrm{CO}_{2}$
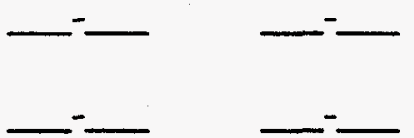

$\mathrm{N}_{2}$

$\mathrm{H}_{2} \mathrm{O}$
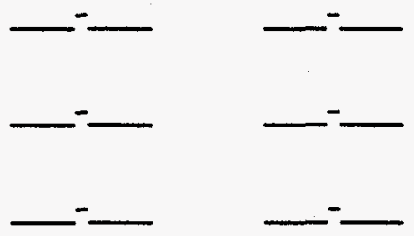

- Other
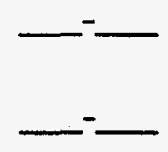

What is the specified concentration of the following components in the product gas at the mentioned locations in the process? (units? corrected to

$\begin{array}{ll}\text { at the gasifier outlet } & \text { after gas cleaning } \\ \text { design } & \text { real }\end{array}$

real
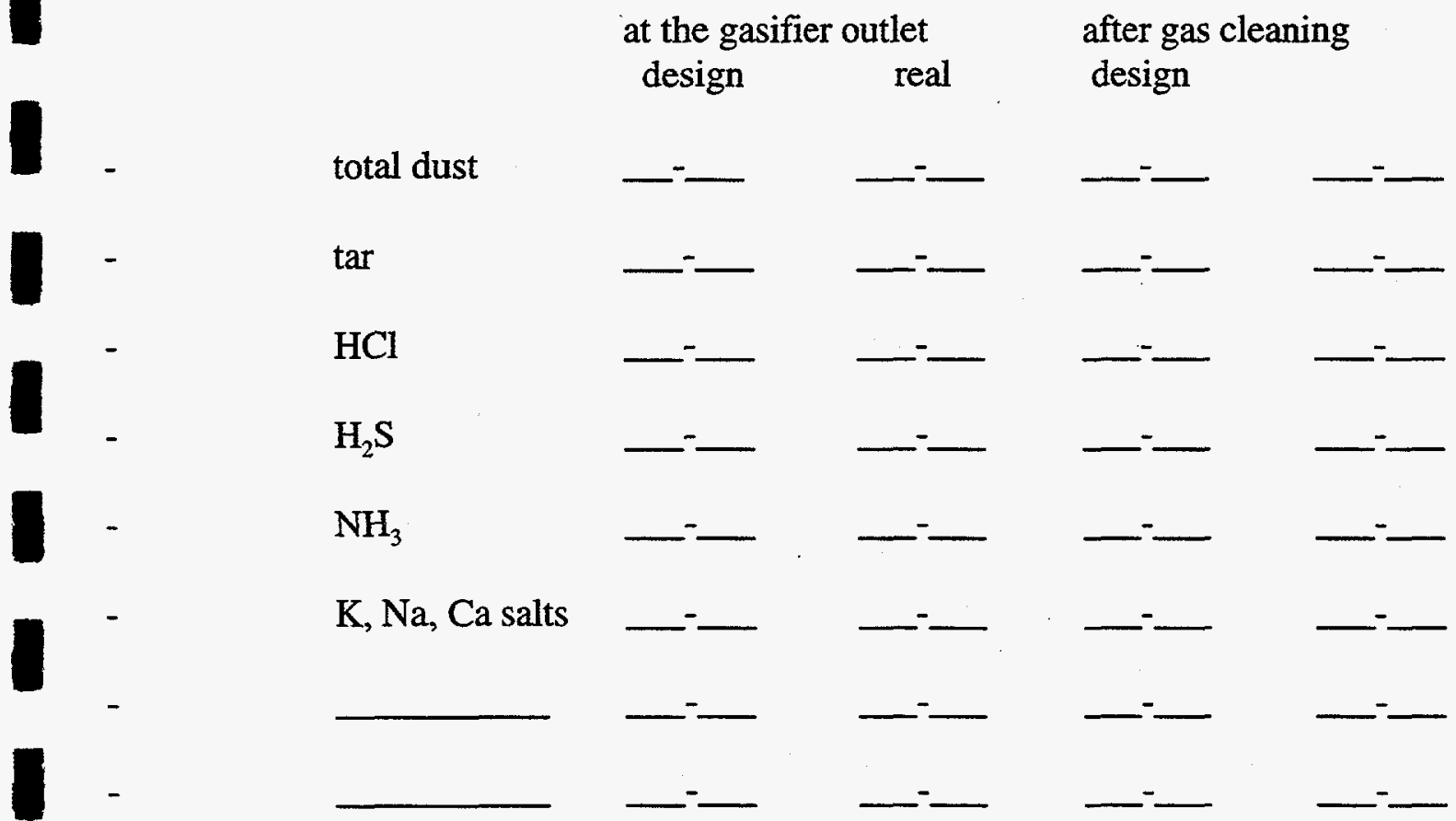

What is the specified dust particle size $(\mu \mathrm{m})$ in the gas after the gas cleaning section? What is the specified calorific value ( $\mathrm{LHV}$ or $\mathrm{HHV}_{\ldots}$ ) of the product gas $\left(\mathrm{MJ} / \mathrm{m}_{0} 3, \mathrm{Btu} / \mathrm{cft}\right)$ ? What is the specified enthalpy of the product gas $\left(\mathrm{MJ} / \mathrm{m}_{0}{ }^{3}, \mathrm{Btu} / \mathrm{cft}\right)$ ? 
pressure (bar absolute)

temperature $\left({ }^{\circ} \mathrm{F}\right)$

What is the production rate?

( $\mathrm{Nm}^{3} /$ tonne, scft/ton)

5.

OPTIMIZATION ${ }^{1}$

Can the process be optimized with respect to the energy efficiency?

Yes

No

How much improvement in efficiency do you expect?

$\begin{array}{ll}\text { Electric efficiency } & \text { \% } \\ \text { Thermal efficiency } & -\%\end{array}$

Can the process be optimized with respect to the emissions?

$\begin{array}{ll}- & \text { Yes } \\ - & \text { No }\end{array}$

Is more energy needed to achieve minimum emissions?

$\begin{array}{ll}- & \text { Yes } \\ - & \text { No }\end{array}$

Please fill out the minimum achievable emissions under "Environmental aspects".

6.

\section{SCALE-UP ${ }^{2}$}

Where in the process are any limitations in scale-up?

In the reactor sections

In the process train after the reactor sections

What is the expected maximum capacity of one process-line?

With respect to the present plant configuration; concerns optimization by fine tuning etc.

Concerns future plants, which might differ from the present plant. 
tonnes of waste/hr, ton/hr of waste

heat input $\left(\mathrm{MW}_{\text {input }}, \mathrm{Btu} / \mathrm{hr}\right)$

7.

ENVIRONMENTAL ASPECTS

What are the emissions (in $\mathrm{mg} / \mathrm{m}_{0}{ }^{3}$, gr/cft dry flue gas at $11 \% \mathrm{O}_{2}, 7 \% \mathrm{O}_{2}$ ) of the plant (if you have more data on realized emissions, please specify)? specified realized after optimization

(expected)

total dust

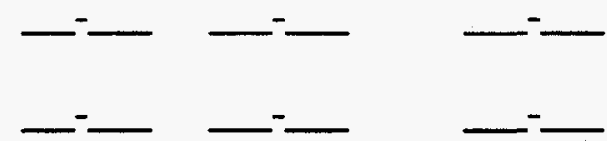

$\mathrm{HCl}$

fluorides
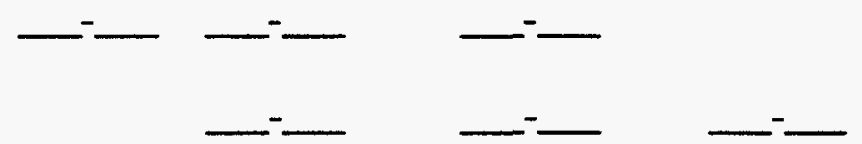

$\mathrm{CO}$

organic compounds (as C)
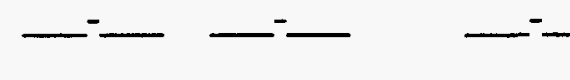

sulphur oxides

(as $\mathrm{SO}_{\mathrm{x}}$ )

nitrogen oxides

(as $\mathrm{NO}_{2}$ )
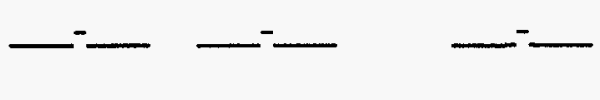

toxic metals $\mathrm{Sb}+\mathrm{Pb}+\mathrm{Cr}+\mathrm{Cu}+\mathrm{Mn}+\mathrm{V}+\mathrm{Sn}+\mathrm{As}$

$+\mathrm{Co}+\mathrm{Ni}+\mathrm{Se}+\mathrm{Te}$

$\mathrm{Cd}$
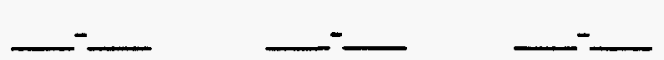

$\mathrm{Hg}$
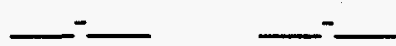

dioxins \& furans

(PCDDs and PCDFs in $\mathrm{ng}$ TEQ $/ \mathrm{m}_{0}{ }^{3}$ )

What residue and effluent discharge streams are produced and in which quantities (in $\mathrm{kg} /$ tonne, $1 /$ tonne, $\mathrm{lb} / \mathrm{ton}$, gal/ton)? Please describe.

Heavy/toxic metals (mg/kg waste):

residue

effluent

$\mathrm{Pb}$ 


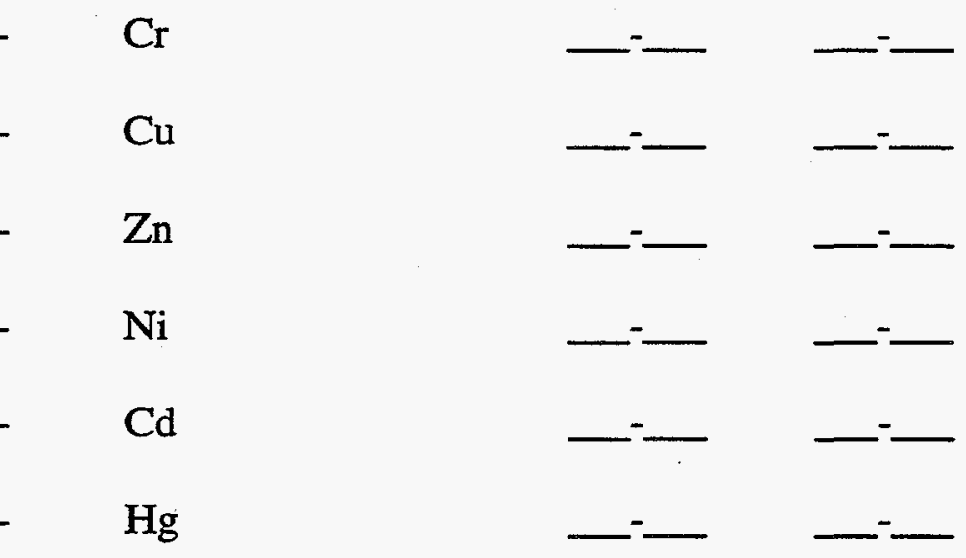

Please supply us with as much information concerning quantity and the characteristics (toxicity, leachability, configuration, composition) and the processing potential of the by-products as possible.

Information attached? $\quad$ Yes

- No

How many total employees are needed for running the plant?

How many annual manhours are needed for running the plant? manhrs/yr

How many shifts are needed for operation? shifts

How many maintenance (man)hours are needed for the plant annually? manhrs/yr

Are there any fundamental problems in plant operation presently?

- Yes

Are there any problems in plant operation which can be solved in a short term?

- Yes

Is the process sensitive to corrosion/erosion?

- Yes

- No

Are special measures taken/required for safety? e.g. for reducing risk of fire, explosion, etc.?

- Yes

- No 
What?

\section{FINANCIAL ASPECTS}

How many running hours are planned for commercial operation annually? hrs

What is the planned availability of the plant annually?

What is the assessed technical lifetime of the complete plant?

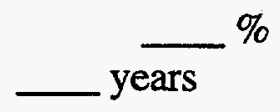

What is the currency in which the amounts are presented?

$\begin{array}{ll}- & \text { Italian Lire } \\ - & \text { German Mark } \\ - & \text { US Dollar } \\ - & \text { Other: }\end{array}$

Please present requested costs in present values:

What are the investment costs of:

- the complete plant:

_ capacity: _ _ tonnes waste/hr

the process line:

capacity: tonnes waste/hr

What are the specific investment costs (per tonne waste) of: the complete plant (two lines): capacity: tonnes waste/hr the process line: capacity: tonnes waste/hr

Please fill in the following table:

Main component invest. cost

technical

lifetime of maintenance component materials personnel 


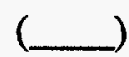

(yr)

/yr)

(manhrs/yr)

Preprocessing

Feeding system

Ash discharge system

Reactor

Flue gas treatment

Product gas treatment

Ash treatment

Water treatment

Heat exchangers

Power generation

What is the accuracy of the afore mentioned investment costs?

within $10 \%$

within $20 \%$

within $30 \%$

other limit: _ $\%$

What are the local operatinging costs of the total plant?

$$
\text { per year }
$$

Breakdown:

$+\quad$ depreciation of investments 
$+1-$

fuel costs

operation

maintenance

consumables

by-products

electricity/heat sold

other

TOTAL COSTS 


\section{Appendix E \\ Conversion Factors, Conventions and Methodologies}

\section{Conversion Factors}

$\begin{array}{lll}\text { From } & \text { To } & \text { Multiply by: } \\ \text { dscm } & & \\ \mathrm{kcal} / \mathrm{kg} & \text { dscf } & 35.31 \\ \mathrm{Mg} / \mathrm{d} & \mathrm{Btu} / \mathrm{lb} & 1.8 \\ \mathrm{MJ} & \mathrm{t} / \mathrm{d} & 1.1023 \\ \mathrm{MJ} / \mathrm{kg} & \mathrm{Btu} & 948.6 \\ \mathrm{MJ} / \mathrm{scm} & \mathrm{kcal} / \mathrm{kg} & 238.9 \\ \mathrm{MWh} & \mathrm{Btu} / \mathrm{scf} & 26.8 \\ \text { meters } & \mathrm{MJ} & 3600 . \\ \text { Pascals } & \text { feet } & 3.281 \\ & \text { psia } & 6894.8\end{array}$

\section{Conventions}

a. Gas Characteristics

1. Unless noted otherwise, all gas heating values and pollutant concentrations are on a dry basis at $20^{\circ} \mathrm{C}\left(68^{\circ} \mathrm{F}\right)$ and $101.3 \mathrm{kPa}(14.7 \mathrm{psi})$ at 7 percent $\mathrm{O}_{2}$.

2. "Normal Conditions" ( as in $\mathrm{Nm}^{3}$ ) means $0.0^{\circ} \mathrm{C}, 101.3 \mathrm{kPa}$ while "Standard Conditions" (as in $\mathrm{sft}^{3}$ ) means $32.0^{\circ} \mathrm{F}, 1.0$ atmosphere.

b. System Configurations - The environmental controls installed for each technology are those selected by the developer firm as compatible with their conception of current environmental emission limits. Some firms exceed these limits as a matter of their internal policy. In some cases, the developer has not yet established a firm flowsheet for wastewater treatment. The energy efficiency for each technology is that inherent in the process. No attempt has been made to re-configure the flowsheet to optimize energy recovery beyond that proposed by the developers.

\section{Conversion Methodology}

a. To convert air emission concentration value $X_{1}$ reported at an oxygen concentration of $\Psi_{1}$ percent to its value $X_{2}$ at an oxygen concentration of $\Psi_{2}$ percent, use the following:

$$
\begin{array}{r}
X_{2}=X_{1} \frac{\left(21.0-\Psi_{1}\right)}{\left(21.0-\Psi_{2}\right)} \\
\mathbf{E}-\mathbf{1}
\end{array}
$$




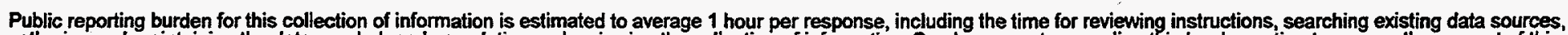

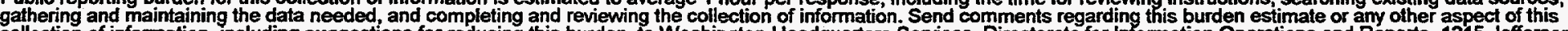

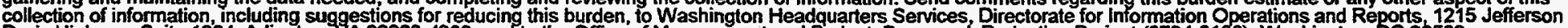

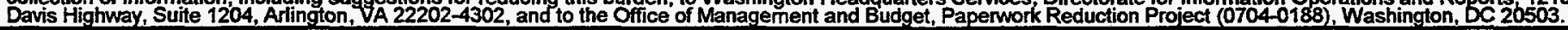
1. AGENCY USE ONLY (Leave
2. REPORT DATE
July 1996
3. REPORT TYPE AND DATES COVERED
Final subcontract report
blank)

4. TITLE AND SUBTITLE

Evaluation and gasification and novel thermal processes for the treatment of municipal solid waste

5. FUNDING NUMBERS

WM51.5151

6. AUTHOR(S)

Walter R. Niessen, Charles H. Marks, Robert E. Sommerlad

7. PERFORMING ORGANIZATION NAME(S) AND ADDRESS(ES)

Camp Dresser \& McKee

10 Cambridge Center

Cambridge, Massachusetts 02142

9. SPONSORING/MONITORING AGENCY NAME(S) AND ADDRESS(ES)

Natonal Renewable Energy Laboratory

1617 Cole Boulevard

Golden, Colorado 80401

8. PERFORMING

ORGANIZATION REPORT

NUMBER

10.

SPONSORING/MONITORING

AGENCY REPORT NUMBER

NREL / TP-430-21612

11. SUPPLEMENTARY NOTES

NREL Technical monitor: Philip Shepherd (303) 275-2929

12a. DISTRIBUTION/AVAILABILITY STATEMENT

National Technical Information Service

U.S. Department of Commerce

5285 Port Royal Road

Springfield, VA 22161 12b. DISTRIBUTION CODE

UC. Category: 1414

13. ABSTRACT (Maximum 200 words)

This report identifies seven developers whose gasification technologies can be used to treat the organic constituents of municipal solid waste: Energy Products of Idaho; TPS Termiska Processer AB; Proler International Corporation; Thermoselect Inc.; Batelle; Pedco Incorporated; and ThermoChem, Incorporated. Their processes recover heat directly, produce a fuel product, or produce a feedstock for chemical processes. The technologies are on the brink of commercial availaility. This report evaluates, for each technology, several kinds of issues. Technical consideratiuons were material balance, energy balance, plant thermal efficiency, and effect of feedstock contaminants. Environmental considerations were the regulatory context, and such things as composition, mass rate, and treatability of pollutants. Business issues were related to liklihood of commercialization. Finally, cost and economic issues such as capital and operating costs, and the refuse-derived fuel preparation and energy conversion costs, were considered. The final section of the report reviews and summarizes the information gathered during the study.

\section{SUBJECT TERMS}

municipal solid waste combustion; refuse gasification; refuse-derived fuel
15. NUMBER OF PAGES

16. PRICE CODE

20. LIMITATION OF

ABSTRACT

\section{SECURITY \\ CLASSIFICATION \\ OF REPORT}

$$
\begin{aligned}
& \text { 18. SECURITY } \\
& \text { CLASSIFICATION } \\
& \text { OF THIS PAGE }
\end{aligned}
$$

\author{
19. SECURITY \\ CLASSIFICATION \\ OF ABSTRACT
}

